MARCOS JUN TSUCHIE

DETECÇÃO E AVALIAÇÃO DE IMPACTOS EM MECANISMOS DE DIREÇÃO AUTOMOTIVO SERVO-ASSISTIDO ATRAVÉS DO USO DA TRANSFORMADA DE WAVELET 
MARCOS JUN TSUCHIE

\section{DETECÇÃO E AVALIAÇÃO DE IMPACTOS EM MECANISMOS DE DIREÇÃO AUTOMOTIVO SERVO-ASSISTIDO ATRAVÉS DO USO DA TRANSFOMADA DE WAVELET}

Dissertação apresentada à Escola Politécnica da Universidade de São Paulo para obtenção do título de Mestre em Engenharia Área de Concentração: Engenharia Elétrica Sistemas Eletrônicos

Orientador: Prof. Dr. Walter Jorge Augusto Ponge-Ferreira 
MARCOS JUN TSUCHIE

\section{DETECÇÃO E AVALIAÇÃO DE IMPACTOS EM MECANISMOS DE DIREÇÃO AUTOMOTIVO SERVO-ASSISTIDO ATRAVÉS DO USO DA TRANSFORMADA DE WAVELET}

Dissertação apresentada à Escola Politécnica da Universidade de São Paulo para obtenção do título de Mestre em Engenharia 
FOLHA DE APROVAÇÃO

MARCOS JUN TSUCHIE

\title{
DETECÇÃO E AVALIAÇÃO DE IMPACTOS EM MECANISMOS DE DIREÇÃO AUTOMOTIVO SERVO-ASSISTIDO ATRAVÉS DO USO DA TRANSFOMADA DE WAVELET
}

\author{
Dissertação apresentada à Escola \\ Politécnica da Universidade de São Paulo \\ para obtenção do Título de: Mestre em \\ Engenharia.
}

Aprovado em:

Banca Examinadora

Professor Doutor:

Instituição:

Assinatura:

Professor Doutor:

Instituição:

Assinatura:

Professor Doutor:

Instituição:

Assinatura: 


\section{DEDICATÓRIA}

Dedico este trabalho a meus pais. 


\section{AGRADECIMENTOS}

Ao professor Dr. Walter Ponge-Ferreira, pela orientação e pelo constante estímulo transmitido durante todo o trabalho.

Aos familiares e amigos e a todos que colaboraram direta ou indiretamente, na execução deste trabalho. 


\section{RESUMO}

Sabe-se que folgas e impactos de partes internas reduzem o desempenho da transmissão, do sistema de controle e a qualidade global do mecanismo. Folgas causam instabilidade, mas impactos também geram ruídos estruturais que perturbam medições e causam ruído acústico que reduz o conforto. Sinais de movimento são frequentemente usados para realimentação e podem ser perturbados por ruídos de impacto. Para avaliar este problema, um procedimento capaz de detectar e quantificar a severidade e a frequência de ocorrência de impactos é proposto. Desta forma, o desempenho de diferentes sistemas em relação à sua robustez ao impacto pode ser comparado. Sinais de vibração na estrutura do sistema são medidos e o sinal é processado digitalmente e decomposto em múltiplas escalas pela Transformada de Wavelet. As wavelets Harmônicas e de Daubechies são comparadas. Escalas que correspondem aos níveis de detalhamento característicos dos impactos são extraídas do sinal de vibração e a severidade do impacto é avaliada. Após o processamento do sinal e a retirada do ruído, o sinal original é disponibilizado para posterior processamento e controle. Foi estudado o ruído de impacto em caixas de direção conhecido como knock noise. Ao final, tentou-se comparar a técnica de Transformada de Wavelet com a técnica de Emissão Acústica. Na sessão Transformada de Wavelets é feito um breve estudo de alguns conceitos necessários para o entendimento de wavelets e é explicada a técnica utilizada para a detecção dos ruídos de impacto. Na sessão Emissão Acústica é explicada a técnica utilizada para comparar com a técnica de wavelets. $\mathrm{Na}$ sessão Direção Hidráulica é explicado o mecanismo de direção estudado. $\mathrm{Na}$ sessão Resultados, são mostrados os sinais de ruídos de impacto detectados pela Transformada de Wavelet e Emissão Acústica e o método adotado para mensurar a severidade dos impactos e a frequência de ocorrência dos mesmos. 


\begin{abstract}
It is well known that backlash and impact of inner parts reduce the performance of transmission, control systems and overall quality of mechanism. Clearance causes instability, but impact also generates structural borne noise that disrupts measurements and cause acoustic noise that reduces the comfort. Motion signals are often used for feedback and can be disrupted by impact noise. In order to overcome this problem a procedure able to detect and quantify the severity and rate of occurrence of impacts is proposed. Thence performance of different systems in regard to their robustness to impact can be compared. A procedure to detect and evaluate impacts of inner parts of mechanical mechanism is presented. Therefore, vibration signals on the structure of the system are measured and the signal is digitally processed and decomposed into multiscales by the Wavelet transform. Both Daubechies and Harmonic Wavelet are compared. Scales that correspond to the impact response are extracted from the overall vibration signal, and the impact severity is rated. After signal processing and de-noising, the original signal without the impact is also available for further processing and control. The analysis technique was applied to study the impact noise in steering boxes known as knock noise. Finally, it was tried to compare the technique of wavelet transform with the Acoustic Emission. First, a brief study is presented of some concepts necessary to understand wavelets and Wavelet Transform technique is explained and the approach used for detection of impact noise is presented. In the following section the technique of Acoustic Emission is explained and how it was compared to the wavelet technique. The Hydraulic Steering System is explained in the next section. In the final section the Results of the study are show, the signal with impact noise, the impact detected by the Wavelet Transform and Acoustic Emission and the method used to measure the severity of impacts and to measure the frequency of their occurrence.
\end{abstract}




\section{LISTA DE ILUSTRAÇÕES}

Figura 1 - Função de escala de Haar. ......................................................30

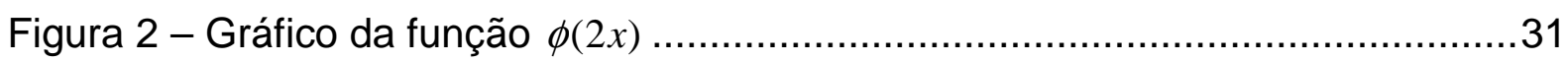

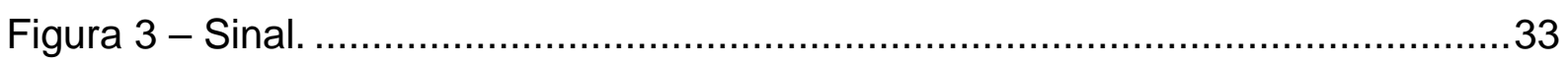

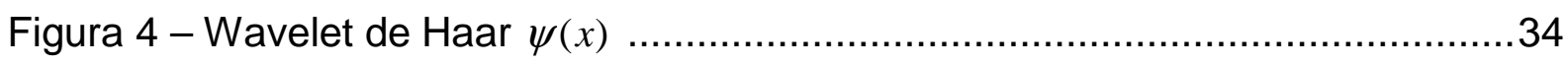

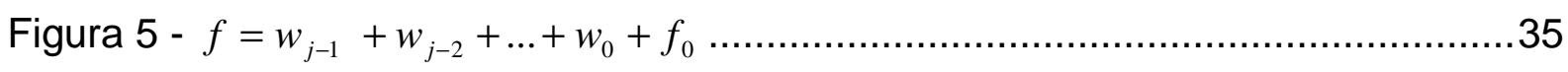

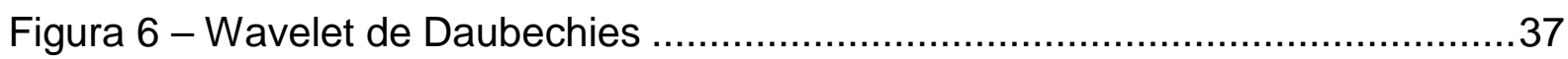

Figura 7 - Função de escala de Daubechies ................................................ 37

Figura 8 - Wavelets de Daubechies....................................................... 38

Figura 9 - Transformada de Fourier....................................................... 40

Figura 10 - Transformada de Fourier.......................................................40

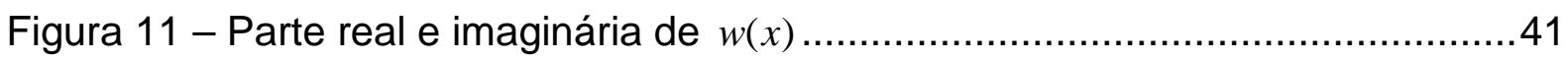

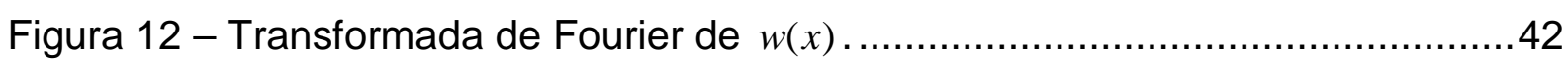

Figura 13 - Transformada de wavelet da função de escala..............................44

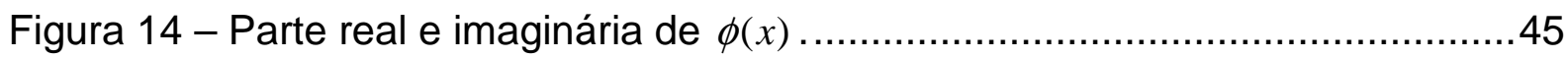

Figura 15 - Sistema de direção hidráulica ...............................................50

Figura 16 - Princípio de funcionamento da caixa de direção hidráulica...................51

Figura 17 - Circuito Hidráulico da caixa de direção. ........................................51

Figura 18 - Carcaça de direção hidráulica..................................................52

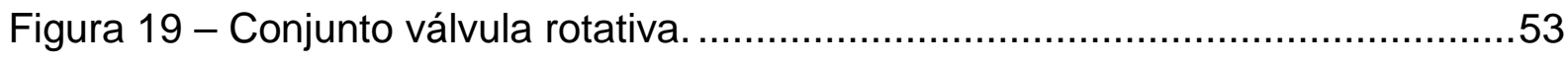

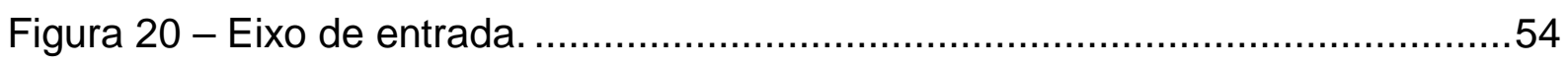

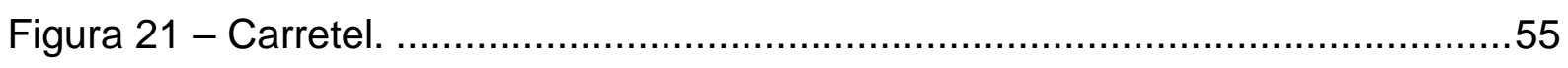

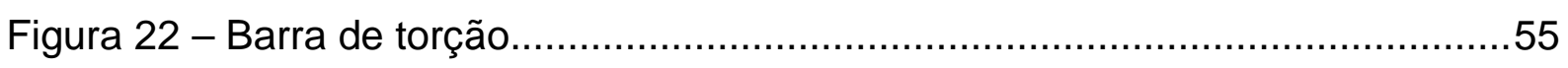

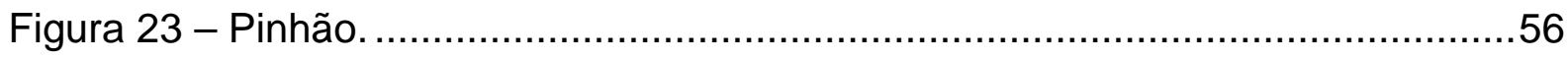

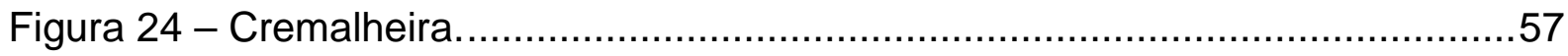

Figura 25 - Bucha + Vedação do Pistão e da Carcaça......................................58

Figura 26 - Conjunto Sujeitador, Mola e Porca..............................................59

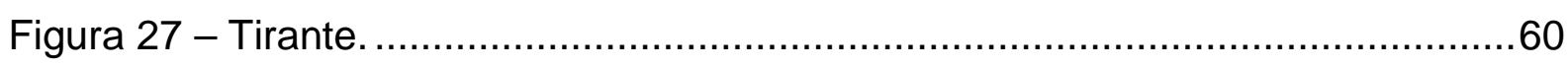

Figura 28 - Terminais da caixa de direção..................................................6 61

Figura 29 - Coxins da caixa de direção. ....................................................62

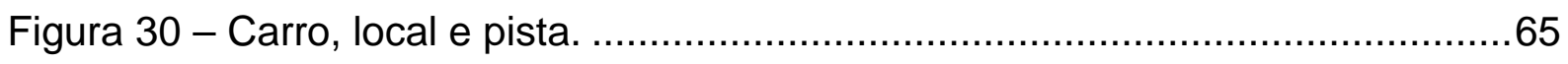

Figura 31 - Acelerômetro fixado próximo aos mancais do pinhão.........................66 
Figura 32 - Acelerômetro fixado próximo ao Sujeitador. .66

Figura 33 - Bancada de Ensaio. 69

Figura 34 - Diagrama de Montagem................................................... 70

Figura 35 - Caixa de Direção Hidráulica..................................................... 71

Figura 36 - Posição de Medição. ............................................................ 71

Figura 37 - Batida do martelo contra a cremalheira....................................... 72

Figura 38 - Foto da caixa de direção aberta utilizada no ensaio de emissão acústica.

Figura 39 - Croqui da caixa de direção ensaiada com localização dos pontos de excitação $A-F$. .74

Figura 40 - Forma de onda e espectro dos sinais típicos de emissão acústica........78

Figura 41 - Histograma do número de registros (hits) por amplitude......................78

Figura 42 - Localização dos pontos de excitação - Amplitude X Posição.................79 Figura 43 - Localização dos pontos de excitação - Energia, contagem e Amplitude X Posição. .79

Figura 44 - Espectro de Frequências. .80

Figura 45 - Função de Resposta em frequência da cremalheira. 81

Figura 46 - Sinal medido em laboratório com D = $140 \mathrm{~mm}$. .81

Figura 47 - Zoom do sinal medido em laboratório com D = $140 \mathrm{~mm}$. .82

Figura 48 - Espectrograma do sinal original. 83

Figura 49 - Wavelet de Daubechies de ordem 3 e 2 níveis de detalhamento. .84

Figura 50 - Espectrograma do sinal reconstruído. .84

Figura 51 - Wavelet de Daubechies de ordem 3 e 3 níveis de detalhamento. .85

Figura 52 - Distorção do sinal original. .85

Figura 53 - Wavelet de Daubechies de ordem 7 e 3 níveis de detalhamento. .86

Figura 54 - Wavelets de Daubechies de ordem 3 e 7 respectivamente. 86

Figura 55 - Espectro de frequência do sinal sem ruídos de impacto. 87

Figura 56 - Espectrograma do sinal reconstruído. .87

Figura 57 - Espectro de freqüência do sinal dos ruídos de impacto. 88

Figura 58 - Espectrograma do sinal dos ruídos de impacto. 89

Figura 59 - Pontos de impacto e Severidade dos Impactos. 90

Figura 60 - Wavelet de Newland e 3 níveis de detalhamento. .91

Figura 61 - wavelet de Newland e 4 níveis de detalhamento. .91

Figura 62 - Sinal medido em laboratório com D = $215 \mathrm{~mm}$. 


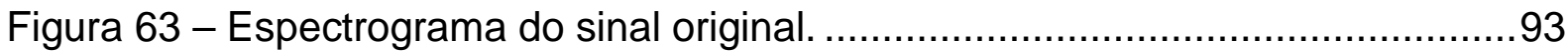

Figura 64 - Wavelet de Daubechies de ordem 7 e 3 níveis de detalhamento. .........93

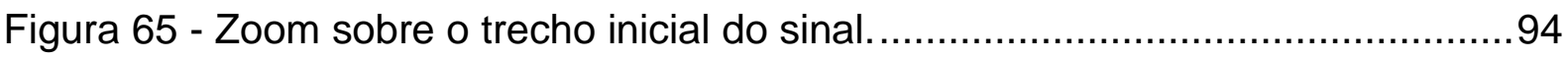

Figura 66 - Wavelet de Daubechies de ordem 12 e 3 níveis de detalhe. ................94

Figura 67 - Espectro de frequência do sinal reconstruído. ...................................95

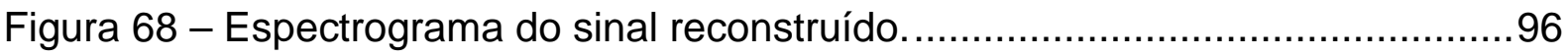

Figura 69 - Espectro de frequência do sinal dos ruídos de impacto.........................96

Figura 70 - Espectrograma do sinal dos ruídos de impacto. ……….....................97

Figura 71 - Pontos de impacto e Severidade dos Impactos. ..................................98

Figura 72 - Sinal medido em laboratório com $D=152 \mathrm{~mm}$...............................98

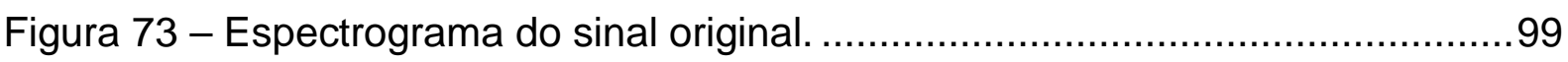

Figura 74 - Wavelet de Daubechies de ordem 7 e 3 níveis de detalhamento. .......100

Figura 75 - Zoom sobre o trecho inicial do sinal.............................................100

Figura 76 - Espectro de frequência do sinal reconstruído. ...................................101

Figura 77 - Espectrograma do sinal reconstruído............................................101

Figura 78 - Espectro de frequência do sinal dos ruídos de impacto.......................102

Figura 79 - Espectrograma do sinal dos ruídos de impacto. ...............................102

Figura 80 - Pontos de impacto e Severidade dos Impactos. .................................103

Figura 81 - Sinal medido em laboratório com D = $180 \mathrm{~mm}$. ...............................104

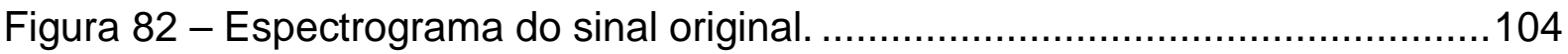

Figura 83 - Wavelet de Daubechies de ordem 7 e 3 níveis de detalhe. ................. 105

Figura 84 - Espectro de frequência do sinal reconstruído. ...................................106

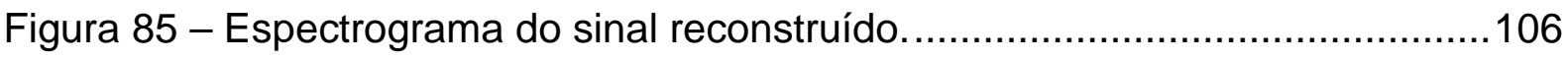

Figura 86 - Espectro de frequência do sinal dos ruídos de impacto.......................107

Figura 87 - Espectrograma do sinal dos ruídos de impacto. ................................107

Figura 88 - Pontos de Impacto e Severidade dos Impactos.................................108

Figura 89 - Sinal medido em laboratório com $\mathrm{D}=180 \mathrm{~mm}$. ..............................109

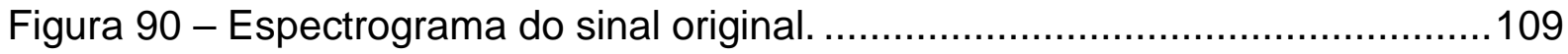

Figura 91 - Wavelet de Daubechies de ordem 7 e 3 níveis de detalhe. ................110

Figura 92 - Espectro de frequência do sinal reconstruído. ...................................110

Figura 93 - Espectrograma do sinal reconstruído............................................111

Figura 94 - Espectrograma do sinal dos ruídos de impacto. ................................111

Figura 95 - Pontos de impacto e Severidade dos Impactos. ...................................112

Figura 96 - Sinal de vibração real medido na rua de paralelepípedos....................113 


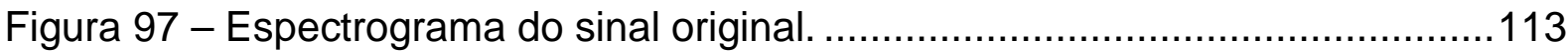

Figura 98 - Wavelet de Daubechies de ordem 7 e 3 níveis de detalhe. ................114

Figura 99 - Espectrograma do sinal reconstruído..........................................114

Figura 100 - Wavelet de Daubechies de ordem 7 e 4 níveis de detalhe. ..............115

Figura 101 - Espectrograma do sinal reconstruído.........................................115

Figura 102 - Espectro de frequências do sinal reconstruído. ..............................116

Figura 103 - Espectrograma do sinal dos ruídos de impacto................................117

Figura 104 - Sinal reconstruído. ............................................................117

Figura 105 - Wavelet de Daubechies de ordem 7 e 5 níveis de detalhe. ...............118

Figura 106 - Wavelet de Daubechies de ordem 12 e 4 níveis de detalhe. .............119

Figura 107 - Sinal reconstruído. ................................................................119

Figura 108 - Espectrograma do sinal reconstruído........................................120

Figura 109 - Wavelet de Daubechies de ordem 18 e 4 níveis de detalhe. .............120

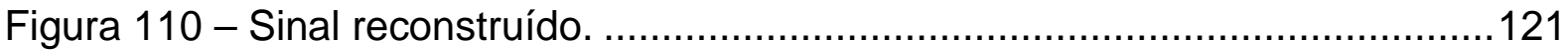

Figura 111 - Espectrograma do sinal reconstruído..........................................121

Figura 112 - Pontos de impacto e Severidade dos Impactos. …….......................123

Figura 113 - Sinal de vibração real medido na rua de paralelepípedos...................123

Figura 114 - Espectrograma do sinal original. ...................................................124

Figura 115 - Wavelet de Daubechies de ordem 7 e 4 níveis de detalhe. ...............124

Figura 116 - Espectrograma do sinal reconstruído..........................................125

Figura 117 - Wavelet de Daubechies de ordem 7 e 5 níveis de detalhe. ...............126

Figura 118 - Wavelet de Daubechies de ordem 12 e 4 níveis de detalhe. .............126

Figura 119 - Espectrograma do sinal reconstruído..........................................127

Figura 120 - Espectro de frequência do sinal reconstruído. .................................128

Figura 121 - Espectrograma do sinal dos ruídos de impacto.................................128

Figura 122 - Pontos de impacto e Severidade dos Impactos. ..............................129

Figura 123 - Sinal de vibração real medido na rua de paralelepípedos..................130

Figura 124 - Espectrograma do sinal original. ..................................................130

Figura 125 - Wavelet de Daubechies de ordem 7 e 4 níveis de detalhe. ...............131

Figura 126 - Espectrograma do sinal reconstruído............................................131

Figura 127 - Wavelet de Daubechies de ordem 7 e 5 níveis de detalhe. ............... 132

Figura 128 - Wavelet de Daubechies de ordem 18 e 4 níveis de detalhe. ............. 133

Figura 129 - Espectrograma do sinal reconstruído...........................................133

Figura 130 - Espectro de frequência do sinal reconstruído. .................................134 
Figura 131 - Espectrograma do sinal dos ruídos de impacto................................135

Figura 132 - Pontos de impacto e Severidade dos Impactos. ...............................135

Figura 133 - Wavelet de Newland e 3 níveis de detalhe. ....................................136

Figura 134 - Espectrograma do sinal reconstruído............................................137

Figura 135 - Wavelet de Newland e 4 níveis de detalhe. .................................137

Figura 136 - Espectrograma do sinal reconstruído..........................................138

Figura 137 - Wavelet de Newland e 7 níveis de detalhe. ..................................138

Figura 138 - Espectrograma do sinal reconstruído..........................................139

Figura 139 - Sinal de vibração real medido na rodovia Ayrton Senna....................140

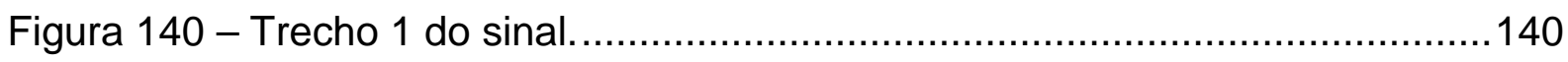

Figura 141 - Espectrograma do sinal original. ...............................................141

Figura 142 - Wavelet de Daubechies de ordem 7 e 4 níveis de detalhe. ..............142

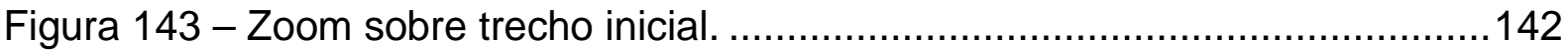

Figura 144 - Espectro de frequência do sinal reconstruído. .................................143

Figura 145 - Espectrograma do sinal reconstruído..........................................143

Figura 146 - Espectro de frequências do sinal dos ruídos de impacto. ...................144

Figura 147 - Pontos de Impacto e Severidade dos Impactos................................ 145

Figura 148 - Trecho 2 do sinal.................................................................... 145

Figura 149 - Espectrograma do sinal original. ...............................................146

Figura 150 - Wavelet de Daubechies de ordem 7 e 4 níveis de detalhe. ..............147

Figura 151 - Zoom sobre a região de impacto....................................................147

Figura 152 - Espectro de frequência do sinal reconstruído. .................................148

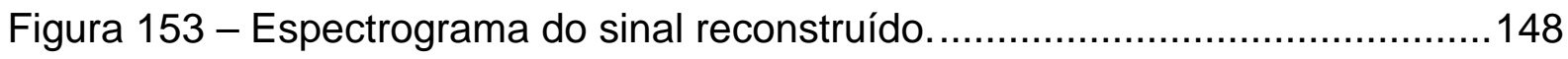

Figura 154 - Espectro de frequências do sinal dos ruídos de impacto. ...................149

Figura 155 - Pontos de Impacto e Severidade dos Impactos. ...............................150

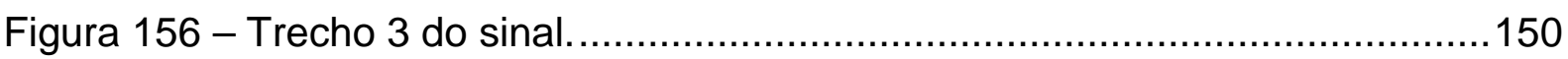

Figura 157 - Espectrograma do sinal original. ...............................................151

Figura 158 - Wavelet de Daubechies de ordem 7 e 4 níveis de detalhe. ............... 151

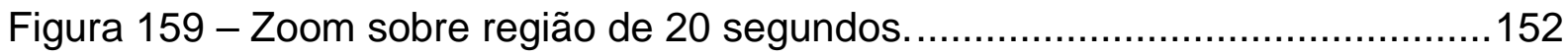

Figura 160 - Espectro de frequência do sinal reconstruído. .................................152

Figura 161 - Espectrograma do sinal reconstruído...........................................153

Figura 162 - Espectro de frequências do sinal dos ruídos de impacto. ...................153

Figura 163 - Pontos de Impacto e Severidade de Impactos.................................154

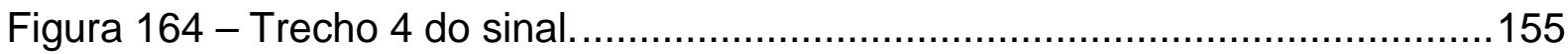




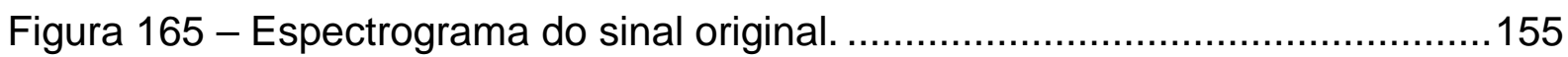

Figura 166 - Wavelet de Daubechies de ordem 7 e 4 níveis de detalhe. ...............156

Figura 167 - Zoom sobre região em torno de 5 segundos...................................156

Figura 168 - Espectro de frequência do sinal reconstruído. .................................157

Figura 169 - Espectrograma do sinal reconstruído........................................157

Figura 170 - Espectro de frequências do sinal dos ruídos de impacto. ..................158

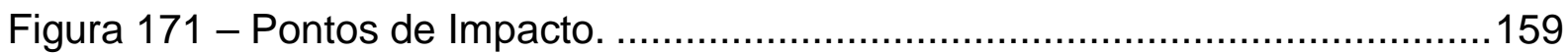

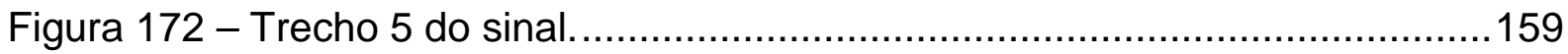

Figura 173 - Espectrograma do sinal original. ................................................160

Figura 174 - Wavelet de Daubechies de ordem 7 e 4 níveis de detalhe. ...............161

Figura 175 - Zoom sobre a região em torno de 11 segundos.................................161

Figura 176 - Espectro de frequência do sinal reconstruído. ..................................162

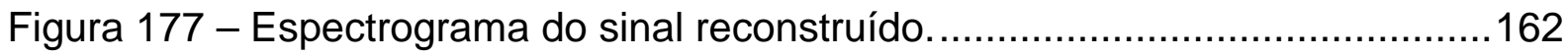

Figura 178 - Espectro de frequências do sinal dos ruídos de impacto. ...................163

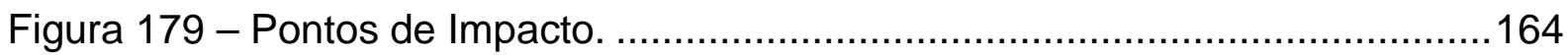

Figura 180 - Forma de onda e espectro dos sinais típicos de emissão acústica -

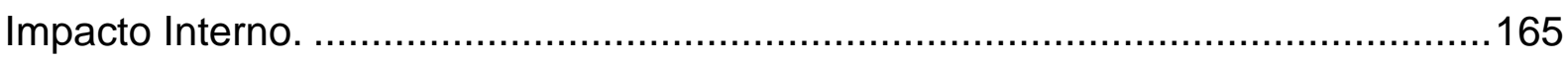

Figura 181 - Localização dos pontos de excitação - Amplitude X Posição - Impacto

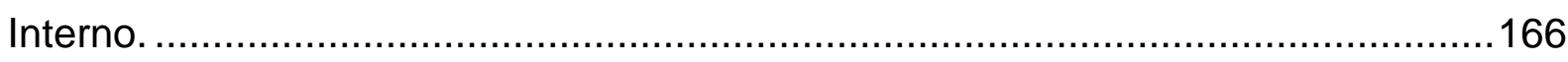

Figura 182 - Wavelet de Daubechies de ordem 7 e 3 níveis de detalhamento. ......167

Figura 183 - Pontos de impacto e Severidade dos Impactos. ...............................167

Figura 184 - Wavelet de Daubechies de ordem 7 e 4 níveis de detalhe. ...............168

Figura 185 - Pontos de impacto e Severidade dos Impactos. ...............................168

Figura 186 - Wavelet de Daubechies de ordem 7 e 4 níveis de detalhe. ................169

Figura 187 - Pontos de Impacto e Severidade dos Impactos. ...............................170

Figura 188 - wavelet de Newland e 4 níveis de detalhamento. ............................170

Figura 189 - Localização dos pontos de excitação - Amplitude X Posição - Impacto Interno. 


\section{LISTA DE SÍMBOLOS}

$\theta$

$\psi(t)$

$\phi(t)$

$\|\nu\|$

$A \oplus B$

$\mathrm{dbN}$

$\langle X, Y\rangle$
ÂNGULO (em graus decimais)

FUNÇÃO DE WAVELET

FUNÇÃO DE ESCALA

NORMA DE V

SOMA ORTOGONAL DE A COM B

DAUBECHIES DE ORDEM N

PRODUTO INTERNO DE X E Y 
SUMÁRIO

RESUMO

.6

ABSTRACT

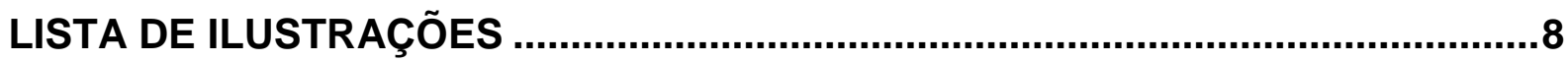

LISTA DE SÍMBOLOS..............................................................................14

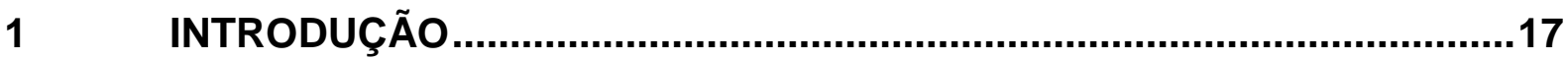

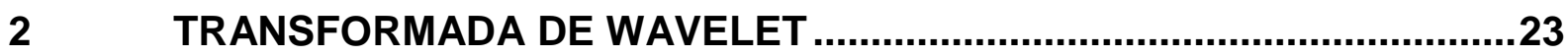

2.1 DECOMPOSIÇÃO DE FUNÇÕES EM BASES DE FUNÇÕES ORTOGONAIS .....................24

2.2 TRANSFORMADA CONTÍNUA DE WAVELET ….......................................................28

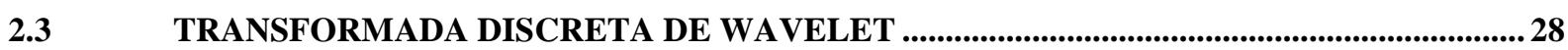

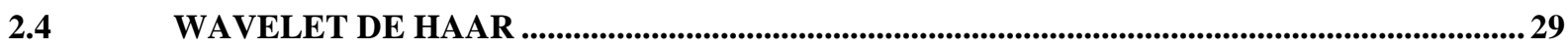

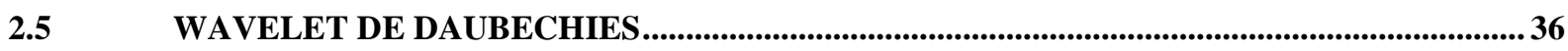

2.6 WAVELET HARMÔNICA......................................................................................................39

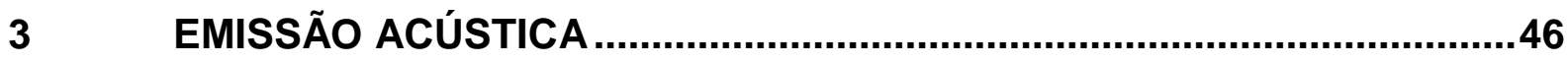

$4 \quad$ SISTEMA DE DIREÇÃO HIDRÁULICA …..........................................49

4.1 SUBSISTEMA DE CAIXA DE DIREÇÃO PINHÃO-CREMALHEIRA....................................50

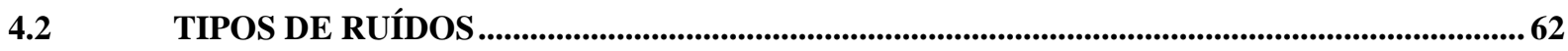

$5 \quad$ MEDIÇÕES DE SINAIS EM CAIXA DE DIREÇÃO ..................................64

5.1 MEDIÇÕES DE SINAIS DE VIBRAÇÃO EM CAMPO.....................................................64

5.2 MEDIÇÕES DE SINAIS DE VIBRAÇÃO EM LABORATÓRIO............................................67

5.3 MEDIÇÕES DE SINAIS DE EMISSÃO ACÚSTICA EM LABORATÓRIO ..............................73

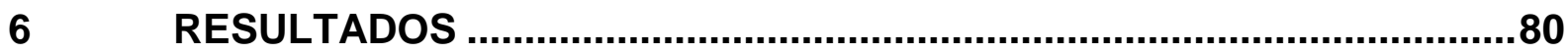

6.1 Escolha dos Parâmetros para Análise com Wavelet de Daubechies ............................................... 83 
6.2 Escolha dos Parâmetros para Análise com Wavelet Harmônica de Newland ................................90

6.3 Análise dos Sinais de Laboratório com Wavelet de Daubechies ...................................................92

6.4 Análise dos Sinais de Campo com Wavelet de Daubechies..................................................... 112

6.5 Análise dos Sinais de Campo com Wavelet de Newland .................................................... 136

6.6 Análise dos Sinais de Campo em Estrada com Wavelet de Daubechies .................................... 139

6.7 Análise dos Sinais de Laboratório com Emissão Acústica .............................................................. 164

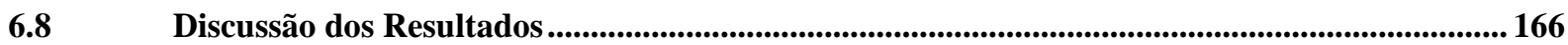

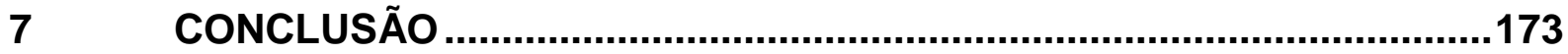

$8 \quad$ REFERÊNCIAS BIBLIOGRÁFICAS.................................................176

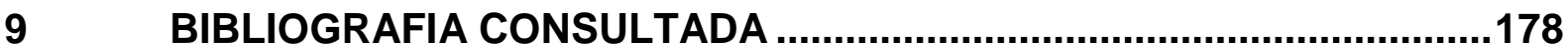

10 APÊNDICES ................................................................................180

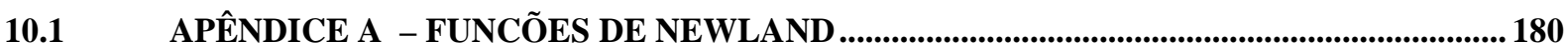

10.2 APÊNDICE B - FUNCÕES DE DAUBECHIES ................................................................ 181 


\section{INTRODUÇÃO}

Os usuários automotivos estão cada vez mais exigentes em relação a qualidade do veículo e isto envolve principalmente aspectos relacionados à ruídos e vibrações.

Ruídos e vibrações provenientes do sistema de direção, além de causar desconforto aos usuários, estão associados à questão de segurança.

O objetivo deste trabalho é desenvolver um procedimento de análise de sinais de vibrações medidas em veículos para a detecção e avaliação de impactos entre partes internas nos mecanismos de direção servo-assistidos. O mecanismo de direção estudado apresenta impactos internos entre os componentes mecânicos da direção devido a folgas e vibrações que produzem um ruído acústico na cabine do automóvel, conhecido como knock noise. No presente trabalho, inicialmente foram comparadas diversas técnicas de análise de sinais tais como: Cepstrum, Transformada de Hilbert, Transformada de Gabor, Transformada de Fourier Janelada, Intensidade Acústica, Emissão Acústica e Transformada de Wavelet.

O Cepstrum é uma operação matemática que consiste em extrair a Transformada de Fourier do espectro do sinal na forma logarítmica. Esta técnica é bastante útil para analisar sinais periódicos provenientes, por exemplo, de engrenamentos e rolamentos. Entretanto ela não é recomendada para análise de sinais transitórios, pois nesse caso o espectro não é periódico.

A Transformada de Hilbert produz um sinal ortogonal ao sinal original. Dessa maneira, pode-se construir uma função complexa chamada de função analítica, cuja parte real é o próprio sinal e cuja parte imaginária é a Transformada de Hilbert desse sinal. Pode-se determinar a envoltória do sinal original através do módulo da função analítica e a fase instantânea através da fase da função analítica. Por isso, essa técnica é útil para analisar sinais modulados em amplitude e freqüência. Essa técnica é bastante utilizada na análise de sinais de rolamentos e engrenamentos e é comumente designada de técnica do envelope. Ela permite extrair a envoltória dos impactos, que nesses casos são periódicos com relação à passagem das esferas ou gaiolas pelas irregularidades das pistas. Dessa maneira o espectro da envoltória permite detectar e avaliar diretamente a freqüência e intensidade dessas passagens 
por irregularidades. Essa técnica não é indicada para análise dos sinais de knocknoise, pois esse não produz uma envoltória periódica, principal característica detectável pela técnica da Transformada de Hilbert.

A Transformada de Fourier Janelada (Short Time Frequency Analysis) é usada para determinar a freqüência senoidal e o conteúdo de fase de seções locais de um sinal. Desta forma, o sinal a ser analisado é dividido em partes de igual intervalo de tempo e sobre estas partes é aplicada a Transformada de Fourier. Tratase de uma técnica bastante indicada para decomposição dos sinais de vibração de caixas de direção com impactos de knock-noise. A limitação dessa técnica é não permitir a reconstituição das duas parcelas dos sinais, pois devido ao uso de janelas de ponderação, não é mais possível efetuar a transformação inversa para obter o sinal original decomposto.

A Transformada de Gabor é um caso especial da Transformada de Fourier Janelada. A função a ser analisada é multiplicada por uma função gaussiana, que pode ser considerada como uma função janelada, e em seguida é aplicada a Transformada de Fourier sobre a função resultante da multiplicação para obter a análise tempo - freqüência. A função gaussiana é utilizada com o objetivo de dar um peso maior para o sinal próximo ao tempo em que está sendo analisado. Essa técnica tem como principal vantagem a boa localização no tempo e na freqüência, entretanto, apresenta as mesmas limitações quanto à reconstituição do sinal original sem o ruído de impacto.

Outra técnica que pode ser utilizada é a Intensidade acústica que analisa e caracteriza as fontes sonoras diretamente. A intensidade acústica descreve a taxa de energia que flui em um determinado ponto e pode ser definida como a potência do som por unidade de área.

Para quantificar os ruídos de impacto provenientes da caixa de direção utilizando esta técnica é necessário calcular a potência do som. Desta forma, calcula-se a intensidade acústica média sobre uma superfície que engloba a fonte de ruído e multiplica-se pela área dessa superfície. Neste trabalho, esta técnica é difícil de ser aplicada nas medições realizadas em campo.

A Emissão Acústica é uma técnica de análise de vibração estrutural proveniente de fontes de emissão acústica que permite registrar ondas de superfície, através de sensores piezelétricos. Embora a técnica seja denominada acústica, ela mede na realidade as ondas estruturais de alta freqüência, bem acima da faixa 
audível do ser humano. Originalmente essa técnica foi desenvolvida para detecção e localização de propagação de trincas estruturais. No momento da propagação das trincas há emissão de energia, que se propaga pela estrutura através de ondas superficiais de Lamb e Rayleigh. Os sensores são fixados sobre a superfície e detectam a passagem dessas ondas pela superfície da estrutura. Pela análise estatística desses sinais e por técnicas de triangulação é possível detectar a ocorrência das trincas e localizar a sua posição espacial sobre a estrutura. Embora o fenômeno estudado nesse trabalho seja outro, durante o impacto entre peças metálicas ocorre a geração de diversas ondas mecânicas, que se propagam pela estrutura. Portanto, pode-se utilizar a capacidade de detecção e localização dos sistemas de medição de emissão acústica para analisar os sinais de impacto interno. As principais limitações dessa técnica são: a intensidade do sinal medido não tem significado físico direto, pois depende essencialmente do acoplamento mecânico entre a superfície da peça e o sensor, que varia significativamente e de forma não controlada; a técnica depende da ocorrência de um número elevado de impactos para que a análise estatística seja significativa; e a impossibilidade de interpretação física da forma de onda dos sinais registrados.

Dentre estas técnicas de análise de sinais, foram escolhidas as técnicas de análise de sinais pela Transformada de Wavelet e Emissão Acústica. Em seguida, foram realizadas medições de sinais de vibração em campo, com o veículo em operação, e em ensaios controlados em laboratório através de acelerômetros. Para os ensaios em laboratório, foram realizadas também medições de sinais através de transdutores piezelétricos.

Estes sinais foram amplificados, digitalizados pelo sistema de aquisição e salvos em formato de arquivo de texto por um software de análise de sinais. Posteriormente estes sinais foram analisados com software de análise de sinais.

Com base nos sinais medidos em laboratório, foi elaborado um procedimento utilizando a Transformada de Wavelet para detectar a ocorrência dos impactos, selecionar suas características predominantes e mensurar a severidade do fenômeno e a frequência de ocorrência de impactos. Em seguida, este procedimento foi aplicado aos sinais medidos em condições reais de utilização do veículo.

Foi utilizada a biblioteca de funções para wavelet do programa MATLAB no caso da Transformada de Daubechies. A Transformada Harmônica foi 
implementada de acordo com as referências de Newland (1993) e apresentada no Apêndice A.

Os procedimentos numéricos foram implementados em linguagem de altonível (MATLAB) para análise de sinais off-line.

Por último, tentou-se comparar esta técnica com a técnica de Emissão Acústica.

Justificam-se estes estudos pelo fato de atualmente a detecção do ruído acústico na cabine do automóvel ser feita de modo subjetiva por um especialista que possui a audição treinada e, portanto, não há parâmetros objetivos para julgar a aprovação ou não do nível de ruído.

Embora a primeira menção às wavelets tenha ocorrido há muitos anos, é somente nestas últimas duas décadas que esta ferramenta tem se tornado popular na análise de sinal.

Segundo Burrus; Gopinath e Guo (1998), wavelet significa uma "pequena onda" que possui sua energia concentrada no tempo o que a torna uma ferramenta extremamente útil para análise de transientes e sinais não estacionários.

De acordo com Lima (2003), o pioneiro no estudo dessa técnica foi A.Haar que criou as wavelets de Haar, mas estas ficaram no anonimato por muitos anos e, por um período muito longo, elas continuaram a ser a única base ortonormal de wavelets conhecida.

Peng e Chu (2002) assinalam que em 1984, Morlet definiu o conceito de wavelet, mas foi somente em 1985 que as wavelets ganharam um grande impulso com os trabalhos de Stephane Mallat na área de processamento digital de imagens. Inspirado nos resultados de Mallat, Y. Meyer construiu a primeira wavelet não-trivial (suave). Diferentemente das wavelets de Haar, as wavelets de Meyer são continuamente diferenciáveis, porém elas não possuem suporte compacto. Alguns anos mais tarde, Ingrid Daubechies baseou-se nos trabalhos de Mallat para construir um conjunto de bases ortonormais de wavelets suaves com suportes compactos. Este conjunto tornou-se o alicerce das aplicações atuais de wavelets.

De acordo com Li e Liao (2006), a Transformada de Wavelet é uma técnica utilizada para decompor os sinais em vários níveis de resolução em que cada nível está associado à sua escala. Esta transformada possui uma excelente propriedade de localização de tempo-frequência, permitindo distinguir as componentes de interesse do sinal sob a aplicação de certas escalas. 
Segundo Mahmoud; Dessouky e Elfouly (2007), pela sua capacidade de representação multi-resolução, a Transformada de Wavelet tem sido utilizada eficientemente em aplicações vitais tais como análise de sinais transientes, análises numéricas, compressão de imagem e aplicações audiovisuais.

A análise de wavelets permite utilizar vários tipos de funções. A escolha da wavelet dependerá do objetivo do pesquisador, isto é, se a forma da função refletir as características da série temporal, sintetizar dados e fizer compressões ou obtiver informações quantitativas que é o caso deste trabalho. Para, estes, é interessante o uso de wavelets ortogonais. Para redundâncias de informações como em análise exploratória, as wavelets não ortogonais são úteis; e no caso que seja necessária a análise de mudanças de amplitude e fase, as wavelets complexas são mais interessantes.

No capítulo 2 é abordado o embasamento teórico para realizar a decomposição de funções em bases de funções ortogonais. Em seguida é explicada brevemente a Transformada Contínua de Wavelet e a Transformada Discreta de Wavelet. Para explicar a teoria sobre wavelets, faz-se o uso da wavelet de Haar por ser a wavelet mais simples. Por último são explicadas as wavelets de Daubechies e Newland, escolhidas para aplicação neste trabalho por serem semelhantes aos ruídos de impacto analisados, por serem funções contínuas e principalmente por formarem bases ortogonais permitindo a reconstrução perfeita do sinal.

No capítulo 3 é abordada a técnica de Emissão Acústica utilizada para comparar com a técnica de Transformada de Wavelet. Explica-se a limitação do uso da medida da amplitude do sinal de emissão acústica como parâmetro de energia do sinal. Esta técnica foi utilizada para tentar-se localizar os pontos de ocorrência de impacto dentro da caixa de direção estudada.

No capítulo 4 é abordado o princípio de funcionamento do sistema de direção hidráulica e são listadas e explicadas as principais peças que compõem este sistema. Atentar-se para o pinhão, cremalheira e bucha guia que são os componentes deste sistema que geram os ruídos de impacto estudados neste trabalho.

No capítulo 5 tem início a parte experimental deste trabalho. São listados os equipamentos utilizados para as medições de sinais em campo, na rua de paralelepípedos e na rodovia Ayrton Senna, e em laboratório. No caso das medições em campo, foram utilizados sensores posicionados próximos aos mancais do 
pinhão, bucha do eixo da cremalheira e sujeitador. No caso das medições em laboratório é ilustrada a bancada de medição montada, a localização dos sensores e transdutores na caixa de direção e explica-se como foram gerados os sinais medidos.

No capítulo 6 são mostrados os resultados obtidos com a aplicação da técnica da Transformada de Wavelet e Emissão Acústica sobre os sinais medidos. No caso da Transformada de Wavelet são explicados como foram escolhidos os parâmetros de análise tais como ordem da wavelet de Daubechies, níveis de detalhamento retirados dos sinais medidos e são mostrados os resultados obtidos da decomposição do sinal em níveis de escala. No caso da Emissão Acústica são mostrados os pontos de impacto localizados pelo software de emissão acústica. Ao final deste capítulo é realizada uma discussão dos resultados obtidos.

No capítulo 7 é apresentada a conclusão deste trabalho. São apresentados os motivos para não se conseguir realizar a comparação entre as técnicas de Transformada de Wavelet e Emissão Acústica e são citados alguns pontos de melhoria que devem ser estudados para aprimorar o uso destas duas técnicas. 


\section{TRANSFORMADA DE WAVELET}

Neste capítulo é abordado o embasamento teórico para realizar a decomposição de funções em bases de funções ortogonais. Em seguida é explicada brevemente a Transformada Contínua de Wavelet e a Transformada Discreta de Wavelet. Por último, explica-se a teoria sobre wavelets.

De acordo com Mertins (1998), no início da década de 80, Morlet introduziu o conceito de Transformada de Wavelet ao utilizar esta transformada para estudar dados sísmicos.

Desde então, vários tipos de transformadas de wavelet foram desenvolvidas e novas aplicações foram encontradas.

O objetivo da Transformada Wavelet é decompor um sinal arbitrário $f(x)$ em uma soma infinita de wavelets de diferentes escalas.

Segundo Nigro (2009), uma wavelet é geralmente expressa por uma função $\psi(t)$ e esta não precisa ser nem suave e nem simétrica, mas é necessária que esta função pertença ao espaço funcional das funções de quadrado integrável, cobrindo o domínio dos reais $L^{2}(R)$.

Inicialmente foi desenvolvida a Transformada Contínua de Wavelet e em seguida a Transformada Discreta de Wavelet.

Esta última por ser computacionalmente muito eficiente, tem sido aplicada a quase todos os campos técnicos tais como compressão de imagem, integração numérica, reconhecimento de padrões entre outros. 


\subsection{DECOMPOSIÇÃO DE FUNÇÕES EM BASES DE FUNÇÕES} ORTOGONAIS

Neste trabalho deseja-se decompor os sinais medidos em duas parcelas: vibração mecânica da cremalheira e a onda produzida pelo impacto de metal com metal.

A Transformada de Wavelet é uma das técnicas utilizadas para realizar essa decomposição do sinal em funções elementares.

Desta forma, nesse parágrafo serão discutidos os fundamentos, conceitos e nomenclatura básica da decomposição de sinal em bases de funções ortogonais, necessária ao entendimento da análise de wavelet. Utilizam-se bases de funções ortogonais por permitirem a reconstrução perfeita do sinal a partir dos coeficientes da Transformada de Wavelet.

\subsubsection{PRODUTO INTERNO}

O produto interno de dois vetores $X=\left(x_{1}, x_{2}, x_{3}\right)$ e $Y=\left(y_{1}, y_{2}, y_{3}\right)$ em $R^{3}$ é definido pela eq. (1) abaixo:

$$
\langle X, Y\rangle=x_{1} y_{1}+x_{2} y_{2}+x_{3} y_{3}
$$

Esta definição de produto interno pode ser generalizada para o espaço $R^{n}$ para qualquer dimensão $n$. Desta maneira, o produto interno de dois vetores $X=\left(x_{1}, x_{2}, x_{3}, \ldots, x_{n}\right)$ e $Y=\left(y_{1}, y_{2}, y_{3}, \ldots, y_{n}\right)$ em $R^{n}$ é definido por:

$$
\langle X, Y\rangle=\sum_{j=1}^{n} x_{j} y_{j}
$$

Esta definição de produto interno para o espaço dos números reais pode ser estendida ao espaço dos vetores complexos $\mathrm{C}$. 
Considere dois vetores $Z=\left(z_{1}, z_{2}, \ldots, z_{n}\right)$ e $W=\left(w_{1}, w_{2}, \ldots, w_{n}\right)$ em C". O produto interno desses dois vetores é definido pela eq. (3).

$$
\langle Z, W\rangle=\sum_{j=1}^{n} z_{j} \overline{w_{j}}
$$

onde $\overline{w_{j}}$ é o complexo conjugado de $w_{j}$

Definição: Segundo Bogess e Narcowich (2001), o produto interno do espaço dos vetores complexos $V$ é uma função $\left\langle{ }^{\circ},{ }^{\circ}\right\rangle: V x V \rightarrow C$ que satisfaz as seguintes propriedades:

a) Positividade: $\langle v, v\rangle>0$ para cada $v$ não nulo pertencente a $V$

b) Simetria conjugada: $\overline{\langle v, w\rangle}=\langle w, v\rangle$ para todos os vetores $v$ e $w$ em $V$

c) Homogeneidade: $\langle c v, w\rangle=c\langle v, w\rangle$ para todos os vetores $v$ e $w$ em $V$ e o escalar $c$ pertencente a $C$.

d) Aditividade: $\langle u+v, w\rangle=\langle u, w\rangle+\langle v, w\rangle$ para todo $u, v$ e $w$ pertencente a $V$.

\subsubsection{ESPAÇO $L^{2}$}

Para um intervalo $a \leq t \leq b$, o espaço $L^{2}([a, b])$ é o conjunto de todas as funções quadráticas integráveis definidas no intervalo $a \leq t \leq b$ como na eq. (4) abaixo.

$$
L^{2}([a, b])=\left\{f:[a, b] \rightarrow C, \int_{a}^{b}|f(t)|^{2} d t<\infty\right\}
$$

O produto interno de duas funções $f$ e $g$ pertencentes a $L^{2}([a, b])$ é definido por. 


$$
\langle f, g\rangle_{L^{2}}=\int_{a}^{b} f(t) \overline{g(t)} d t
$$

\subsubsection{ESPAÇO $l^{2}$}

O espaço $l^{2}$ é o conjunto de todas as sequências $X=\ldots, x_{-1}, x_{0}, x_{1}, \ldots, x_{i} \in C$, com $\sum_{-\infty}^{\infty}\left|x_{n}\right|^{2}<\infty$. O produto interno deste espaço é definido por:

$$
\langle X, Y\rangle_{l^{2}}=\sum_{n=-\infty}^{\infty} x_{n} \overline{y_{n}}
$$

\subsubsection{ORTOGONALIDADE}

Esta é um dos conceitos mais importantes deste trabalho uma vez que as wavelets utilizadas neste trabalho formam uma base ortogonal.

Para o produto interno em $R^{3}$, a lei dos cossenos é

$$
\langle X, Y\rangle=\|x\|\|y\| \cos (\theta)
$$

onde $\theta$ é o ângulo entre $x$ e $y$.

Portanto, $X$ e $Y$ são ortogonais se e somente se $\langle X, Y\rangle=0$.

Um conjunto de vetores $v_{i}$, com $\mathrm{i}=1, \ldots, \mathrm{N}$ é ortonormal se cada $v_{i}$ tem comprimento de uma unidade, ou seja, $\left\|v_{i}\right\|=1$ e $v_{i}$ e $v_{j}$ são ortogonais para $i \neq j$.

Desta forma, 2 subespaços $v_{1}$ e $v_{2}$ de $V$ são ortogonais se cada vetor em $v_{1}$ é ortogonal a todo vetor em $v_{2}$. 


\subsubsection{DEFINIÇÕES E PROPRIEDADES DA DECOMPOSIÇÃO DE SINAIS}

A seguir são apresentados alguns fundamentos que servem de suporte para entender a teoria sobre wavelets.

Suponha que $V_{0}$ é um subespaço dimensional finito de um espaço de produto interno $V$. Para qualquer vetor $v \in V$, a projeção ortogonal de $v$ em $V_{0}$ é um único vetor $v_{0} \in V_{0}$ que é:

$$
\left\|v-v_{0}\right\|=\min \|v-w\|
$$

Suponha que $V_{0}$ é um subespaço dimensional finito de um espaço de produto interno $V$. Seja $v$ um elemento pertencente a $V$. A projeção ortogonal $v_{0}$ tem a seguinte propriedade: $v-v_{0}$ é ortogonal a todos os vetores de $V_{0}$.

Suponha $V$ um espaço de produto interno e $V_{0}$ é um subespaço dimensional $N$ com base ortonormal $\left(e_{1}, e_{2}, \ldots, e_{n}\right)$. A projeção ortogonal de um vetor $v$ pertencente a $V$ em $V_{0}$ é dado por

$$
v_{0}=\sum_{j=1}^{N} \alpha_{j} e_{j} \operatorname{com} \alpha_{j}=\left\langle v, e_{j}\right\rangle
$$

Suponha que $V_{0}$ é um subespaço do espaço de produto interno $V$. O complemento ortogonal de $V_{0}$, denominado $V_{0}^{\perp}$, é o conjunto de todos os vetores em $V$ que são ortogonais a $V_{0}$, isto é

$$
V_{0}^{\perp}=\{v \in V ;\langle v, w\rangle=0\} \text { para todo } w \in V_{0}
$$


Suponha $V_{0}$ um subespaço de dimensão finita do espaço de produto interno $V$. Cada vetor $v \in V$ pode ser escrito unicamente como $v=v_{0}+v_{1}$, onde $v_{0} \in V_{0} \mathrm{e}$ $v_{1} \in V_{0}^{\perp}$.

\subsection{TRANSFORMADA CONTÍNUA DE WAVELET}

Em 1984, Morlet definiu o conceito de wavelet, mas somente alguns anos mais tarde com a ajuda de Grossman que Morlet formalizou a Transformada Contínua de Wavelet.

A Transformada Contínua de Wavelet é definida pela eq. (11) a seguir.

$$
W_{x}(a, b ; \psi)=\int x(t) \psi_{a, b}(t) d t
$$

onde $a$ é o parâmetro de escala, $b$ é o parâmetro de tempo, $\psi(t)$ é a wavelet , $\psi_{a b}(t)=\frac{1}{\sqrt{a}} \psi\left(\frac{t-b}{a}\right)$ e $x(t)$ é um sinal contínuo que pertence a $L^{2}(R)$.

\subsection{TRANSFORMADA DISCRETA DE WAVELET}

Daubechies juntamente com Mallat são os responsáveis pelo desenvolvimento da teoria de wavelet de sinais contínuos para discreto. $\mathrm{Na}$ Transformada Discreta de Wavelet, os parâmetros de escala $a$ e tempo $b$ são discretizados da seguinte forma:

$$
a=2^{-j}, b=k 2^{-j}
$$


onde $j$ e $k$ são inteiros.

Desta maneira a função contínua de wavelet $\psi_{a, b}(t)$ transforma-se na função discreta de wavelet a seguir.

$$
\psi_{j, k}(t)=2^{j / 2} \psi\left(2^{j} x-k\right)
$$

Segundo Nigro (2009), a vantagem de se trabalhar com wavelets que formam bases ortogonais é que elas permitem a geração perfeita do sinal a partir dos coeficientes da transformada. Uma transformada ortogonal é compacta, sendo cada coeficiente calculado como o produto interno do sinal analisado com a função da base $\psi(t)$.

A discretização dos parâmetros de escala e tempo e o uso de wavelets ortogonais conduzem à Transformada Discreta de Wavelet definida da seguinte forma:

$$
W_{x}(j, k ; \psi)=\int_{-\infty}^{+\infty} x(t) \psi_{j, k}(t) d t=\left\langle x, \psi_{j, k}\right\rangle
$$

Neste trabalho, a teoria de wavelet é explicada utilizando a wavelet mais simples que é a de Haar e a detecção de impactos de knock noise foi feita utilizando as wavelets de Daubechies e Newland.

\subsection{WAVELET DE HAAR}

A teoria de wavelet é explicada baseando-se na wavelet mais simples que é a de Haar. Mas antes de prosseguir, é necessário conhecer duas definições.

Definição: Uma função tem suporte compacto, se existe um intervalo fechado e limitado, fora do qual $f(x)=0$. 
Definição: Uma wavelet é uma função $\psi(x) \in L^{1}(R) \cap L^{2}(R)$, tal que a família de funções $\psi_{j, k}(x)=2^{-j / 2} \psi\left(2^{-j} x-k\right)$, onde $j$ e $k$ são inteiros arbitrários, seja uma base ortonormal para $L^{2}(R)$.

\subsubsection{FUNÇÃO DE ESCALA DE HAAR}

$\mathrm{Na}$ teoria de wavelet existem duas funções importantes, a função de escala $\phi$ e a função wavelet $\psi$.

A função de escala de Haar está ilustrada na figura 1 abaixo.

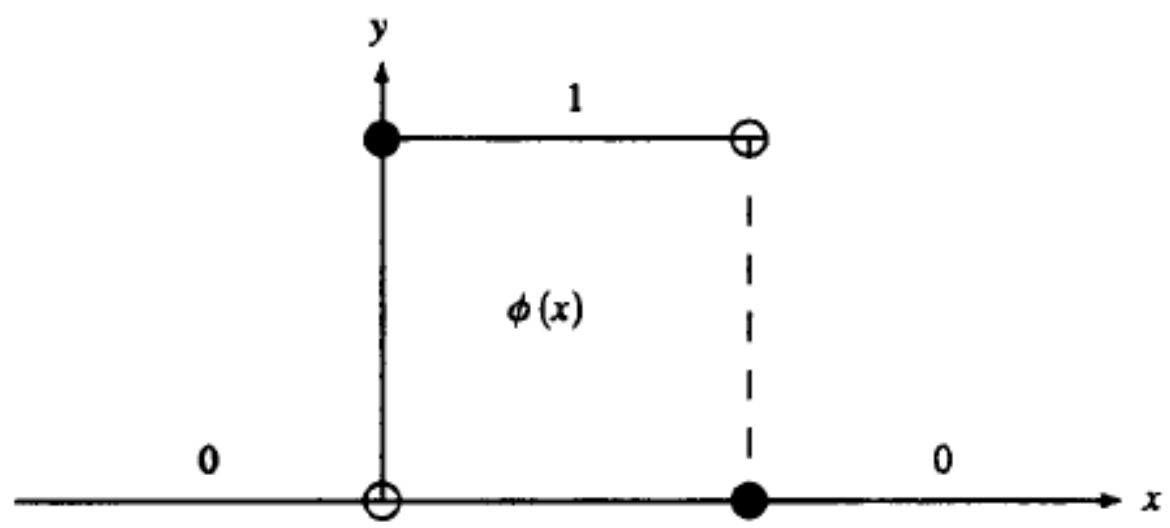

Figura 1 - Função de escala de Haar.

Esta função assume valor 1 para o intervalo $0 \leq x<1$ e valor 0 para qualquer valor de $x$ fora desse intervalo e portanto, de acordo com a definição acima, é uma função com suporte compacto.

A função $\phi(x-k)$ tem o mesmo gráfico da função $\phi$, mas transladada para a direita de $k$ unidades. Desta forma, adota-se $V_{0}$ como o espaço de todas as funções definidas por:

$$
\sum_{k \in z} a_{k} \phi(x-k), \text { com } a_{k} \in R
$$


onde $k$ pode ser qualquer valor inteiro positivo ou negativo.

Em muitas situações, são necessários blocos mais finos do que os representados por $\phi(x)$ para analisar sinais de alta frequência. Neste caso, pode-se utilizar a função de escala $\phi(2 x)$ cujo bloco possui metade da largura do bloco de $\phi(x)$. A figura 2 abaixo ilustra o gráfico da função $\phi(2 x)$.

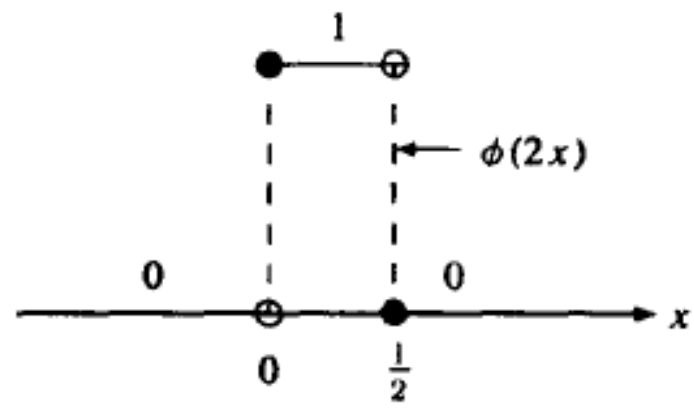

Figura 2 - Gráfico da função $\phi(2 x)$

A função $\phi(2 x-k)$ possui o mesmo gráfico da função $\phi(2 x)$, mas deslocado para a direita de $\mathrm{k} / 2$ unidades. Desta forma, adota-se $V_{1}$ como o espaço de todas as funções definidas por:

$$
\sum_{k \in z} a_{k} \phi(2 x-k), \text { com } a_{k} \in R
$$

Utilizando o mesmo raciocínio, pode-se definir o espaço das funções $V_{j}$ por:

$$
\left\{\ldots, \phi\left(2^{j} x+1\right), \phi\left(2^{j} x\right), \phi\left(2^{j} x-1\right), \phi\left(2^{j} x-2\right), \ldots\right\}
$$

Nota-se que a função contida em $V_{0}$ possui descontinuidades no conjunto dos números inteiros. Já a função contida em $V_{1}$ possui descontinuidades no conjunto dos números formados pela metade dos inteiros. Seguindo esse pensamento, percebe-se que qualquer função em $V_{0}$ está contida em $V_{1}$ e qualquer função em $V_{1}$ está contida em $V_{2}$ e assim por diante, ou seja, 


$$
V_{0} \subset V_{1} \subset V_{2} \ldots \subset V_{j} \subset V_{j+1} \cdots
$$

O conjunto $V_{j}$ contém todas as informações relevantes para uma resolução de escala da ordem de $2^{-j}$ e, portanto quanto maior o valor de $j$, melhor é a resolução. Observa-se também que aumentando o valor de $j$, o gráfico de $\phi\left(2^{j} x\right)$ aproxima-se do formato de um sinal de impacto. Isto é extremamente importante para se detectar os sinais de ruído de impacto mecânico na análise dos sinais de vibração deste trabalho.

Portanto para detectar os ruídos de impacto de knock noise do sinal de vibração é necessário decompor este sinal nas componentes pertencentes ao conjunto $V_{j}$ em que cada componente deste conjunto representa um detalhe do sinal. Uma forma de decompor o sinal de vibração é construindo uma base ortonormal para $V_{j}$ e para isto considere a definição a seguir.

Definição: o conjunto de funções $\left\{2^{j / 2} \phi\left(2^{j} x-k\right) ; k \in Z\right\}$ é uma base ortonormal de $V_{j}$.

\subsubsection{WAVELET DE HAAR}

Neste trabalho, deseja-se detectar os ruídos de impactos mecânicos nos sinais de vibração medidos em campo e em laboratório. Como ilustração, considere o sinal da figura 3 a seguir. 


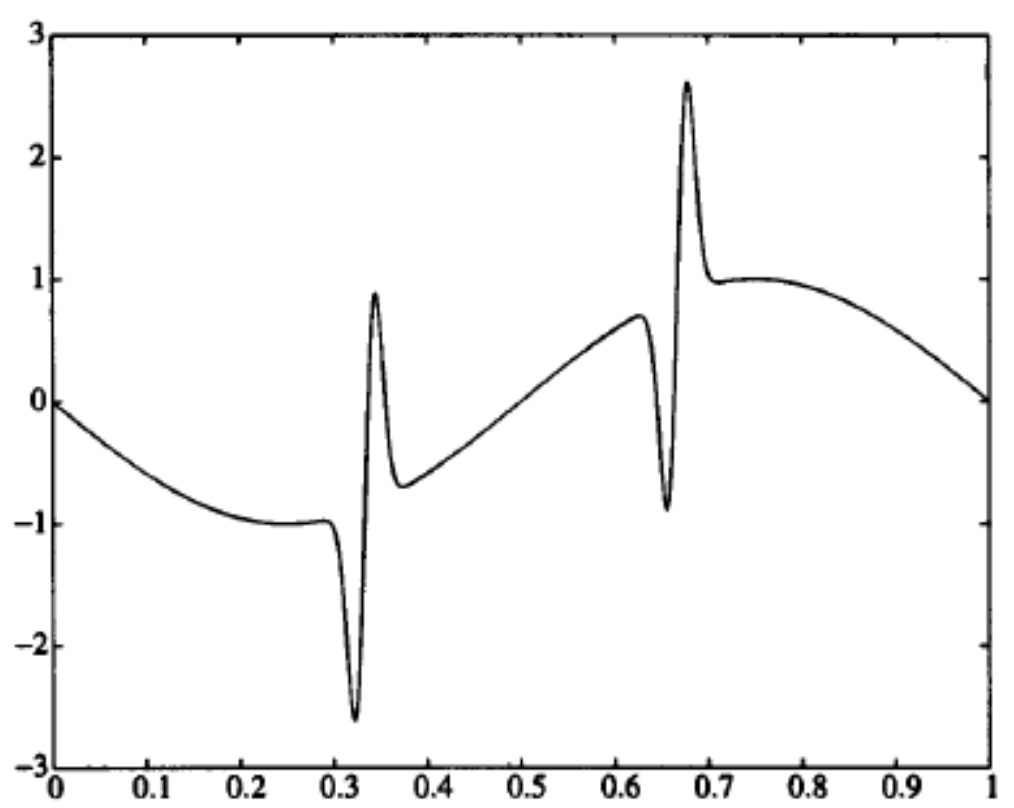

Figura 3 - Sinal.

Nesta figura nota-se a presença de dois "spikes" que representam os ruídos de impacto que se deseja detectar. Para isolar estes "spikes" do sinal é necessário decompor o sinal em níveis de detalhe, em que cada detalhe deste sinal pertença ao espaço $V_{j}$, mas não pertença ao espaço $V_{j-1}$. Uma forma de decompor o sinal é utilizando wavelets.

A idéia é decompor $V_{j+1}$ como uma soma ortogonal de $V_{j}$ mais o seu complemento $W_{j}$.

Duas condições são necessárias para construir a wavelet $\psi$.

a) $\psi$ é membro de $V_{1}$ e portanto $\psi$ pode ser escrita da seguinte forma:

$$
\psi(x)=\sum_{l} a_{l} \phi(2 x-l), \text { com } a_{l} \in R
$$

b) $\psi$ é ortogonal a $V_{0}$.

A wavelet mais simples que satisfaz as duas condições acima é a Wavelet de Haar. Esta wavelet está ilustrada na figura 4 abaixo e é definida pela eq. (20) a seguir.

$$
\psi(x)=\phi(2 x)-\phi(2 x-1)
$$




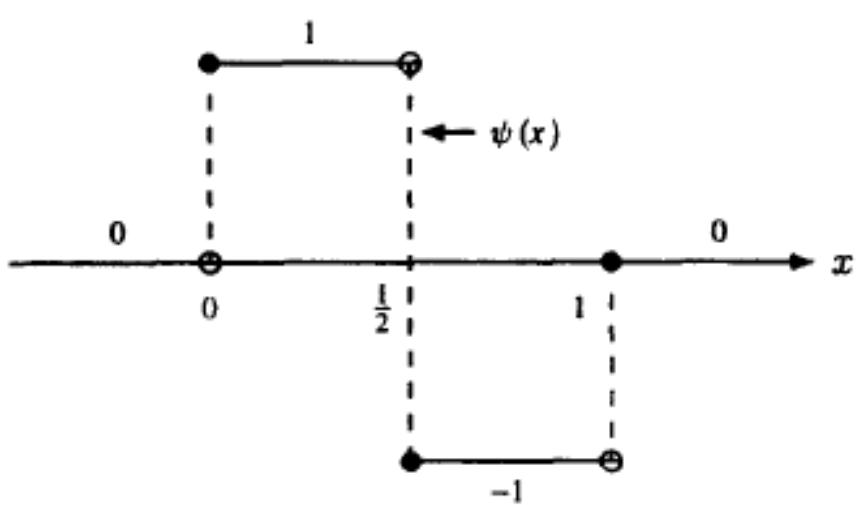

Figura 4 - Wavelet de Haar $\psi(x)$

Segundo Bogess e Narcowich (2001), qualquer equação da seguinte forma:

$$
f_{1}=\sum_{k} a_{k} \phi(2 x-k) \in V_{1}
$$

É ortogonal a $V_{0}$ se e somente se:

$$
a_{1}=-a_{0}, a_{3}=-a_{2} \ldots .
$$

Neste caso a função $f_{1}$ por manipulação algébrica pode ser escrita da seguinte forma:

$$
f_{1}=\sum_{k \in Z} a_{2 k} \psi(x-k)
$$

Adota-se o espaço $W_{0}$ como o espaço das funções da seguinte forma:

$$
\sum_{k \in Z} a_{k} \psi(x-k)
$$

Portanto, $W_{0}$ é o complemento ortogonal de $V_{0}$ em $V_{1}$.

Generalizando o raciocínio, adota-se o espaço $W_{j}$ como o espaço das funções da seguinte forma: 


$$
W_{j}=a_{k} \psi\left(2^{j} x-k\right)
$$

Onde foi assumido que apenas um finito número de $a_{k}$ são diferentes de zero. $W_{j}$ é o complemento ortogonal de $V_{j}$ em $V_{j+1}$ como mostrado na eq. (26) a seguir.

$$
V_{j+1}=V_{j} \oplus W_{j}
$$

Dois fatos são importantes na eq. (26):

a) Cada função em $W_{j}$ é ortogonal a toda função em $V_{j}$

b) Qualquer função em $V_{j+1}$ que é ortogonal a $V_{j}$ deve pertencer a $W_{j}$

Decompondo sucessivamente $V_{j}$ de acordo com a equação (26) tem-se:

$$
V_{j}=W_{j-1} \oplus W_{j-2} \ldots \oplus W_{0} \oplus V_{0}
$$

Portanto, cada função $f$ em $V_{j}$ pode ser decomposta unicamente como uma soma da seguinte forma:

$$
f=w_{j-1}+w_{j-2}+\ldots+w_{0}+f_{0}
$$

A figura 5 abaixo ilustra essa decomposição.

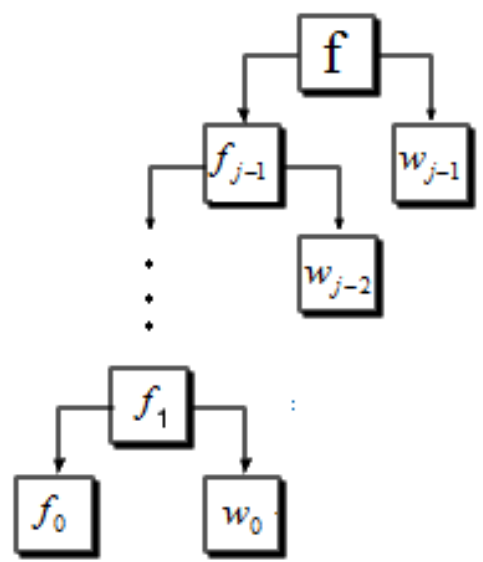

Figura $5-f=w_{j-1}+w_{j-2}+\ldots+w_{0}+f_{0}$ 
Nesta decomposição, cada $w_{l}$ pertence a $W_{l}, 0 \leq l \leq j-1$ e $f_{0}$ pertence a $V_{0}$. Intuitivamente, $w_{l}$ representa os "spikes" ou detalhes da função $f$ de largura $\frac{1}{2^{l+1}}$ que não podem ser representados por combinação linear de "spikes" de outras larguras e, portanto consegue-se separar os "spikes" ou detalhes do sinal.

Esta mesma teoria pode ser aplicada para as wavelets de Newland e Daubechies descritas abaixo.

\subsection{WAVELET DE DAUBECHIES}

As wavelets de Daubechies foram descobertas por Ingrid Daubechies e formam uma família de wavelets ortogonais suaves com suporte compacto.

A wavelet mais simples dessa família é a wavelet de Haar que é a única descontínua.

Para a detecção dos ruídos de knock noise foi utilizada esta família de wavelets devido à sua similaridade com o "spike" ou ruídos de impacto dos sinais de vibração medidos.

A figura 6 ilustra o exemplo de uma wavelet de Daubechies e a figura 7 ilustra a função de escala associada a essa wavelet. 


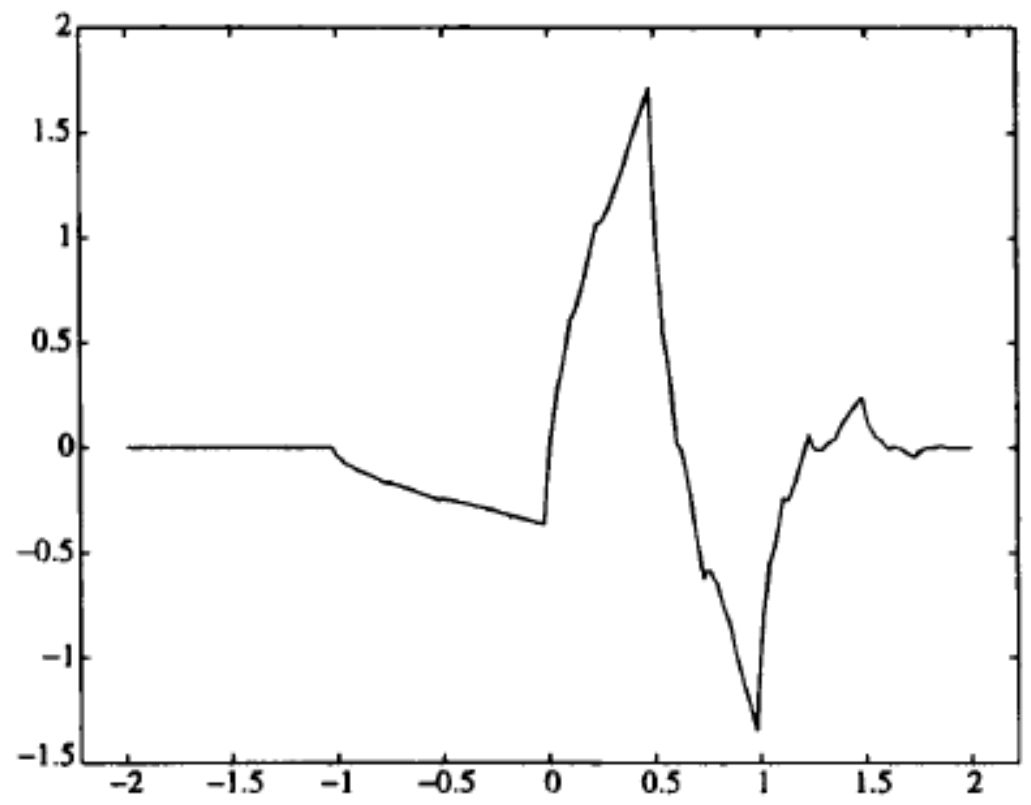

Figura 6 - Wavelet de Daubechies

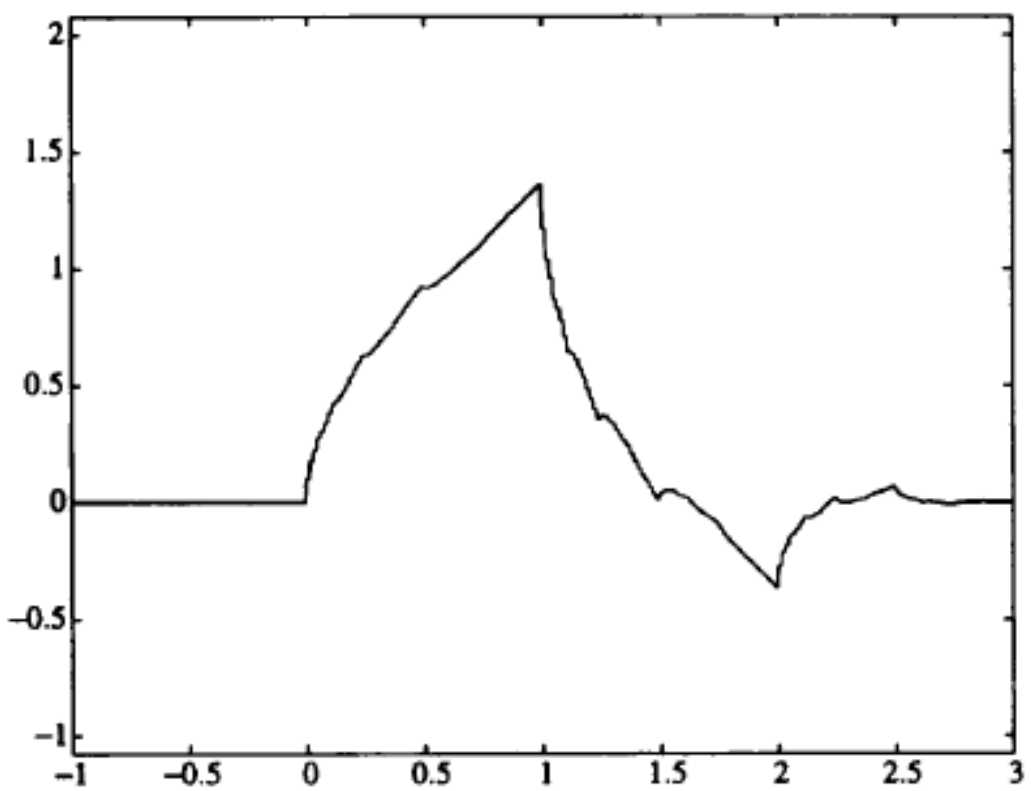

Figura 7 - Função de escala de Daubechies

$\mathrm{Na}$ figura 8 abaixo, encontram-se mais alguns exemplos de wavelets da família de Daubechies. Neste caso, o número à frente da nomenclatura "db" referese à ordem da wavelet. 


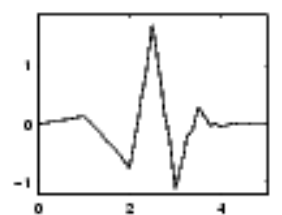

$\mathrm{db} 3$

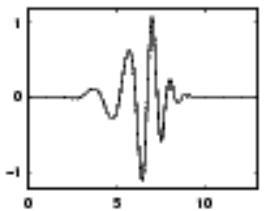

$\mathrm{db} 7$

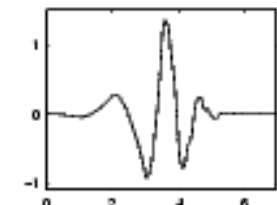

$\mathrm{db} 4$

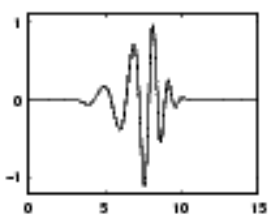

$\mathrm{db} 8$

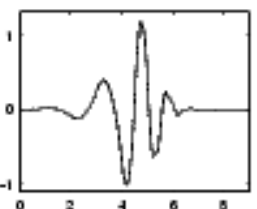

$\mathrm{db} 5$

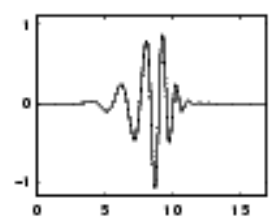

$\mathrm{db} 9$

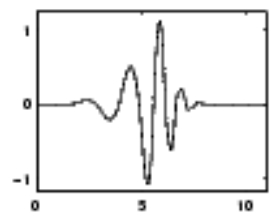

db6

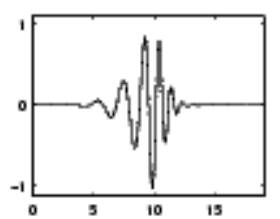

$\mathrm{db} 10$

Figura 8 - Wavelets de Daubechies

Em geral, as wavelets de Daubechies são escolhidas para ter o maior número possível de momentos nulos, definidos a seguir.

Em mecânica, integrais da forma $\int_{-\infty}^{\infty} x^{k} \rho(x) d x$ são conhecidas por momentos de inércia de uma distribuição de massa $\rho$ em relação a uma potência $\mathrm{k}$ de uma distância x. O termo "momento" indica uma integral de qualquer função contra $x^{k}$.

As wavelets de Daubechies são classificadas de acordo com o número de momentos nulos que elas têm.

De acordo com Lima (2003), a vantagem de uma wavelet possuir vários momentos nulos é o fato de conduzir a uma alta compressividade, uma vez que os coeficientes das wavelets das escalas mais finas são essencialmente nulos onde a função é suave.

Cada wavelet possui um número de momentos nulos igual a metade do número de coeficientes.

Um momento nulo limita a habilidade da wavelet em representar o comportamento polinomial ou a informação de um sinal. Por exemplo, wavelets com 4 coeficientes e 2 momentos nulos codificam polinômios com dois coeficientes, isto é, funções constantes e funções lineares.

Para detectar o ruído acústico proveniente de impactos internos entre os componentes mecânicos da direção, foi necessário identificar qual a wavelet da família Daubechies que mais se assemelha fisicamente aos ruídos de impacto dos sinais medidos objetivando a separação desses ruídos dos sinais de vibração. 
De acordo com Newland (1993), as formas das componentes ou níveis de detalhe do sinal decomposto dependem da forma da wavelet analisada e isto pode ser observado pelos resultados apresentados na sessão "Resultados".

\subsection{WAVELET HARMÔNICA}

A Transformada de Wavelet Harmônica foi introduzida em 1993 por David Edward Newland. Esta wavelet é baseada na transformação linear de uma dada função para a representação tempo-frequência e combina as vantagens da Transformada Contínua de Wavelet e Transformada de Fourier Janelada.

Newland (1993) assinala que a sua idéia de utilizar wavelet harmônica surgiu após analisar alguns problemas de engenharia. Ele percebeu que seria conveniente utilizar uma wavelet cujo espectro estivesse confinado exatamente em uma oitava de banda.

Para a detecção dos ruídos de impacto também foi utilizada esta família de wavelets devido à sua similaridade com o "spike" dos sinais de vibração medidos.

A seguir, encontra-se uma breve explicação sobre wavelet harmônica e função de escala harmônica.

\subsubsection{WAVELET HARMÔNICA}

Considere uma função real $w_{p}(x)$ cuja Transformada de Fourier é definida por:

$$
W_{p}(\omega)=\left\{\begin{array}{l}
1 / 4 \pi, \text { para }-4 \pi \leq \omega<-2 \pi \\
1 / 4 \pi, \text { para } 2 \pi \leq \omega<4 \pi \\
0, \text { para outros int ervalos }
\end{array}\right.
$$


A figura 9 a seguir ilustra esta Transformada de Fourier.

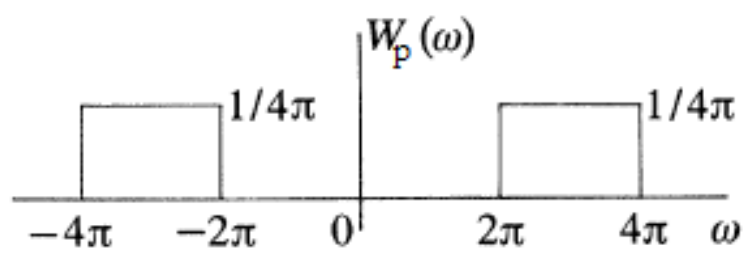

Figura 9 - Transformada de Fourier.

Aplicando a Transformada Inversa de Fourier sobre $W_{p}(\omega)$, obteve-se 0 seguinte resultado:

$$
w_{p}(x)=\int_{-\infty}^{\infty} W_{p}(\omega) \exp (i \omega x) d \omega=(\sin 4 \pi x-\sin 2 \pi x) / 2 \pi x
$$

O subscrito "p" indica que $w_{p}(x)$ é uma função par de $\mathrm{x}$.

Considere agora a função real $w_{i}(x)$ cuja Transformada de Fourier é dada por:

$$
W_{i}(\omega)=\left\{\begin{array}{l}
i / 4 \pi, \text { para }-4 \pi \leq \omega<-2 \pi \\
i / 4 \pi, \text { para } 2 \pi \leq \omega<4 \pi \\
0, \text { paraoutros int ervalos }
\end{array}\right.
$$

A figura 10 ilustra o gráfico dessa transformada.

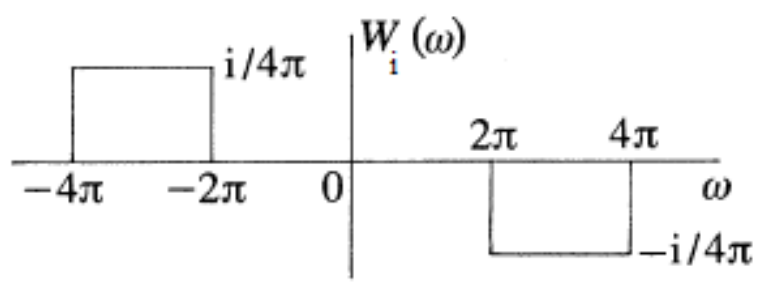

Figura 10 - Transformada de Fourier.

Aplicando a Transformada Inversa de Fourier, obteve-se o seguinte resultado: 


$$
w_{i}(x)=\int_{-\infty}^{\infty} W_{i}(\omega) \exp (i \omega x) d \omega=-(\cos 4 \pi x-\cos 2 \pi x) / 2 \pi x
$$

O subscrito "i" indica que $w_{i}(x)$ é uma função ímpar de $x$.

Combinando $w_{p}(x)$ e $w_{i}(x)$ em uma função complexa, obteve-se:

$$
w(x)=w_{p}(x)+i w_{i}(x)
$$

Assim, a wavelet harmônica é definida pela função abaixo:

$$
w(x)=\{\exp (i 4 \pi x)-\exp (i 2 \pi x)\} / i 2 \pi x
$$

A figura 11 ilustra a parte real e imaginária da wavelet harmônica $w(x)$.
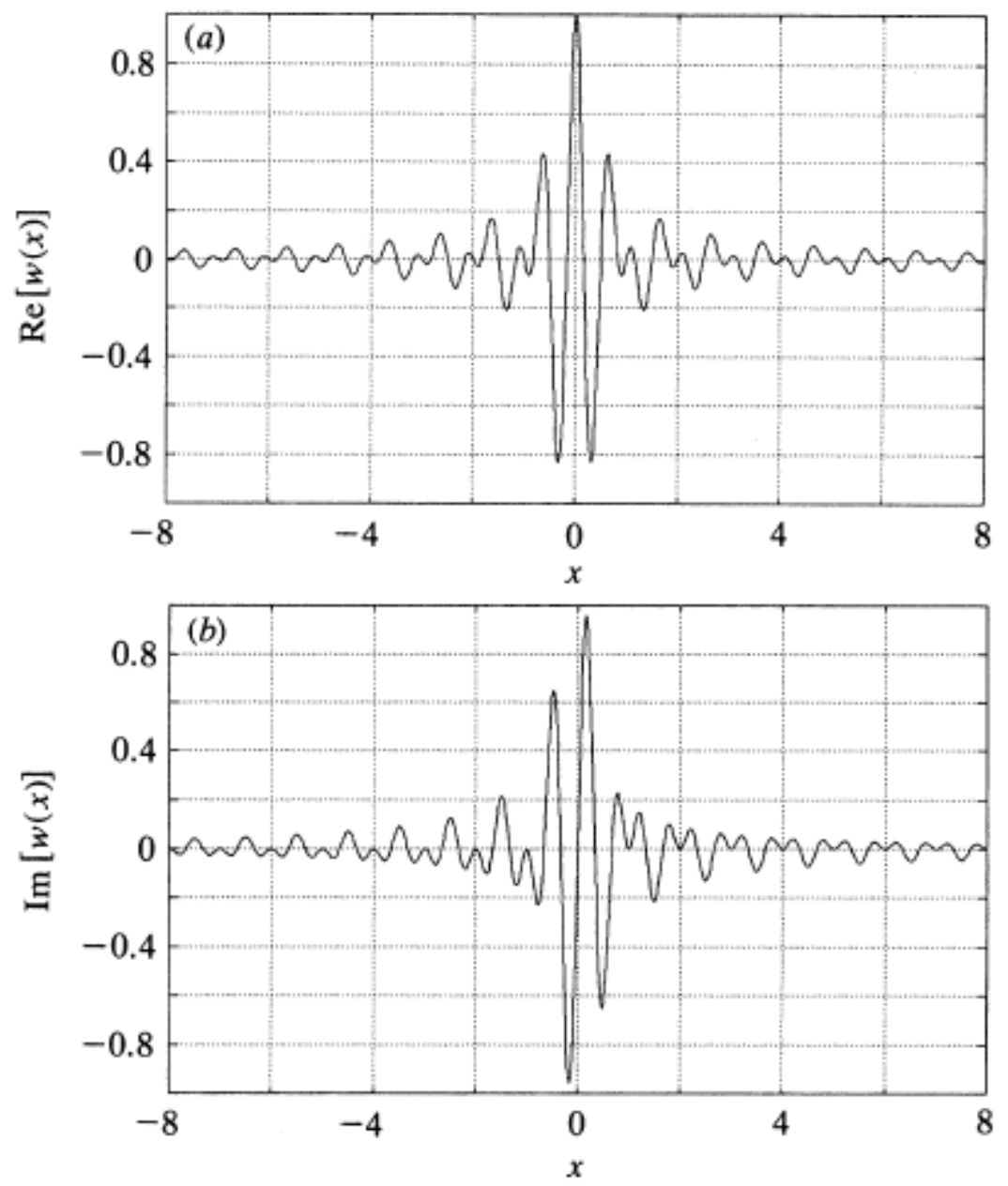

Figura 11 - Parte real e imaginária de $w(x)$. 
Aplicando a Transformada de Fourier sobre a função $w(x)$ obteve-se 0 resultado a seguir:

$$
W(\omega)=W_{p}(\omega)+i W_{i}(\omega)
$$

Portanto,

$$
W(\omega)=\left\{\begin{array}{l}
1 / 2 \pi, \text { para } 2 \pi \leq \omega<4 \pi \\
0 \text { para outros int ervalos }
\end{array}\right.
$$

A figura 12 ilustra $W(\omega)$

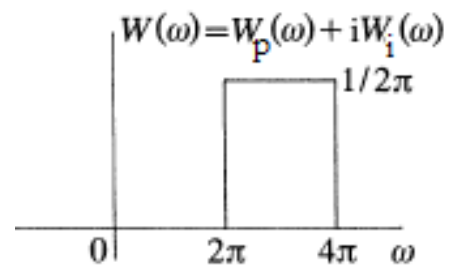

Figura 12 - Transformada de Fourier de $w(x)$.

Modificando o argumento de $w(x)$ para $w\left(2^{j} x-k\right)$ onde $j$ e $k$ são inteiros, a forma da wavelet harmônica não muda, mas a sua escala horizontal é comprimida pelo fator $2^{j}$ e a sua posição é transladada por $k$ unidades. Como explicado na wavelet de Haar, o fator $j$ determina o nível da wavelet. Para $j=0$, a Transformada de Fourier da wavelet harmônica ocupa a largura de banda de $2 \pi$ a $4 \pi$. No nível $j$, a Transformada de Fourier da wavelet ocupa a largura de banda de $2 \pi 2^{j}$ para $4 \pi 2^{j}$. Newland (1993) afirma que quanto maior o nível $j$, maior a resolução dos detalhes e maior a quantidade de coeficientes obtidos com a Transformada Harmônica de Wavelet.

Segundo Newland (1993), a família de wavelet harmônica definida por $w\left(2^{j} x-k\right)$ forma uma base ortogonal. 


\subsubsection{FUNÇÃO DE ESCALA HARMÔNICA}

Para obter a função de escala harmônica, considere a seguinte Transformada de Fourier:

$$
\phi_{p}(\omega)=\left\{\begin{array}{l}
1 / 4 \pi \text { para }-2 \pi \leq \omega<2 \pi \\
0 \text { para outros intervalos }
\end{array}\right.
$$

Aplicando Transformada Inversa de Fourier sobre $\phi_{p}(\omega)$, obteve-se a função de escala par ilustrada na eq. (38) a seguir.

$$
\phi_{p}(x)=\sin 2 \pi x / 2 \pi x
$$

O subscrito "p" indica que $\phi_{p}(x)$ é uma função par de $x$.

Considere agora a seguinte Transformada de Fourier:

$$
\phi_{i}(\omega)=\left\{\begin{array}{l}
i / 4 \pi \text { para }-2 \pi \leq \omega<0 \\
-i / 4 \pi \text { para } 0 \leq \omega<2 \pi \\
0 \text { para outros int ervalos }
\end{array}\right.
$$

Aplicando a Transformada Inversa de Fourier, obteve-se a função de escala ímpar a seguir.

$$
\phi_{i}(x)=-(\cos 2 \pi x-1) / i 2 \pi x
$$

O subscrito "i”" indica que $\phi_{i}(x)$ é uma função ímpar de $x$.

Combinando $\phi_{p}(x)$ com $\phi_{i}(x)$, obteve-se a função de escala complexa $\phi(x)$ ilustrada na eq. (41) a seguir.

$$
\phi(x)=\{\exp (i 2 \pi x)-1\} / i 2 \pi x
$$


Aplicando a Transformada de Fourier sobre a função $\phi(x)$ obteve-se o seguinte resultado:

$$
\phi(\omega)=\phi_{p}(\omega)+i \phi_{i}(\omega)
$$

Pela eq. (42) observa-se que,

$$
\phi(\omega)=\left\{\begin{array}{l}
1 / 2 \pi \text { para } 0 \leq \omega<2 \pi \\
0 \text { para outros intervalos }
\end{array}\right.
$$

A figura 13 ilustra graficamente essa transformada de Fourier.

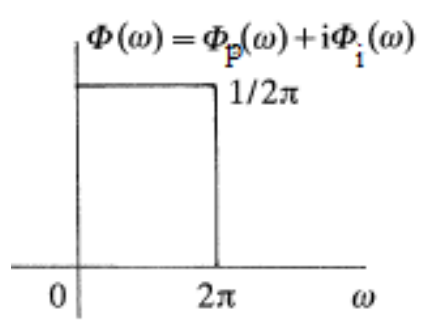

Figura 13 - Transformada de wavelet da função de escala.

A figura 14 ilustra a parte real e imaginária da função $\phi(x)$. 

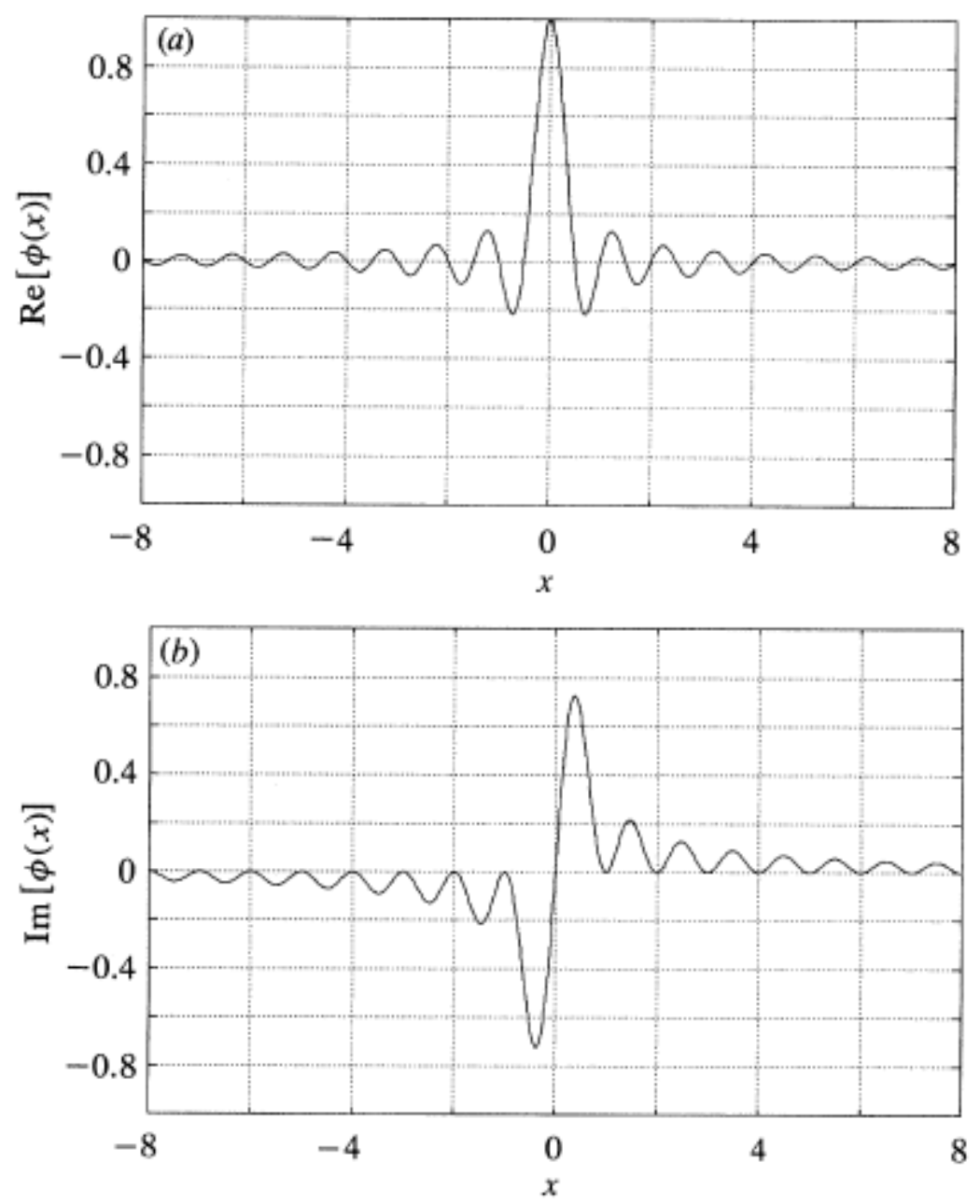

Figura 14 - Parte real e imaginária de $\phi(x)$.

Segundo Nigro (2009), a wavelet harmônica possui algumas vantagens e desvantagens em relação à wavelet de Daubechies. A desvantagem reside no fato de que a wavelet harmônica não é bem definida no domínio do tempo, decaindo em uma proporção de $1 / t$ e que seus coeficientes são geralmente complexos. A vantagem reside no fato de que a wavelet harmônica pode ser descrita por funções analíticas simples e são bem definidas no domínio da frequência. 


\section{EMISSÃO ACÚSTICA}

A história da acústica começou, em 1638, com Galileu quando ele associou um tom musical a uma frequência de vibração.

Este fenômeno foi cientificamente investigado em 1948 por Schockley, entretanto, o trabalho pioneiro sobre emissão acústica foi desenvolvido em 1950 por Joseph Kaiser.

De acordo com Miettinen e Pataniitty (1999), as fontes de emissões acústicas compreendem vários mecanismos de deformação e fratura, vários mecanismos que envolvem deslocamentos, transformações de fase em materiais, de ebulição e descargas elétricas.

Segundo Leahy et al. (2006), emissão acústica descreve uma classe de fenômenos transitórios em que ondas elásticas são geradas pela liberação rápida de energia de fontes localizadas dentro ou na superfície de um material.

Fontes de emissão acústica podem ser classificadas basicamente em 4 diferentes grupos:

a) Movimentos de deslocamento

b) Transformação de fase

c) Mecanismos de fricção

d) Formação de trincas

Como exemplo de movimento de deslocamento, pode-se citar o deslocamento de um determinado tipo de linha de imperfeição através da rede cristalina. 
Como exemplo de transformação de fase, pode-se citar a formação da martensita.

A formação de trincas ocorre na superfície ou em pontos no interior do material onde a tensão local excede a tensão de fratura.

Fricção ocorre entre materiais adjacentes e o mecanismo de deslizamento libera ondas elásticas.

Fontes de emissão acústica em sistemas de direção hidráulica incluem impactos, atritos, turbulência, etc. A interação entre os componentes internos desse sistema resultam na geração de emissões acústicas. Estas emissões se propagam na superfície do material como ondas de Rayleigh e o deslocamento destas ondas é medido por um sensor de emissão acústica conhecido por transdutor piezelétrico.

Um transdutor piezelétrico é um dispositivo capaz de converter energia mecânica em elétrica e vice-versa.

O efeito piezelétrico foi descoberto em 1880 pelos irmãos Curie. Este é uma propriedade do estado cristalino cuja característica é a relação linear entre a polarização elétrica que aparece em uma direção cristalina e uma deformação mecânica em qualquer direção.

O material piezelétrico pode ser feito de quartzo, cristais de lítio e predominantemente de cerâmica de zirconato de titânio.

A amplitude do sinal medido de emissão acústica é afetada por diversos parâmetros tais como: taxa de deformação do material, tamanho do grão do material, temperatura, homogeneidade, isotropia, material de acoplamento, etc.

Algumas precauções devem ser tomadas na montagem dos transdutores na peça em análise para garantir bons resultados. A superfície na qual o transdutor será montado deve ser plana e estar limpa para permitir um acoplamento efetivo e de 
uma forma geral, é desejável que a camada de material utilizado como acoplador seja fina para permitir máxima sensitividade.

A principal limitação desta técnica está relacionada a sua dependência do tipo de material analisado, do tipo de material utilizado como acoplador e no método de acoplamento, uma vez que este fato influi diretamente no resultado da medição da amplitude do sinal. A amplitude do sinal está associada a energia do sinal medido e será utilizada, neste trabalho, como base de cálculo para a medição da severidade do impacto.

A faixa de frequência típica associada à emissão acústica é entre 100 kHz e 1 $\mathrm{MHz}$ e portanto, acima da freqüência audível do ser humano que é em torno de 20 $\mathrm{kHz}$.

Desta forma, esta técnica não foi utilizada para analisar a faixa de freqüência audível ou medir a intensidade do ruído audível para avaliar a caixa de direção e sim utilizada para tentar localizar os pontos de ocorrência de impactos dentro da caixa de direção servo-assistida a partir de análise estatística aplicada sobre os sinais medidos. Para tanto, transdutores piezelétricos foram fixados junto à caixa de direção hidráulica, nas medições em laboratório, e os sinais medidos foram analisados com software dedicado à análise de emissão acústica.

Na sessão Resultados, será mostrado que não se conseguiu obter resultados expressivos com esta técnica e, portanto não foi possível realizar uma comparação entre a técnica de Transformada de Wavelet e a técnica de Emissão Acústica. 


\section{SISTEMA DE DIREÇÃO HIDRÁULICA}

O mecanismo de direção hidráulica descrito a seguir apresenta impactos entre os componentes mecânicos da direção devido a folgas e vibrações internas que produzem um ruído acústico na cabine do automóvel, conhecido como knock noise. Para detectar estes ruídos, foi aplicada a técnica de processamento de sinais tempo-frequência conhecida por Transformada de Wavelet utilizando as wavelets de Daubechies e Newland.

Para entender melhor o problema, é feita a seguir uma breve explicação do sistema de direção hidráulica do tipo pinhão-cremalheira, onde ocorrem os ruídos de impacto que serão analisados por wavelets.

Segundo Cruz (2006), o sistema de direção hidráulica do tipo pinhãocremalheira pode ser subdividido nos seguintes subsistemas:
a) Sistema de coluna de direção;
b) Sistema de bomba hidráulica + reservatório;
c) Sistema de mangueiras hidráulicas;
d) Sistema de caixa de direção pinhão-cremalheira.

A figura 15 abaixo ilustra um esquema do sistema de direção hidráulica do tipo pinhão-cremalheira. 


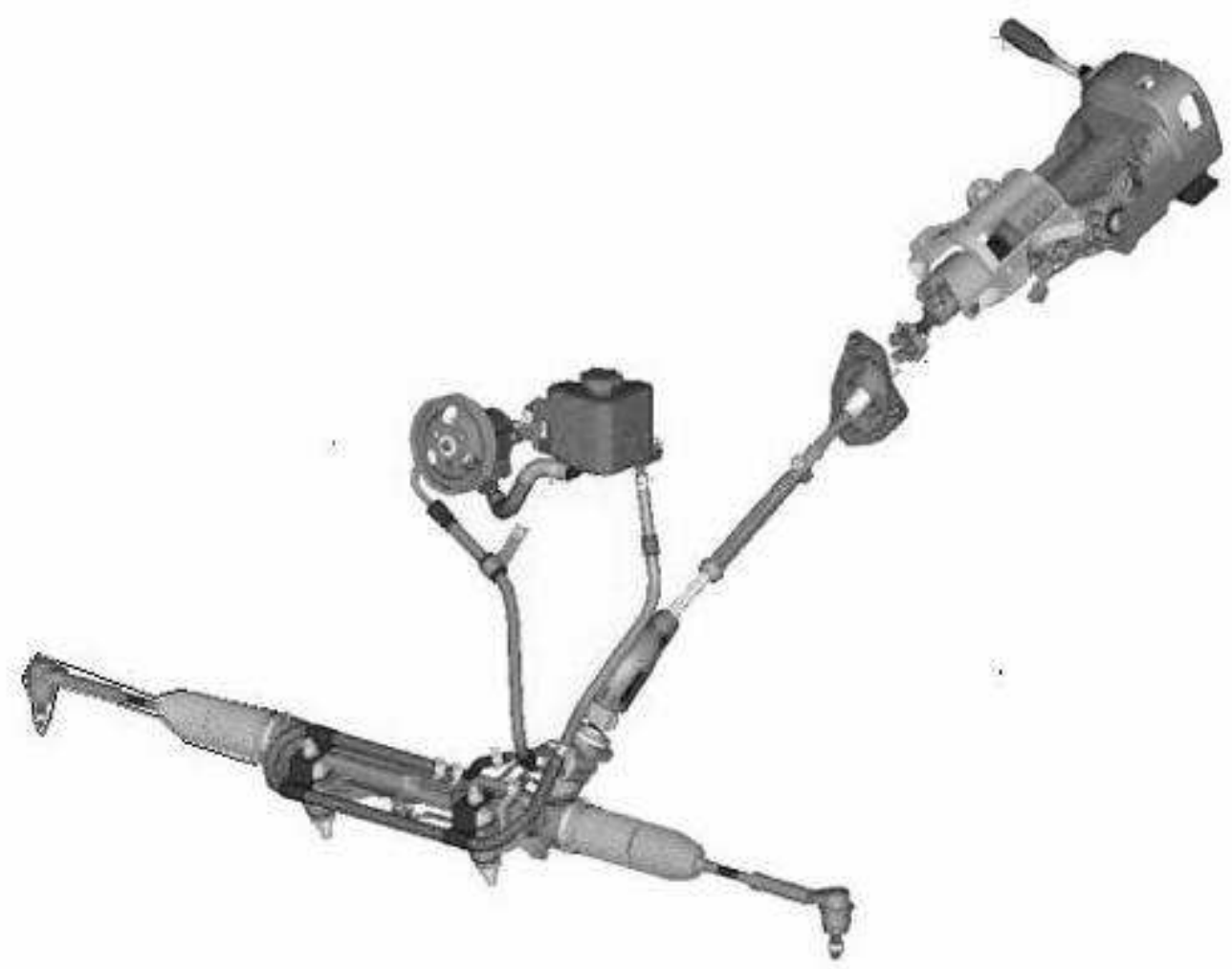

Figura 15 - Sistema de direção hidráulica

(Fonte: Cruz, 2006)

Neste trabalho será analisado o subsistema de caixa de direção pinhãocremalheira, local onde ocorrem os ruídos de impacto de interesse para este trabalho.

\subsection{SUBSISTEMA DE CAIXA DE DIREÇÃO PINHÃO-CREMALHEIRA}

O sistema de caixa de direção hidráulica pinhão-cremalheira tem o objetivo de direcionar o veículo de acordo com a manobra do motorista.

O mecanismo hidráulico tem a função de reduzir o esforço do motorista para realizar manobras como, por exemplo, de estacionamento.

Esta assistência é obtida pela interação de componentes hidráulicos e ligações mecânicas e funciona da seguinte maneira: uma válvula rotativa de centro aberto direciona o fluído hidráulico fornecido por uma bomba para um dos lados do 
êmbolo do pistão montado na cremalheira. Desta forma, a pressão hidráulica é convertida em força que movimenta a cremalheira para a esquerda ou para a direita e estes movimentos são transmitidos, através de um sistema articulado, para os braços de direção promovendo o giro das rodas.

$\mathrm{Na}$ figura 16 abaixo, é ilustrado o princípio de funcionamento da caixa de direção hidráulica citado acima.

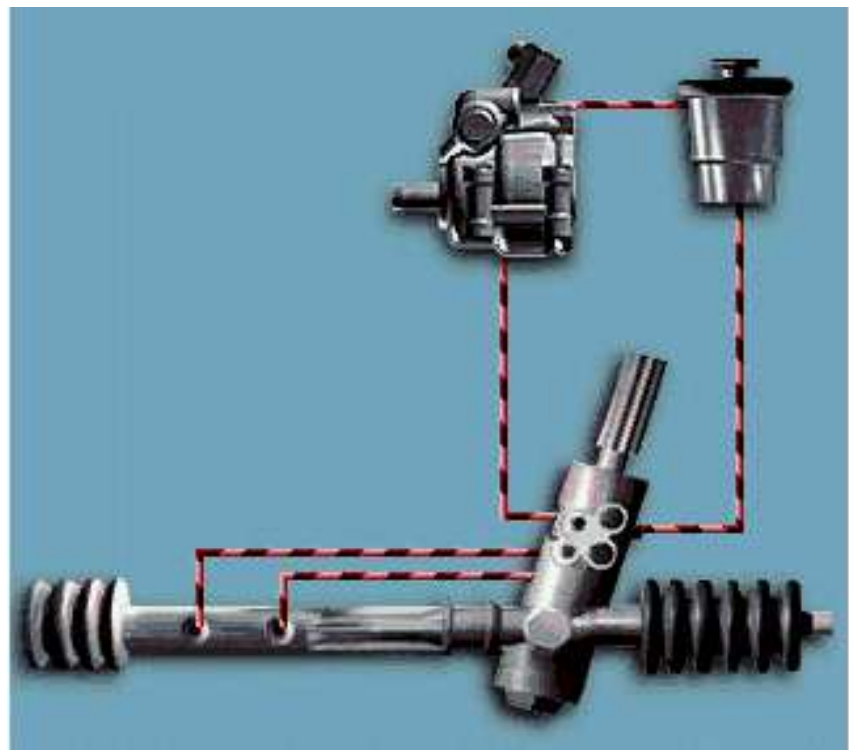

Figura 16 - Princípio de funcionamento da caixa de direção hidráulica. (Fonte: Cruz, 2006)

Na figura 17 é ilustrado o circuito hidráulico da caixa de direção.

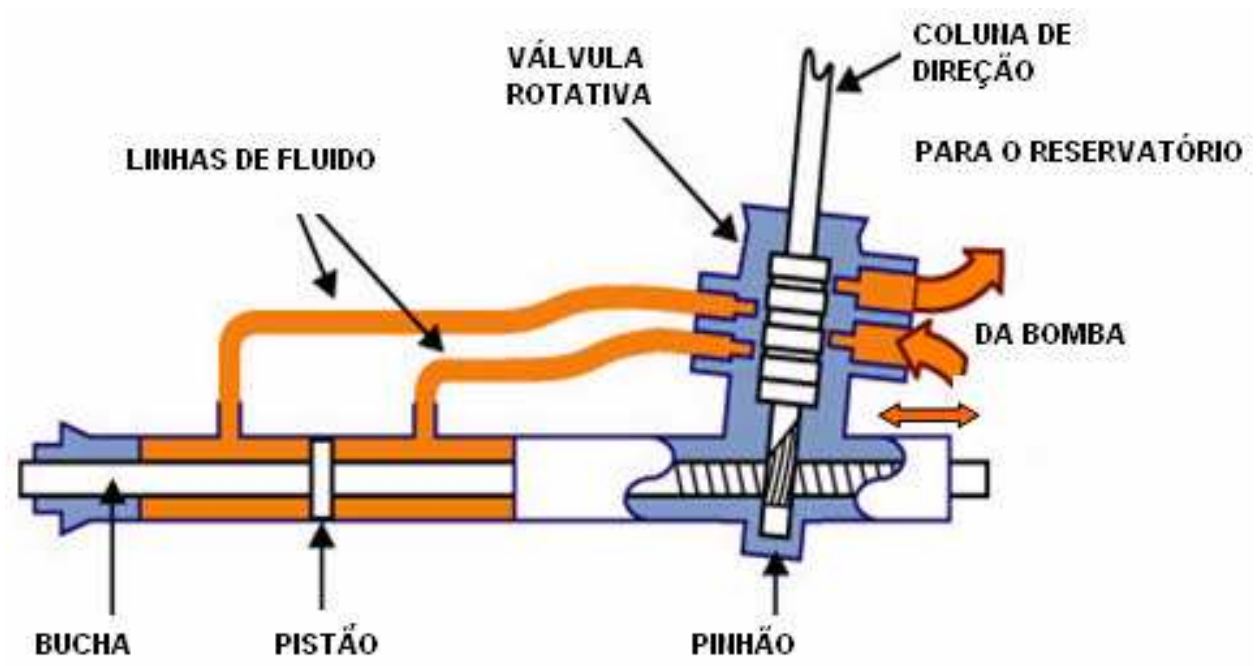

Figura 17 - Circuito Hidráulico da caixa de direção.

(Fonte: Cruz, 2006) 


\subsubsection{COMPONENTES DA CAIXA DE DIREÇÃO HIDRÁULICA TIPO PINHÃO-CREMALHEIRA}

A seguir são apresentados os principais componentes da caixa de direção hidráulica, importantes no estudo do ruído de knock noise.

\subsubsection{CARCAÇA}

Na figura 18 a seguir é ilustrado o esquema de uma carcaça.

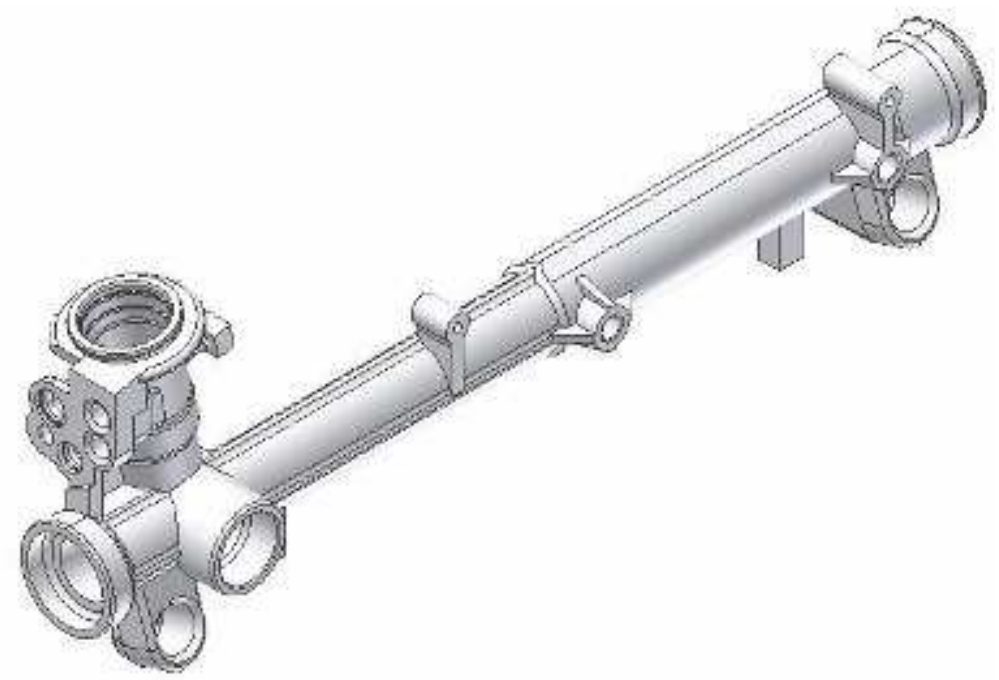

Figura 18 - Carcaça de direção hidráulica.

(Fonte: Cruz, 2006)

A carcaça envolve o conjunto de engrenamento pinhão-cremalheira e, no caso do mecanismo hidráulico, é responsável por prover os compartimentos onde o óleo hidráulico sob pressão, direcionado pela válvula rotativa, aciona o pistão cremalheira gerando a assistência hidráulica. 


\subsubsection{VÁLVULA}

A figura 19 ilustra um conjunto de válvula rotativa.

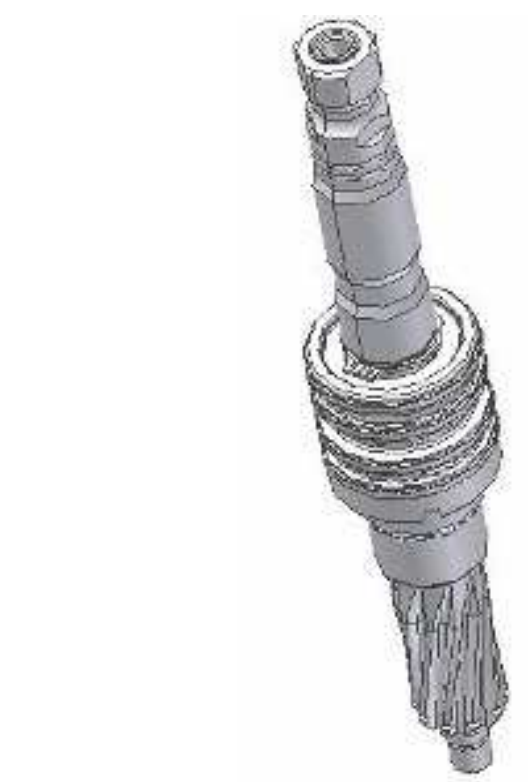

Figura 19 - Conjunto válvula rotativa.

(Fonte: Cruz, 2006)

Este conjunto é o responsável por controlar a quantidade e a direção da assistência hidráulica gerada pelo sistema de direção.

É formado por 4 componentes principais:
a) Eixo de entrada;
b) Barra de torção;
c) Carretel da válvula;
d) Pinhão.

A seguir é descrito cada um desses componentes. 


\subsection{EIXO DE ENTRADA}

A figura 20 ilustra o eixo de entrada.

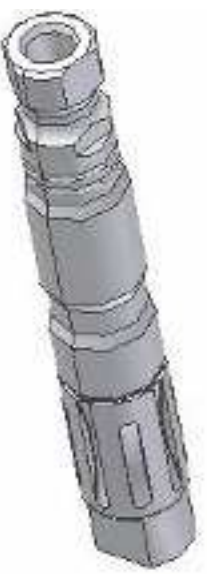

Figura 20 - Eixo de entrada.

(Fonte: Cruz, 2006)

Uma extremidade do eixo de entrada se liga ao volante através da coluna de direção e outra extremidade se liga ao pinhão através da barra de torção.

$\mathrm{Na}$ extremidade inferior do eixo de entrada está conectado o carretel da válvula cuja função é direcionar o fluído hidráulico de acordo com a posição do volante.

\subsection{CARRETEL}

A figura 21 ilustra o carretel. 


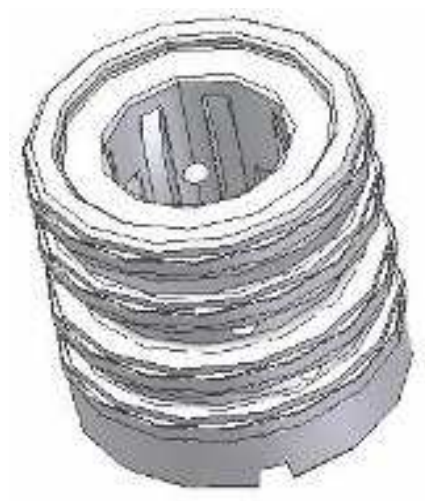

Figura 21 - Carretel.

(Fonte: Cruz, 2006)

O carretel possui na parte externa canais circulares mais largos formando câmaras que se interligam com as ranhuras internas por meio de furos transversais.

Os furos de maior diâmetro estão na câmara central por onde circula o óleo com a válvula na posição central. Os furos de menor diâmetro estão, dois a dois, nas câmaras externas que levam o óleo para os lados direito e esquerdo do pistãocremalheira.

\subsection{BARRA DE TORÇÃO}

A figura 22 ilustra a barra de torção.

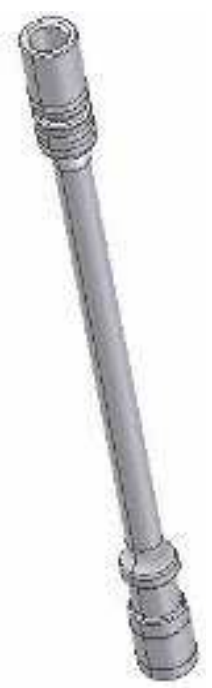

Figura 22 - Barra de torção.

(Fonte: Cruz, 2006) 
A extremidade superior da barra de torção é conectada ao eixo de entrada e a extremidade inferior é conectada ao pinhão. Dessa forma o torque que o motorista aplica ao volante é o mesmo torque aplicado na barra de torção.

\subsection{PINHÃO}

A figura 23 ilustra o pinhão.

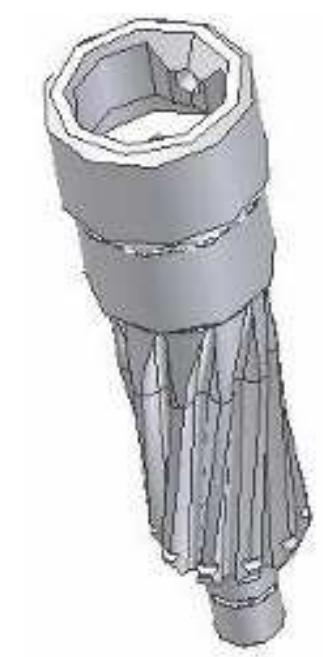

Figura 23 - Pinhão.

(Fonte: Cruz, 2006)

A função do pinhão é converter o movimento angular do volante em movimento linear da cremalheira.

\subsubsection{CREMALHEIRA}

A figura 24 ilustra a cremalheira. 


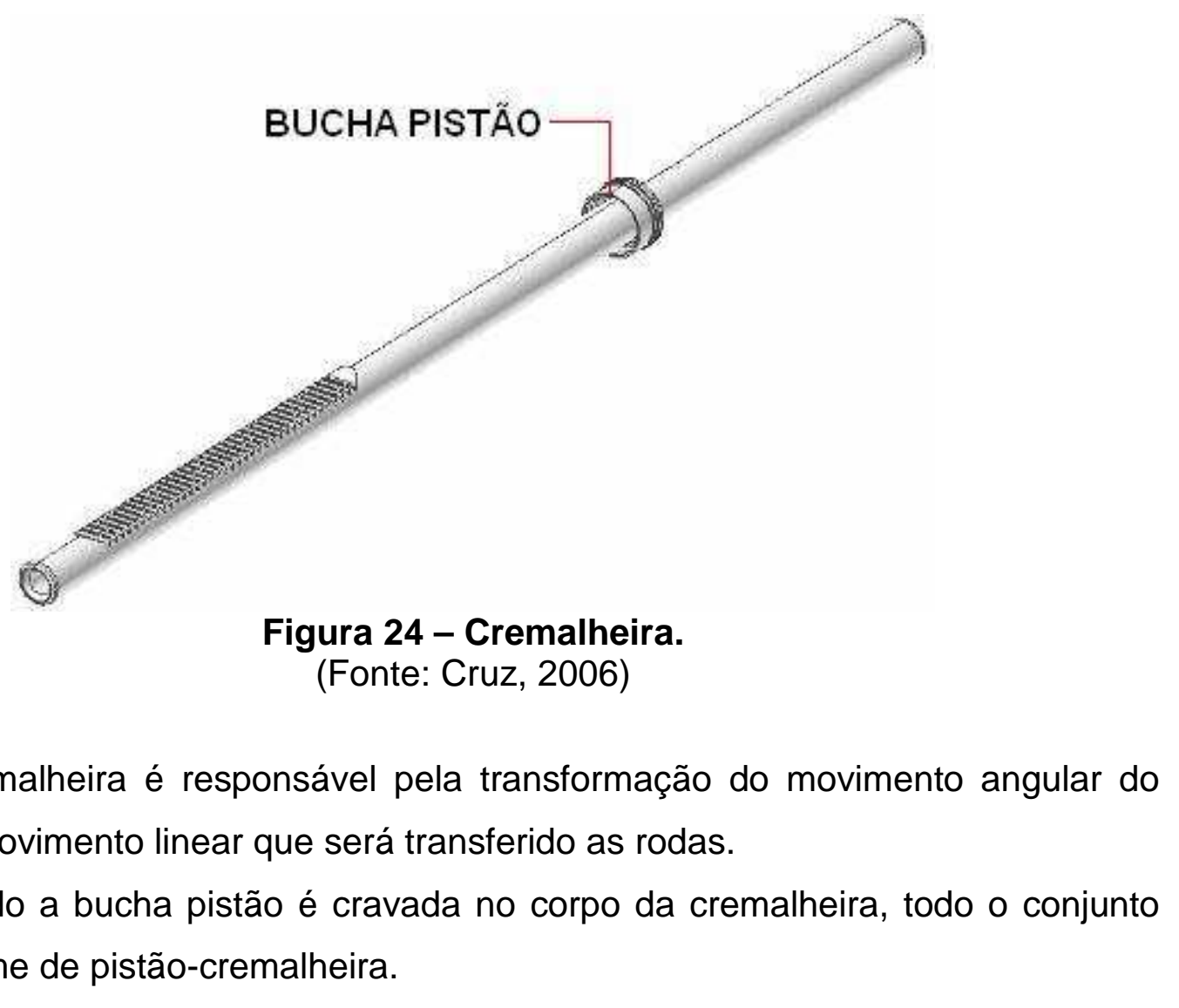

A cremalheira é responsável pela transformação do movimento angular do pinhão em movimento linear que será transferido as rodas.

Quando a bucha pistão é cravada no corpo da cremalheira, todo o conjunto recebe o nome de pistão-cremalheira.

\subsubsection{BUCHA + VEDAÇÃO DO PISTÃO E DA CARCAÇA}

A figura 25 a seguir ilustra a bucha e vedação tanto do pistão quanto da carcaça. 


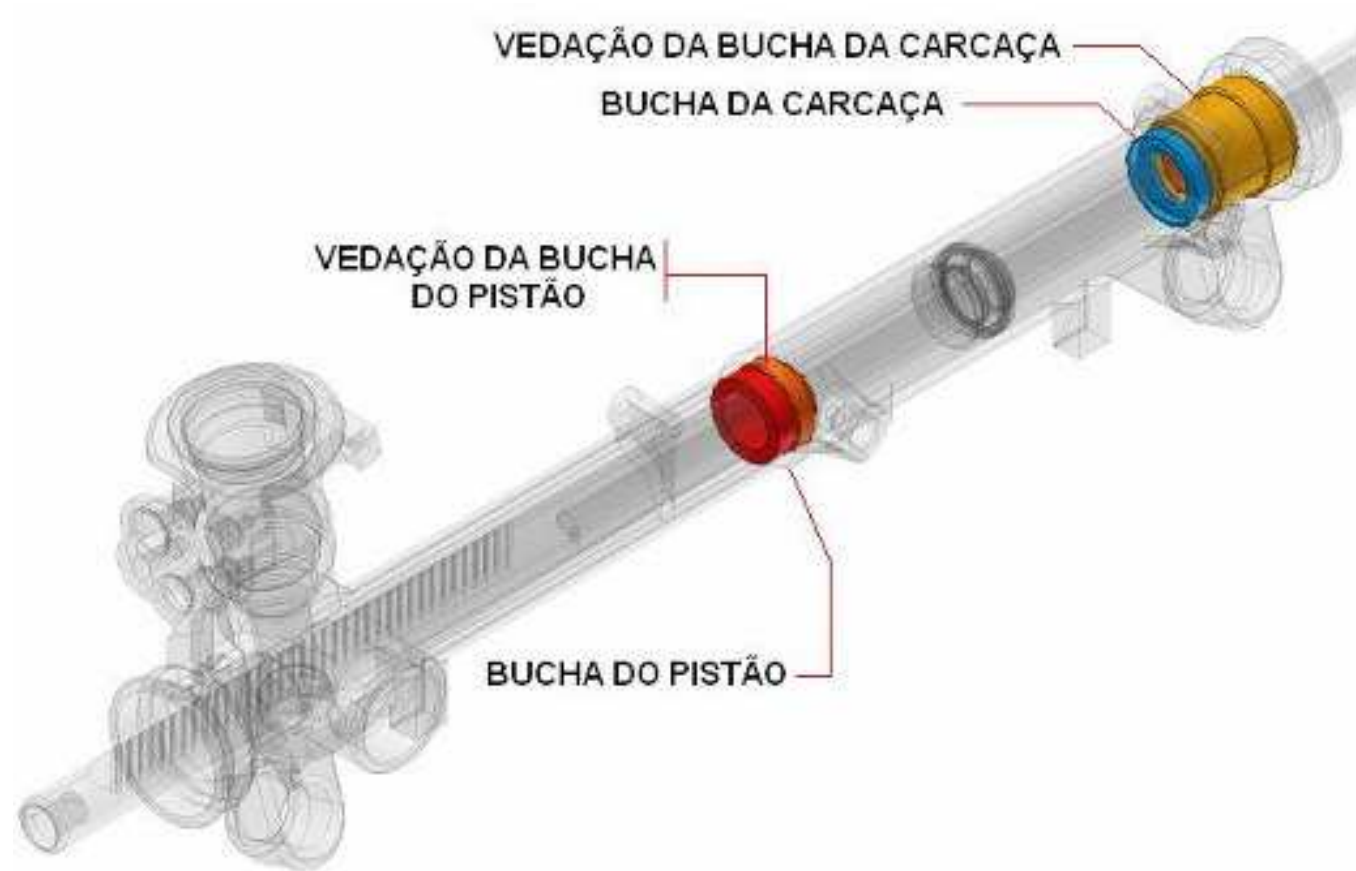

Figura 25 - Bucha + Vedação do Pistão e da Carcaça.

(Fonte: Cruz, 2006)

O conjunto bucha e vedação do pistão é responsável pela limitação da câmara de óleo do cilindro hidráulico da caixa de direção do lado próximo à válvula.

O conjunto bucha e vedação da carcaça é responsável pela limitação da câmara de óleo do cilindro hidráulico da caixa de direção do lado oposto à válvula.

\subsubsection{CONJUNTO SUJEITADOR, MOLA E PORCA}

A figura 26 ilustra esse conjunto. 


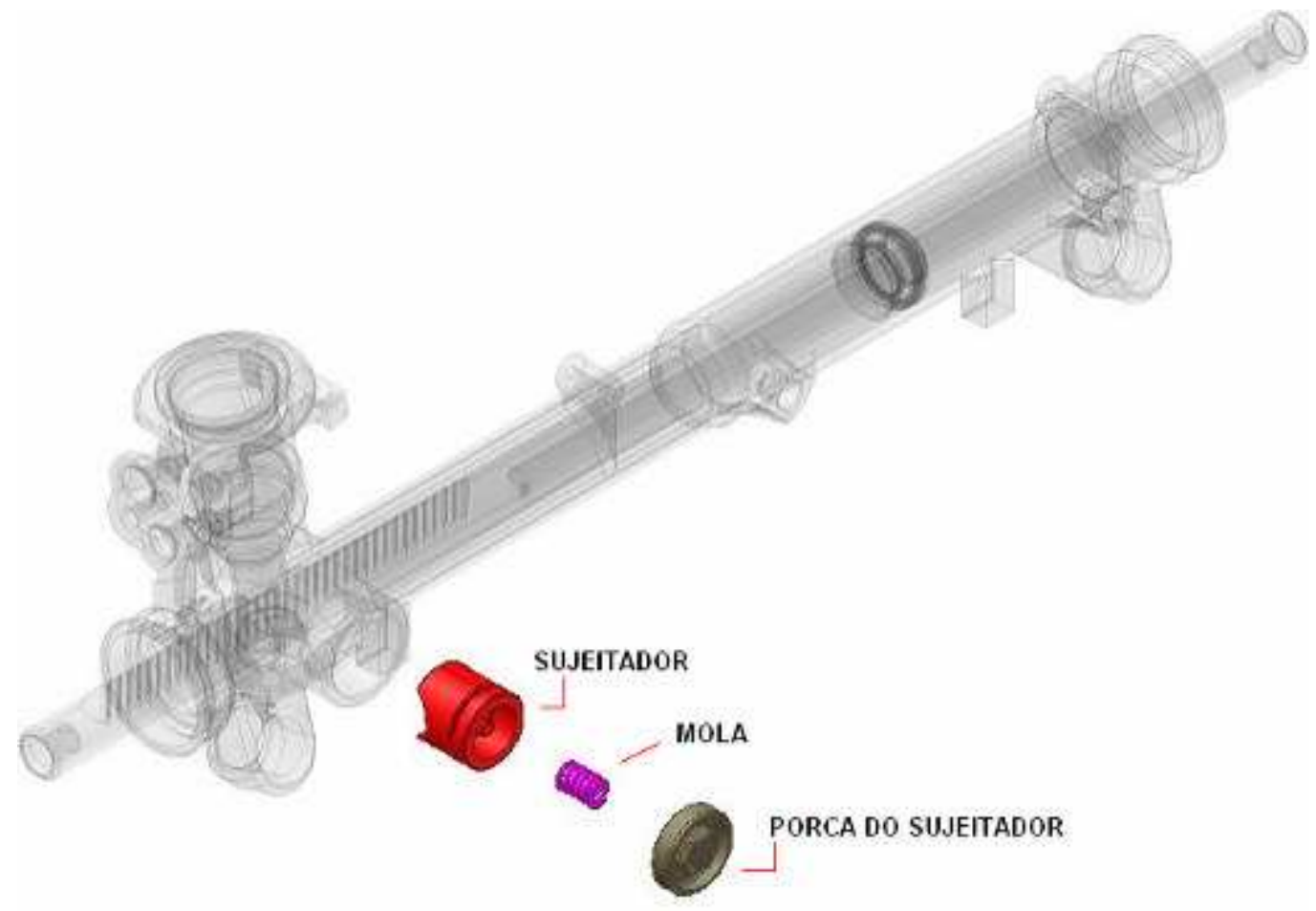

Figura 26 - Conjunto Sujeitador, Mola e Porca.

(Fonte: Cruz, 2006)

O sujeitador é o elemento responsável por pressionar a cremalheira contra o pinhão devido à ação da mola.

A mola do sujeitador tem a função de garantir a carga do sujeitador contra a cremalheira.

A porca do sujeitador tem a função de garantir a carga que a mola impõe contra o sujeitador.

\subsubsection{TIRANTE}

A figura 27 ilustra o tirante. 


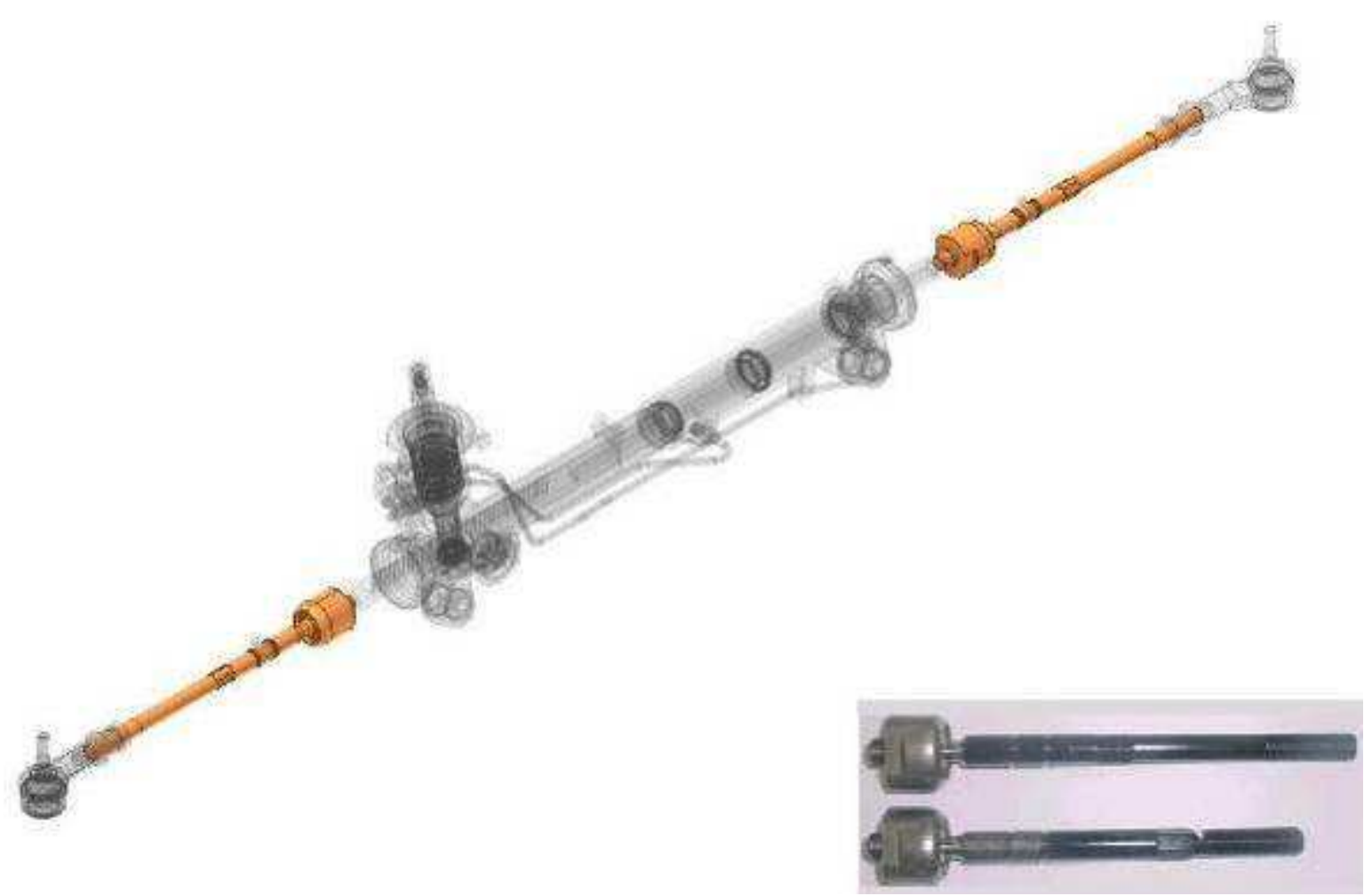

Figura 27 - Tirante.

(Fonte: Cruz, 2006)

O tirante é responsável pela interligação da cremalheira aos terminais da caixa de direção.

Este componente transmite a vibrações axiais e radiais das rodas à cremalheira da caixa de direção.

\subsubsection{TERMINAL}

A figura 28 ilustra o terminal. 


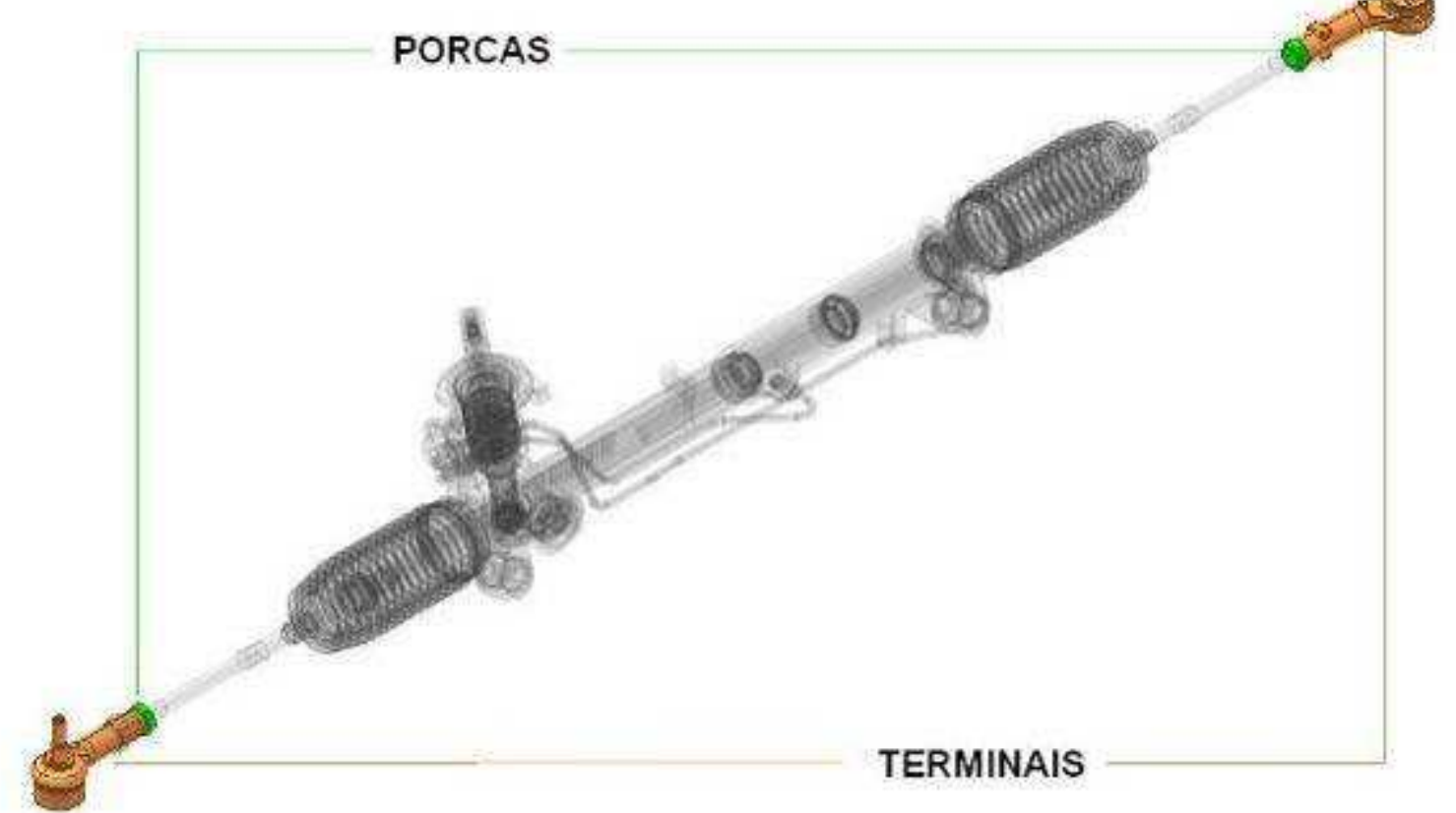

Figura 28 - Terminais da caixa de direção. (Fonte: Cruz, 2006)

Os terminais são fixados aos tirantes através de roscas travadas por porcas. $\mathrm{Na}$ outra extremidade, os terminais se prendem às rodas através do cubo de roda.

\subsubsection{COXINS}

A figura 29 ilustra os coxins. 


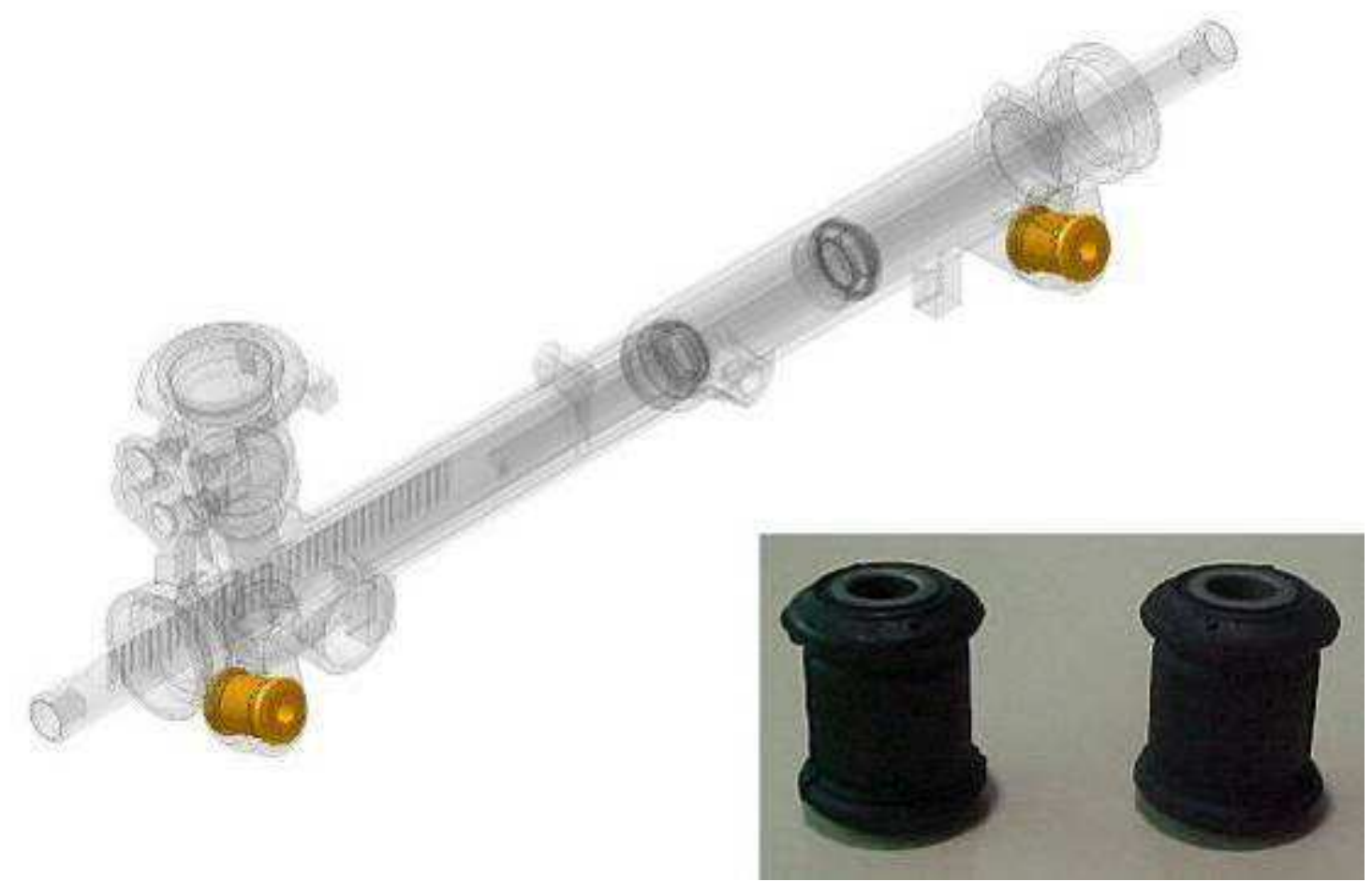

Figura 29 - Coxins da caixa de direção.

(Fonte: Cruz, 2006)

Os coxins são responsáveis por amortecer as vibrações da suspensão que possam ser transmitidas à carcaça da caixa de direção.

\subsection{TIPOS DE RUÍDOS}

O sistema de direção do tipo pinhão-cremalheira possui os seguintes ruídos característicos abaixo.

- $\quad$ Trepidação: caracterizado por som metálico repetido rapidamente.

- Tinido: som característico quando o êmbolo do pistão não está rigidamente preso à cremalheira. 
- $\quad$ Abrasivo: som originado pela alta rugosidade dos dentes do pinhão ou cremalheira.

- Mordida: som gerado pelo desbalanceamento da roda e oscilação da suspensão.

- Chocalho: som originado pela folga excessiva entre o duro da torre do sujeitador e o corpo do sujeitador.

- $\quad$ Rangido: é o ruído gerado pela fricção dos vedadores da torre da válvula e o eixo de entrada.

- Impacto: ruído de estudo desse trabalho, mais conhecido por knock noise. Originado pelo impacto direto dos dentes da cremalheira contra o pinhão ou pelo impacto do sujeitador contra a porca do sujeitador ou da cremalheira contra a bucha da carcaça.

A justificativa da escolha pelo estudo do ruído de impacto mecânico baseia-se no fato deste fenômeno ocorrer no interior da caixa de direção hidráulica e ser o ruído mais frequentemente percebido pelos usuários de automóvel. A caixa de direção ao ser trocada devido ao ruído gera um alto custo para as montadoras de veículo. 


\section{MEDIÇÕES DE SINAIS EM CAIXA DE DIREÇÃO}

Neste capítulo são explicados como foram realizadas as medições de sinais em campo e em laboratório e são listados os equipamentos utilizados.

\subsection{MEDIÇÕES DE SINAIS DE VIBRAÇÃO EM CAMPO}

Nas medições dos sinais de vibração em campo, acelerômetros piezelétricos foram fixados em algumas posições da caixa de direção hidráulica. Foram colocados acelerômetros em três posições: próximo aos mancais do pinhão, próxima à bucha do eixo da cremalheira e próximo ao sujeitador. O veículo percorreu em baixa velocidade um trecho de uma rua de paralelepípedos e um trecho da rodovia Ayrton Senna. A perturbação produzida pela irregularidade da pista de paralelepípedos acentua a ocorrência de impactos na caixa de direção. Para a medição dos sinais, foram utilizados os seguintes equipamentos:

1) Três Acelerômetros

Fabricante: Bruel \& Kjaer

Modelos: 4371 e 4384

sensibilidade: $10 \mathrm{pC} / \mathrm{g}$

2) Três Amplificadores de Carga

Fabricante: Bruel \& Kjaer

Modelo: 2635

Ganho: $100 \mathrm{mV} /$ unidade de entrada

3) Notebook

Fabricante: Toshiba

Modelo: Satellite X205

Intel(R) Core(TM) 2 Duo CPU T8100@2.10GHz 2.00 GHz 
Memória Ram: $3.00 \mathrm{~GB}$

4) Software de Aquisição de Sinal

LabView Signal Express

5) Placa de Aquisição de Sinal

Fabricante: National Instruments

As medições foram realizadas em um veículo equipado com uma caixa de direção com acentuada ocorrências de impacto.

A figura 30 a seguir ilustra o carro, o local e o tipo de pista em que foi conduzido o veículo para se medir o sinal de vibração real com acentuada ocorrência de impactos. A imagem do veículo foi propositadamente preservada.

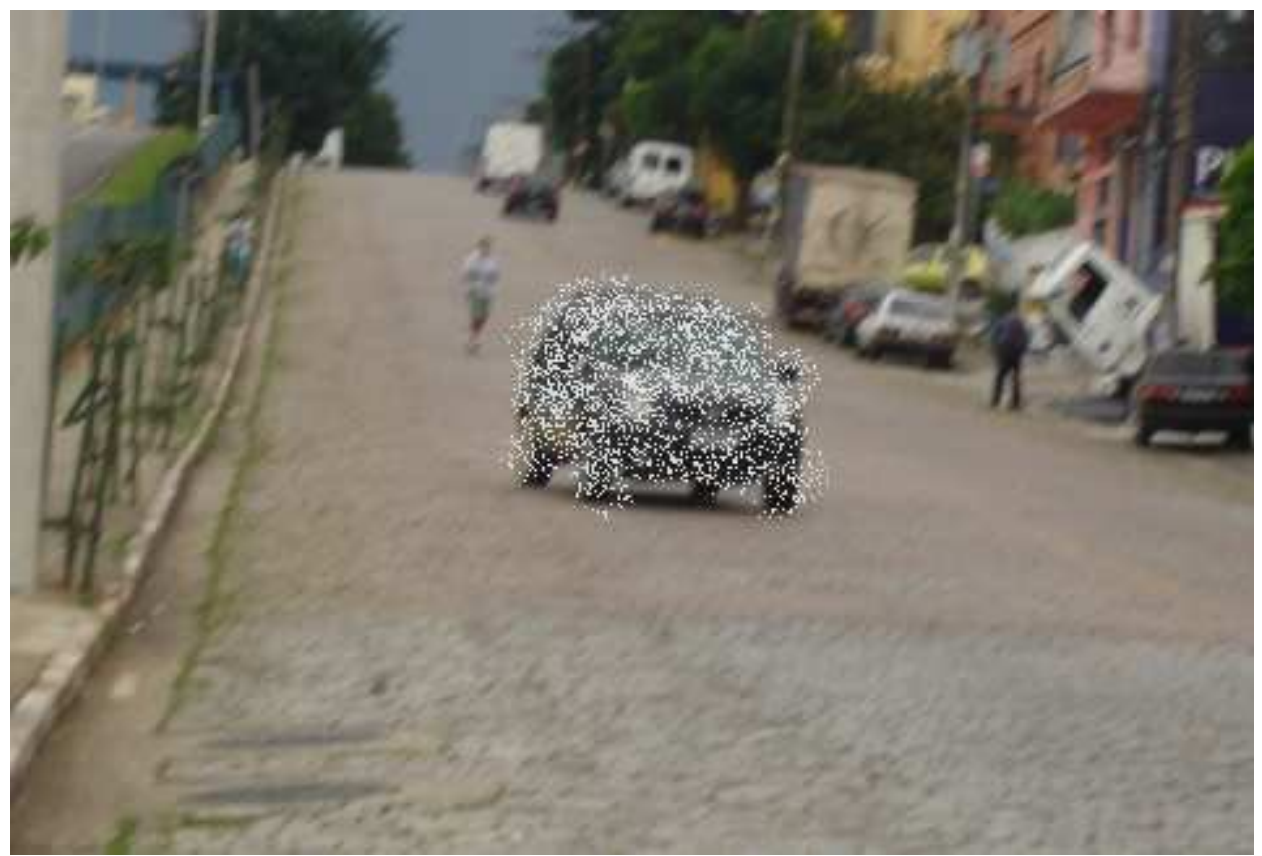

Figura 30 - Carro, local e pista.

A figura 31 ilustra o acelerômetro fixado próximo aos mancais do pinhão e a figura 32 ilustra o acelerômetro fixado próximo ao sujeitador. 


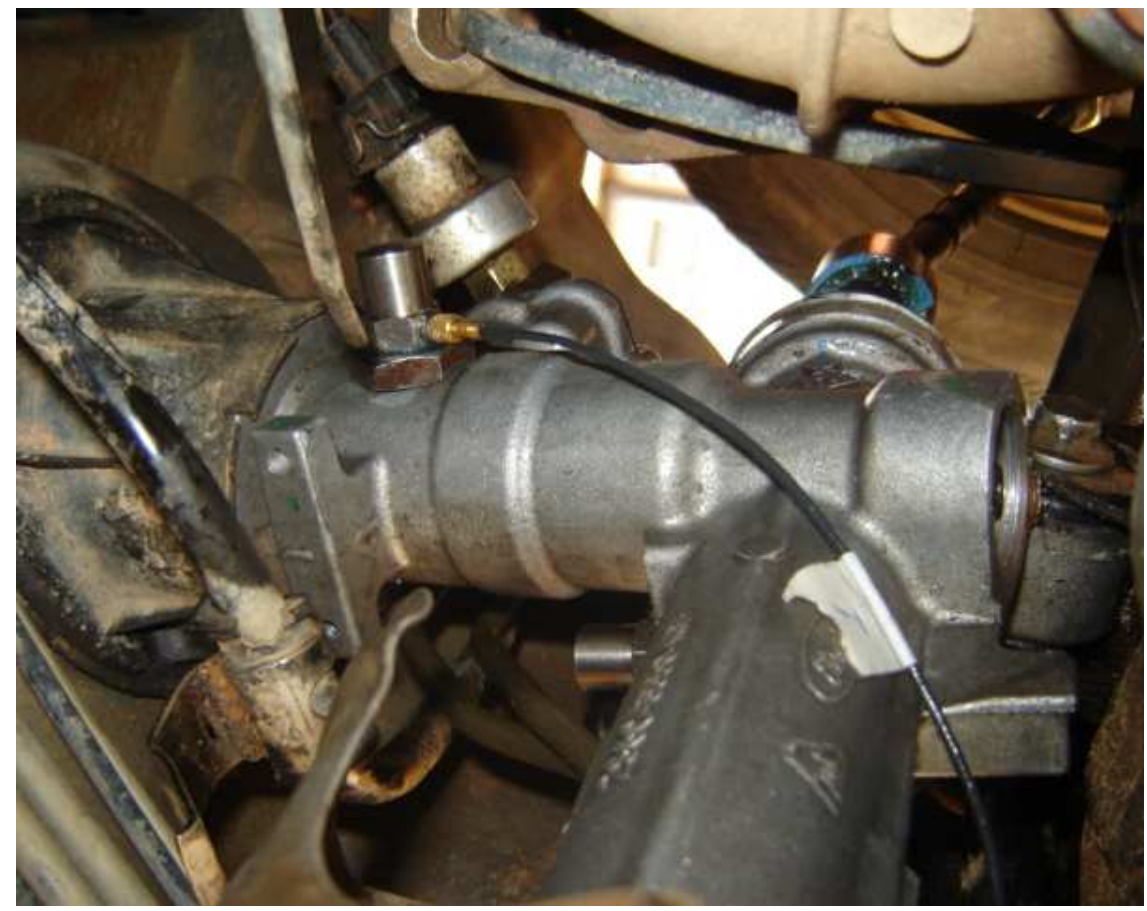

Figura 31 - Acelerômetro fixado próximo aos mancais do pinhão.

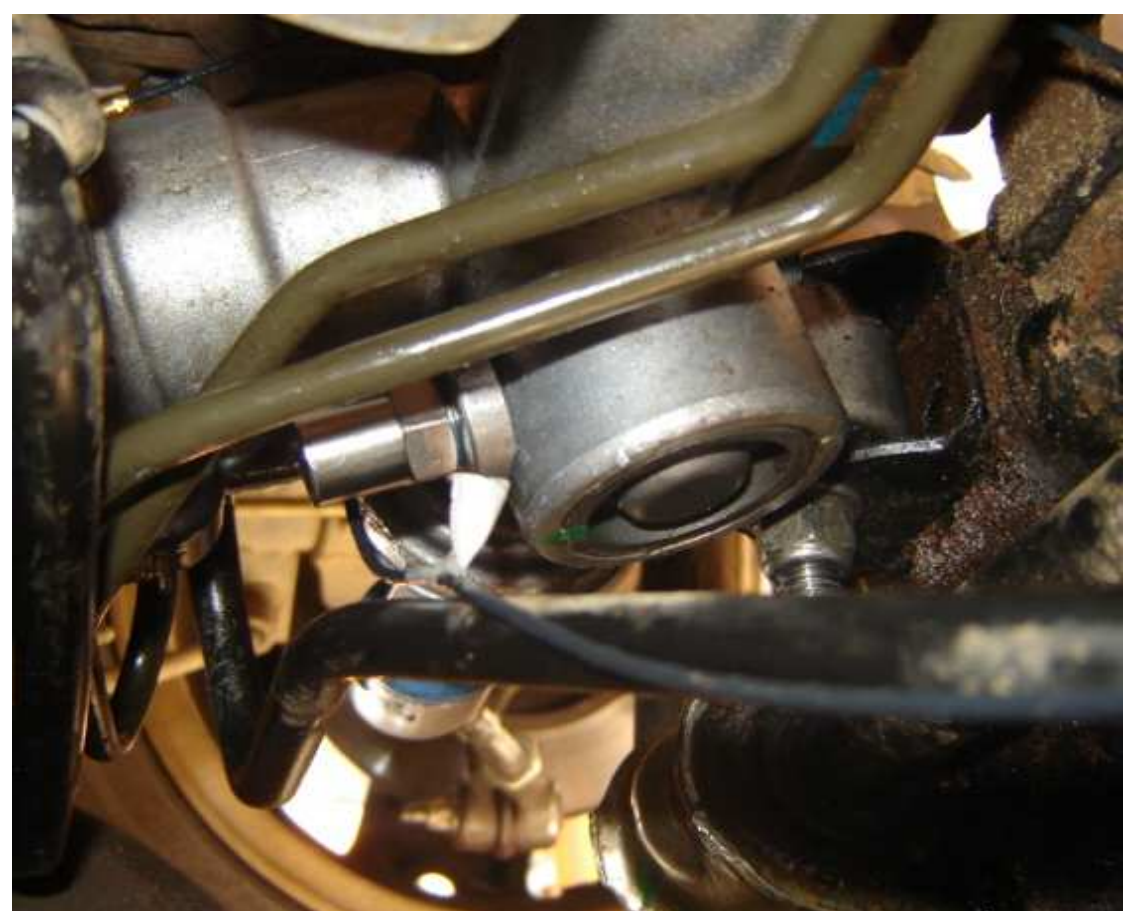

Figura 32 - Acelerômetro fixado próximo ao Sujeitador. 


\subsection{MEDIÇÕES DE SINAIS DE VIBRAÇÃO EM LABORATÓRIO}

Para a medição dos sinais de vibração em ensaios de laboratório foi montada uma bancada de ensaio com duas caixas de direção hidráulica fixadas rigidamente ao bloco inercial.

Foram utilizados os seguintes equipamentos:

1) Condicionador de sinal de Emissão Acústica

Fabricante: Physical Acoustic Corporation SAMOS $^{\mathrm{TM}}$

Modelo: $\mu \mathrm{DISP}$

Ganho: $60 \mathrm{~dB}$

2) Três Amplificadores de Carga

Fabricante: Bruel \& Kjaer

Modelo: 2635

Ganho: $100 \mathrm{mV} /$ unidade de entrada

3) Dois Acelerômetros

Fabricante: Bruel \& Kjaer

Modelos: 4371 e 4384

Sensibilidade: $10 \mathrm{pC} / \mathrm{g}$

4) Dois Transdutores Piezoelétricos

Fabricante:

Modelo: WDI-AST

5) Placa de aquisição de sinal

Fabricante: National Instruments

Modelo: 9233

6) Martelo

Fabricante: Bruel \& Kjaer

Modelo: 8202

Ganho: $100 \mathrm{mV} /$ unidade de entrada 
7) Notebook

Fabricante: Toshiba

Modelo: Satellite X205

Intel(R) Core(TM) 2 Duo CPU T8100 @2.10GHz 2.00 GHz

Memória Ram: 3.00 GB

8) Notebook

Fabricante: HP

Modelo: Olive 586

AMD Turion 64

9) Software de Aquisição de Sinal LabView Signal Express

10) Software de Emissão Acústica Aewin for Samos

Na figura 33 é mostrada esta bancada de ensaio utilizada para a realização do experimento de laboratório. Sobre a massa inercial pode-se ver duas caixas de direção montadas. Uma na configuração original e outra modificada, com aberturas na carcaça, para permitir estudar o movimento interno da cremalheira.

Nos extremos da cremalheira foram adicionadas duas massas para representar a inércia das barras de conexão às rodas (inners), sobre as quais foram afixados os acelerômetros. 


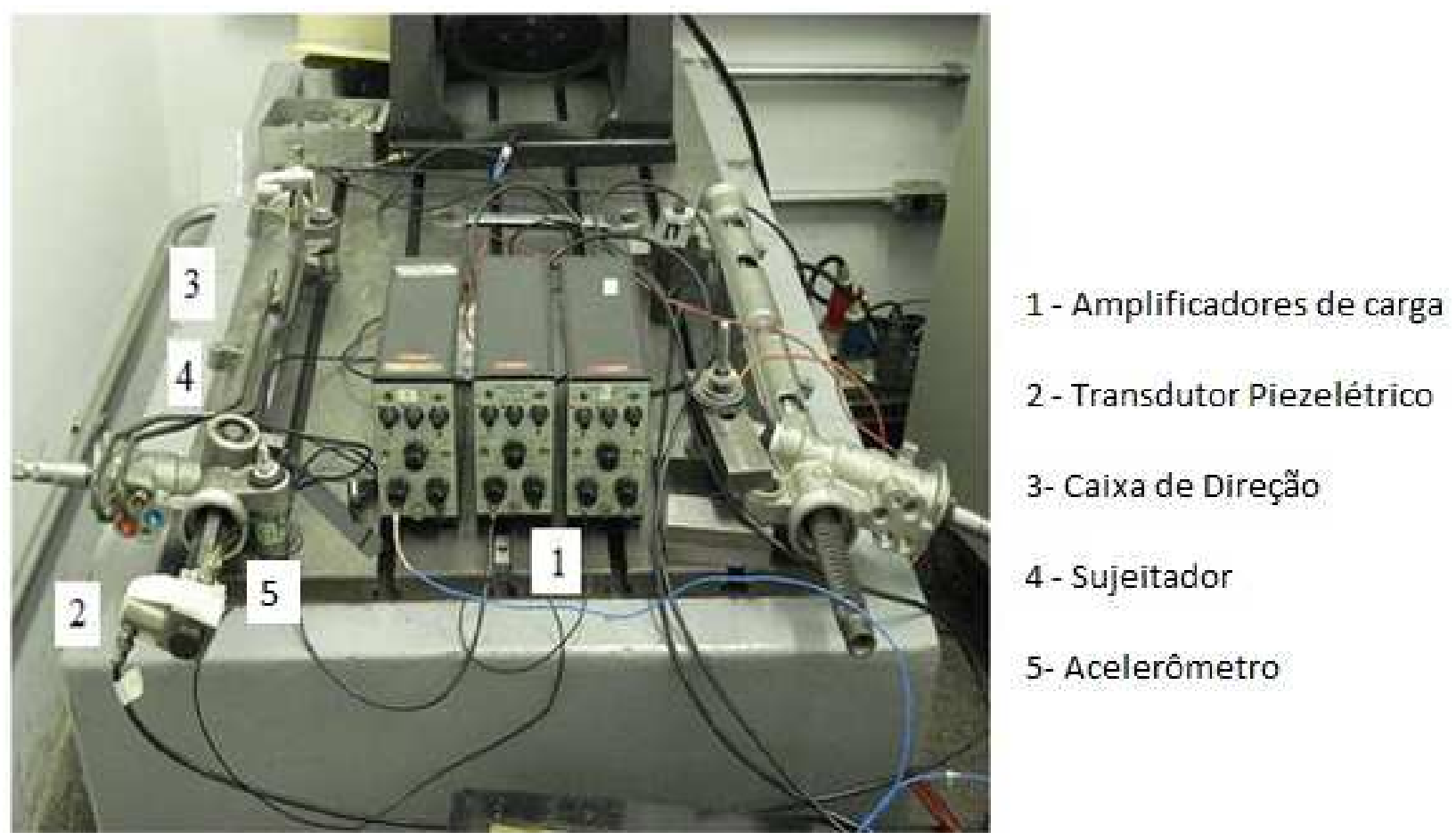

Figura 33 - Bancada de Ensaio.

A figura 34 ilustra um diagrama dos equipamentos utilizados e as suas interligações.

A figura 35 ilustra a caixa de direção hidráulica utilizada no experimento. Nota-se que nos extremos da cremalheira foram adicionadas duas massas para representar a inércia das barras de conexão (inners), sobre as quais foram afixados os acelerômetros. 


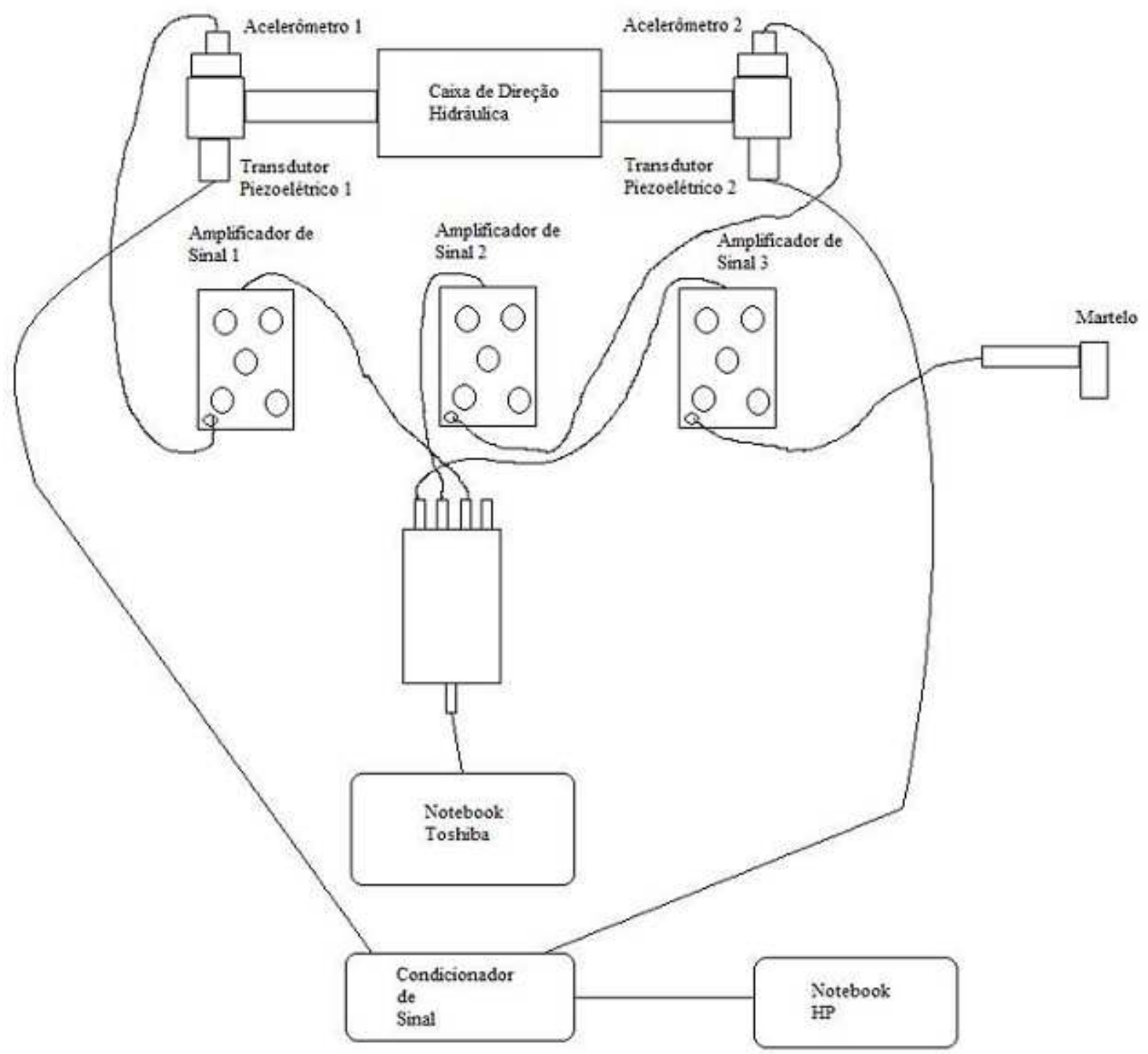

Figura 34 - Diagrama de Montagem. 


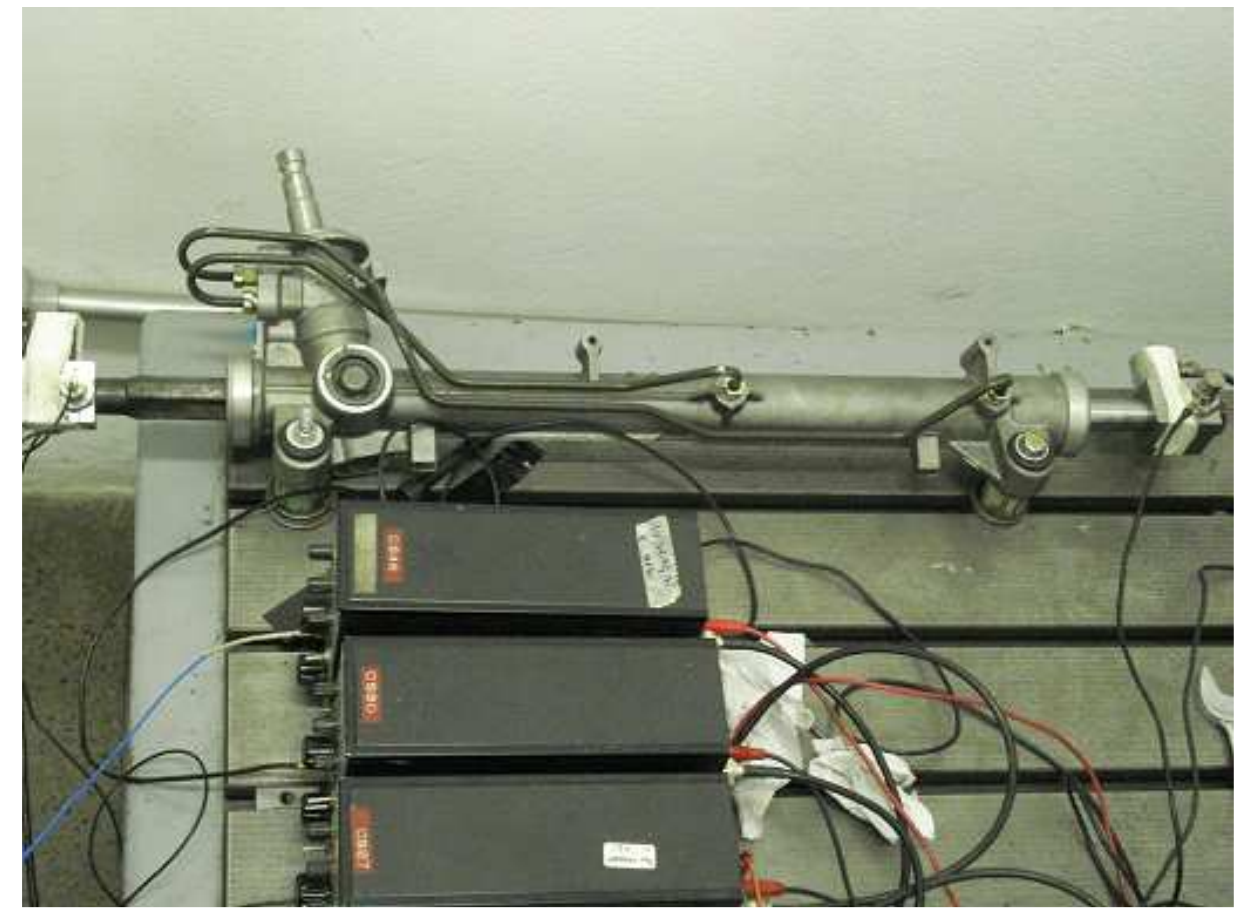

Figura 35 - Caixa de Direção Hidráulica.

Para a medição dos dados, foram escolhidas algumas posições da cremalheira dentro da caixa de direção hidráulica. Estas posições foram identificadas pela distância D ilustrada na figura 36 abaixo. Esta distância D representa a distância do acelerômetro 1 em relação ao sujeitador.

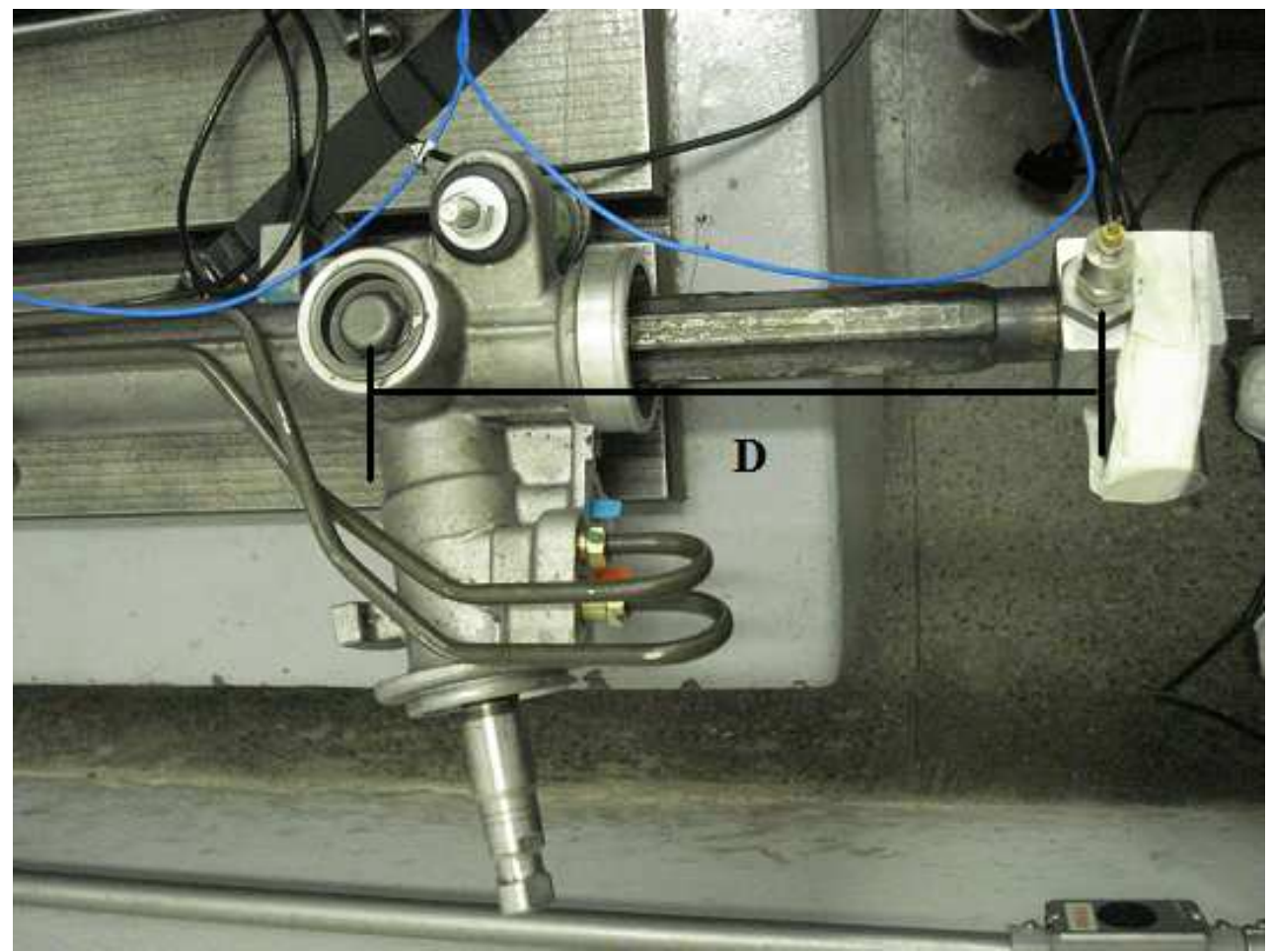

Figura 36 - Posição de Medição. 
Para excitar a cremalheira dentro da caixa de direção, foi utilizado um martelo com ponta de borracha. O martelo com ponta de borracha foi utilizado para excitar freqüências baixas, até cerca de $120 \mathrm{~Hz}$, características das primeiras freqüências naturais de vibração transversal da cremalheira.

Com o martelo produziram-se impactos nas extremidades da cremalheira, na direção transversal, alinhada com a linha de ação do sujeitador, e, portanto próximos aos acelerômetros e transdutores, excitando-a. A figura 37 ilustra o momento da batida do martelo contra a cremalheira.

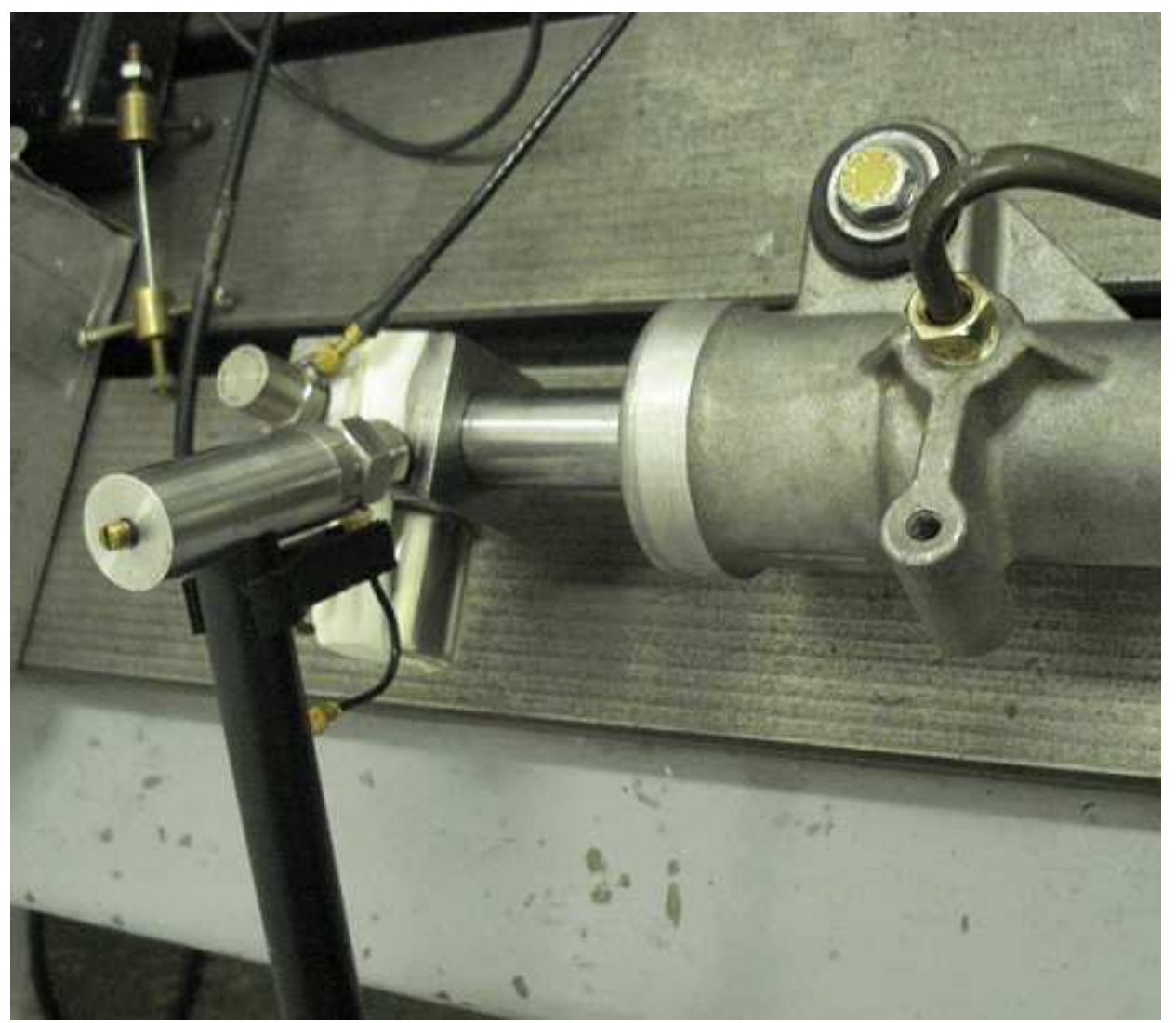

Figura 37 - Batida do martelo contra a cremalheira.

Estes sinais provenientes da batida do martelo contra a cremalheira foram medidos pelos acelerômetros e transdutores e analisados pelos softwares LabView Signal Express e Aewin for SAMOS. 


\subsection{MEDIÇÕES DE SINAIS DE EMISSÃO ACÚSTICA EM LABORATÓRIO}

Para avaliar a capacidade do sistema de medição de emissão acústica na detecção e localização dos impactos internos foi ensaiada a caixa de cremalheiras aberta mostrada na figura 38. Trata-se de uma caixa de direção completa, sem óleo, com quatro aberturas na carcaça da caixa da cremalheira para inspeção interna. A caixa de direção foi montada pelos seus dois pontos de fixação em uma base de ensaio. Os tirantes de acoplamento às rodas (inners) foram substituídos por massas equivalentes fixadas aos dois extremos da cremalheira por parafusos. Dois sensores de emissão acústica e dois acelerômetros foram fixados a estas massas nos dois extremos da cremalheira.

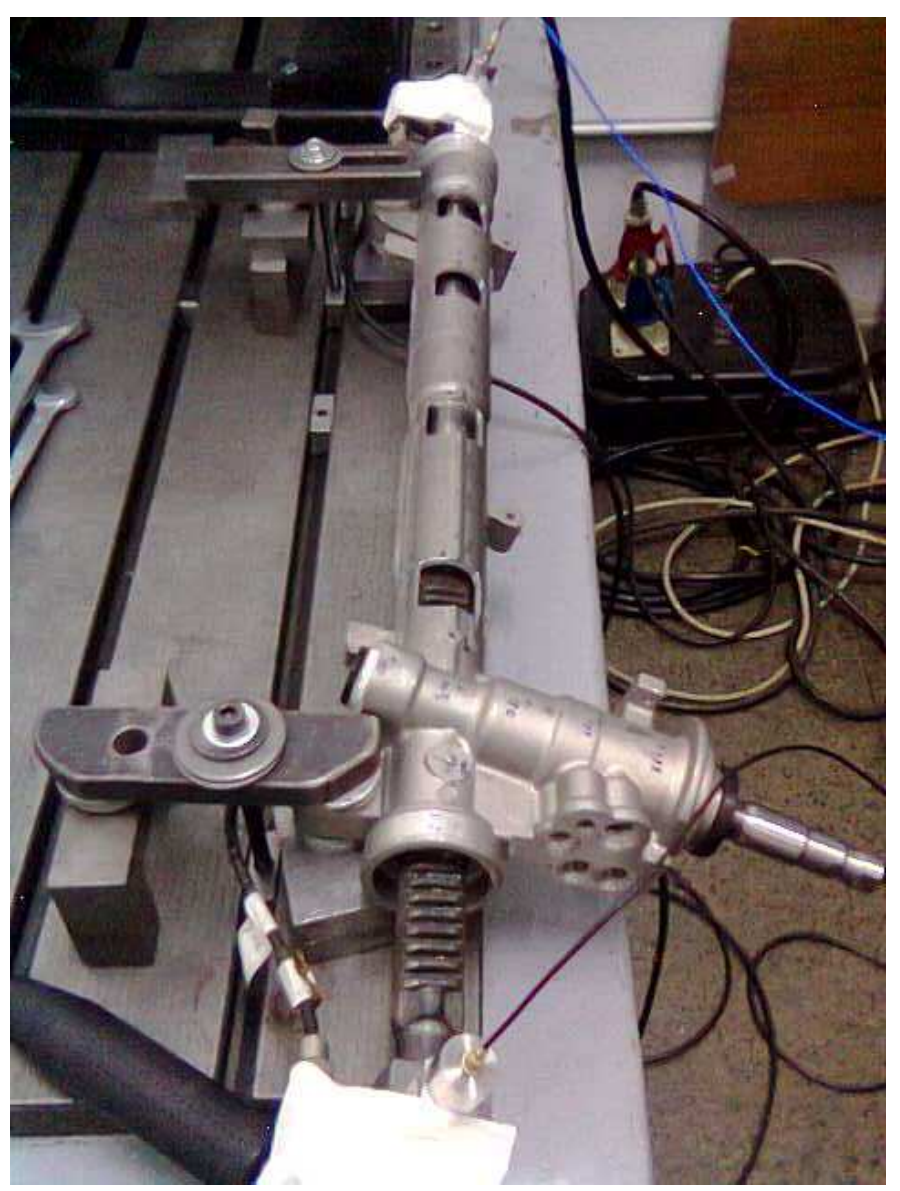

Figura 38 - Foto da caixa de direção aberta utilizada no ensaio de emissão acústica. 
O sensor 1 foi colocado no extremo esquerdo, do lado do pinhão (parte de baixo da foto da figura 38). O sensor 2 foi colocado no extremo direito, oposto ao pinhão. Após a aplicação de uma fina camada de vaselina na superfície dos sensores para permitir o acoplamento acústico, estes foram fixados por meio de fita adesiva nos extremos da cremalheira, mais precisamente sobre as duas massas que substituem os tirantes (inners) nos dois extremos da cremalheira. Os acelerômetros foram aparafusados às mesmas massas. Foi adotada uma coordenada de posição com origem no extremo esquerdo, conforme pode ser observado na figura 39. Podese ver também os pontos utilizados para aplicação da excitação, denotados por A a $F$ na figura.

Todas as medições foram realizadas com o sensor 1 afastado de $160 \mathrm{~mm}$ do ponto de engrenamento da cremalheira com o pinhão, conforme indicado na figura 39.

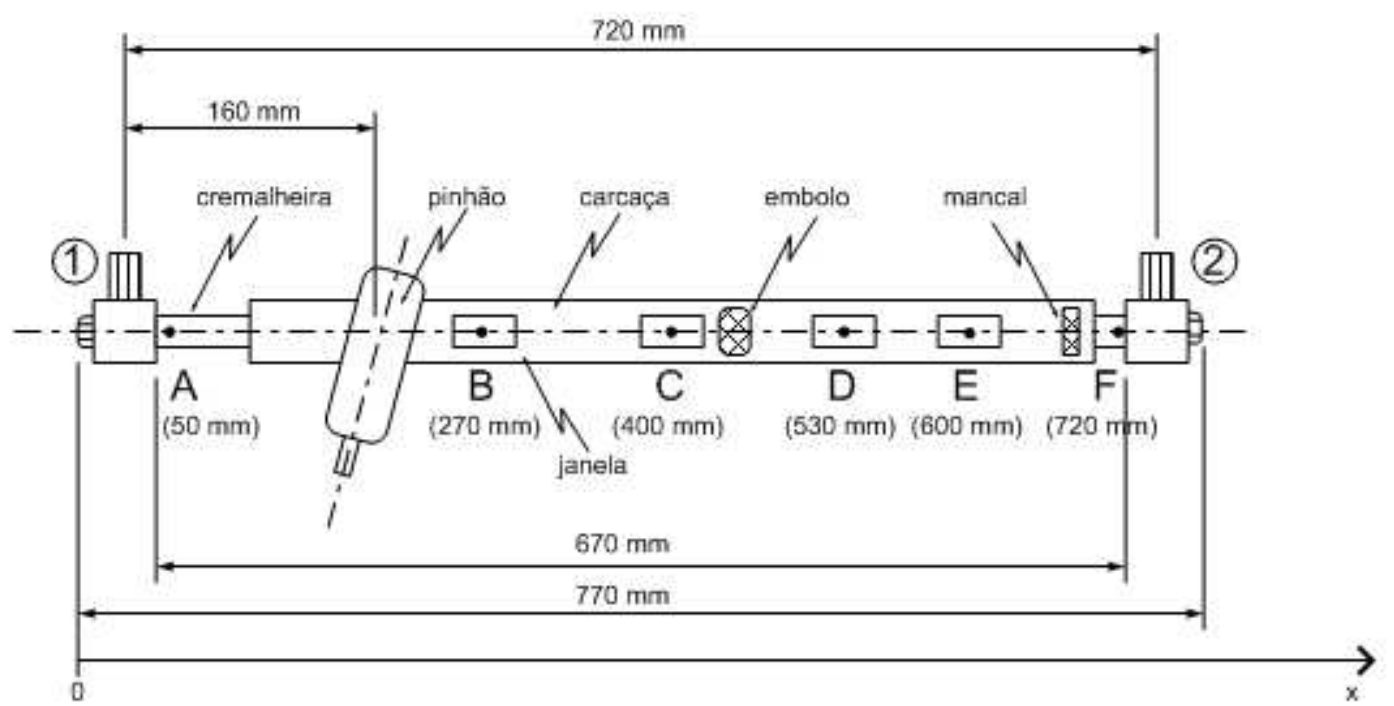

Figura 39 - Croqui da caixa de direção ensaiada com localização dos pontos de excitação A - F.

Para regulagem dos parâmetros de análise do sistema de emissão acústica a cremalheira foi excitada quebrando-se uma ponta de grafite de $0,3 \mathrm{~mm}$ em diferentes pontos. As ondas acústicas emitidas pela quebra do grafite são reprodutíveis e servem para regular os parâmetros do sistema.

O sistema foi ajustado com os parâmetros de medição mostrados na Tabela 1 e Tabela 2. 
Tabela 1 - Parâmetros de regulagem utilizados nos ensaios de emissão acústica.

\begin{tabular}{|c|c|c|c|c|c|c|c|}
\hline Canal & \multirow{2}{*}{$\begin{array}{c}\text { Limiar } \\
\text { de } \\
\text { Disparo }\end{array}$} & \multirow[b]{2}{*}{$\begin{array}{c}\text { Pré- } \\
\text { Amplificação }\end{array}$} & \multicolumn{2}{|c|}{$\begin{array}{c}\text { Filtros } \\
\text { Analógicos }\end{array}$} & \multicolumn{3}{|c|}{$\begin{array}{c}\text { Parâmetros para amostragem da forma de } \\
\text { onda }\end{array}$} \\
\hline$\#$ & & & $\begin{array}{c}\text { Passa } \\
\text { Alta }\end{array}$ & $\begin{array}{l}\text { Passa } \\
\text { Baixa }\end{array}$ & $\begin{array}{l}\text { Freqüência de } \\
\text { Amostragem }\end{array}$ & $\begin{array}{c}\text { Pré- } \\
\text { disparo }\end{array}$ & $\begin{array}{c}\text { Tamanho } \\
\text { do } \\
\text { Registro }\end{array}$ \\
\hline & $(\mathrm{dB})$ & $(\mathrm{dB})$ & $\begin{array}{c}(\mathrm{kHz} \\
)\end{array}$ & $\begin{array}{c}(\mathrm{kHz} \\
)\end{array}$ & $\left(10^{6}\right.$ amostras $\left./ \mathrm{s}\right)$ & Amostras & Amostras \\
\hline 1 & 45 & 40 & 1 & 400 & 1 & 512 & 4000 \\
\hline 2 & 45 & 40 & 1 & 400 & 1 & 512 & 4000 \\
\hline
\end{tabular}

Tabela 2 - Parâmetros da janela de análise utilizados nos ensaios de emissão acústica.

\begin{tabular}{|c|c|c|c|}
\hline Canal & PDT & HDT & HLT \\
\hline & $(\mu \mathrm{s})$ & $(\mu \mathrm{s})$ & $(\mu \mathrm{s})$ \\
\hline 1 & 1200 & 2400 & 8000 \\
\hline 2 & 1200 & 2400 & 8000 \\
\hline
\end{tabular}

PDT, HDT e HLT são parâmetros de tempo do processo de medição do sinal. Em resumo, a configuração adequada do PDT garante a correta identificação do pico do sinal para o tempo de subida e medições da amplitude de pico. A configuração adequada do HDT garante que cada sinal de emissão acústica da estrutura seja relatado como um único registro. A configuração adequada do HLT evita falsas medições durante o decaimento do sinal.

Primeiramente foi determinada a velocidade de propagação da onda na estrutura. $O$ grafite foi quebrado no extremo esquerdo da cremalheira $(x=0 \mathrm{~mm})$, a esquerda do sensor 1 . O sinal era primeiramente captado pelo sensor 1 e $160 \mu \mathrm{s}$ depois pelo sensor 2. A distância entre os dois sensores era de $720 \mathrm{~mm}$, correspondendo a uma velocidade de propagação de $4.500 \mathrm{~m} / \mathrm{s}$. Entretanto, verificou-se posteriormente durante os vários ensaios realizados que a adoção da velocidade de propagação de $4.800 \mathrm{~m} / \mathrm{s}$ gerava resultados mais adequados para localização dos pontos de emissão acústica. Este valor foi então adotado nos ensaios.

Também verificou-se a amplitude do sinal captado e atenuação do sinal, variando-se o ponto de aplicação das excitações ao longo da cremalheira (pontos A 
a F). Verificou-se que não há alteração significativa da amplitude do sinal com a variação do ponto de aplicação, permanecendo em torno de $84 \mathrm{~dB} \pm 9 \mathrm{~dB}$ para 0 sensor 1 e $75 \mathrm{~dB} \pm 7 \mathrm{~dB}$ para o sensor 2 .

Por último foram ajustados os parâmetros para localização do ponto de emissão acústica. Para isso foi novamente aplicada uma série de excitações em cada um dos pontos de A a F. Os pontos de excitação adotados são mostrados na Tabela 3, situados nas janelas de acesso à cremalheira. O software foi ajustado para localizar os pontos de emissão do sinal. Foram utilizados os parâmetros apresentados na Tabela 4.

Tabela 3 - Localização do ponto de excitação pela emissão acústica.

\begin{tabular}{|c|c|c|}
\hline Ponto de Excitação & Ponto de Aplicação & Ponto Localizado \\
\hline & X (mm) & X (mm) \\
\hline A & 50 & 25 \\
\hline B & 270 & 339 \\
\hline C & 400 & 438 \\
\hline D & 530 & 495 \\
\hline E & 600 & 581 \\
\hline F & 720 & 745 \\
\hline
\end{tabular}

Tabela 4 - Parâmetros de regulagem para localização do ponto de emissão acústica.

\begin{tabular}{|c|c|c|c|c|}
\hline Grupo & $\begin{array}{c}\text { Tipo de } \\
\text { Localizador }\end{array}$ & $\begin{array}{c}\text { Velocidade de } \\
\text { Onda }\end{array}$ & $\begin{array}{c}\text { Raio de } \\
\text { definição do } \\
\text { evento }\end{array}$ & $\begin{array}{c}\text { Raio de } \\
\text { travamento de } \\
\text { evento }\end{array}$ \\
\hline 1 & $\begin{array}{c}\text { Interpolação } \\
\text { linear }\end{array}$ & $4.800 \mathrm{~m} / \mathrm{s}$ & $1.000 \mathrm{~mm}$ & $3.200 \mathrm{~mm}$ \\
\hline
\end{tabular}

O raio de definição do evento é o comprimento de um evento em unidade de distância do usuário.

O raio de travamento do evento controla o intervalo entre eventos consecutivos.

Na figura 40 são mostradas as formas de onda medidas pelos sensores 1 e 2 e respectivos espectros de amplitude dos sinais de emissão acústica registrados com a excitação por quebra de grafite. Pode-se ver que os sinais de emissão acústica são de alta freqüência, acima de $25 \mathrm{kHz}$. A magnitude do sinal pode ser medida em amplitude, energia, número de registros (hits) e contagem de picos. A 
medida da amplitude é apresentada em decibéis, sendo somente uma medida relativa que depende de inúmeros fatores, entre outros, do acoplamento acústico entre superfície e sensor. Na figura 41 é apresentado o histograma da contagem de emissões em função da amplitude em dB. Pode-se observar uma predominância de emissões com amplitude em torno de $72 \mathrm{~dB}$. Na figura 42 são apresentados os eventos localizados pelo software. Trata-se da amplitude do sinal versus a coordenada do ponto de emissão localizado por interpolação linear. Pode-se observar que o software foi capaz de localizar razoavelmente bem os pontos de excitação utilizados. Os resultados dessa localização são apresentados na Tabela 3. Verifica-se que há um desvio médio de cerca de $50 \mathrm{~mm}$, vide Tabela 3, entre o ponto localizado e o ponto real de excitação. Há dificuldade de determinar a localização com precisão devido ao comprimento curto da cremalheira de apenas $720 \mathrm{~mm}$, para uma velocidade de propagação de $4.800 \mathrm{~m} / \mathrm{s}$. Um erro de detecção do sinal de $10 \mu \mathrm{s}$ corresponde a uma incerteza de $48 \mathrm{~mm}$ na localização do ponto de emissão acústica. A forma de onda do sinal mostrado na figura 40 ilustra a dificuldade em determinar com precisão o instante de detecção do sinal de emissão acústica, pois este instante depende do nível de disparo adotado na medição. Na figura 43 são apresentados os eventos localizados pelo software em termos de amplitude, energia e contagem de picos versus a posição localizada. Pode-se observar a localização dos seis pontos de excitação utilizados no ensaio.

Com isso, concluiu-se a fase de regulagem de parâmetros do software de emissão acústica. Em seguida foi realizada a tentativa de detecção de impactos internos. 


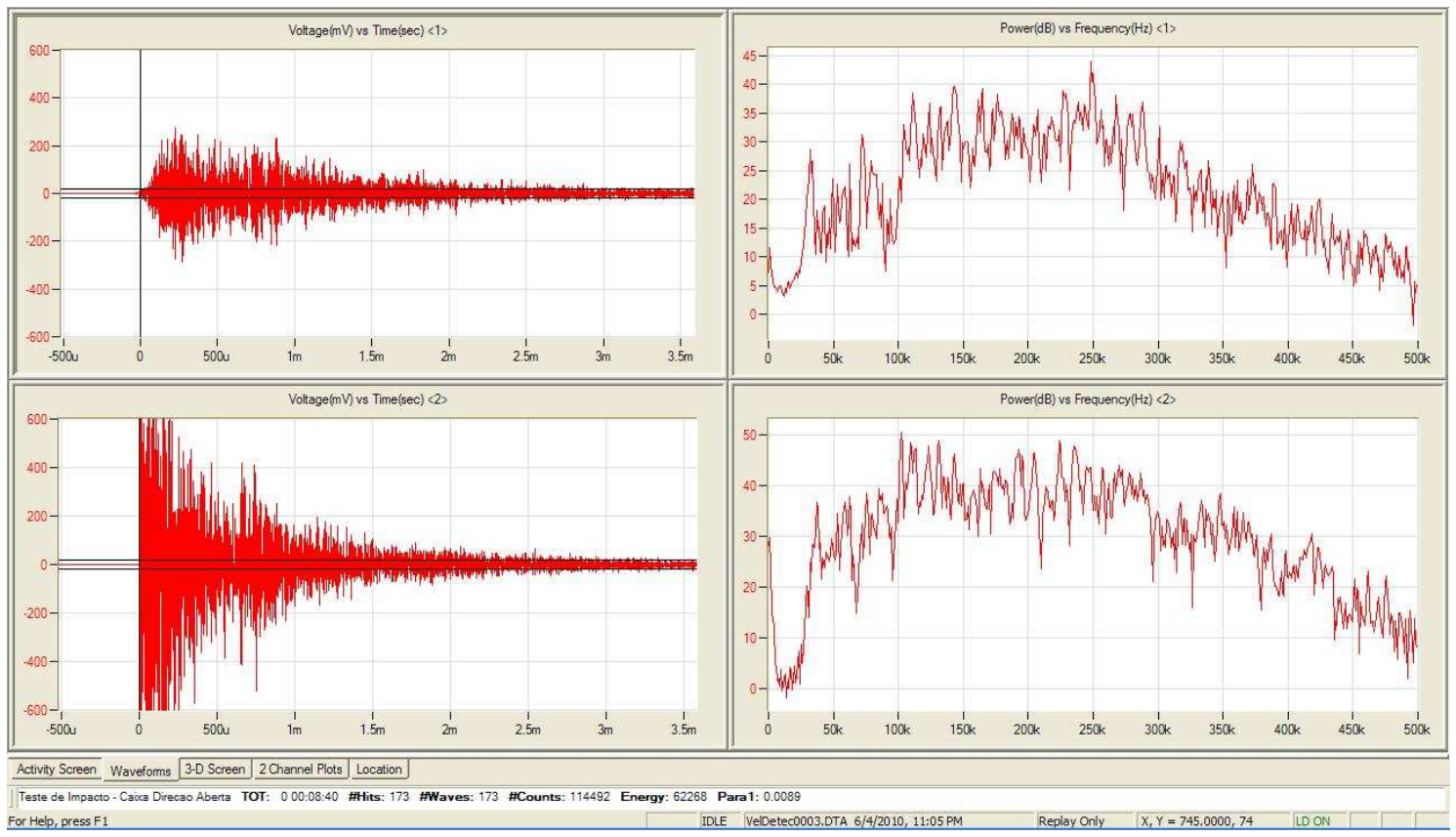

Figura 40 - Forma de onda e espectro dos sinais típicos de emissão acústica.

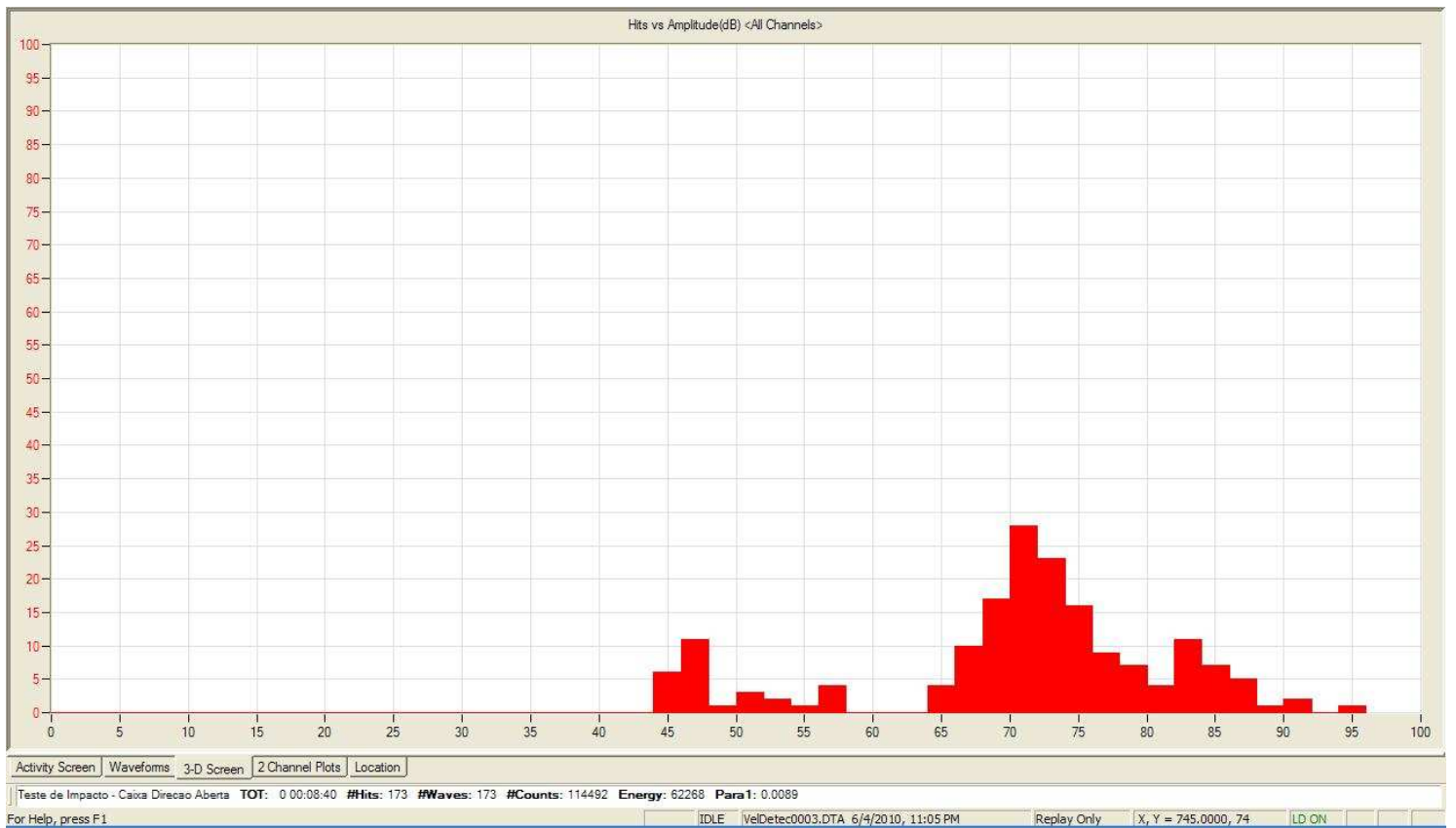

Figura 41 - Histograma do número de registros (hits) por amplitude. 


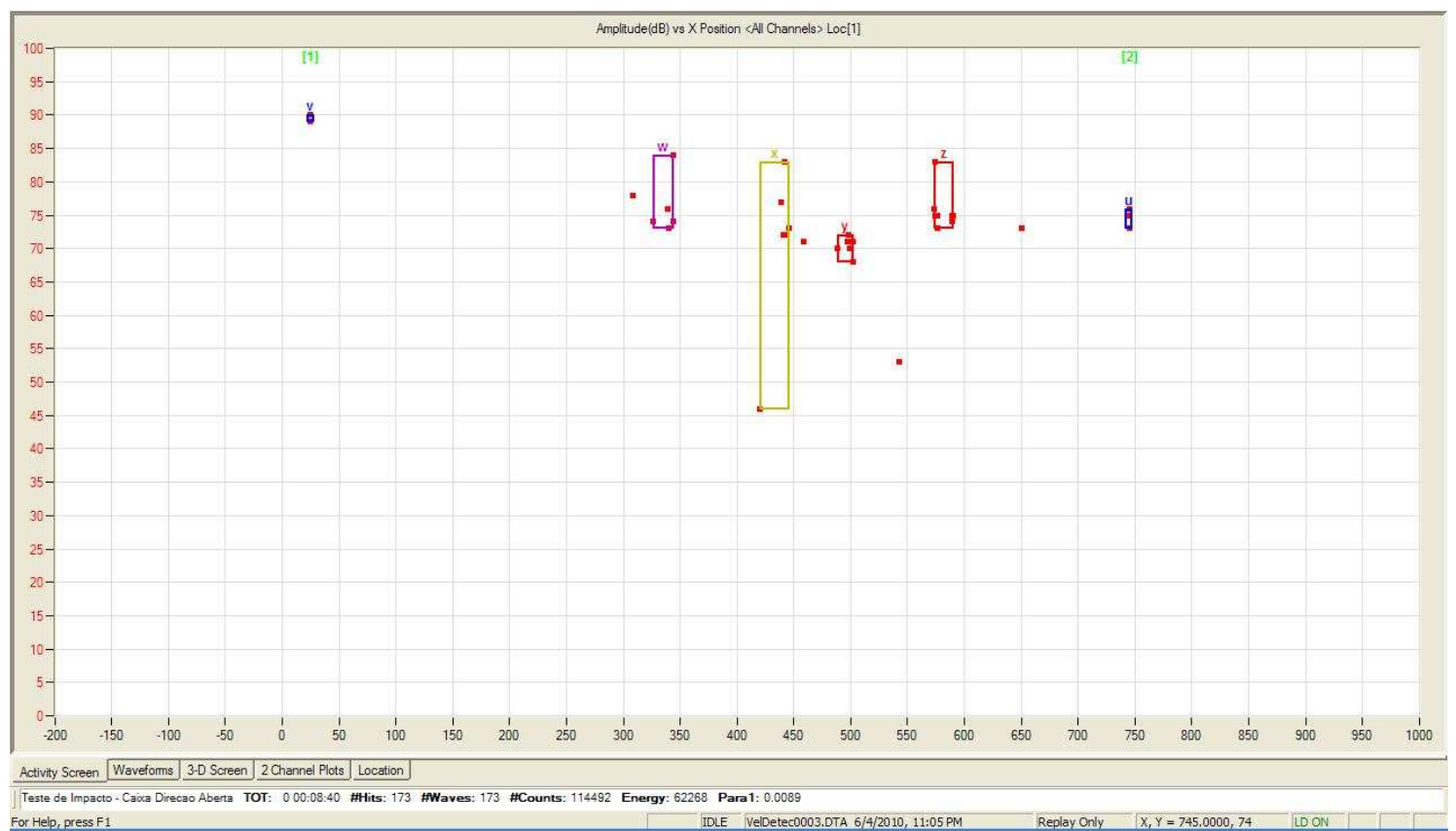

Figura 42 - Localização dos pontos de excitação - Amplitude X Posição.

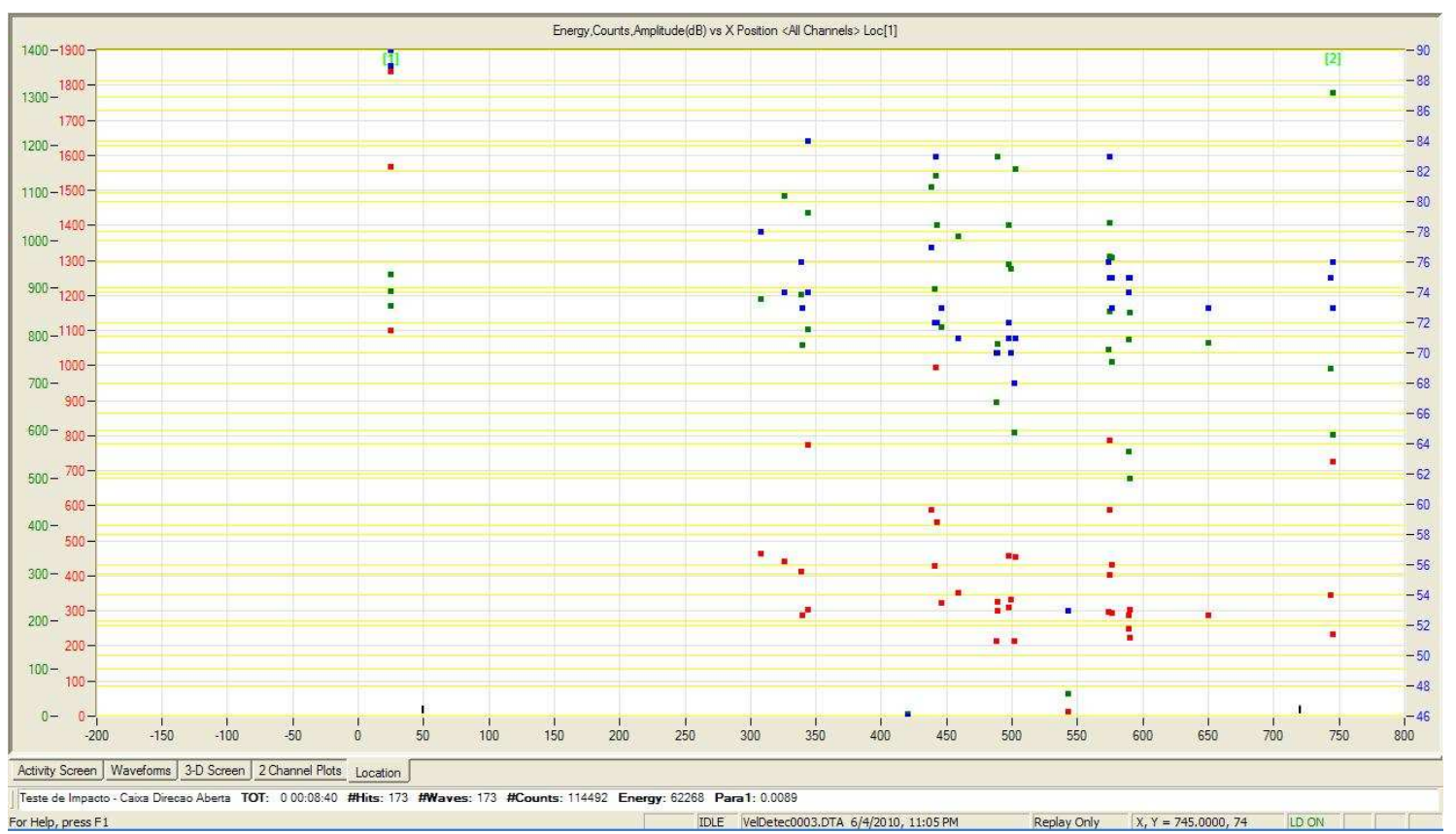

Figura 43 - Localização dos pontos de excitação - Energia, contagem e Amplitude X Posição. 


\section{RESULTADOS}

Primeiramente serão ilustrados os resultados obtidos com a técnica da Transformada de Wavelet e por último os resultados obtidos com a técnica de Emissão Acústica.

Inicialmente, foi gerado um sinal, em laboratório, por excitação por martelo na cremalheira e analisou-se o espectro de freqüências desse sinal com o objetivo de distinguir as freqüências naturais de vibração transversal da cremalheira, das freqüências relacionadas aos ruídos de impacto. O resultado da análise encontra-se na figura 44 abaixo.

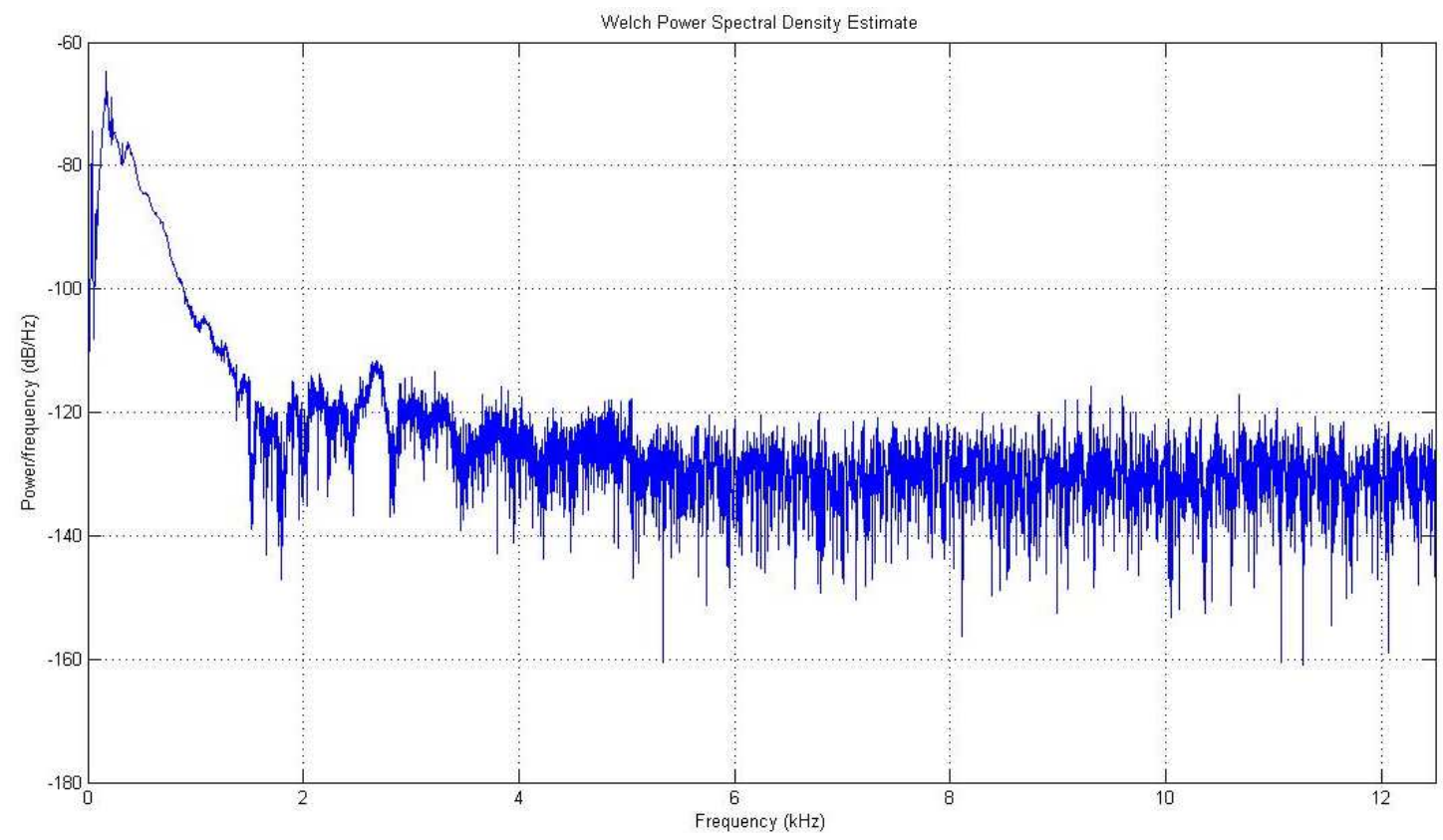

Figura 44 - Espectro de Frequências.

De acordo com Ponge-Ferreira (2007), as freqüências próximas a $120 \mathrm{~Hz}$ estão relacionadas com as primeiras freqüências naturais de vibração transversal da cremalheira e as freqüências na ordem de grandeza de $\mathrm{kHz}$ estão relacionadas com os ruídos de impacto que acontecem dentro da caixa de direção hidráulica.

A figura 45 ilustra a função de resposta em frequência obtida através de excitação por pancada nos estudos de Ponge-Ferreira (2007) indicando que o primeiro modo de vibração transversal da cremalheira ocorre por volta de $120 \mathrm{~Hz}$. 


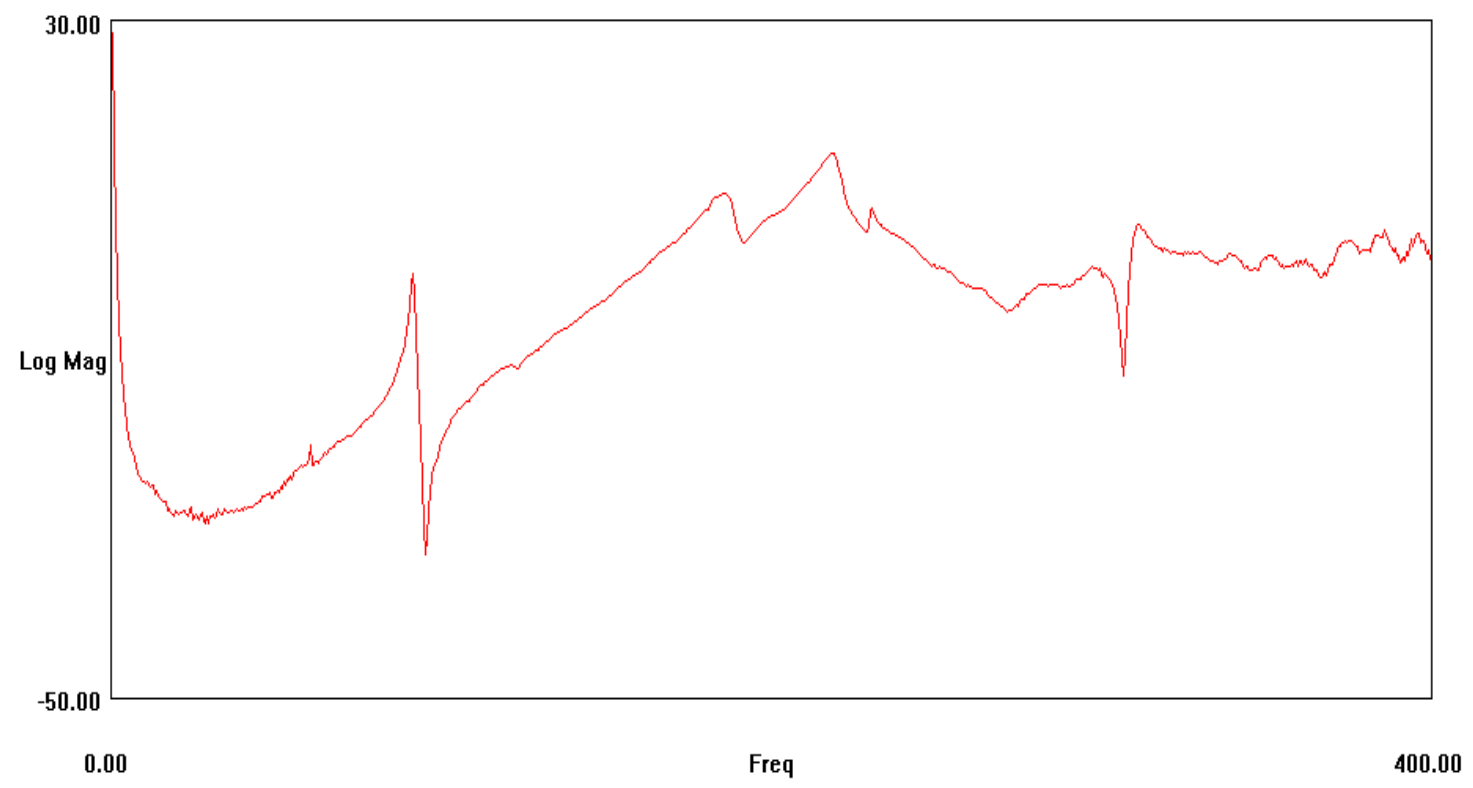

Figura 45 - Função de Resposta em frequência da cremalheira.

Sobre os dados de vibração reais e de laboratório, foi aplicada a técnica de processamento de sinal de análise tempo-frequência wavelets para detecção de ruídos de impacto provenientes da caixa de direção hidráulica. Foram utilizadas as wavelets das famílias de Daubechies e Newland.

Inicialmente foi aplicada a wavelet de Daubechies para detectar os impactos e para isto, considere o sinal de vibração medido em laboratório e ilustrado na figura 46.

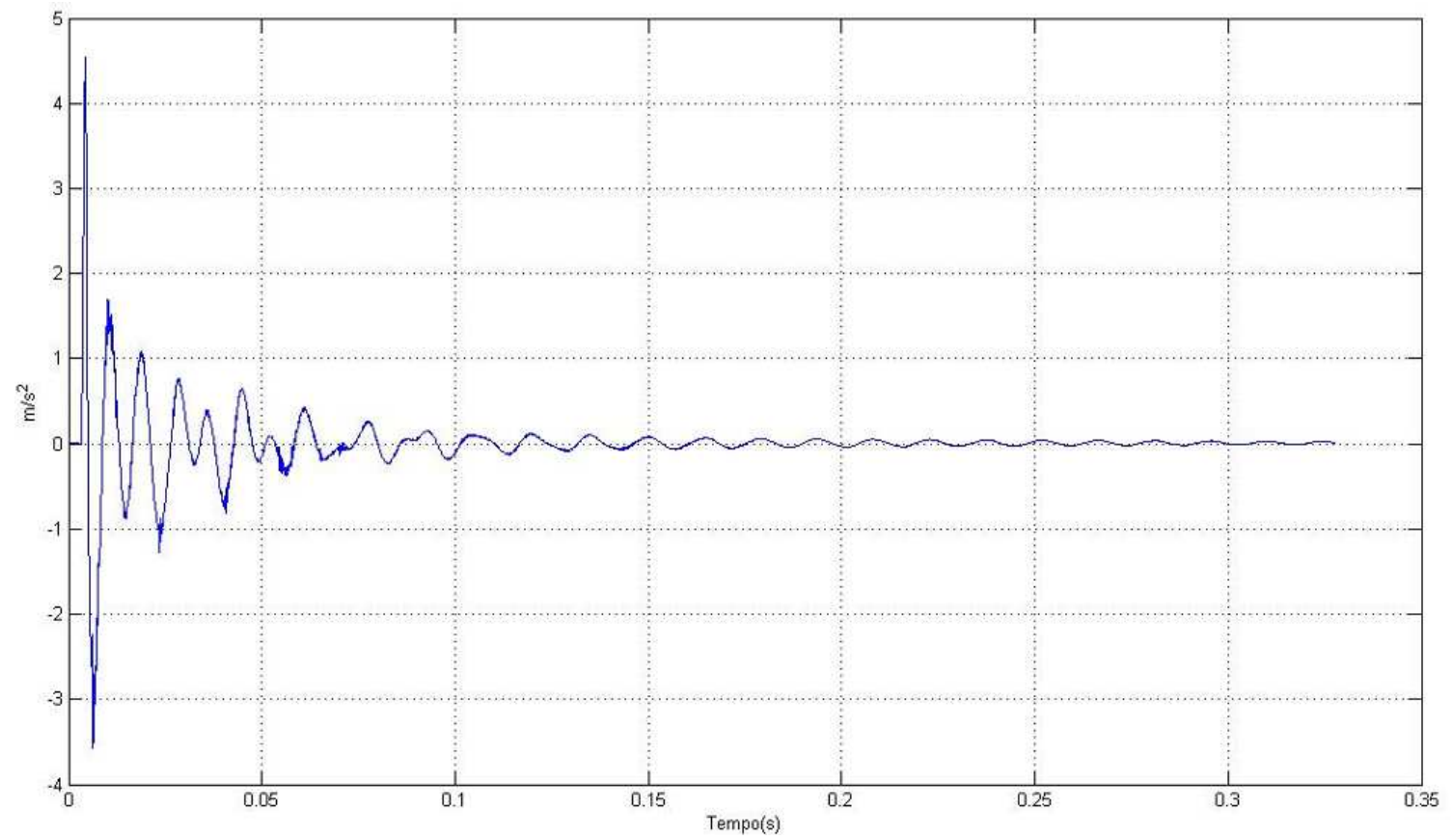

Figura 46 - Sinal medido em laboratório com $D=140 \mathrm{~mm}$. 
Este sinal foi medido pelo acelerômetro 1, posicionando este acelerômetro a $140 \mathrm{~mm}$ de distância do sujeitador e realizando uma batida com o martelo na extremidade da cremalheira deste acelerômetro, na direção transversal e no sentido de compressão da mola do sujeitador.

A figura 47 ilustra este sinal em uma escala maior. Percebem-se, por esta figura, os impactos que aconteceram internamente à caixa de direção em 6, 10, 23 e $42 \mathrm{~ms}$ circulados em vermelho. Estes impactos são provenientes da batida da cremalheira contra as partes metálicas, i.e., pinhão e bucha guia.

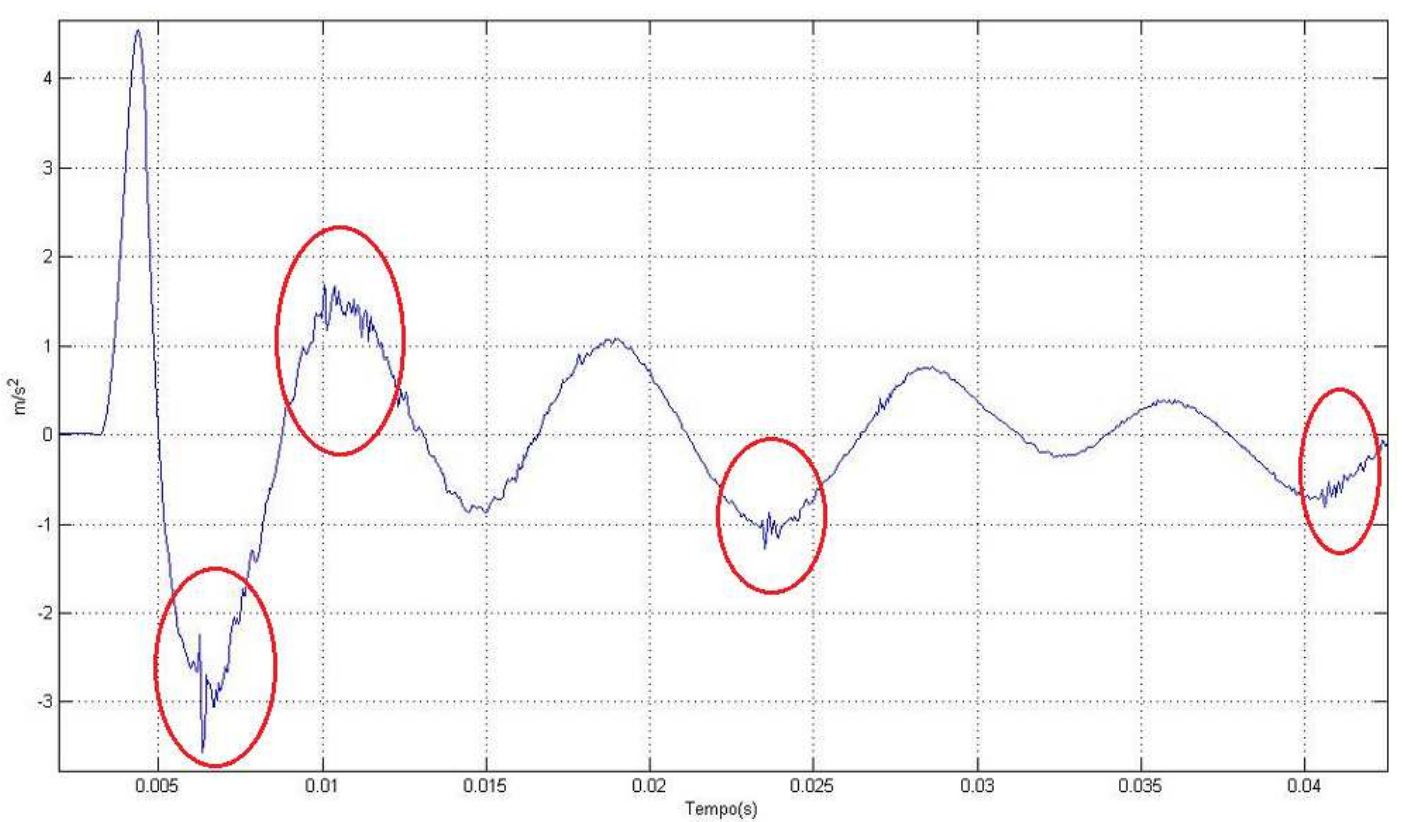

Figura 47 - Zoom do sinal medido em laboratório com D = 140 mm

A figura 48 a seguir ilustra o espectrograma do sinal original. 


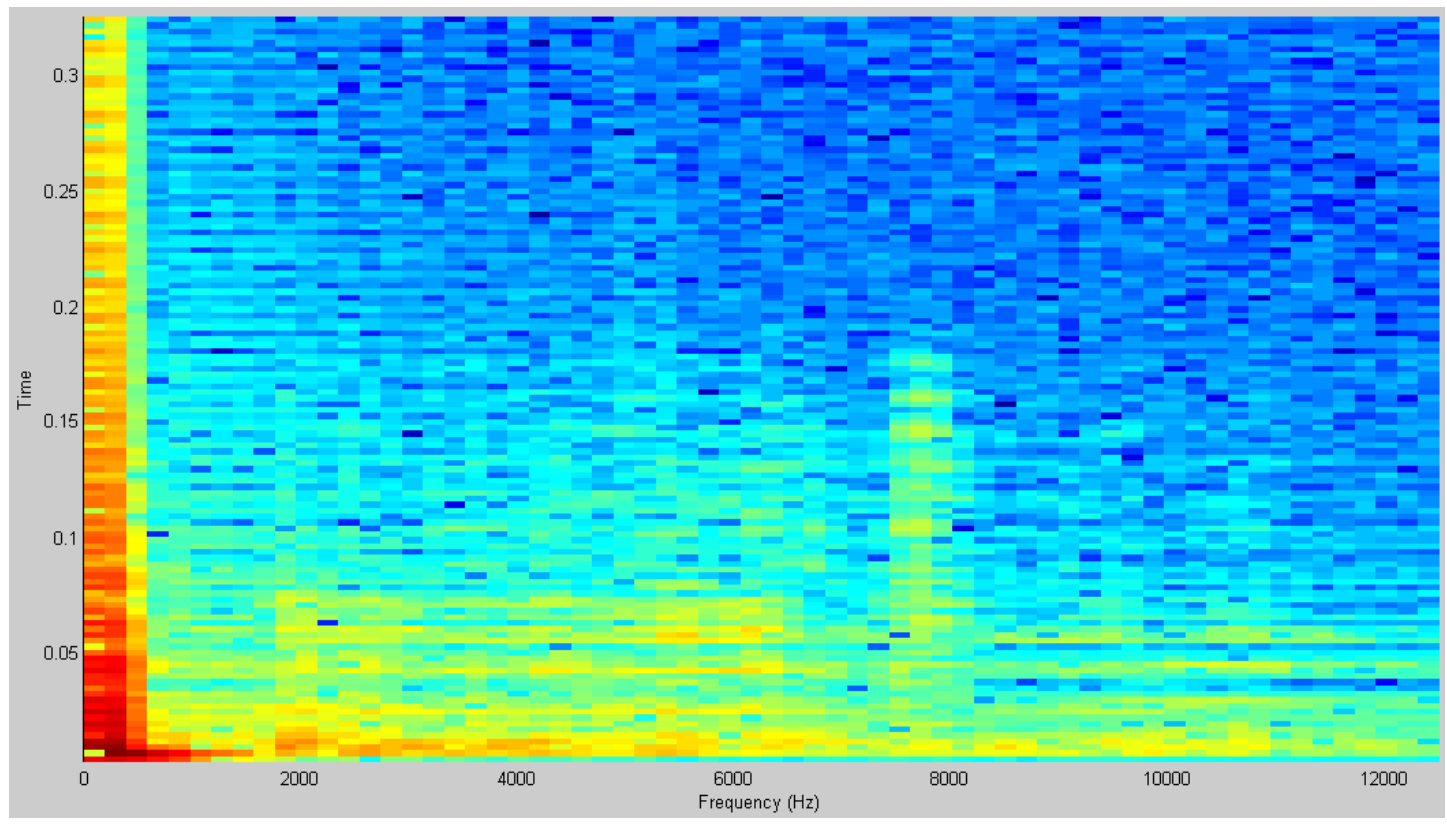

Figura 48 - Espectrograma do sinal original.

Por este resultado, nota-se que próximo aos tempos citados acima, aparecem frequências na ordem de grandeza de $\mathrm{kHz}$ provenientes dos impactos da cremalheira contra o pinhão e a bucha guia.

\subsection{Escolha dos Parâmetros para Análise com Wavelet de Daubechies}

Para se obter um resultado satisfatório utilizando a wavelet de Daubechies foi preciso identificar a melhor ordem desta wavelet a ser aplicada e o nível ou níveis de detalhamento a serem retirados do sinal original na decomposição e filtragem do sinal de impacto.

Inicialmente foi aplicada a wavelet de Daubechies de ordem 3 e foram retirados os 2 últimos níveis de detalhe do sinal original.

A ocorrência de impactos da cremalheira dentro da caixa de direção é simples de ser detectada como ilustrado no resultado obtido pela Figura 49. A curva dos níveis de detalhamento ilustra estes impactos. 


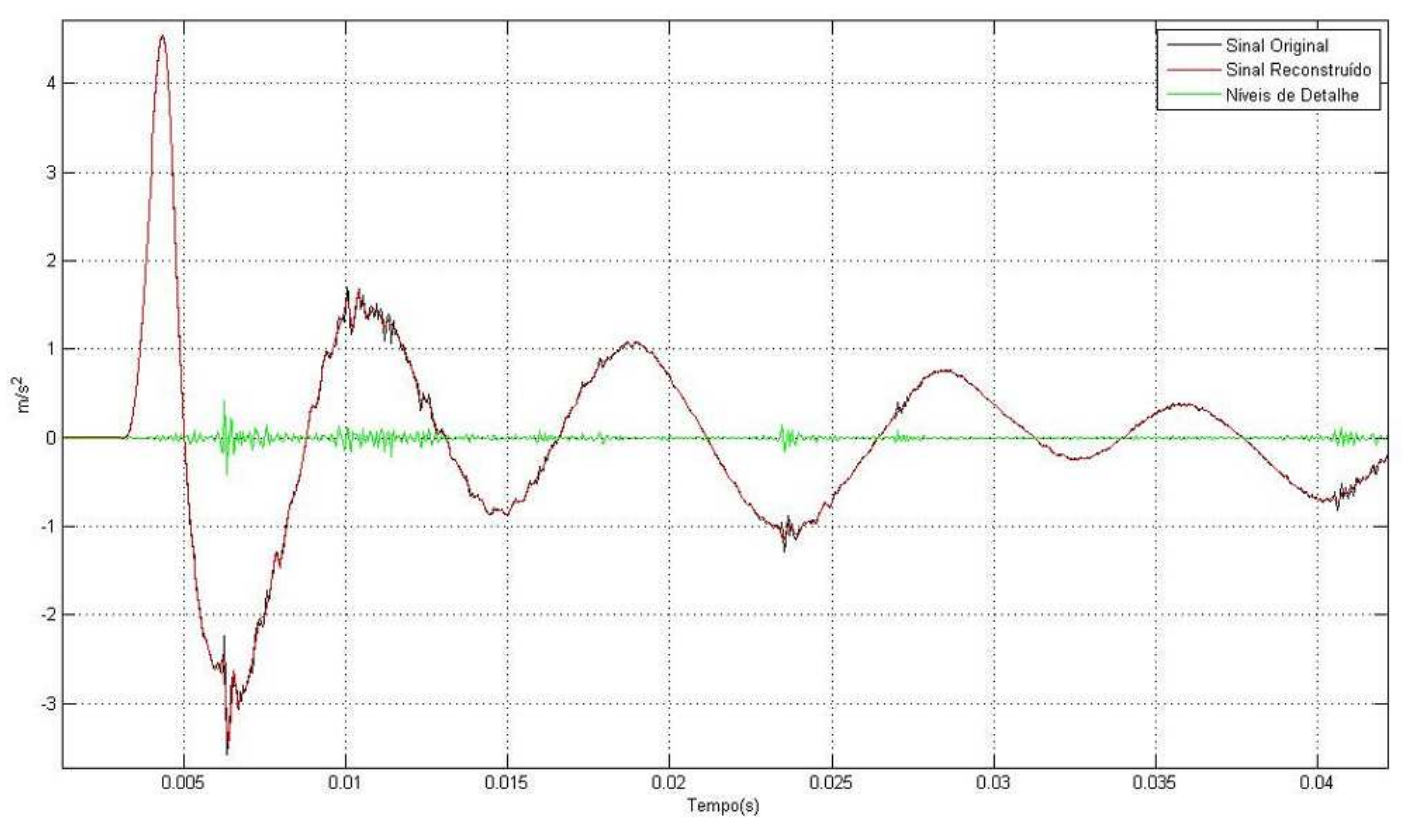

Figura 49 - Wavelet de Daubechies de ordem 3 e 2 níveis de detalhamento.

Nota-se que no sinal reconstruído sem os 2 últimos níveis de detalhe ainda aparecem ruídos de impacto, ou seja, esta wavelet ou este nível de detalhamento escolhidos não foram os ideais.

A figura 50 abaixo ilustra o espectrograma do sinal reconstruído. Observa-se a presença de componentes de frequência na ordem de $\mathrm{kHz}$, comprovando a presença de ruídos de impacto.

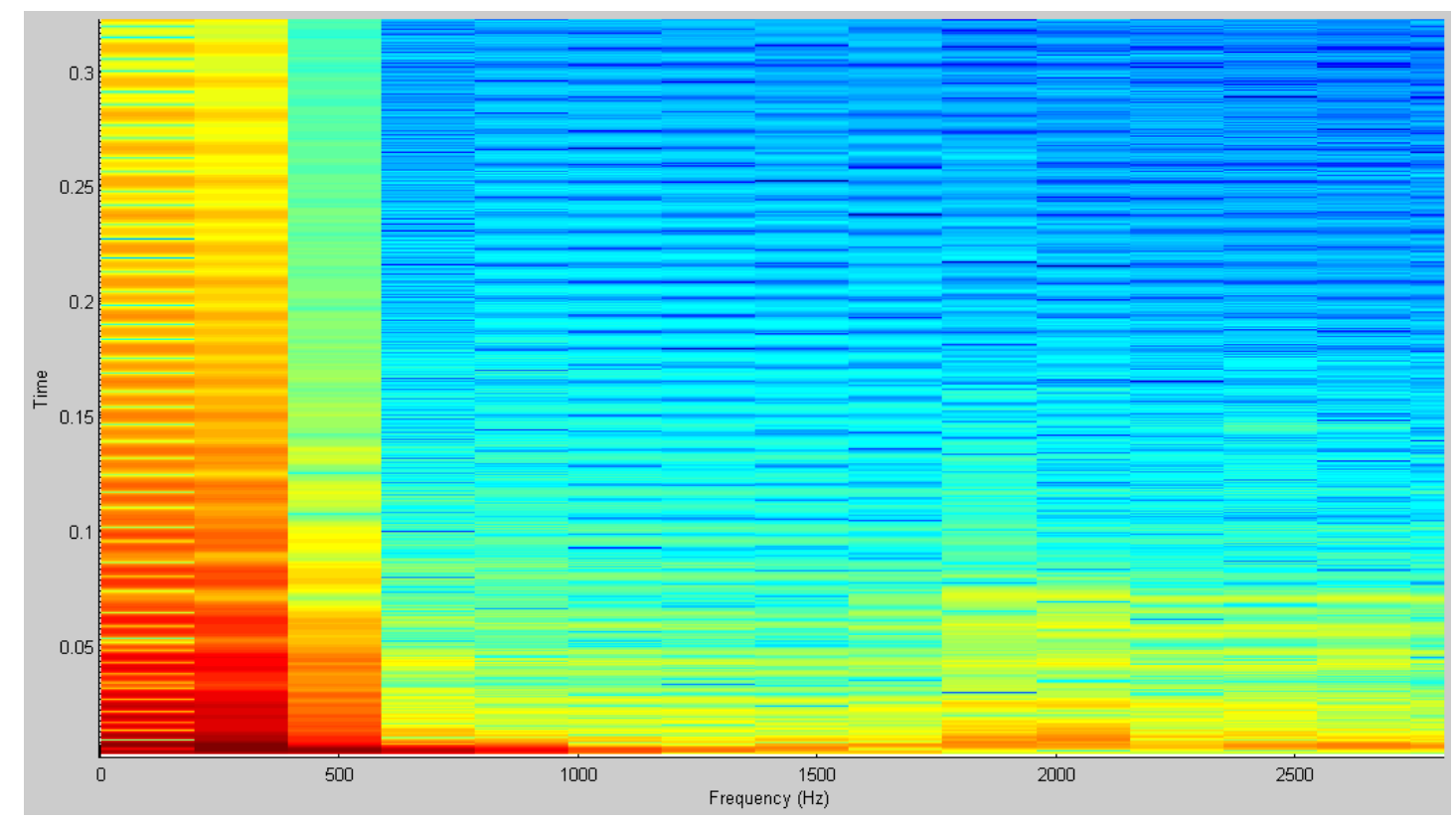

Figura 50 - Espectrograma do sinal reconstruído. 
Para melhorar o resultado anterior, aumentou-se o nível de detalhamento a ser retirado do sinal original para 3 e obteve-se o seguinte resultado ilustrado na figura 51.

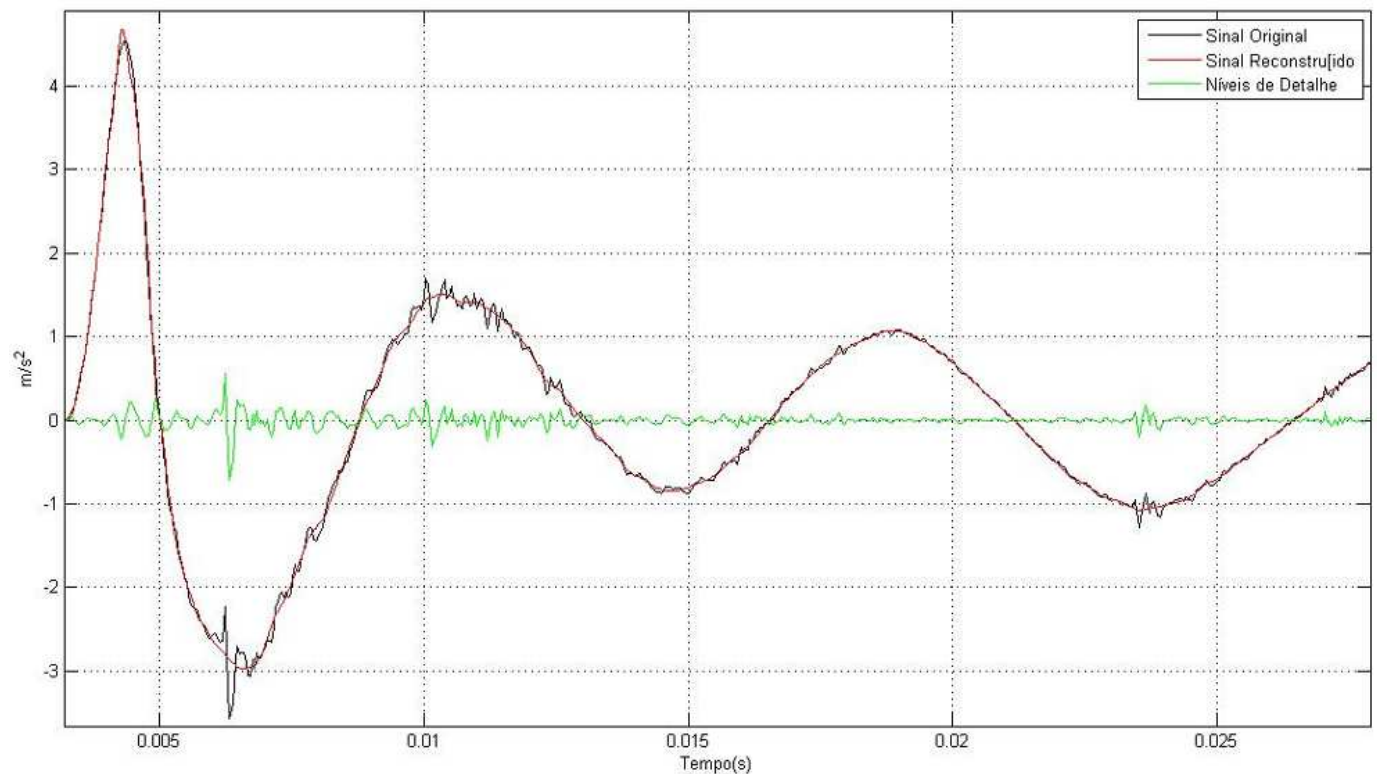

Figura 51 - Wavelet de Daubechies de ordem 3 e 3 níveis de detalhamento.

Pelo resultado obtido, observa-se que 3 níveis de detalhamento foram suficientes para retirar a maior parte dos ruídos de impacto do sinal original mas percebe-se que próximo ao instante de $4 \mathrm{~ms}$ ocorreu uma pequena distorção do sinal reconstruído como ilustrado na figura 52 a seguir.

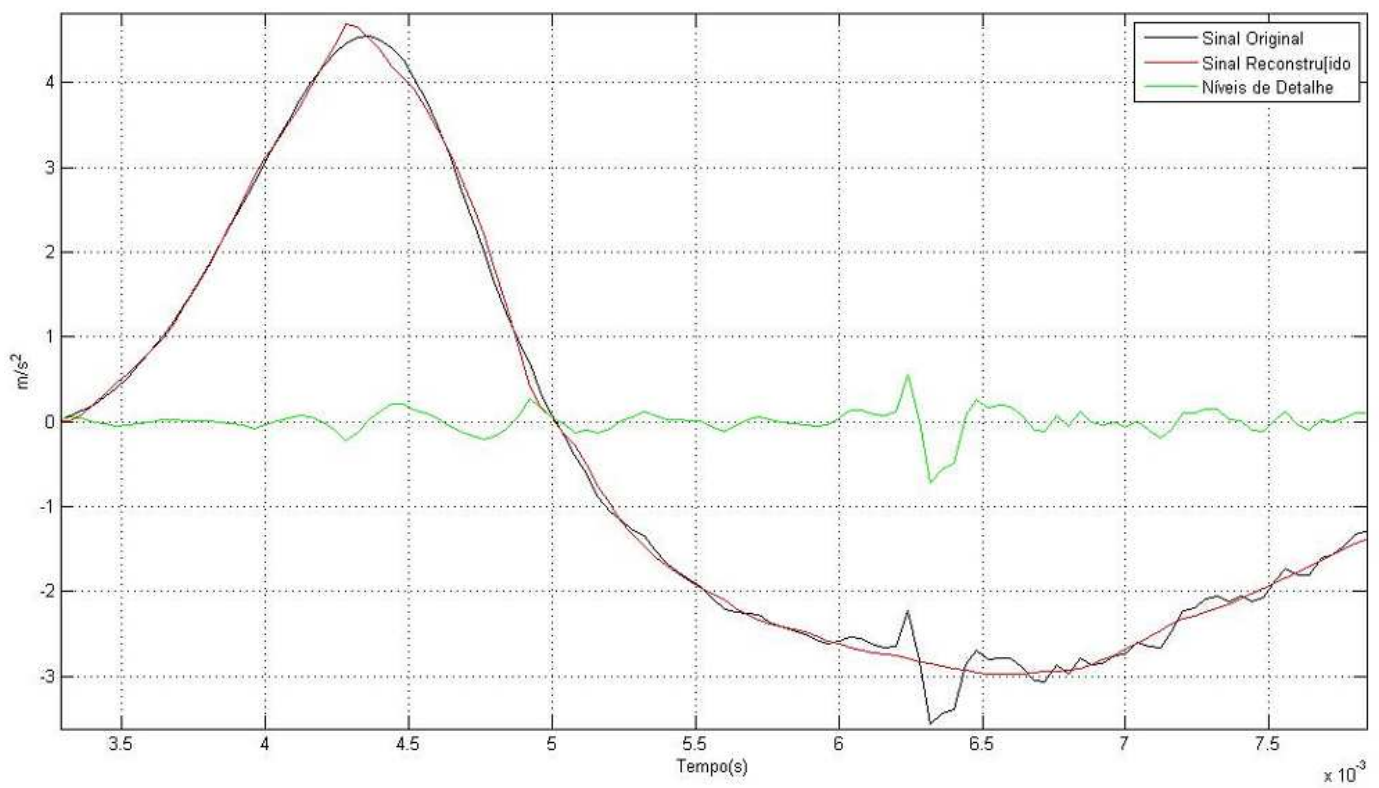

Figura 52 - Distorção do sinal original. 
Para solucionar este problema, aumentou-se a ordem da wavelet para 7. A figura 53 ilustra o resultado obtido com esta modificação.

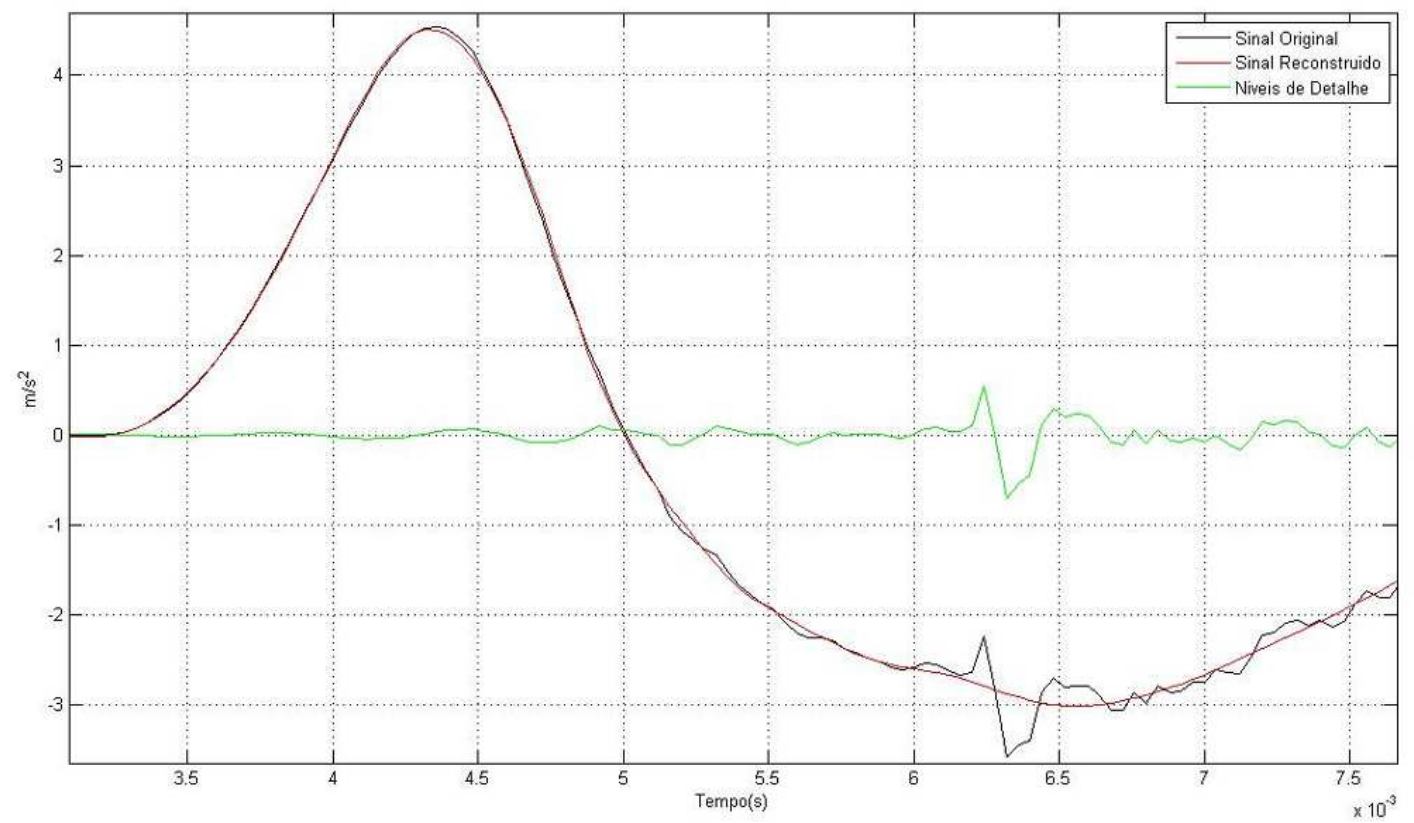

Figura 53 - Wavelet de Daubechies de ordem 7 e 3 níveis de detalhamento.

Por este resultado, percebe-se que a distorção do sinal foi solucionada. Isto se deve ao fato de que o formato da wavelet de Daubechies de ordem 7 ser mais próximo do sinal de impacto e portanto no momento de se realizar a transformada de wavelet, que é o produto interno do sinal de vibração com a wavelet, a wavelet de ordem 7 apresenta melhores características para reconhecer os impactos do sinal de vibração.

A figura 54 ilustra as wavelets de Daubechies de ordem 3 e de ordem 7.

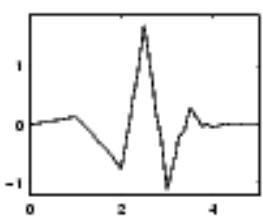

$\mathrm{db} 3$

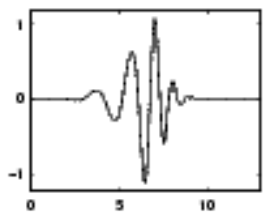

$\mathrm{db} 7$

Figura 54 - Wavelets de Daubechies de ordem 3 e 7 respectivamente.

Em seguida, foi analisado o espectro de freqüência do sinal reconstruído sem os ruídos de impacto e obteve-se o resultado ilustrado na figura 55 a seguir. 


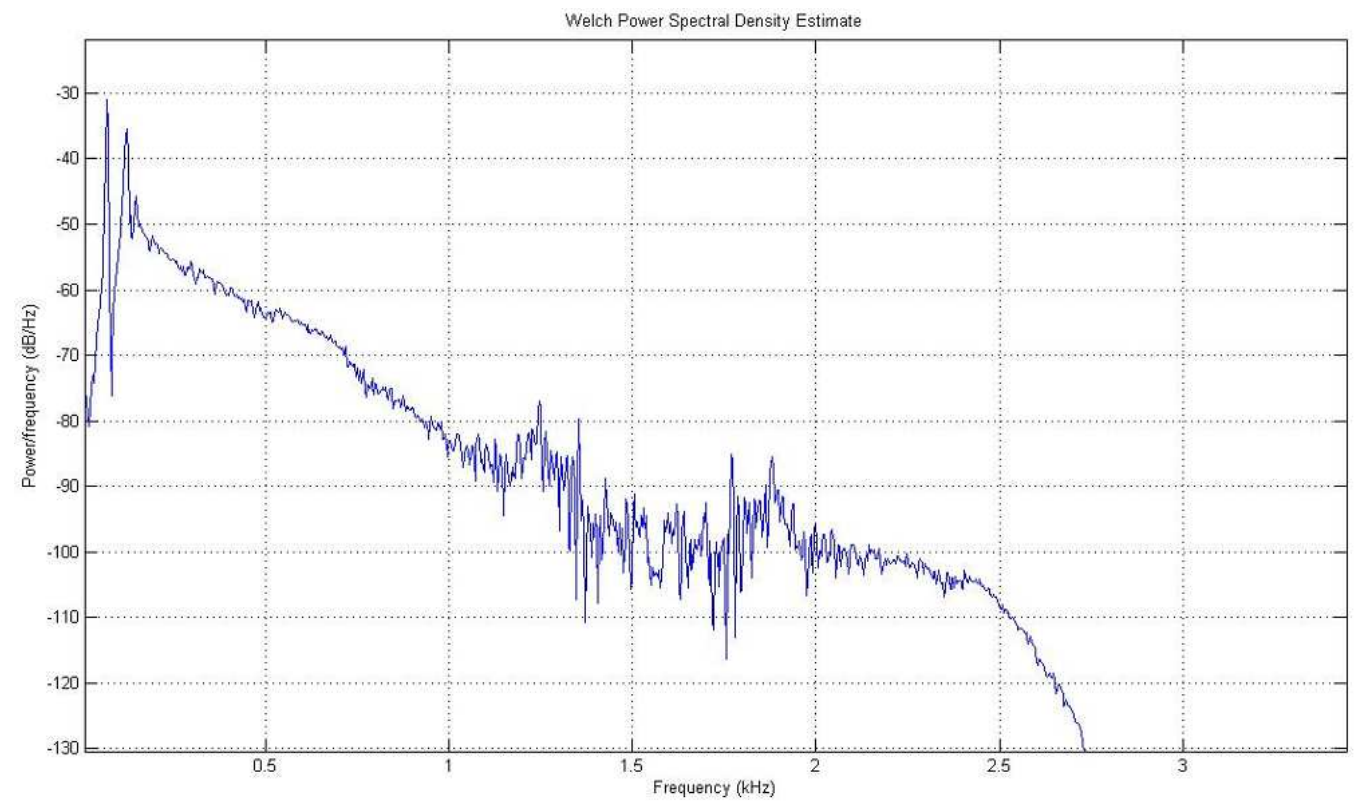

Figura 55 - Espectro de frequência do sinal sem ruídos de impacto.

Este resultado ilustra que no espectro predominam as freqüências em torno de $120 \mathrm{~Hz}$, a qual é aproximadamente a freqüência natural de vibração transversal da cremalheira.

Esta freqüência de ressonância também pode ser observada na figura 47 cujo período da onda do sinal reconstruído é de aproximadamente $8.5 \mathrm{~ms}$ o que reflete em uma freqüência próxima a $120 \mathrm{~Hz}$.

A figura 56 ilustra o espectrograma do sinal reconstruído.

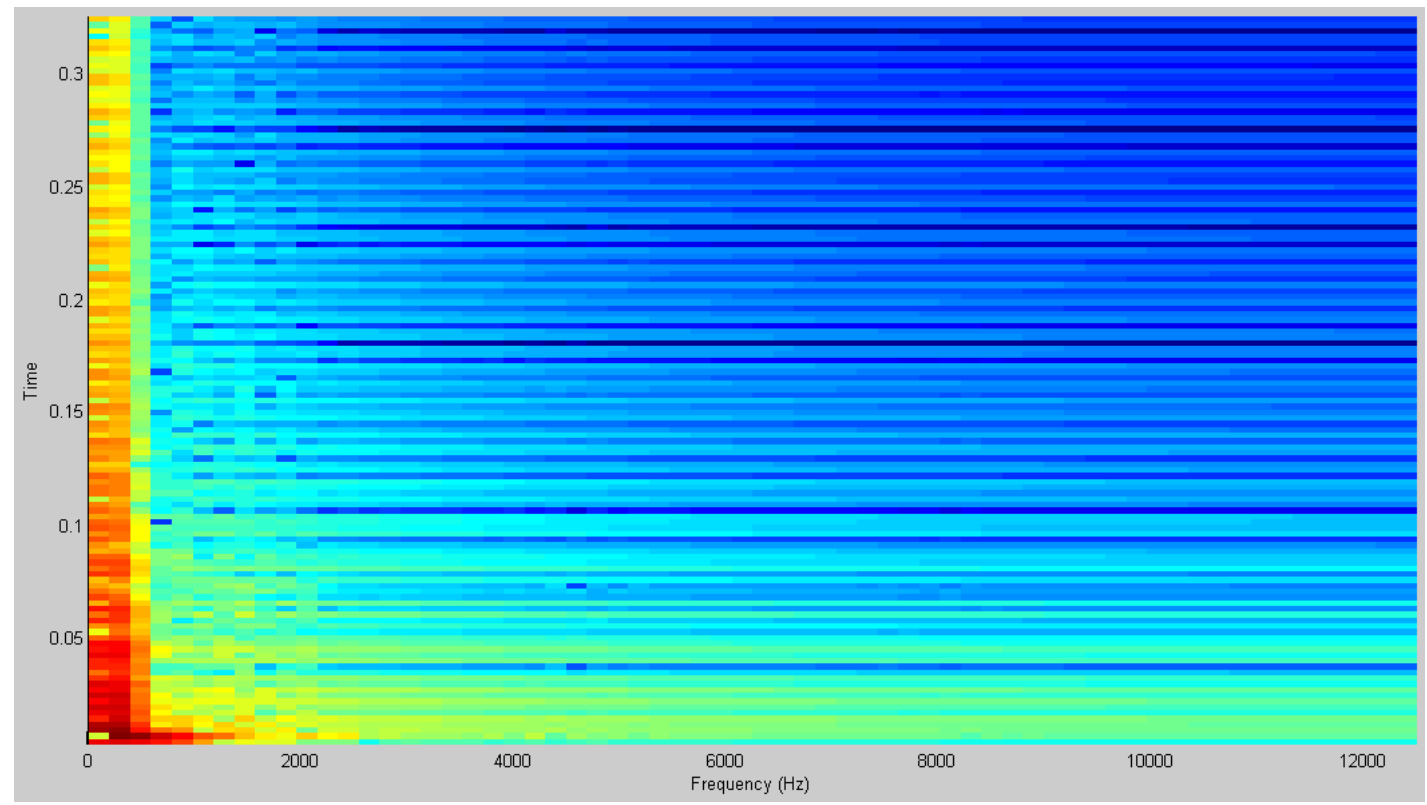

Figura 56 - Espectrograma do sinal reconstruído. 
Este resultado comprova que a maior parte das frequências na ordem de $\mathrm{kHz}$ foi retirada do sinal original.

Analisando o espectro de freqüência dos ruídos de impacto, obteve-se 0 resultado ilustrado na figura 57 a seguir.

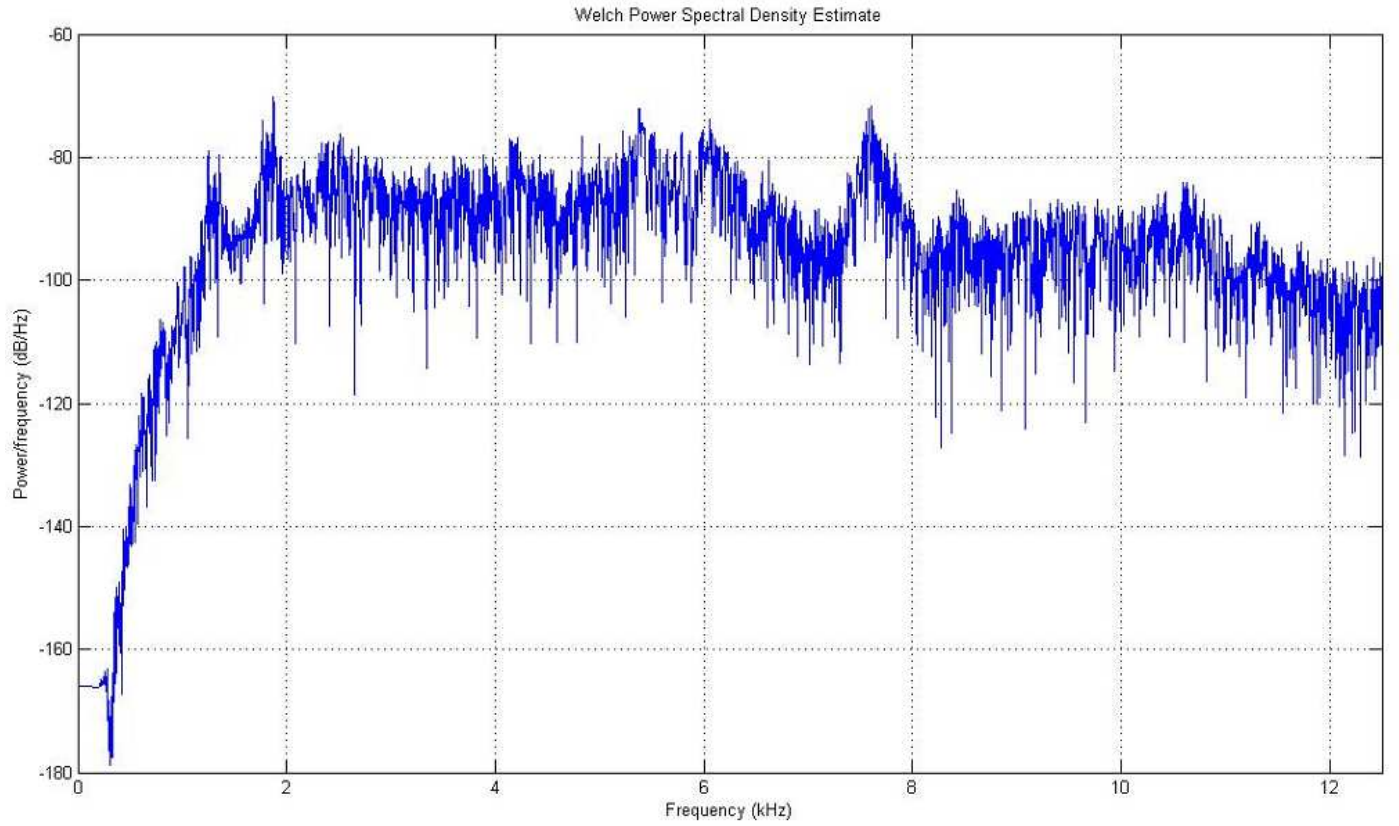

Figura 57 - Espectro de freqüência do sinal dos ruídos de impacto.

Este resultado ilustra que neste espectro predominam as freqüências na ordem de grandeza de $\mathrm{kHz}$, as quais representam os impactos da cremalheira internos à caixa de direção.

$\mathrm{Na}$ figura 58 é ilustrado o espectrograma do sinal referente aos ruídos de impacto retirados do sinal original. 


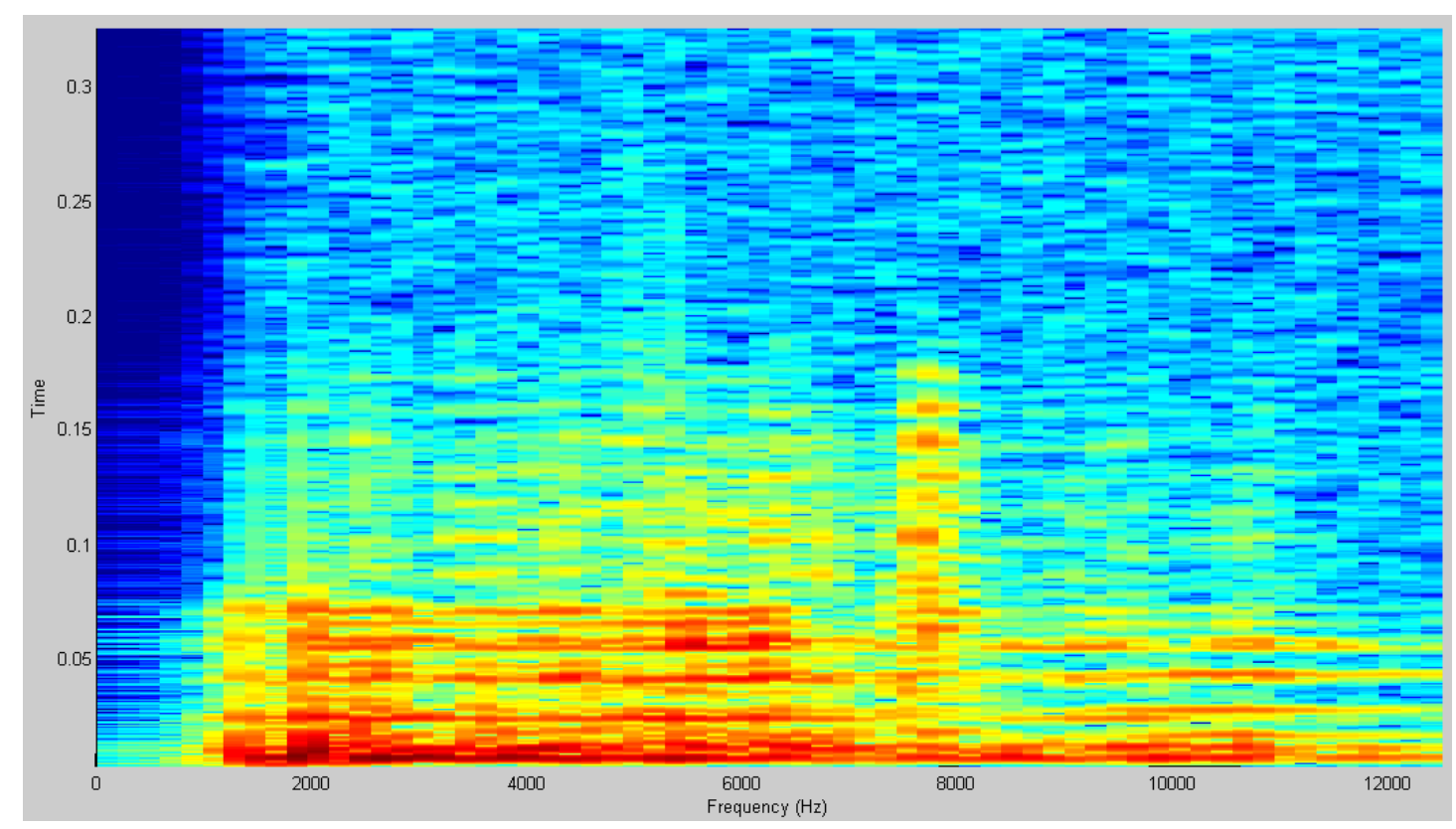

Figura 58 - Espectrograma do sinal dos ruídos de impacto.

Por este resultado, comprova-se que predominam as freqüências na ordem de grandeza de kHz.

Para quantificar a freqüência de ocorrência de impactos, foi realizada uma pré-filtragem no sinal original que eliminou os dados cujo valor absoluto era inferior a $0,2 \mathrm{~m} / \mathrm{s}^{2}$ e foi criada uma janela com largura de $1,3 \mathrm{~ms}$ que percorreu todo o sinal original. Verificou-se se o módulo do sinal original a cada janela de 1,3 ms ultrapassou, em algum momento, $15 \%$ do valor em módulo do sinal reconstruído sem os ruídos de impacto. Caso afirmativo, foi considerada a ocorrência de uma unidade de impacto. Para quantificar a severidade deste impacto, foi calculado o valor R.M.S do sinal do ruído de impacto nessa janela.

Aplicando este procedimento sobre o sinal acima, foram necessárias 256 janelas para percorrer o sinal inteiro e foi registrado que em 20 dessas janelas, 0 sinal original ultrapassou em 15\% o valor do sinal reconstruído, ou seja, ocorreram 20 impactos dentro da caixa de direção e a maior severidade de impacto medida foi de $0,20 \mathrm{~m} / \mathrm{s}^{2}$.

No gráfico superior da figura 59 são ilustrados, em vermelho, os pontos de impacto detectados por este procedimento e no gráfico inferior são ilustrados os valores da severidade medidos para estes pontos. 

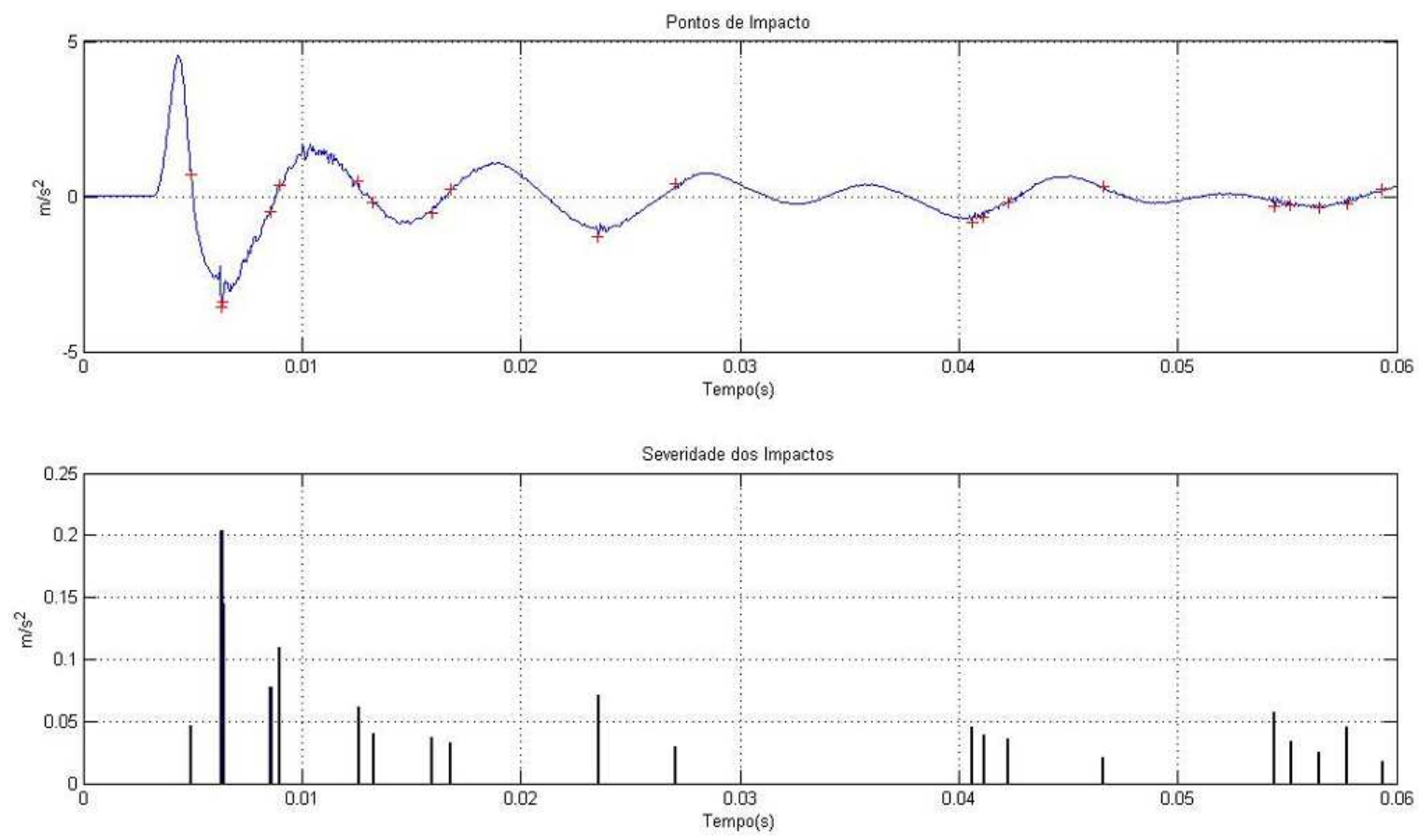

Figura 59 - Pontos de impacto e Severidade dos Impactos.

6.2 Escolha dos Parâmetros para Análise com Wavelet Harmônica de Newland

Aplicando, sobre o mesmo sinal de vibração, a wavelet de Newland e retirando os 3 últimos níveis de detalhamento, obteve-se o seguinte resultado ilustrado na figura 60. 


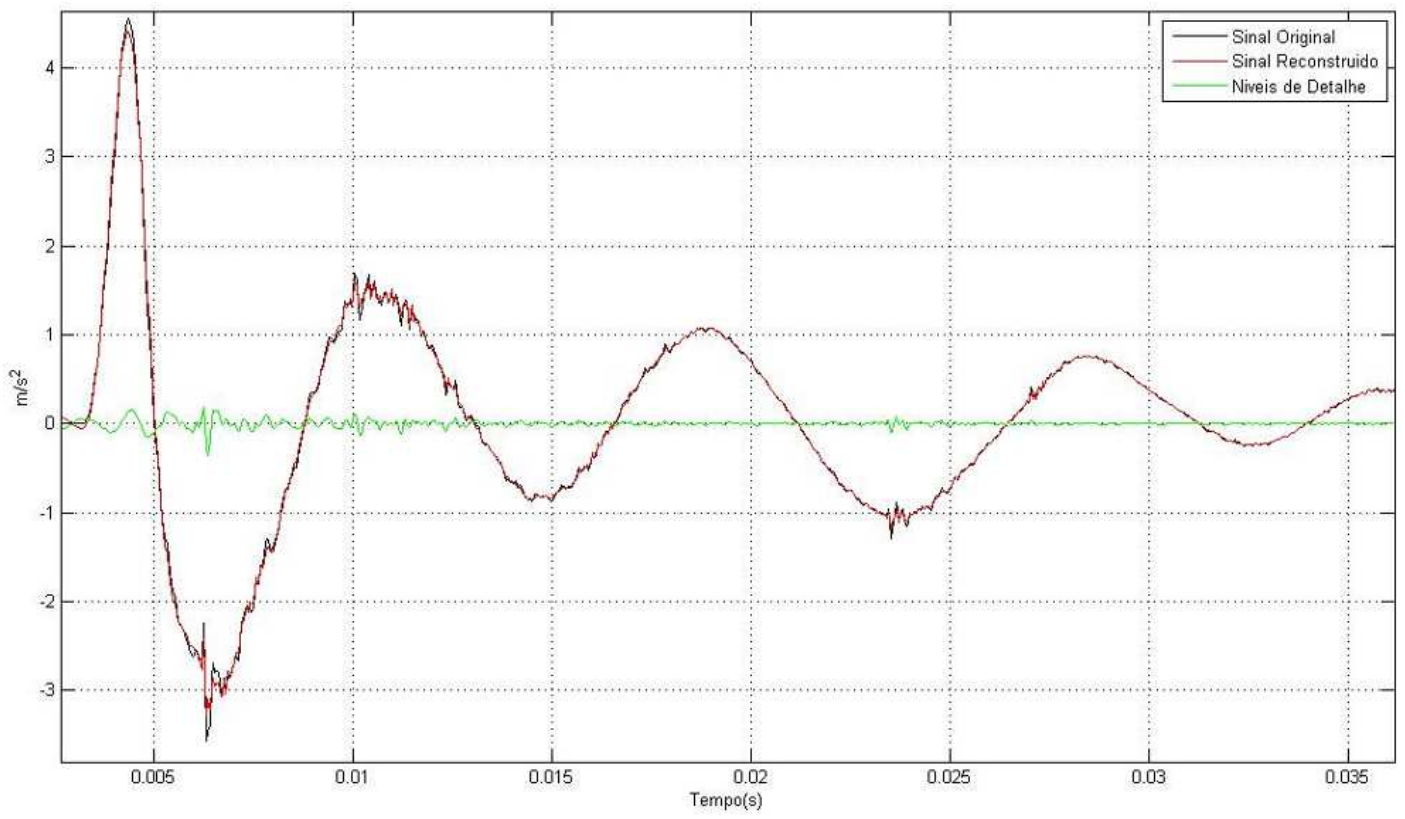

Figura 60 - Wavelet de Newland e 3 níveis de detalhamento.

Observa-se que a wavelet de Newland não conseguiu separar os ruídos de impacto do sinal original.

Aumentando-se o número de níveis de detalhamento retirados para 4, obtevese o seguinte resultado ilustrado na figura 61.

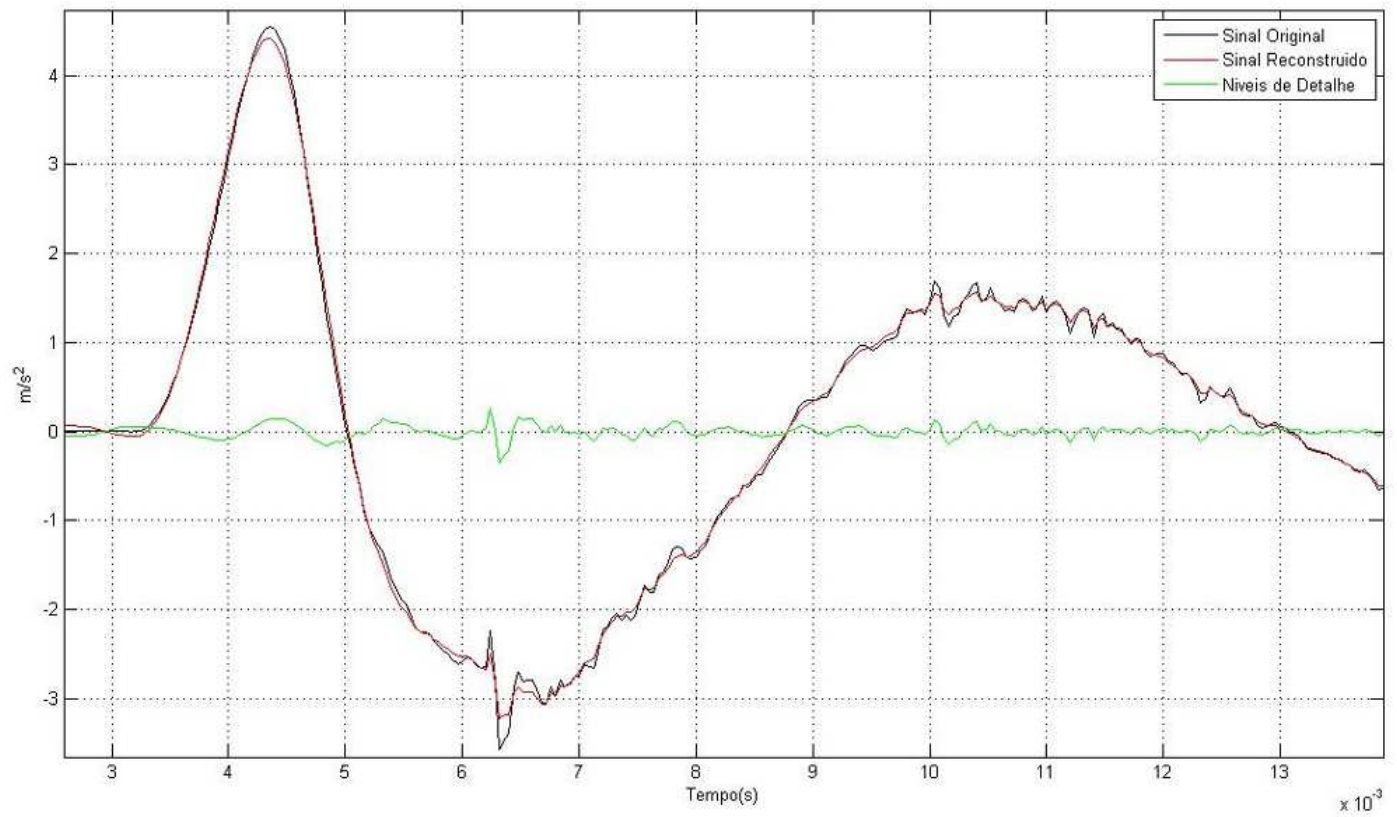

Figura 61 - wavelet de Newland e 4 níveis de detalhamento.

Pelo resultado, percebe-se que próximo a 4 ms o sinal começa a distorcer e que ainda aparecem ruídos de impacto no sinal reconstruído. Portanto a wavelet de Newland não possui boas propriedades para separar os impactos do sinal de 
vibração e assim esta wavelet não foi utilizada para detecção dos impactos nos sinais medidos em laboratório.

\subsection{Análise dos Sinais de Laboratório com Wavelet de Daubechies}

Este mesmo procedimento foi aplicado a outro sinal de vibração medido em laboratório, mas desta vez apenas a wavelet de Daubechies foi utilizada.

Considere o sinal de vibração medido em laboratório e ilustrado na figura 62 abaixo.

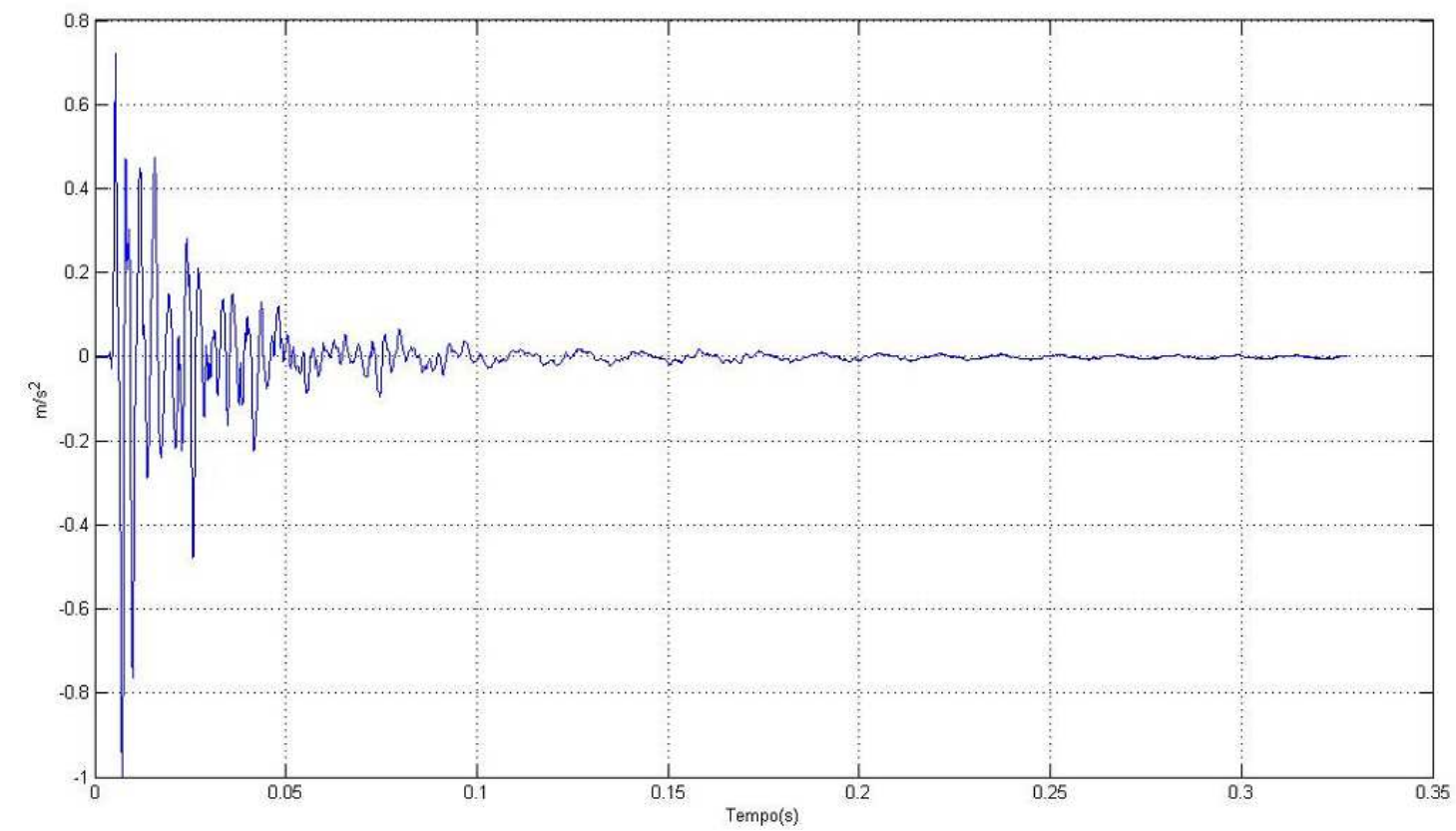

Figura 62 - Sinal medido em laboratório com D = 215 mm.

Este sinal foi medido pelo acelerômetro 1, posicionando-se este acelerômetro a uma distância de $215 \mathrm{~mm}$ do sujeitador e realizando batidas com o martelo na extremidade da cremalheira do acelerômetro 1, na direção transversal e no sentido de compressão da mola do sujeitador.

A figura 63 ilustra o espectrograma do sinal original. 


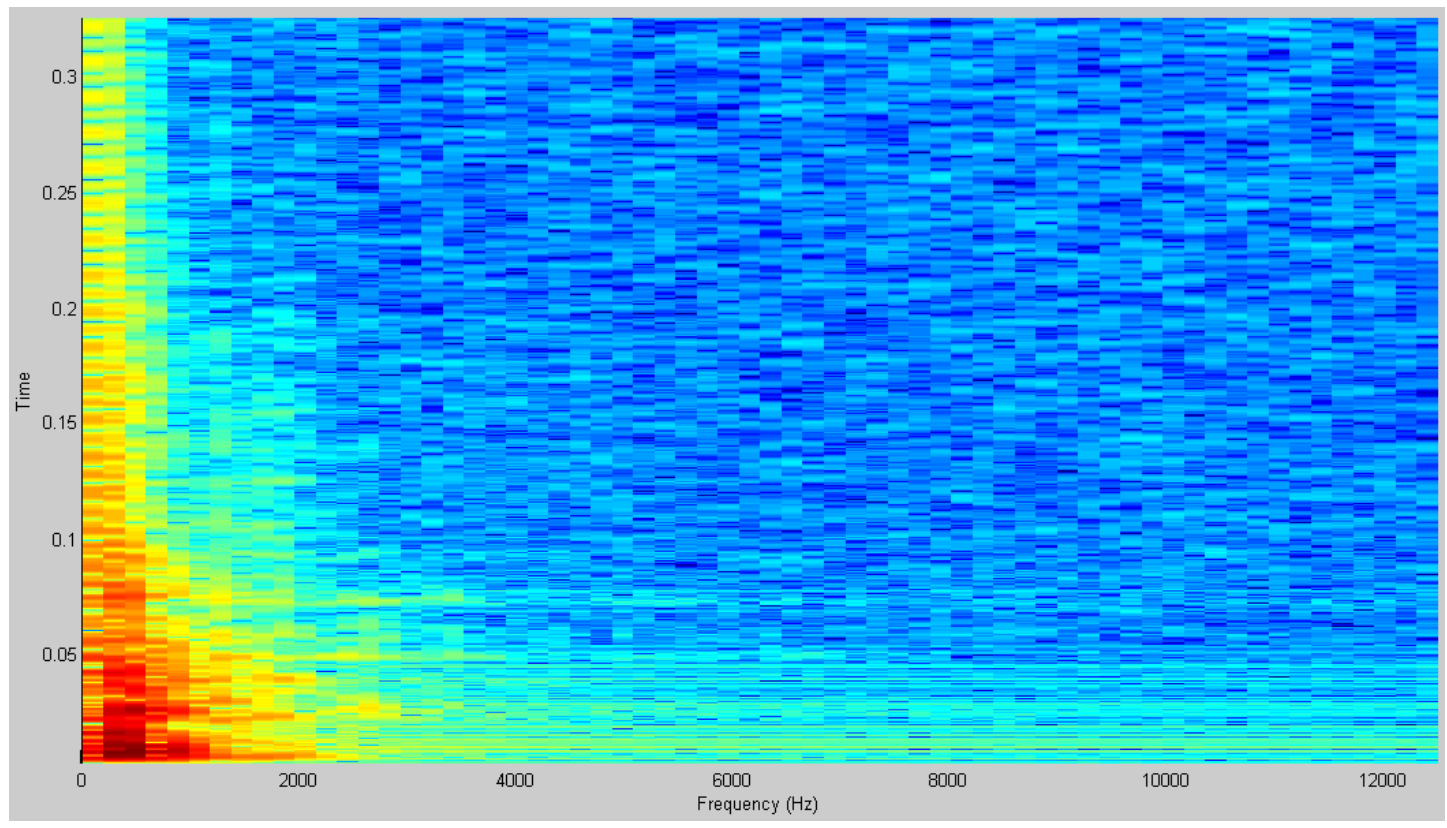

Figura 63 - Espectrograma do sinal original.

Por este resultado, nota-se que este sinal apresenta frequências na ordem de grandeza de $\mathrm{kHz}$, indicando a presença de ruídos de impacto provenientes dos impactos da cremalheira contra o pinhão e a bucha guia.

Aplicando a wavelet de Daubechies de ordem 7 e retirando do sinal original 3 níveis de detalhes, obteve-se o resultado ilustrado na figura 64 a seguir.

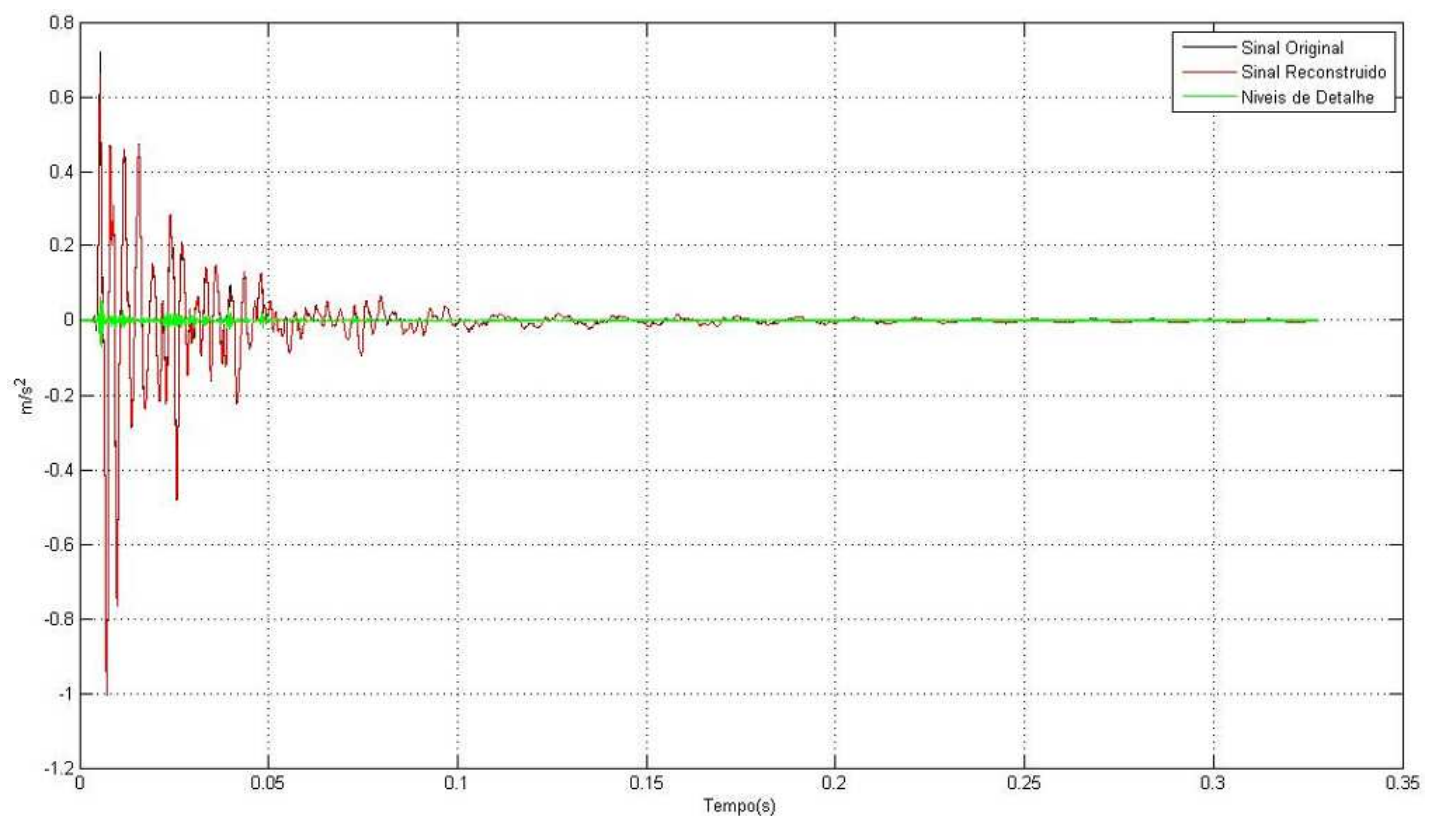

Figura 64 - Wavelet de Daubechies de ordem 7 e 3 níveis de detalhamento. 
Aumentando o zoom sobre a parte inicial do sinal, resulta na figura 65 a seguir.

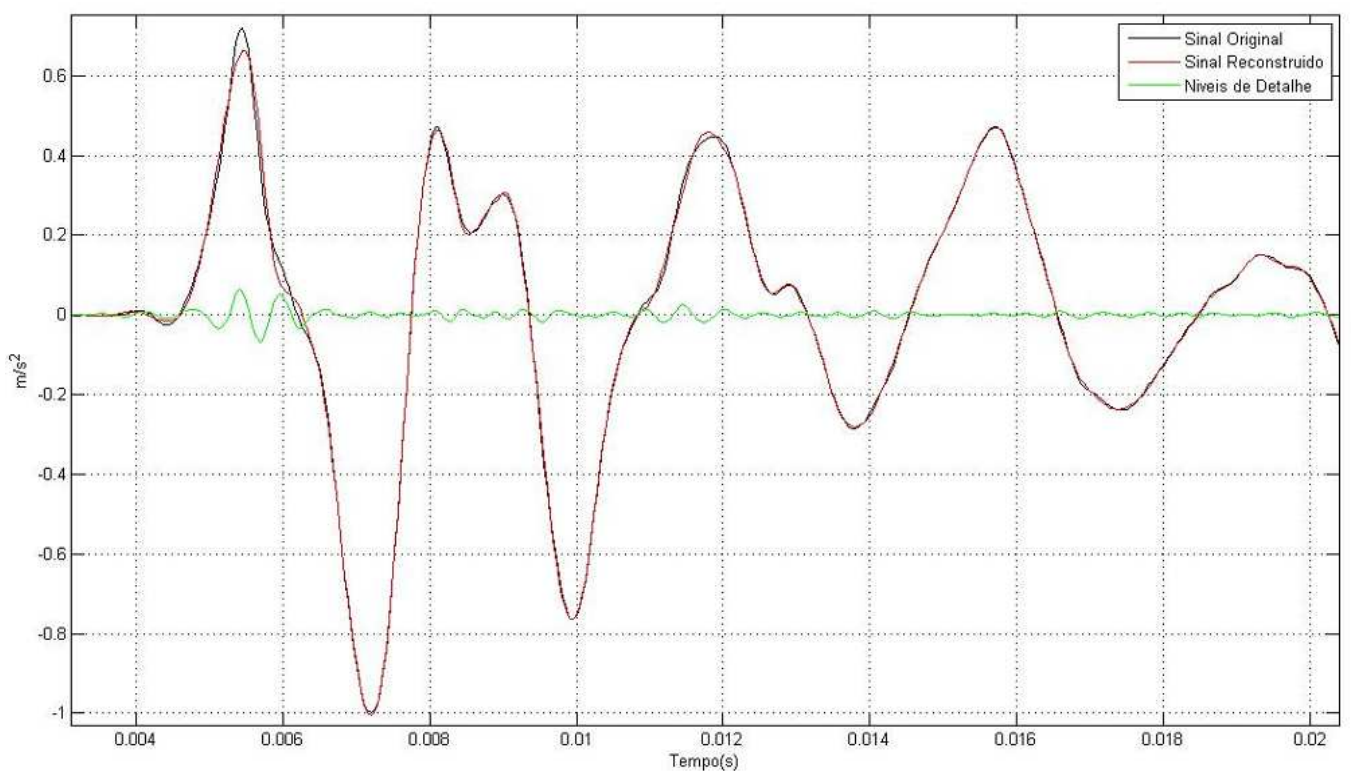

Figura 65 - Zoom sobre o trecho inicial do sinal.

Por este resultado, nota-se que grande parte dos ruídos de impacto foi separada do sinal original de vibração, mas o sinal reconstruído apresentou algumas distorções em relação ao sinal original, como próximas a 6 ms e 12 ms.

Para tentar melhorar este resultado, aumentou-se a ordem da wavelet para 12 e o resultado obtido encontra-se na figura 66 abaixo.

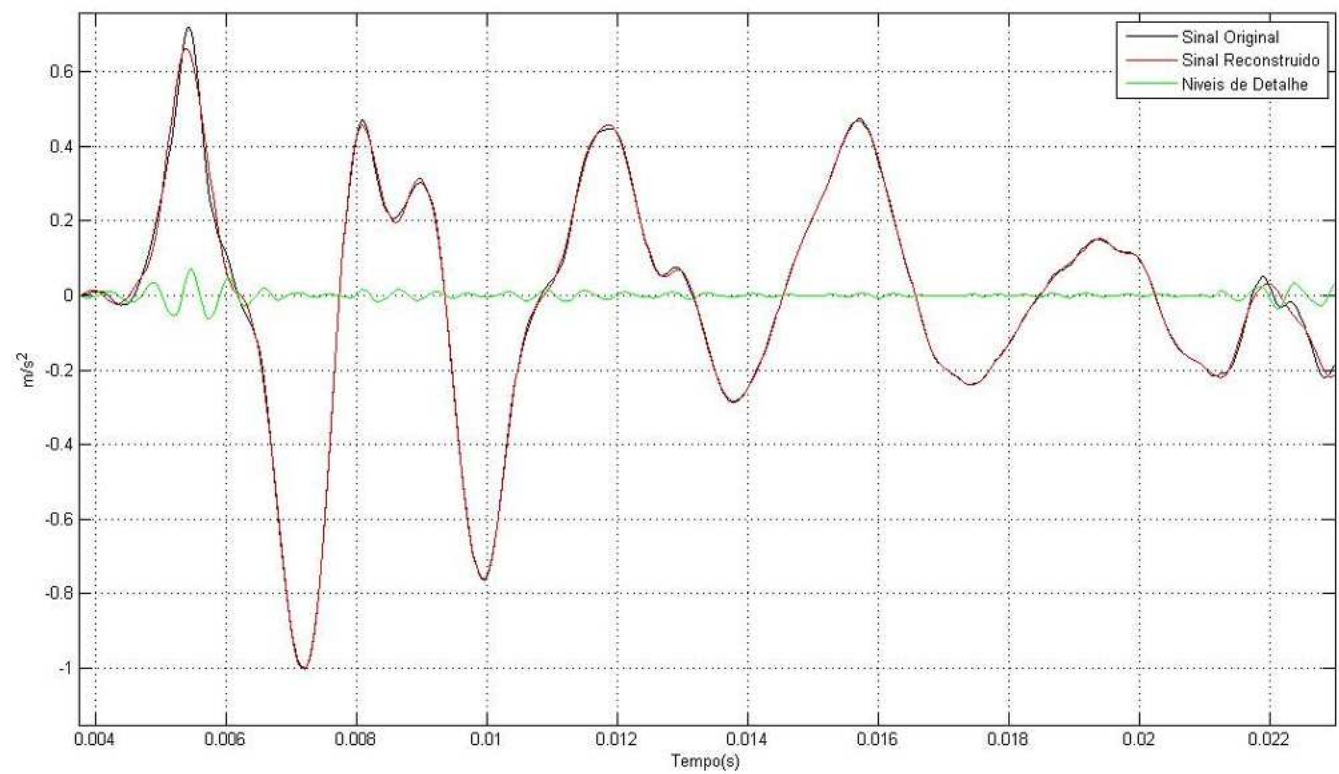

Figura 66 - Wavelet de Daubechies de ordem 12 e 3 níveis de detalhe. 
Por este resultado, nota-se que as distorções ainda aparecem no sinal reconstruído e, portanto o aumento da ordem da wavelet não foi possível corrigir estas distorções.

Desta forma adotou-se, para este caso, como melhor solução o uso da Wavelet de Daubechies de ordem 7 e a retirada dos 3 últimos níveis de detalhamento.

Analisando o espectro de freqüência do sinal reconstruído, obteve-se o seguinte resultado ilustrado na figura 67.

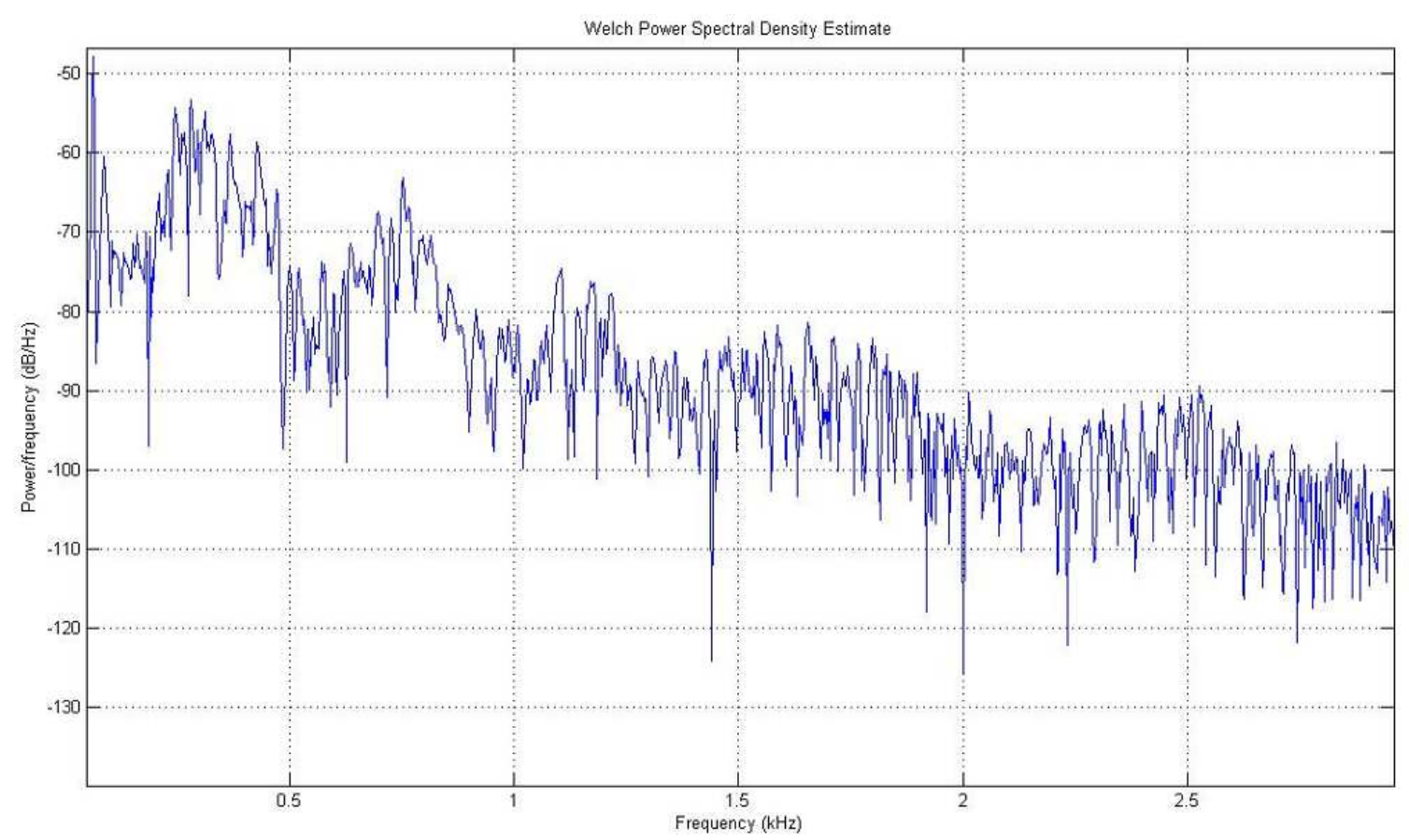

Figura 67 - Espectro de frequência do sinal reconstruído.

Por este resultado, observa-se que predominam as freqüências em torno de $120 \mathrm{~Hz}$ que é a freqüência natural de vibração transversal da cremalheira, indicando que grande parte dos ruídos de impacto foi retirada do sinal original de vibração.

A figura 68 ilustra o espectrograma do sinal reconstruído. 


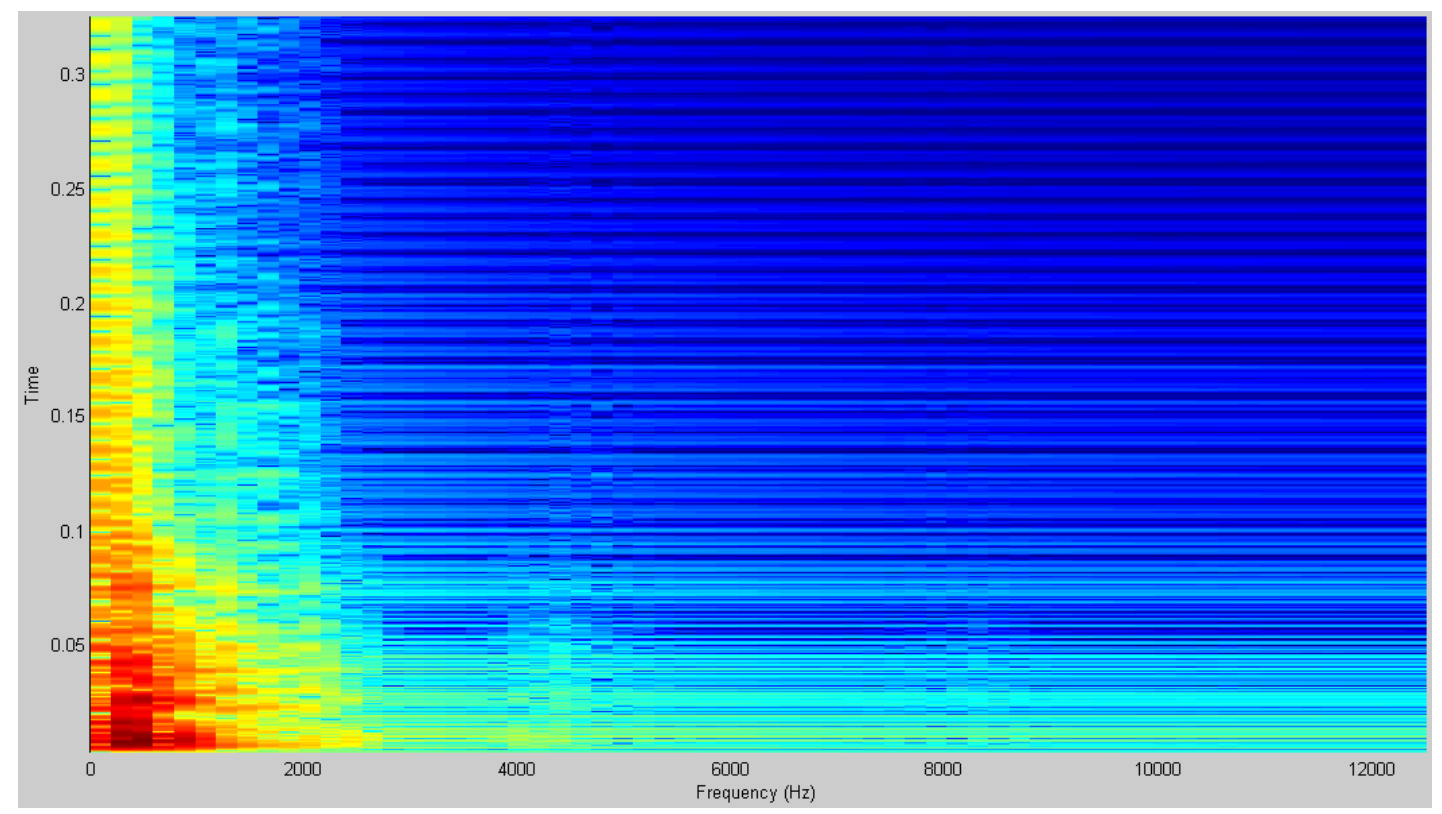

Figura 68 - Espectrograma do sinal reconstruído.

Este resultado ilustra que a maior parte das frequências na ordem de $\mathrm{kHz}$ foi retirada do sinal original de vibração.

A figura 69 a seguir ilustra o espectro de freqüência do sinal que contem os ruídos de impacto retirados do sinal original.

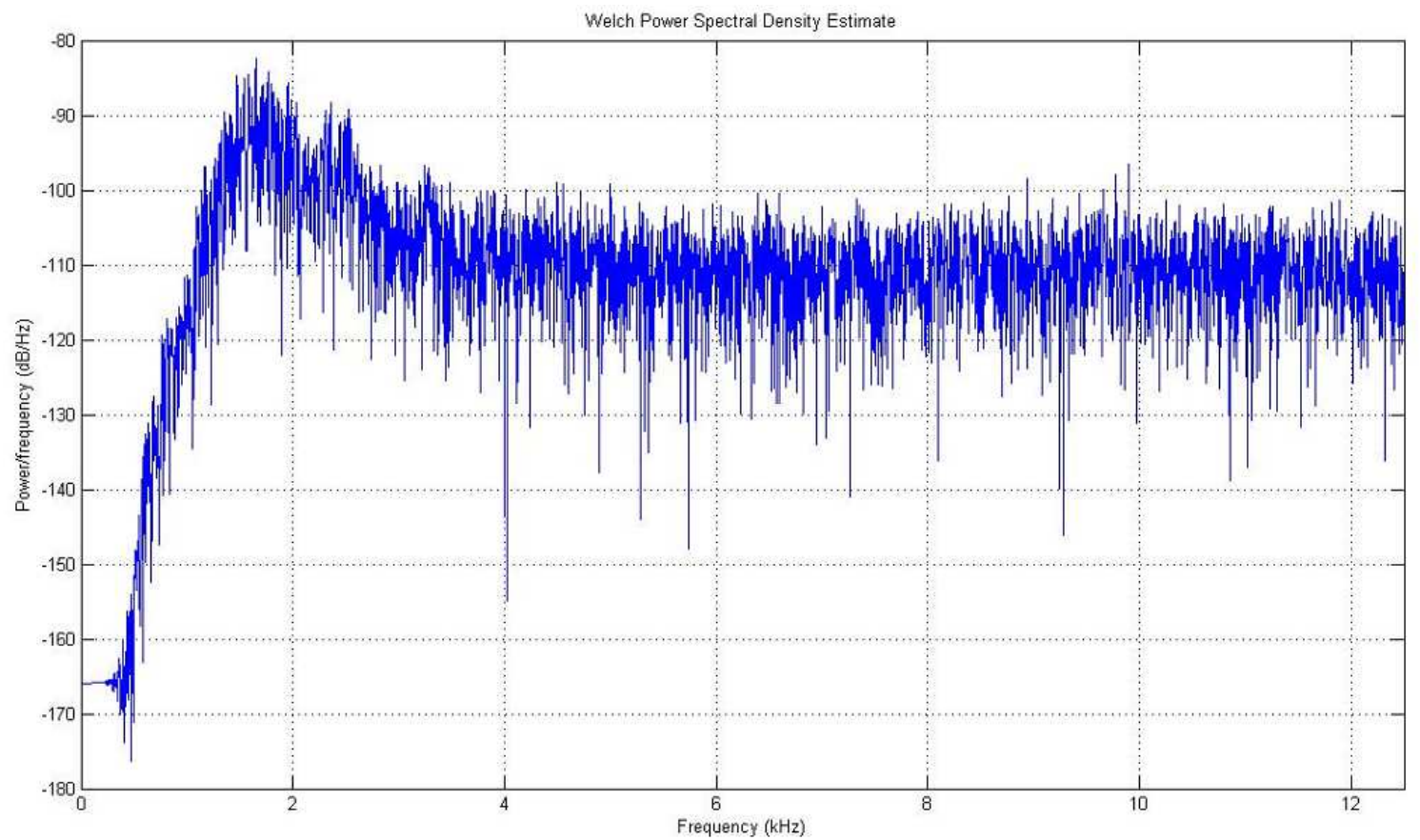

Figura 69 - Espectro de frequência do sinal dos ruídos de impacto. 
Por este resultado, observa-se que predominam as freqüências em torno de 2 $\mathrm{kHz}$, as quais representam os impactos internos à caixa de direção.

$\mathrm{Na}$ figura 70 é ilustrado o espectrograma do sinal dos ruídos de impacto retirados do sinal original.

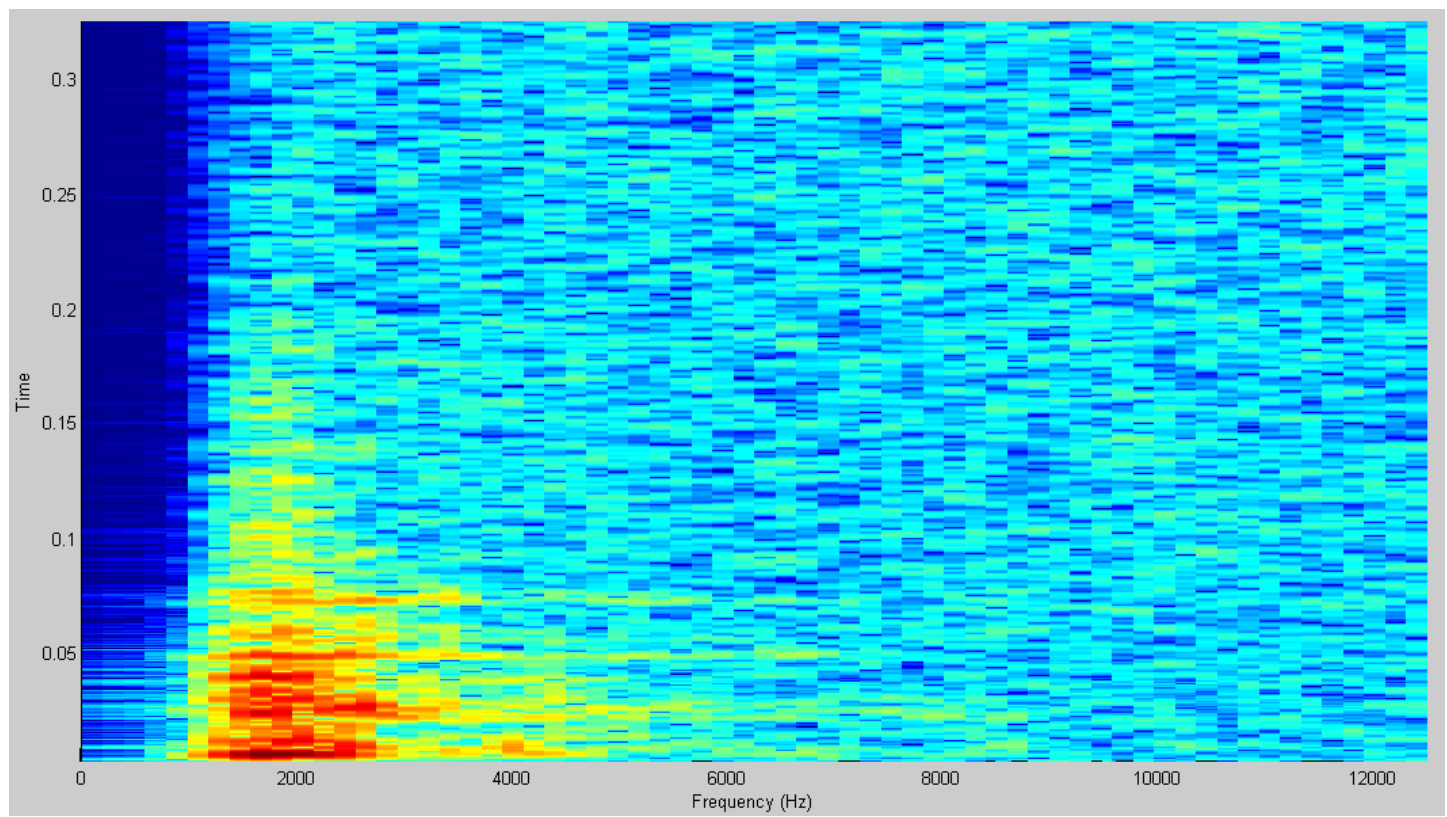

Figura 70 - Espectrograma do sinal dos ruídos de impacto.

Pela figura 70, observa-se que predominam as freqüências próximas a 2 kHz.

Adotando o critério da janela de tempo, mas ajustando a pré-filtragem para $0,02 \mathrm{~m} / \mathrm{s}^{2}$, foi registrada a ocorrência de 25 impactos dentro da caixa de direção e a maior severidade de impacto medida foi de $0,038 \mathrm{~m} / \mathrm{s}^{2}$.

No gráfico superior da figura 71 são ilustrados, em vermelho, os pontos de impacto detectados por este procedimento e no gráfico inferior são ilustrados os valores da severidade medidos para estes pontos. 

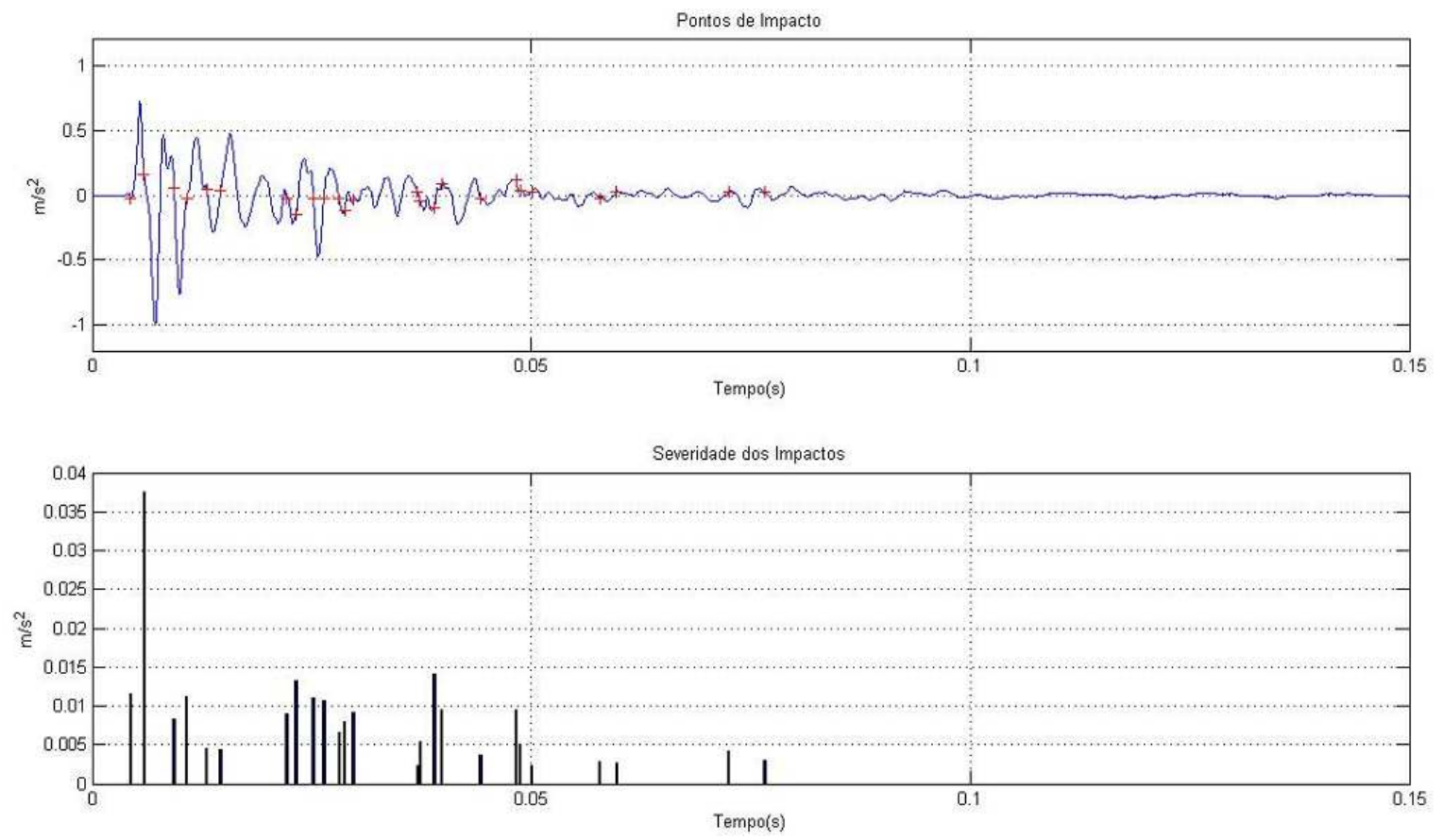

Figura 71 - Pontos de impacto e Severidade dos Impactos.

Considere o sinal de vibração medido em laboratório e ilustrado na figura 72.

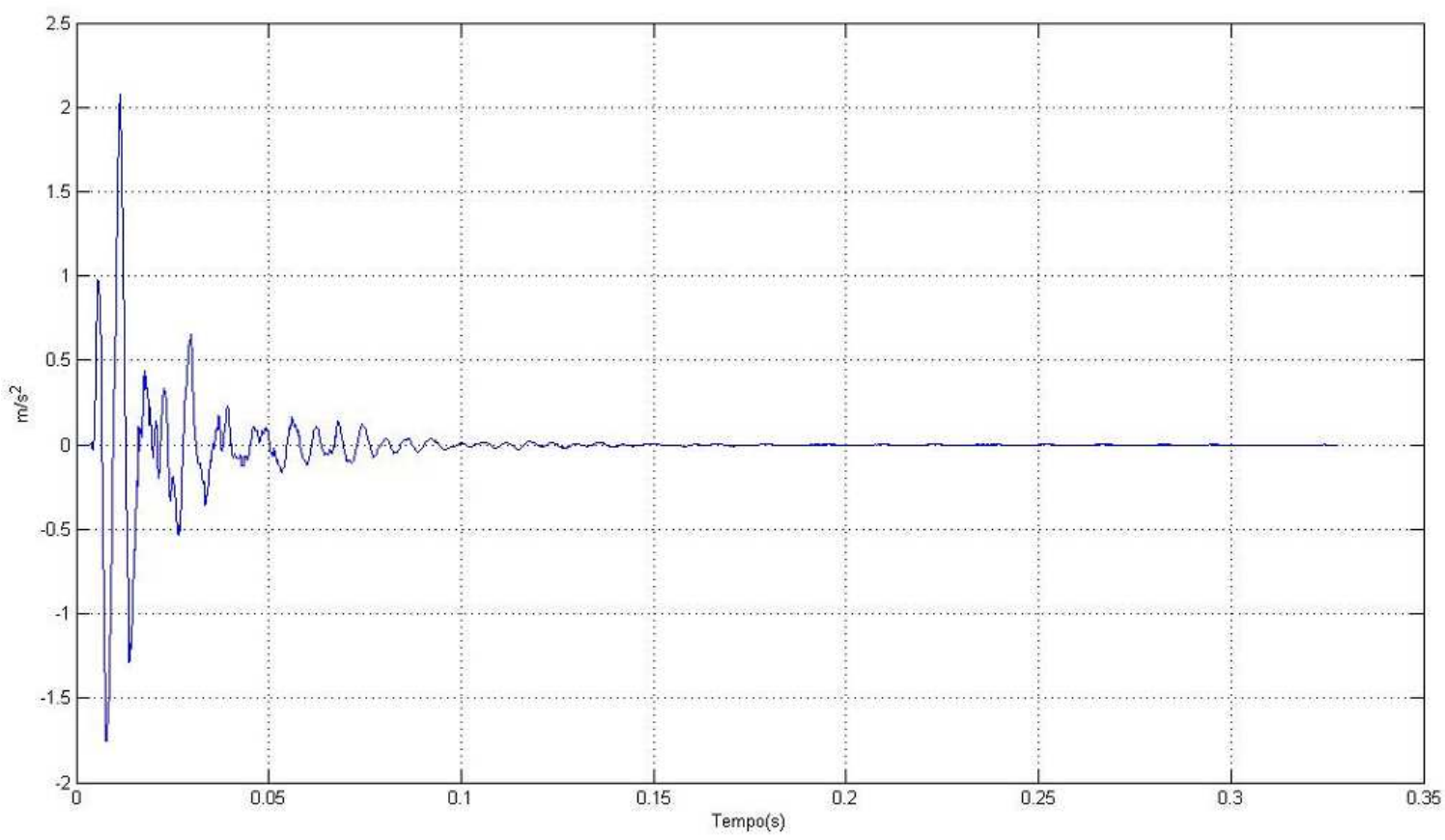

Figura 72 - Sinal medido em laboratório com D = 152 mm.

Este sinal foi medido pelo acelerômetro 1, posicionando-se o mesmo a uma distância de $152 \mathrm{~mm}$ do sujeitador e realizando batidas com o martelo na 
extremidade da cremalheira do acelerômetro 1, na direção transversal e no sentido de compressão da mola do sujeitador.

A figura 73 a seguir ilustra o espectrograma do sinal original.

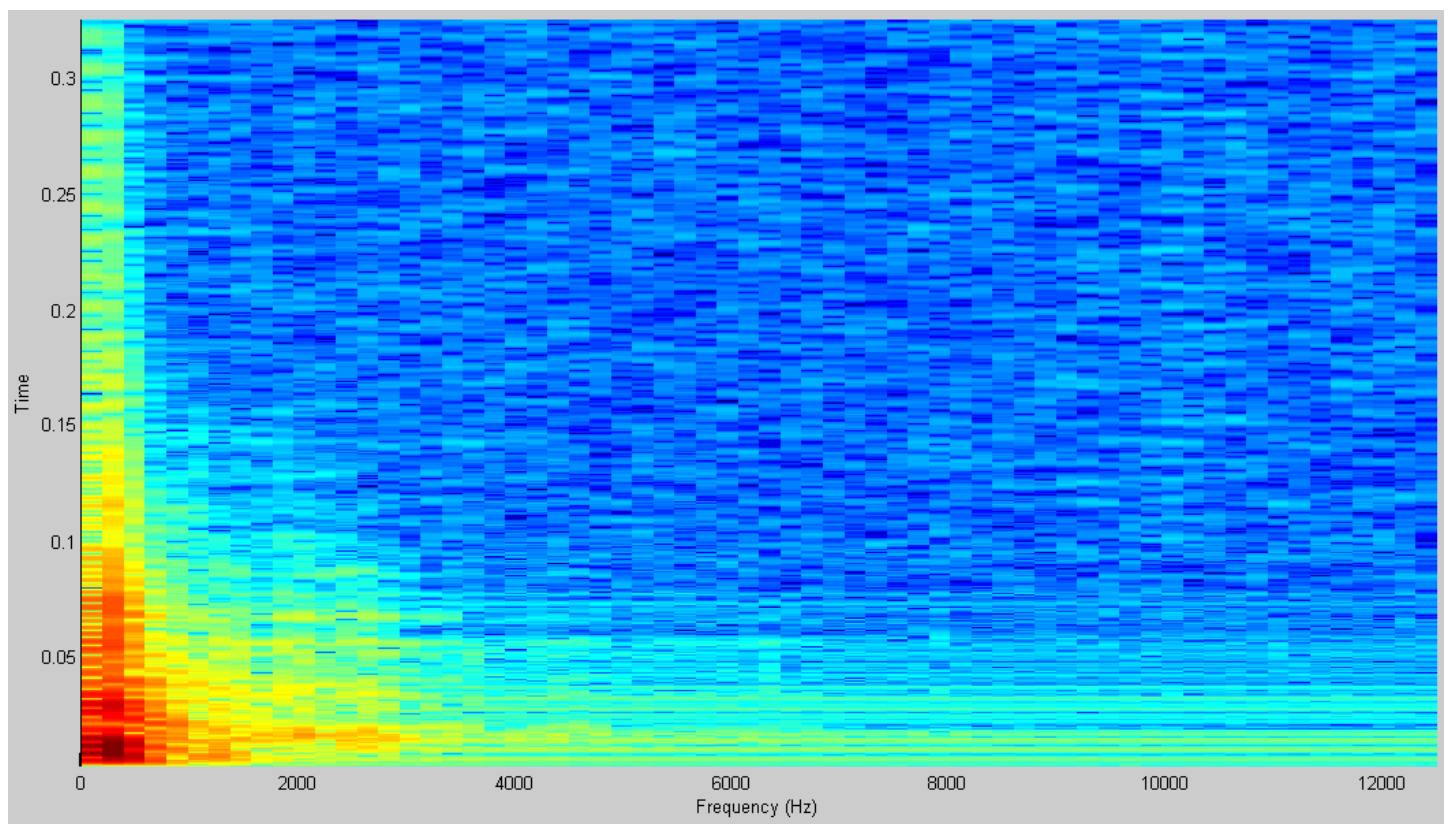

Figura 73 - Espectrograma do sinal original.

Por este resultado, nota-se a presença de frequências na ordem de grandeza de $\mathrm{kHz}$, indicando a presença de ruídos de impacto provenientes dos impactos da cremalheira contra o pinhão e bucha guia.

Aplicando a wavelet de Daubechies de ordem 7 e retirando 3 níveis de detalhe do sinal original, obteve-se o resultado ilustrado na figura 74. 


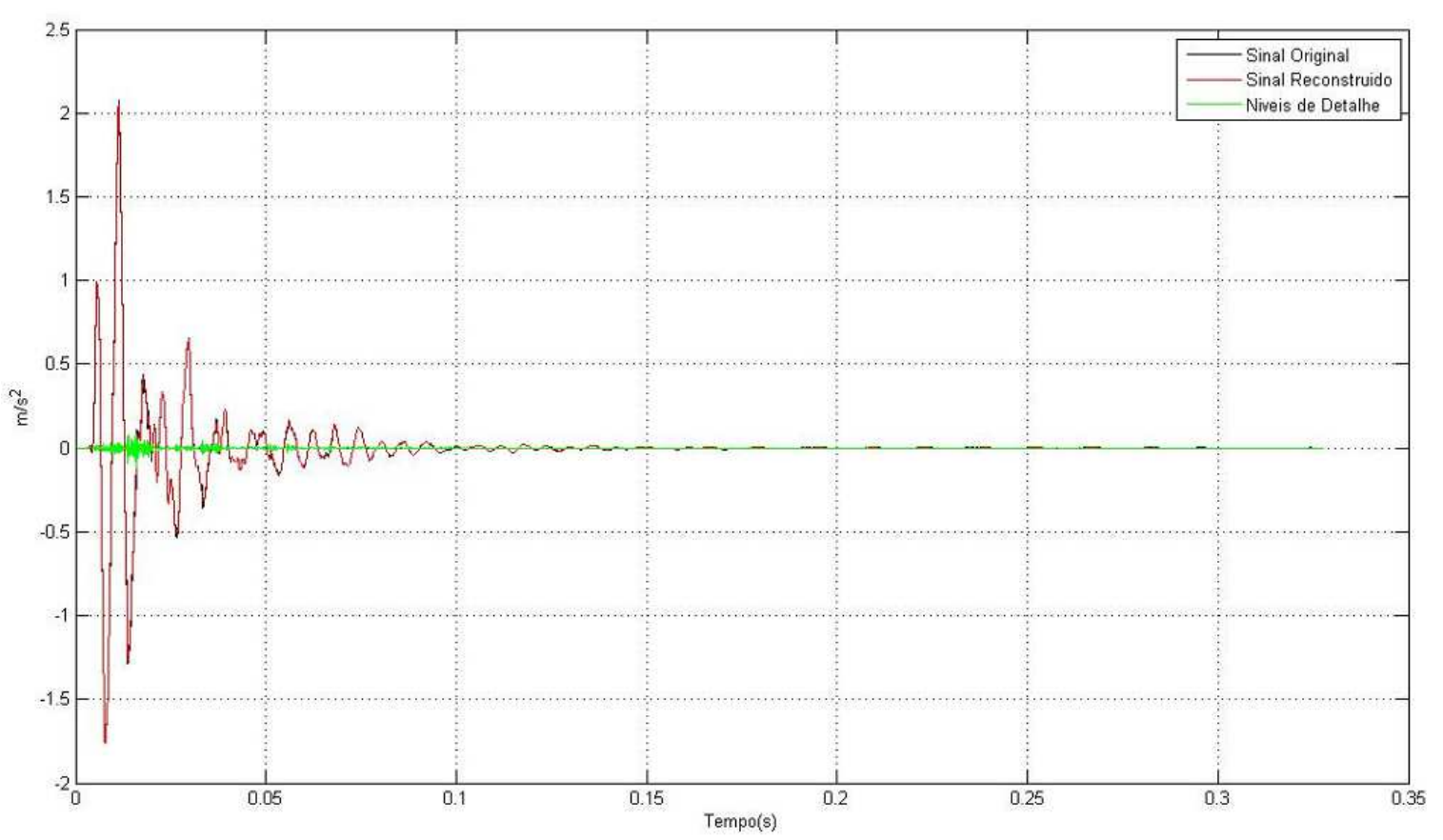

Figura 74 - Wavelet de Daubechies de ordem 7 e 3 níveis de detalhamento.

Aumentando o zoom sobre a parte inicial do sinal, obteve-se a figura 75 a seguir.

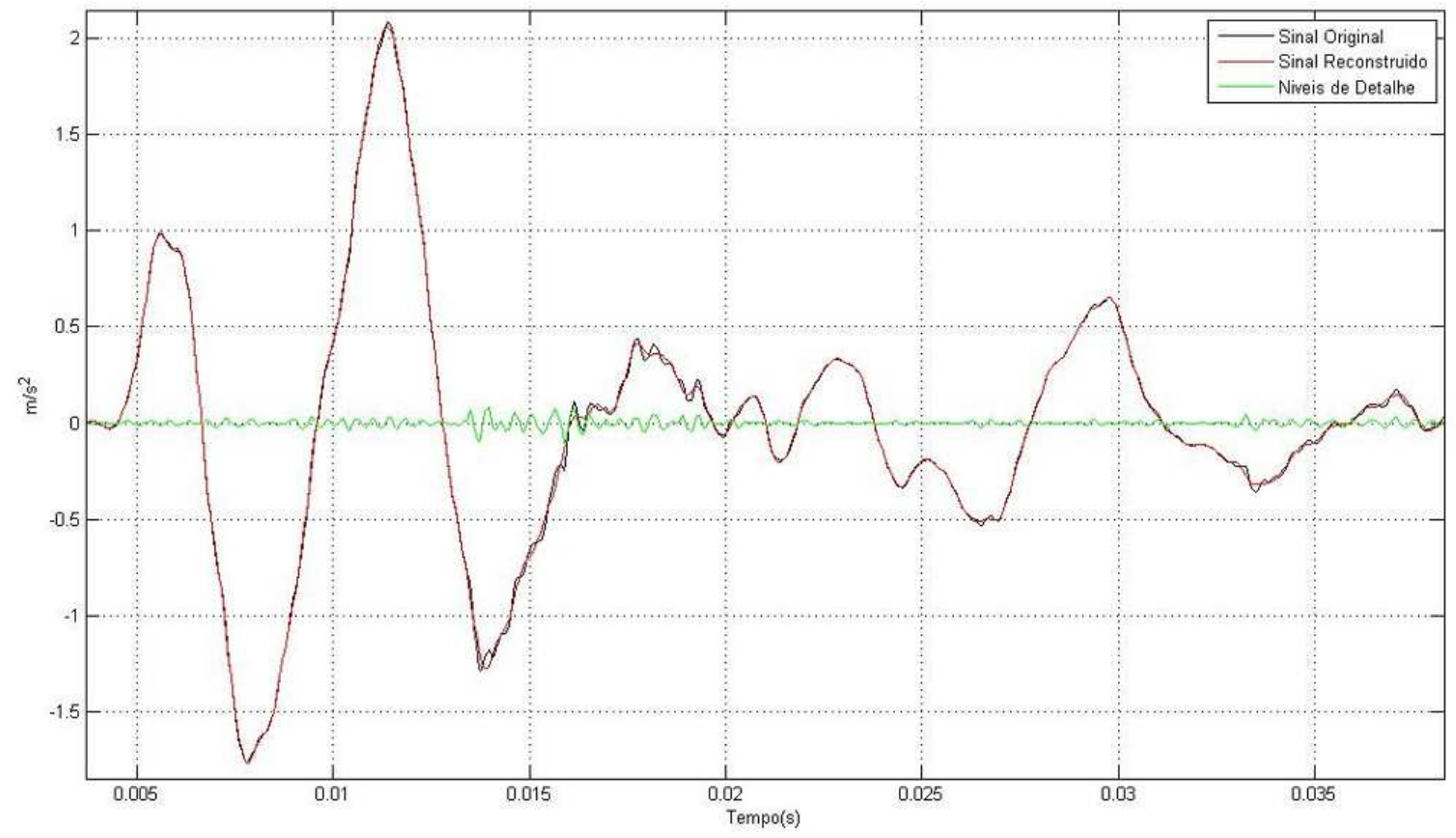

Figura 75 - Zoom sobre o trecho inicial do sinal.

Por este resultado, nota-se que grande parte dos ruídos de impacto foi removida do sinal original de vibração. 
Analisando o espectro de freqüência do sinal reconstruído, obteve-se o resultado ilustrado na figura 76 a seguir.

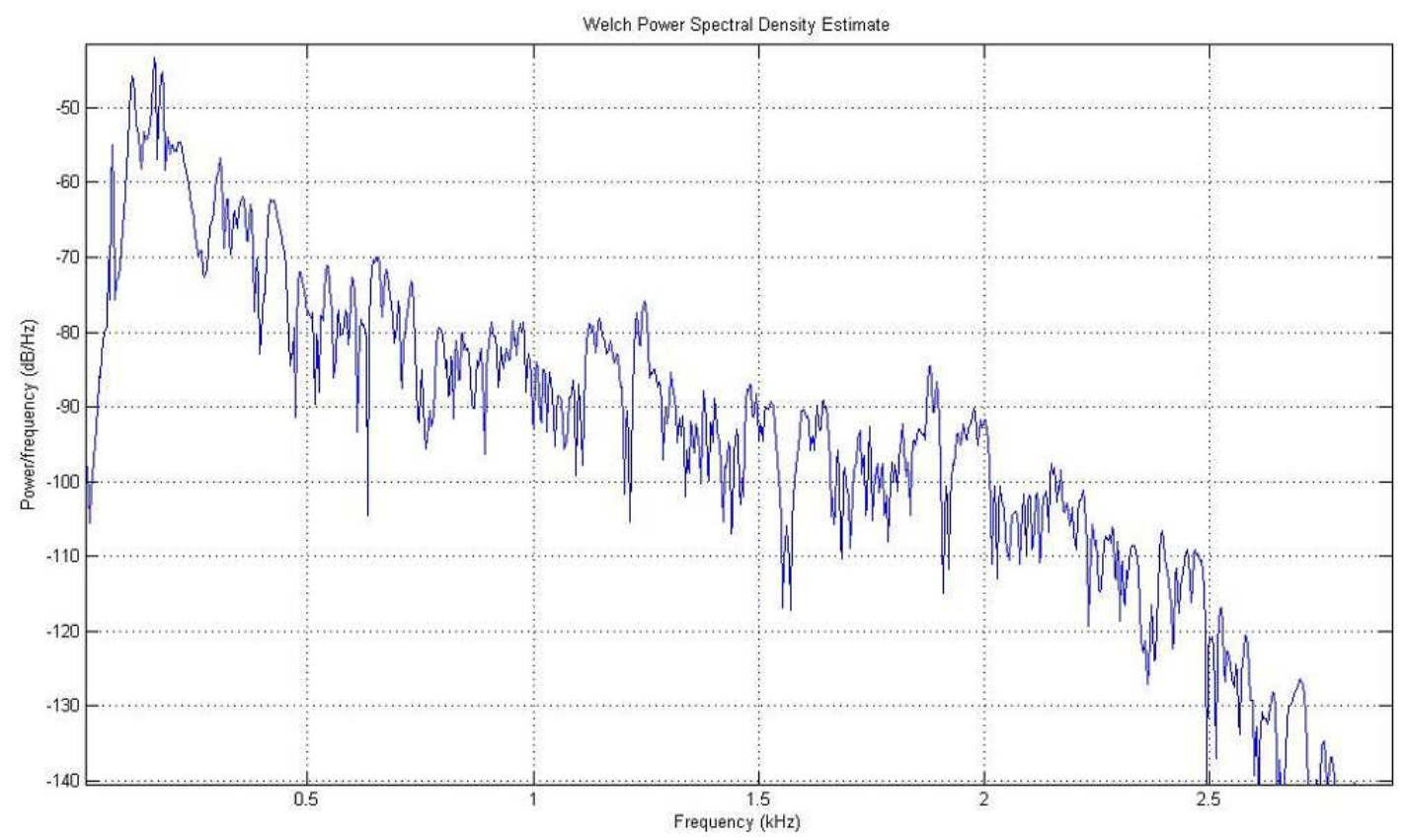

Figura 76 - Espectro de frequência do sinal reconstruído.

Por este resultado, observa-se que predominam as freqüências em torno de $120 \mathrm{~Hz}$ que é a freqüência natural de vibração transversal da cremalheira, indicando que grande parte dos ruídos de impacto foi retirada do sinal original de vibração.

A figura 77 ilustra o espectrograma do sinal reconstruído.

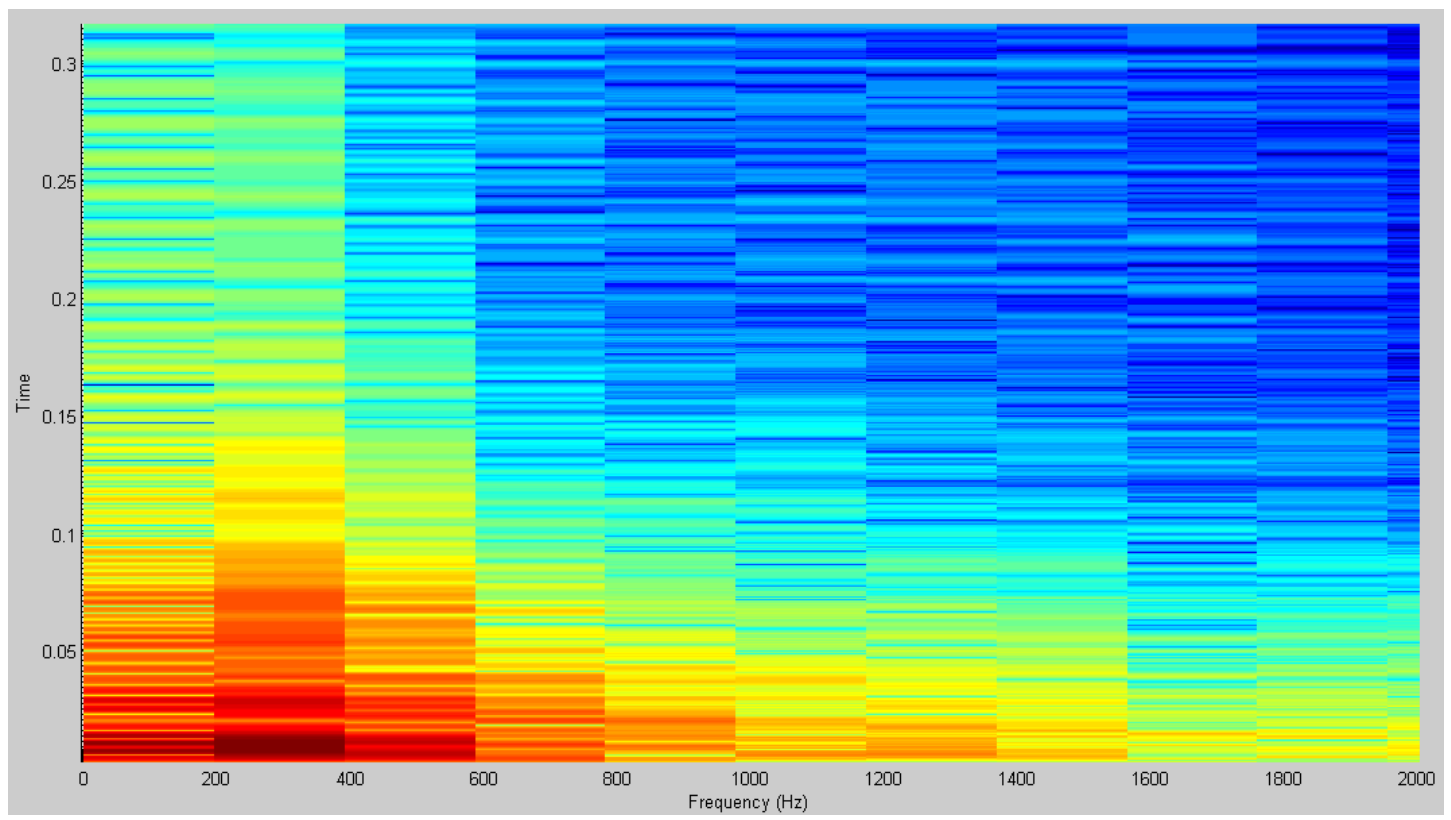

Figura 77 - Espectrograma do sinal reconstruído. 
Comparando este resultado com o obtido na figura 73, observa que a maior parte das frequências na ordem de $\mathrm{kHz}$ foi retirada do sinal original de vibração.

Analisando o espectro de freqüência do sinal dos ruídos de impacto, obtevese $o$ resultado ilustrado na figura 78 a seguir.

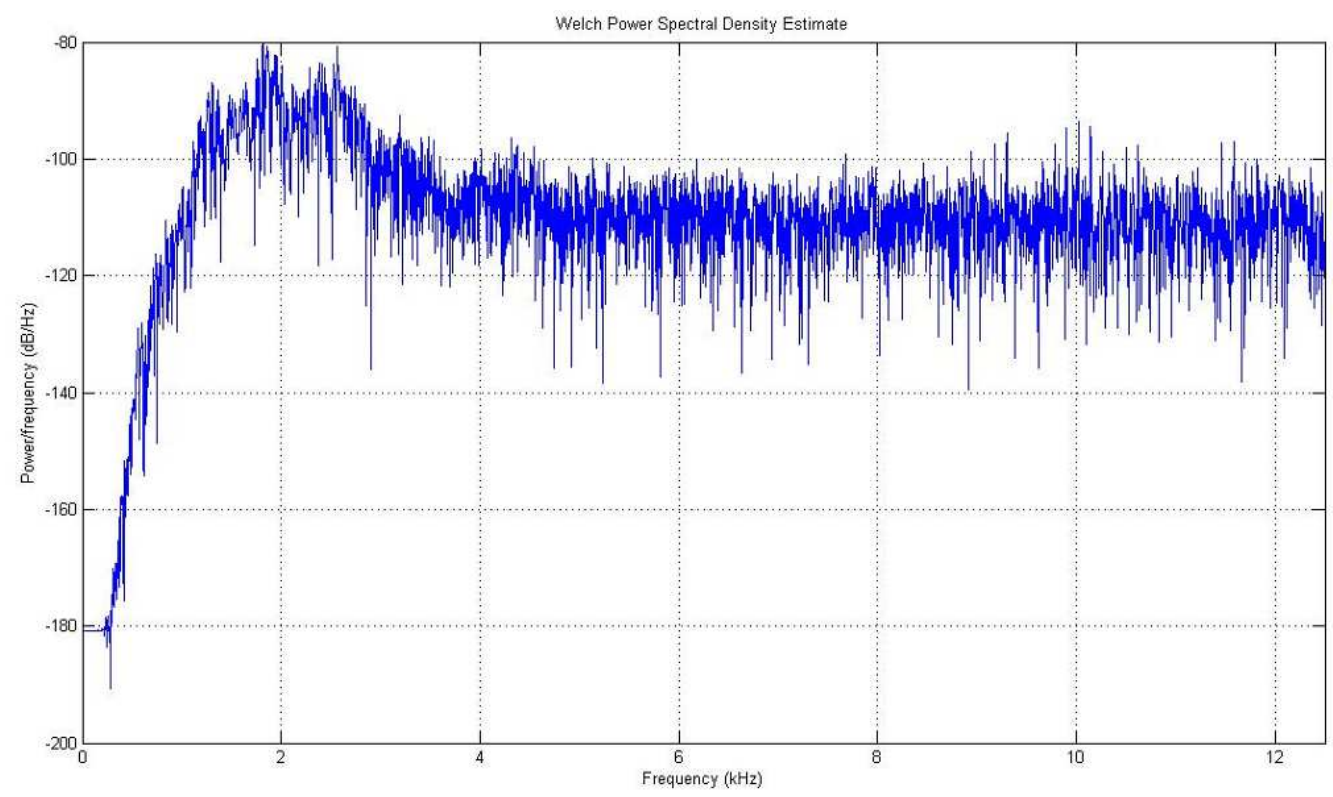

Figura 78 - Espectro de frequência do sinal dos ruídos de impacto.

Por este resultado, observa-se que predominam as frequências na ordem de grandeza de $\mathrm{kHz}$, as quais são referentes aos impactos internos à caixa de direção.

A figura 79 ilustra o espectrograma do sinal dos ruídos de impacto.

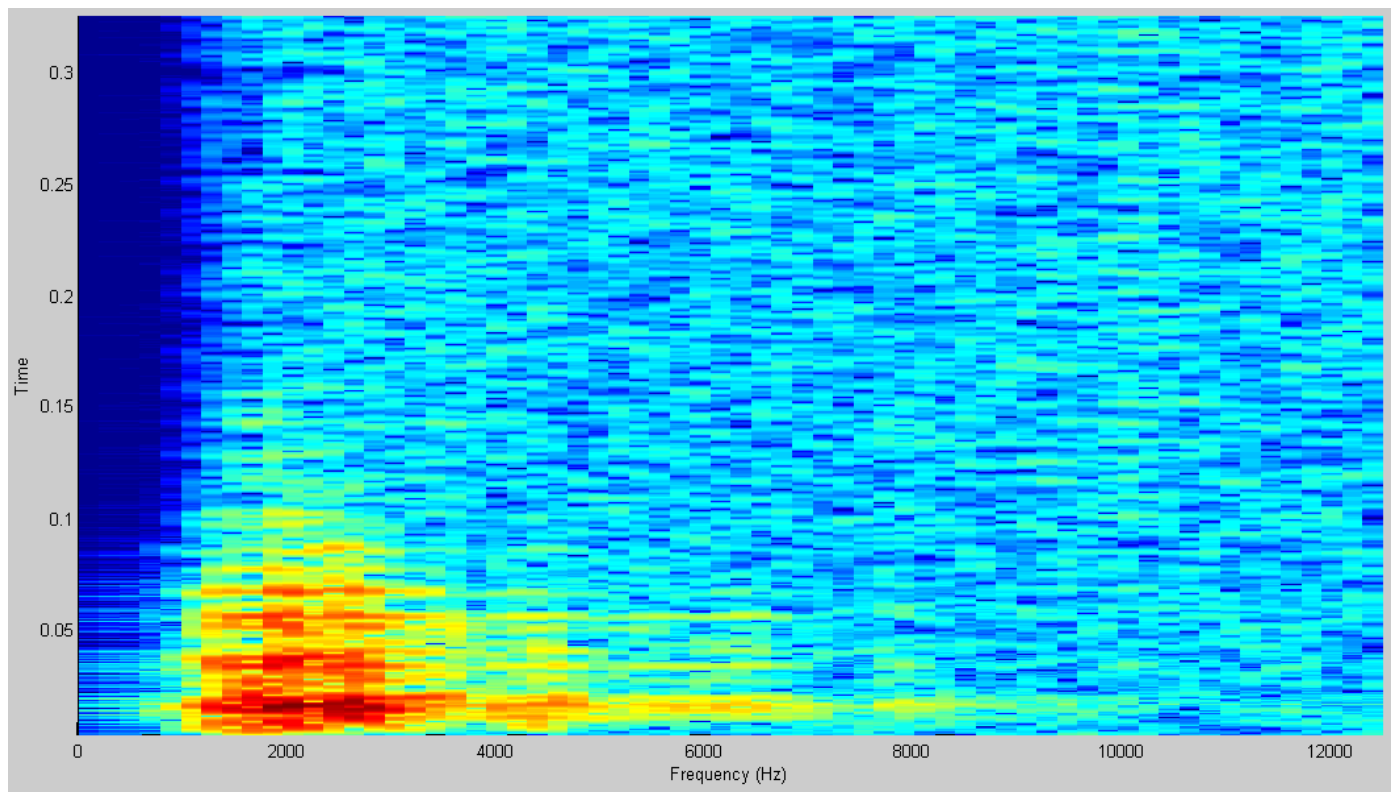

Figura 79 - Espectrograma do sinal dos ruídos de impacto. 
Por este resultado, observa-se que predominam no sinal dos ruídos de impacto as freqüências próximas a $2 \mathrm{kHz}$.

Adotando o critério da janela de tempo e mantendo a pré-filtragem em 0,02 $\mathrm{m} / \mathrm{s}^{2}$, foi registrada a ocorrência de 21 impactos dentro da caixa de direção e a maior severidade de impacto medida foi de $0,051 \mathrm{~m} / \mathrm{s}^{2}$.

No gráfico superior da figura 80 são ilustrados, em vermelho, os pontos de impacto detectados por este procedimento e no gráfico inferior são ilustrados os valores da severidade medidos para estes pontos.
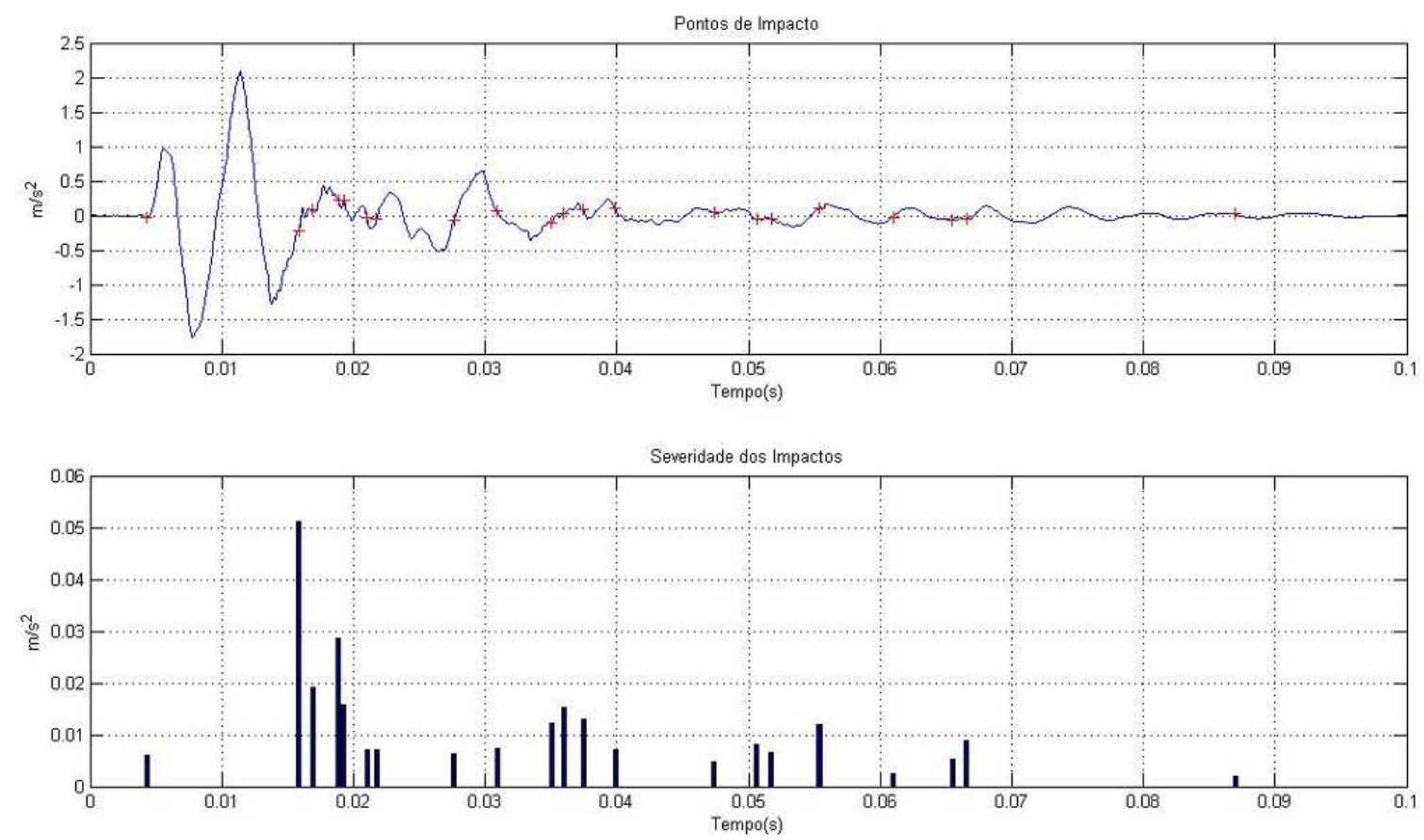

Figura 80 - Pontos de impacto e Severidade dos Impactos.

Considere o sinal de vibração medido em laboratório e ilustrado na figura 81 a seguir. 


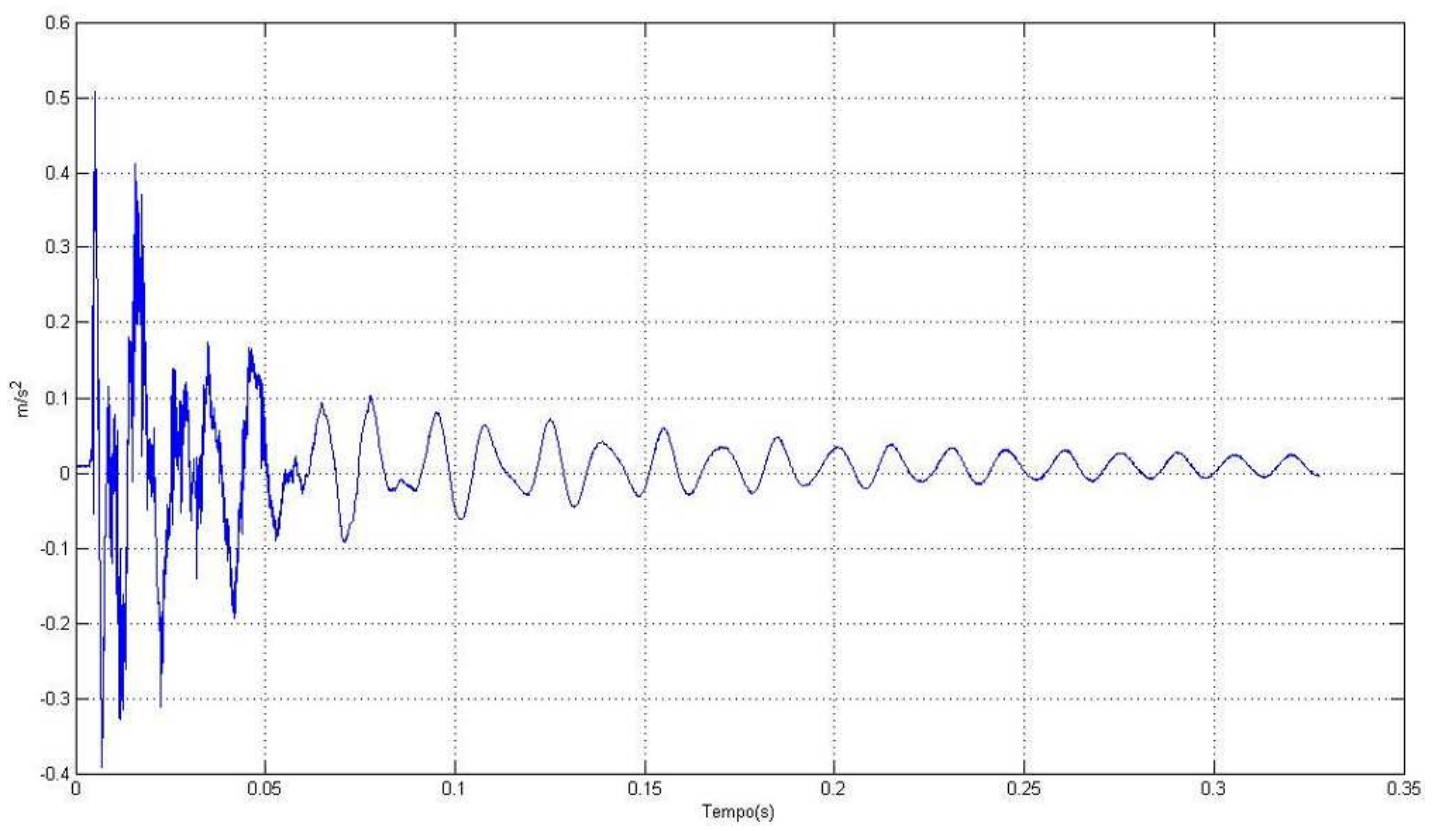

Figura 81 - Sinal medido em laboratório com D = 180 mm.

Este sinal foi medido pelo acelerômetro 1, ao posicionar este acelerômetro a uma distância de $180 \mathrm{~mm}$ do sujeitador e realizar batidas com o martelo na extremidade da cremalheira do acelerômetro 2, na direção transversal e no sentido de compressão da mola do sujeitador.

A figura 82 ilustra o espectrograma do sinal original.

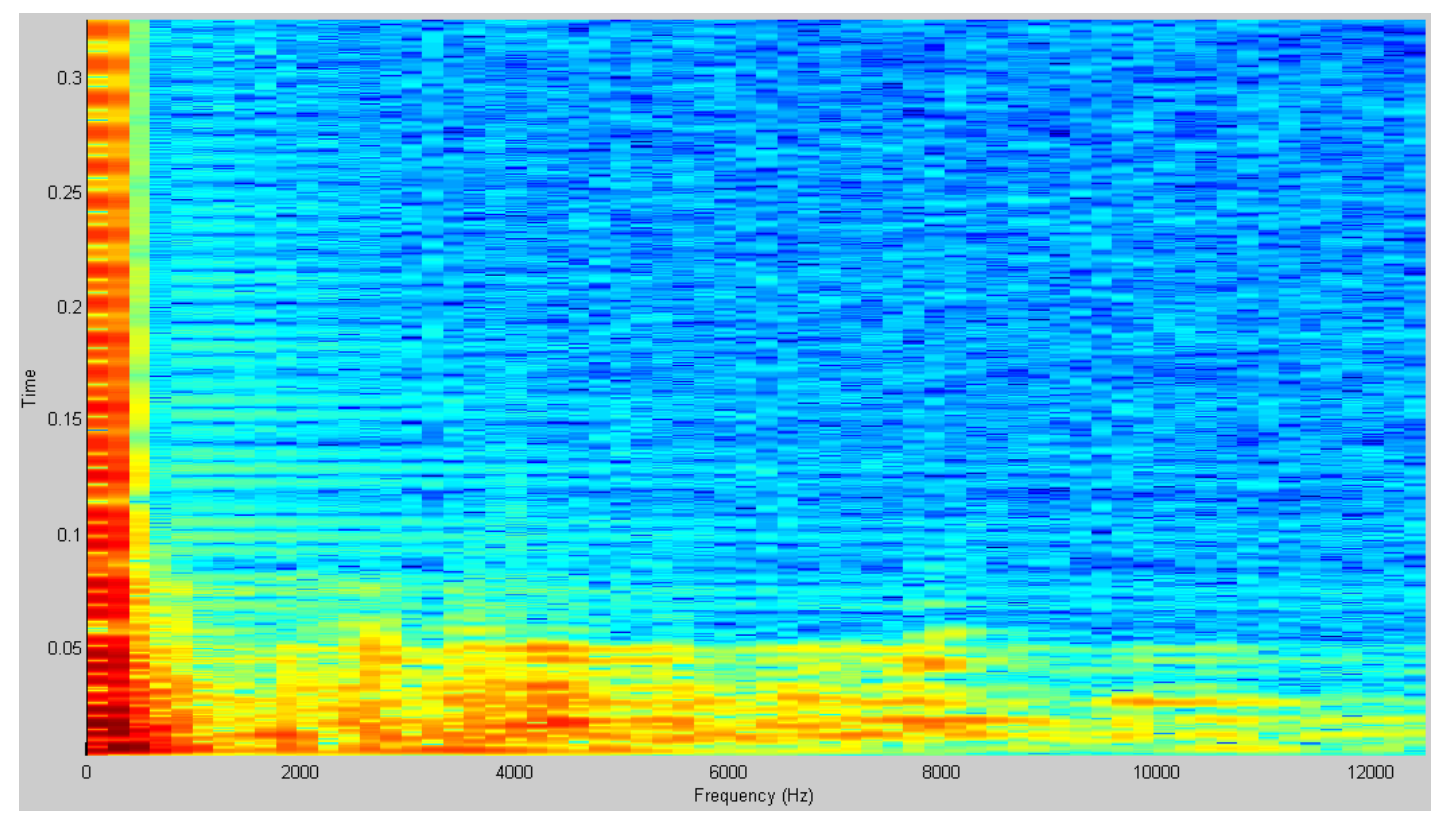

Figura 82 - Espectrograma do sinal original. 
Por este resultado, nota-se a presença de ruídos de impacto, provenientes dos impactos da cremalheira contra o pinhão e bucha guia, a qual excita diversas faixas de frequências.

Aplicando a wavelet de Daubechies de ordem 7 e retirando os 3 últimos níveis de detalhe do sinal original, obteve-se o resultado ilustrado na figura 83.

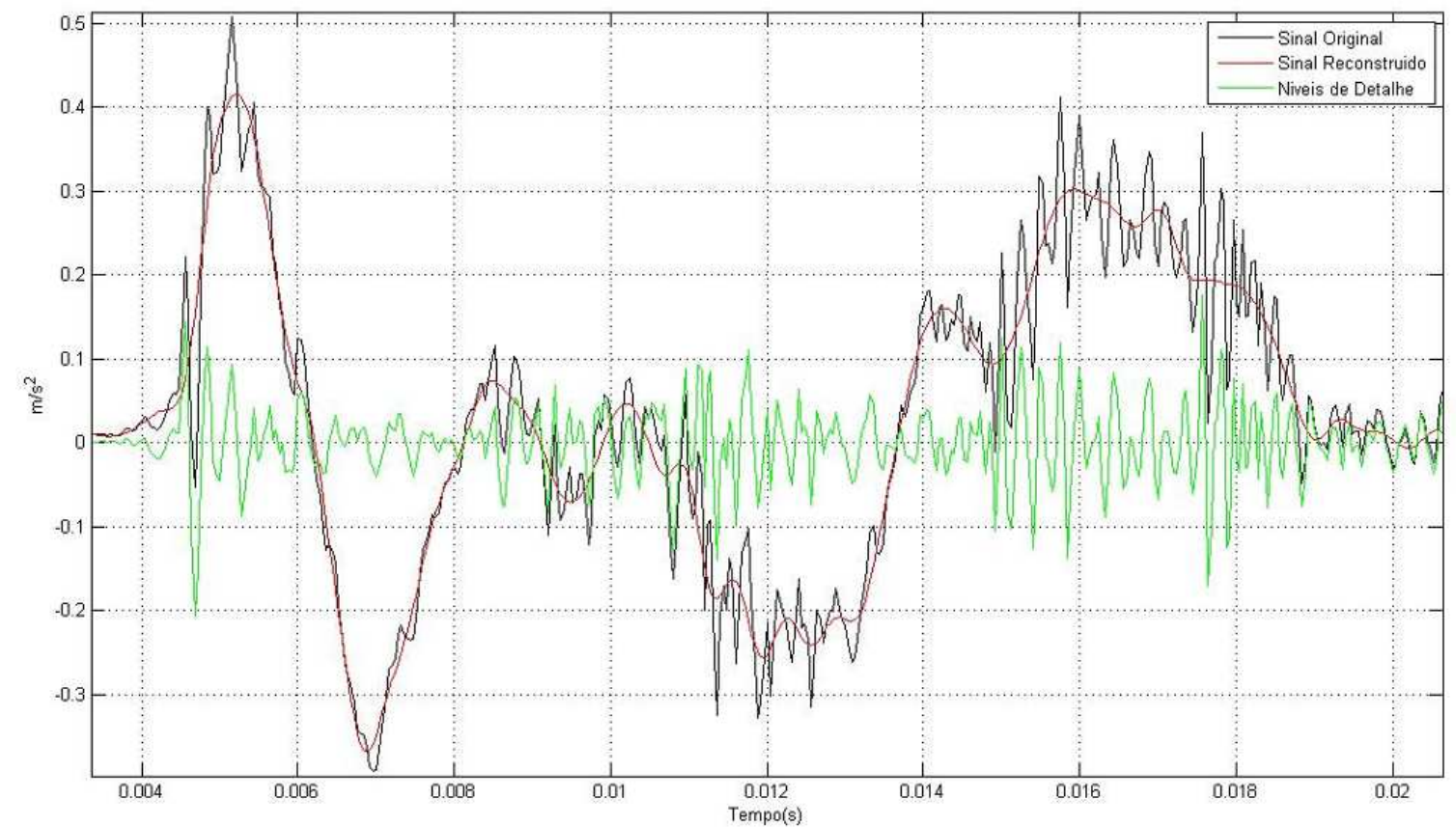

Figura 83 - Wavelet de Daubechies de ordem 7 e 3 níveis de detalhe.

Por este resultado, nota-se que grande parte dos ruídos de impacto foi separada do sinal original de vibração. Isto pode ser comprovado pelos resultados obtidos a seguir.

Analisando o espectro de freqüência do sinal reconstruído, obteve-se o resultado ilustrado da figura 84 a seguir. 


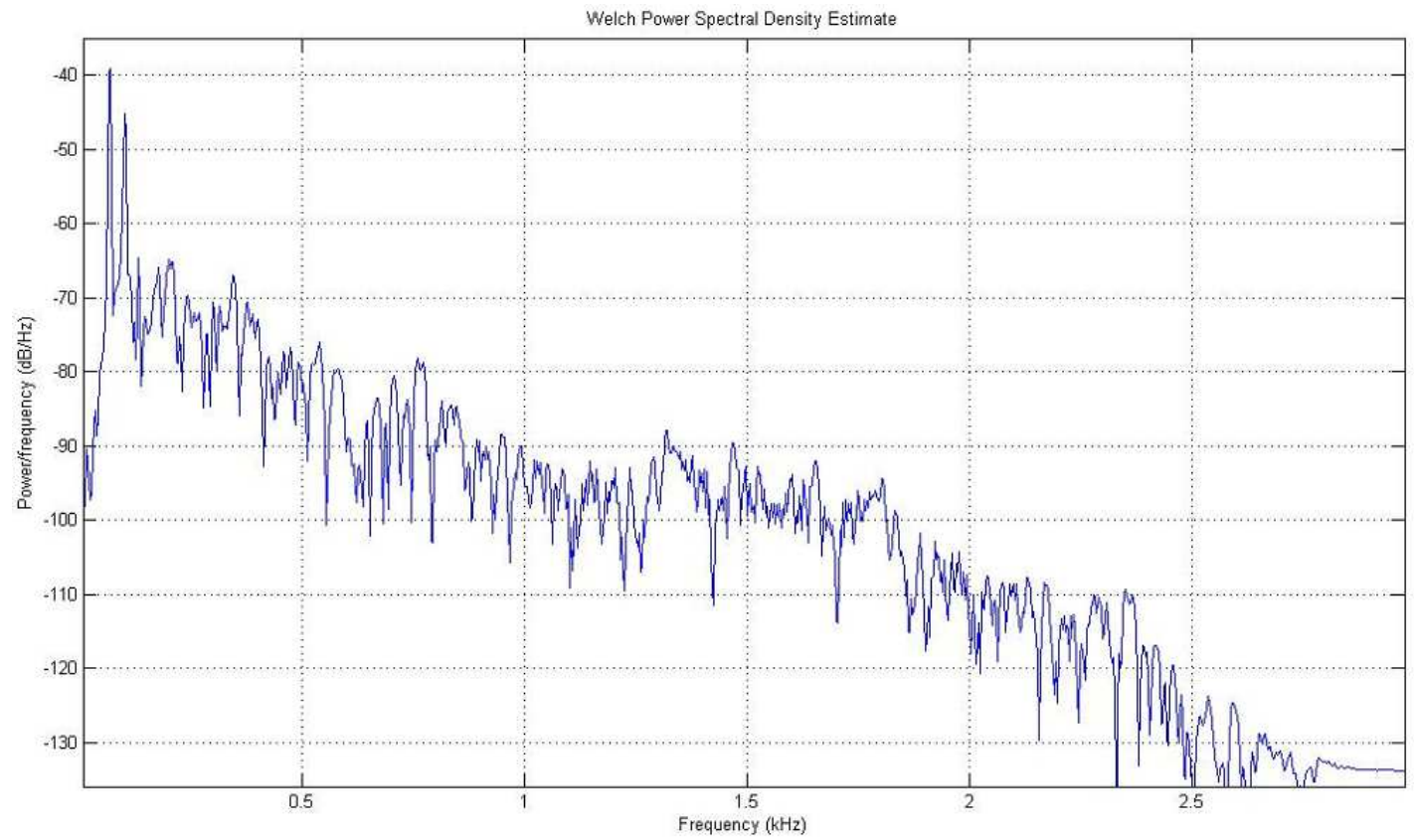

Figura 84 - Espectro de frequência do sinal reconstruído.

Por este resultado, nota-se que predomina no sinal reconstruído as freqüências em torno de $120 \mathrm{~Hz}$, a qual representa a freqüência natural de vibração transversal da cremalheira, indicando que grande parte dos ruídos de impacto foi retirada do sinal original de vibração.

A figura 85 ilustra o espectrograma do sinal reconstruído.

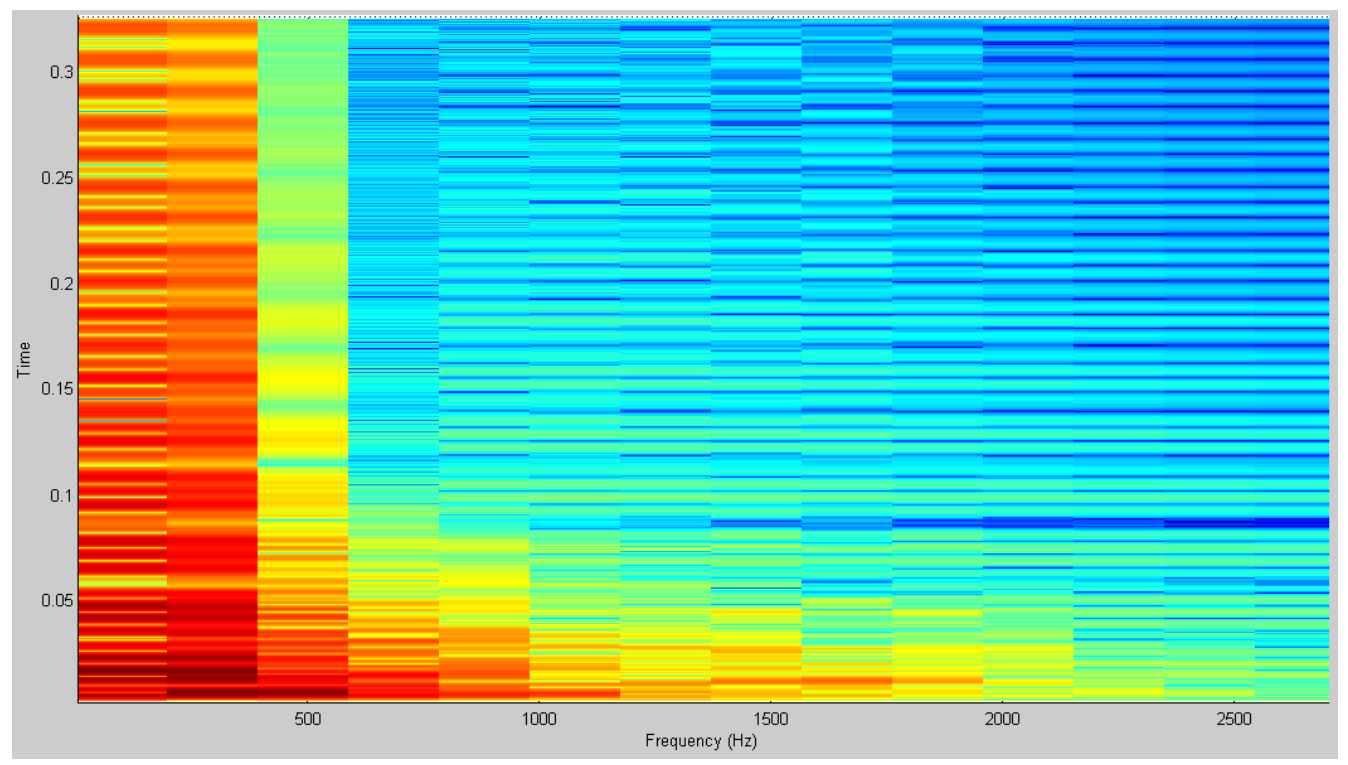

Figura 85 - Espectrograma do sinal reconstruído.

Comparando este resultado com o obtido na figura 82 , conclui-se que a maior parte das frequências na ordem de $\mathrm{kHz}$ foi retirada do sinal original de vibração. 
Analisando o espectro de freqüência do sinal dos ruídos de impacto, obtevese o resultado ilustrado na figura 86 a seguir.

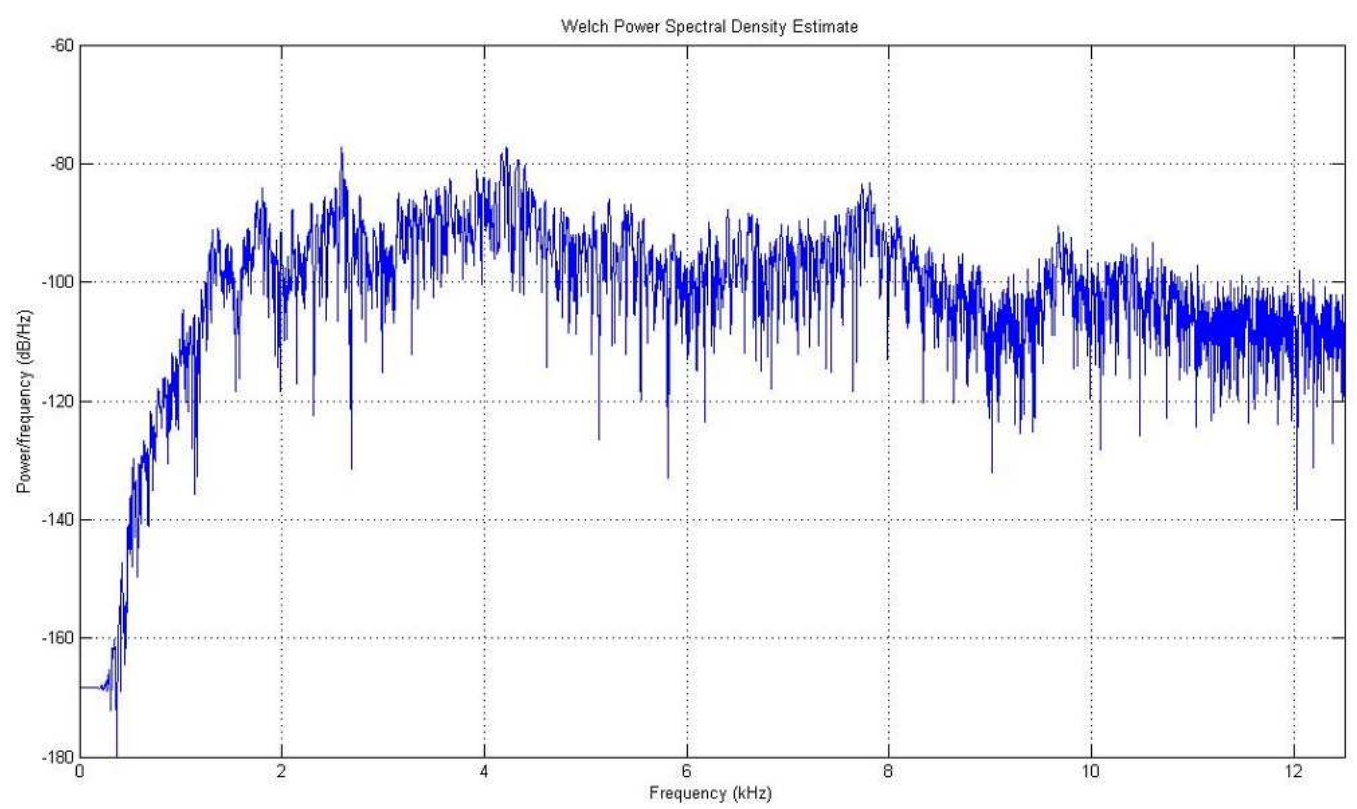

Figura 86 - Espectro de frequência do sinal dos ruídos de impacto.

Pela figura 86 observa-se que predominam, neste sinal, as freqüências da ordem de grandeza de $\mathrm{kHz}$. Estas freqüências representam os impactos que ocorrem dentro da caixa de direção.

A figura 87 ilustra o espectrograma do sinal referente aos ruídos de impacto. Observa-se a predominância das freqüências na ordem de grandeza de kHz.

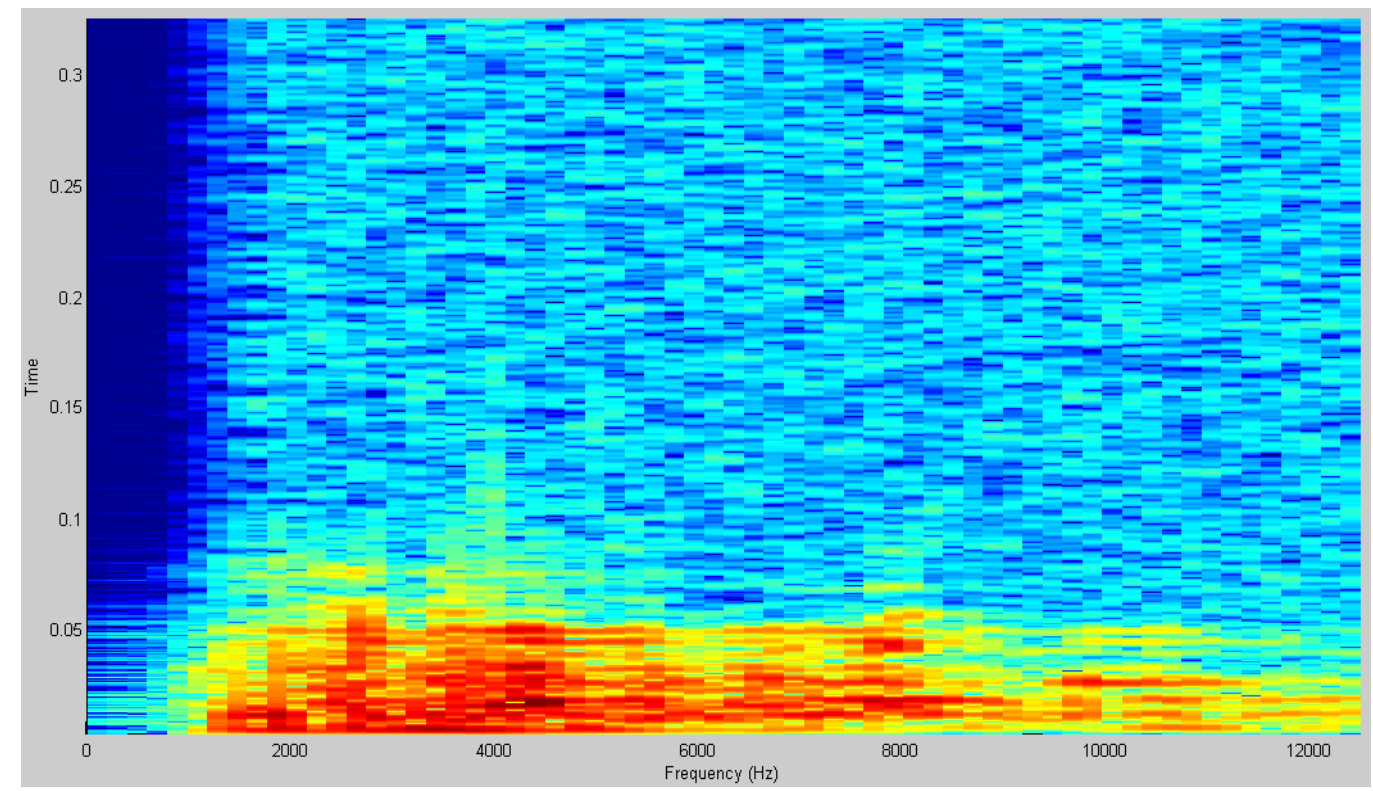

Figura 87 - Espectrograma do sinal dos ruídos de impacto. 
Adotando o critério da janela de tempo e mantendo a pré-filtragem em 0,02 $\mathrm{m} / \mathrm{s}^{2}$, foi registrada a ocorrência de 42 impactos dentro da caixa de direção e a maior severidade de impacto medida foi de $0,070 \mathrm{~m} / \mathrm{s}^{2}$.

No gráfico superior da figura 88 são ilustrados, em vermelho, os pontos de impacto detectados por este procedimento e no gráfico inferior são ilustrados os valores da severidade medidos para estes pontos.
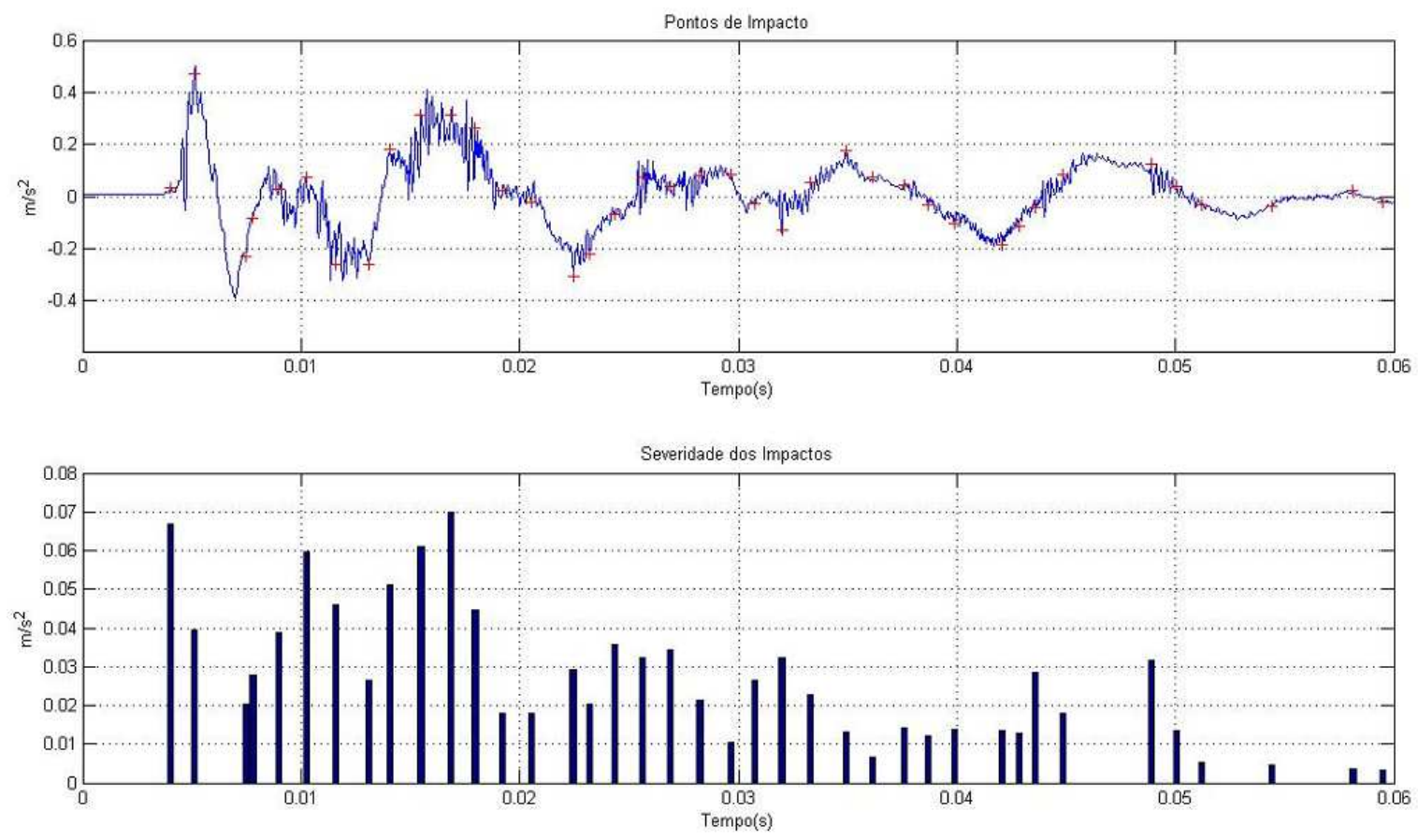

Figura 88 - Pontos de Impacto e Severidade dos Impactos.

Considere as mesmas condições para obtenção do sinal anterior, mas desta vez medido pelo acelerômetro 2. Este sinal está ilustrado na figura 89 a seguir. 


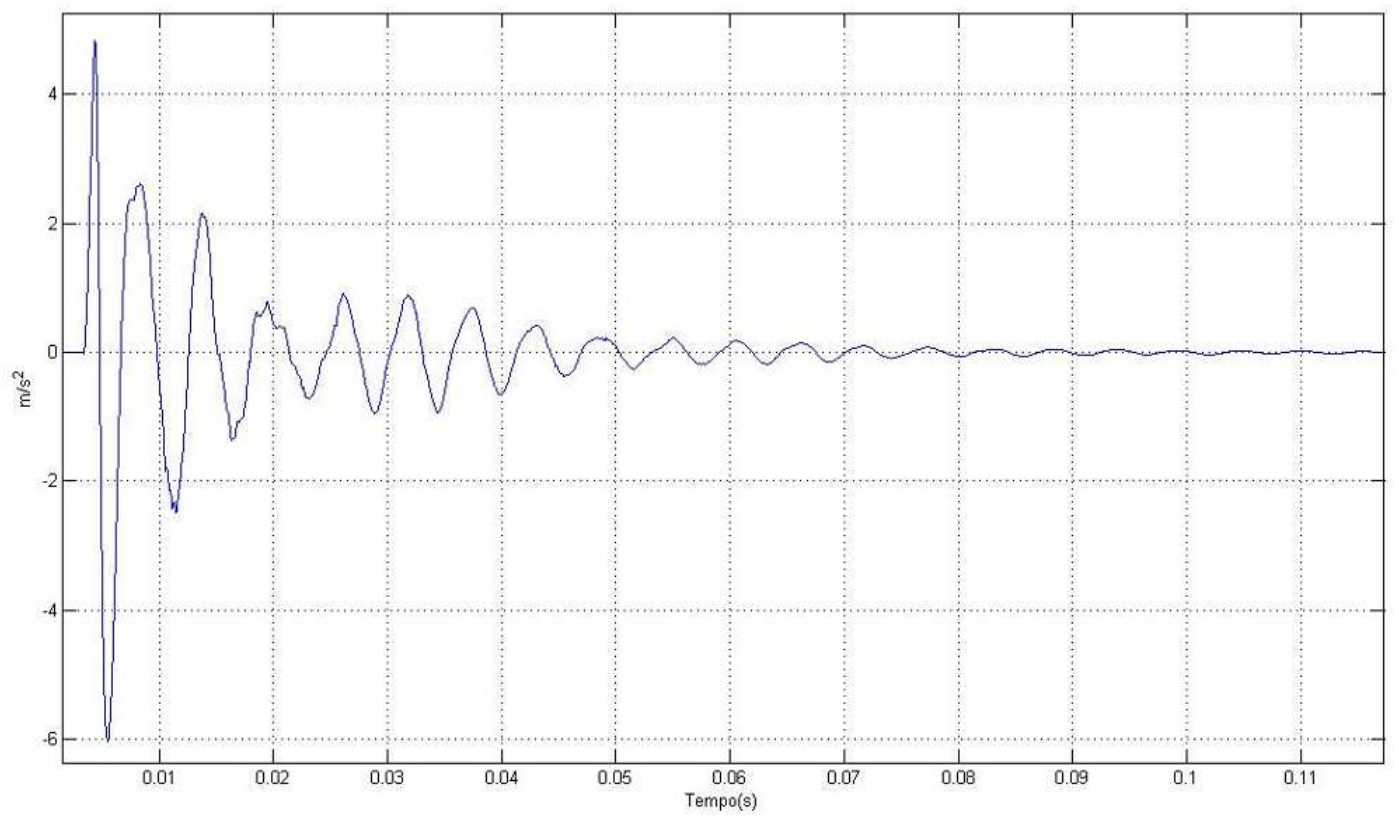

Figura 89 - Sinal medido em laboratório com D = 180 mm.

A figura 90 ilustra o espectrograma do sinal original.

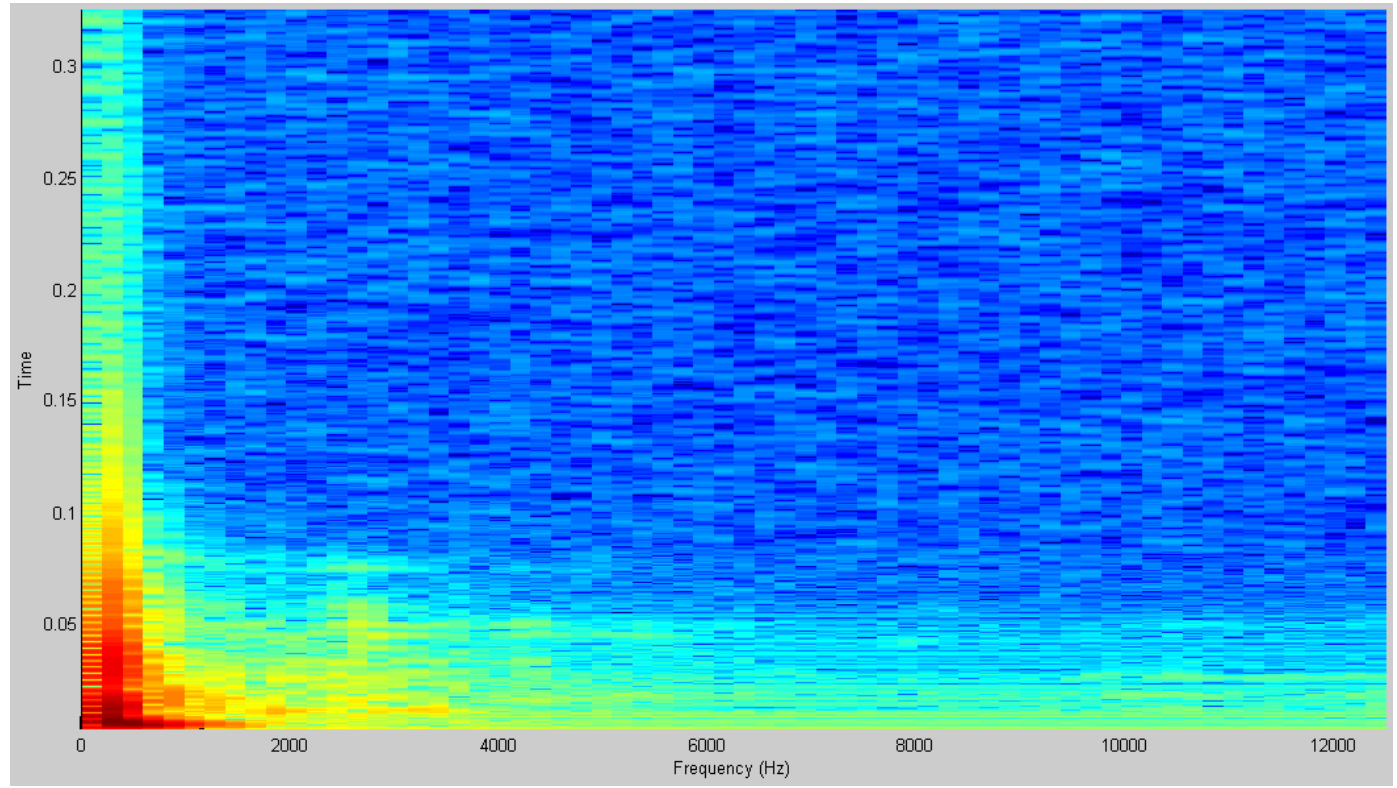

Figura 90 - Espectrograma do sinal original.

Por este resultado, nota-se a presença de ruídos de impacto, provenientes do impacto da cremalheira contra o pinhão e bucha guia, a qual excita diversas faixas de frequências.

Aplicando a wavelet de Daubechies de ordem 7 e retirando os 3 últimos níveis de detalhe do sinal original, obteve-se o resultado ilustrado na figura 91 a seguir. 


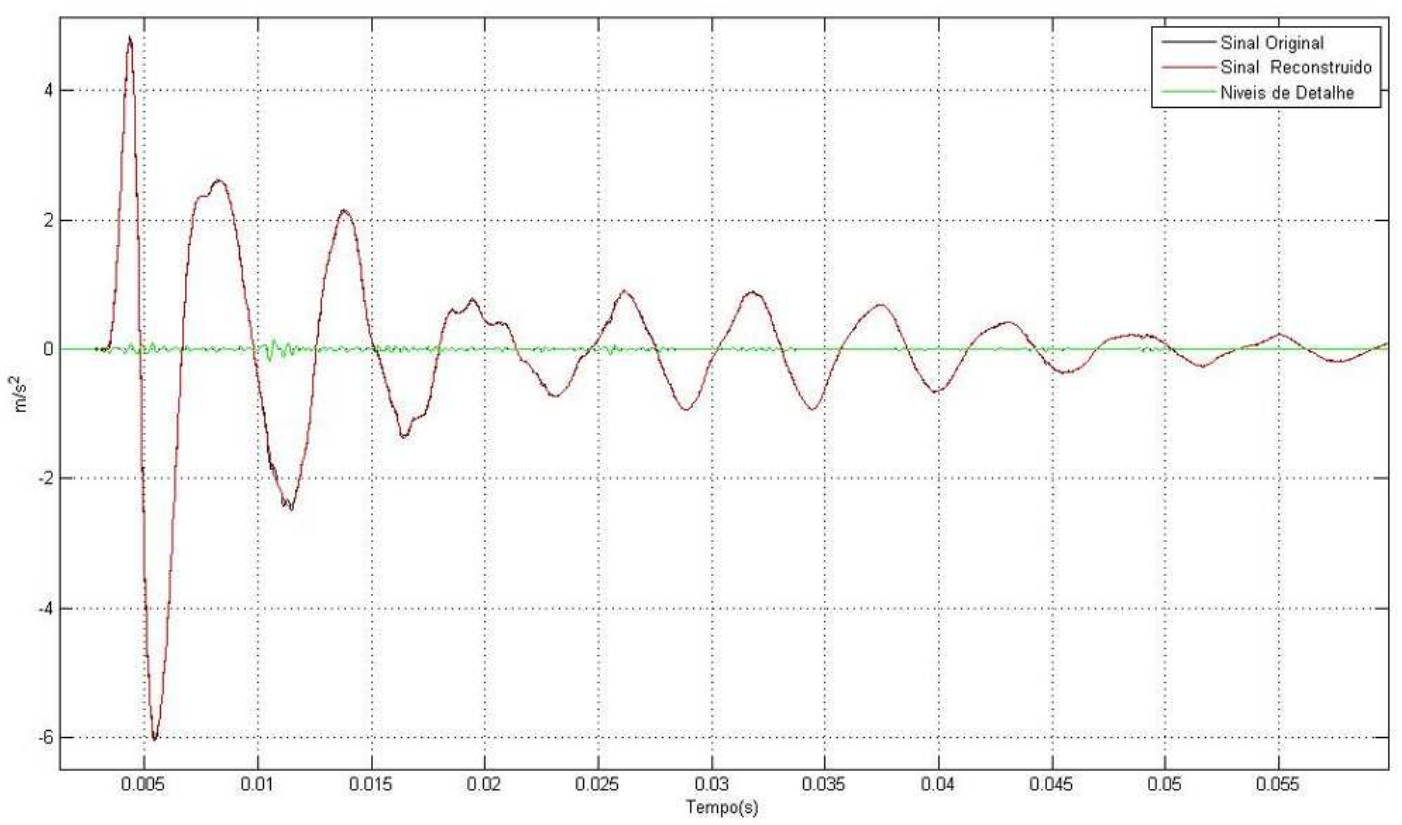

Figura 91 - Wavelet de Daubechies de ordem 7 e 3 níveis de detalhe.

Por este resultado, nota-se que a maior parte dos ruídos de impacto foi retirada do sinal original.

$\mathrm{Na}$ figura 92 é ilustrado o espectro de freqüência do sinal reconstruído. Observa-se que neste espectro predominam as freqüências em torno de $120 \mathrm{~Hz}$ que representam as freqüências naturais de vibração transversal da cremalheira, indicando que grande parte dos ruídos de impacto foi retirada do sinal original de vibração.

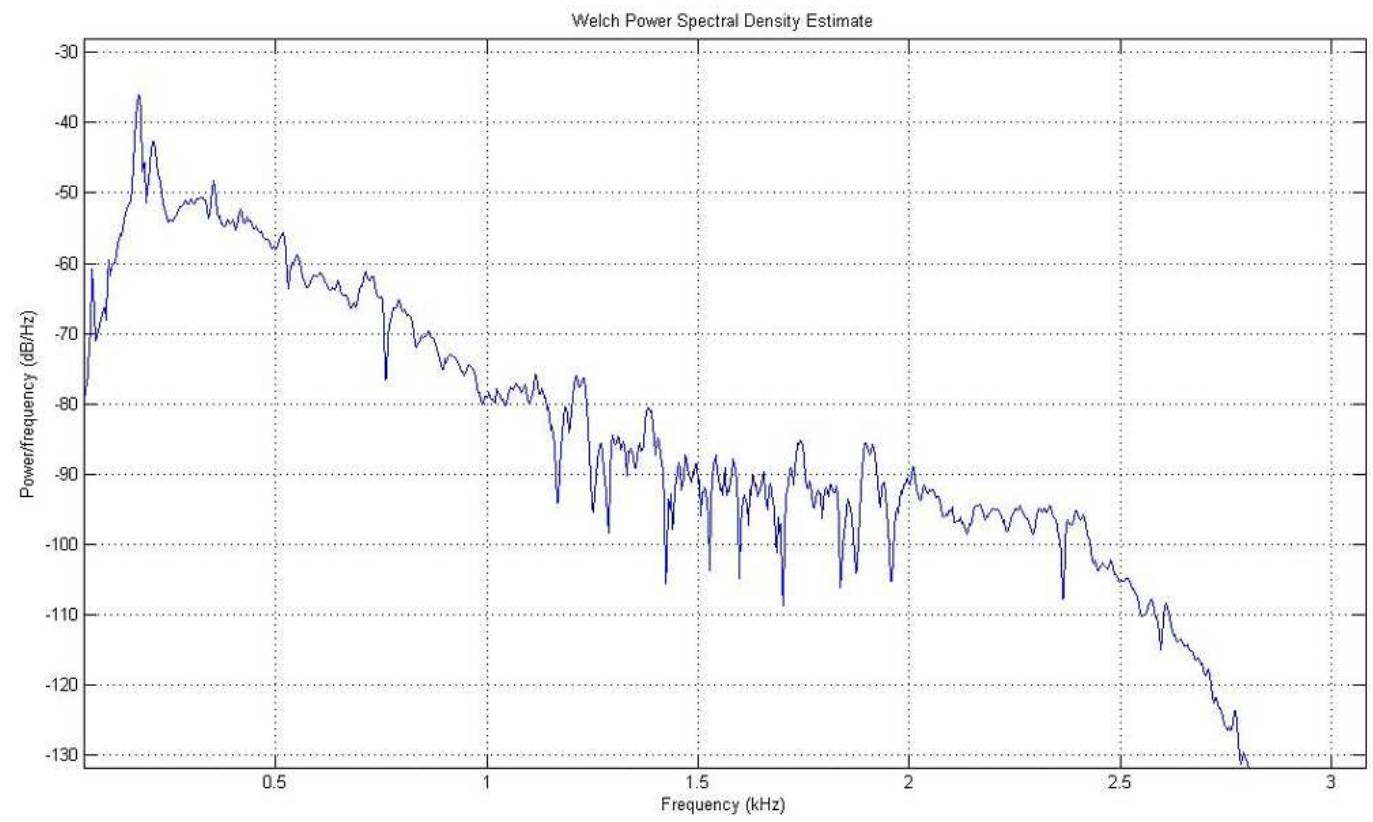

Figura 92 - Espectro de frequência do sinal reconstruído. 
Na figura 93 é ilustrado o espectrograma do sinal reconstruído. Este resultado ilustra baixa presença das frequências na ordem de grandeza de $\mathrm{kHz}$, indicando assim que a maior parte dos ruídos de impacto foi retirada do sinal original.

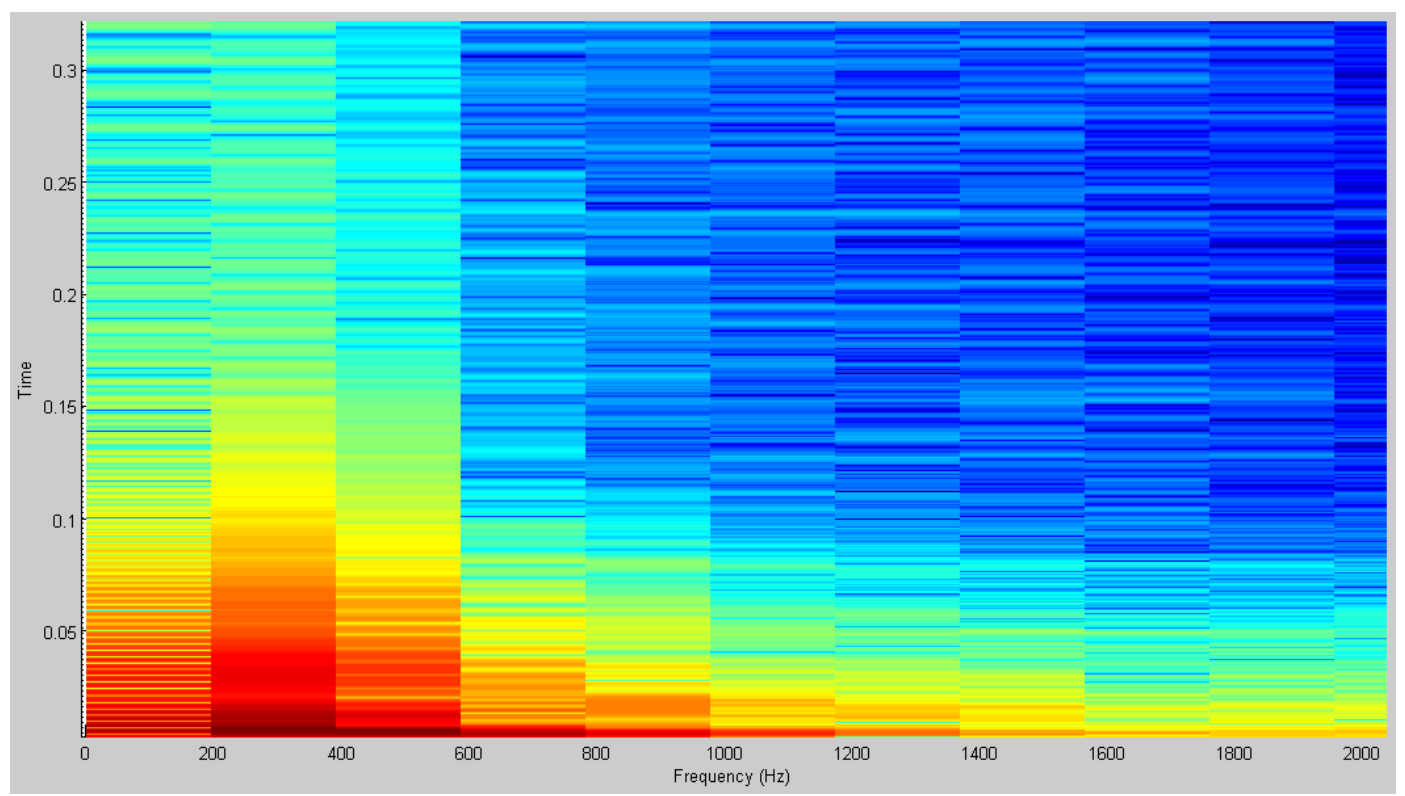

Figura 93 - Espectrograma do sinal reconstruído.

$\mathrm{Na}$ figura 94 é ilustrado o espectrograma do sinal referente aos ruídos de impacto retirados do sinal original. Nota-se que predominam as freqüências na ordem de grandeza de $\mathrm{kHz}$, as quais representam provavelmente os impactos que ocorreram dentro da caixa de direção.

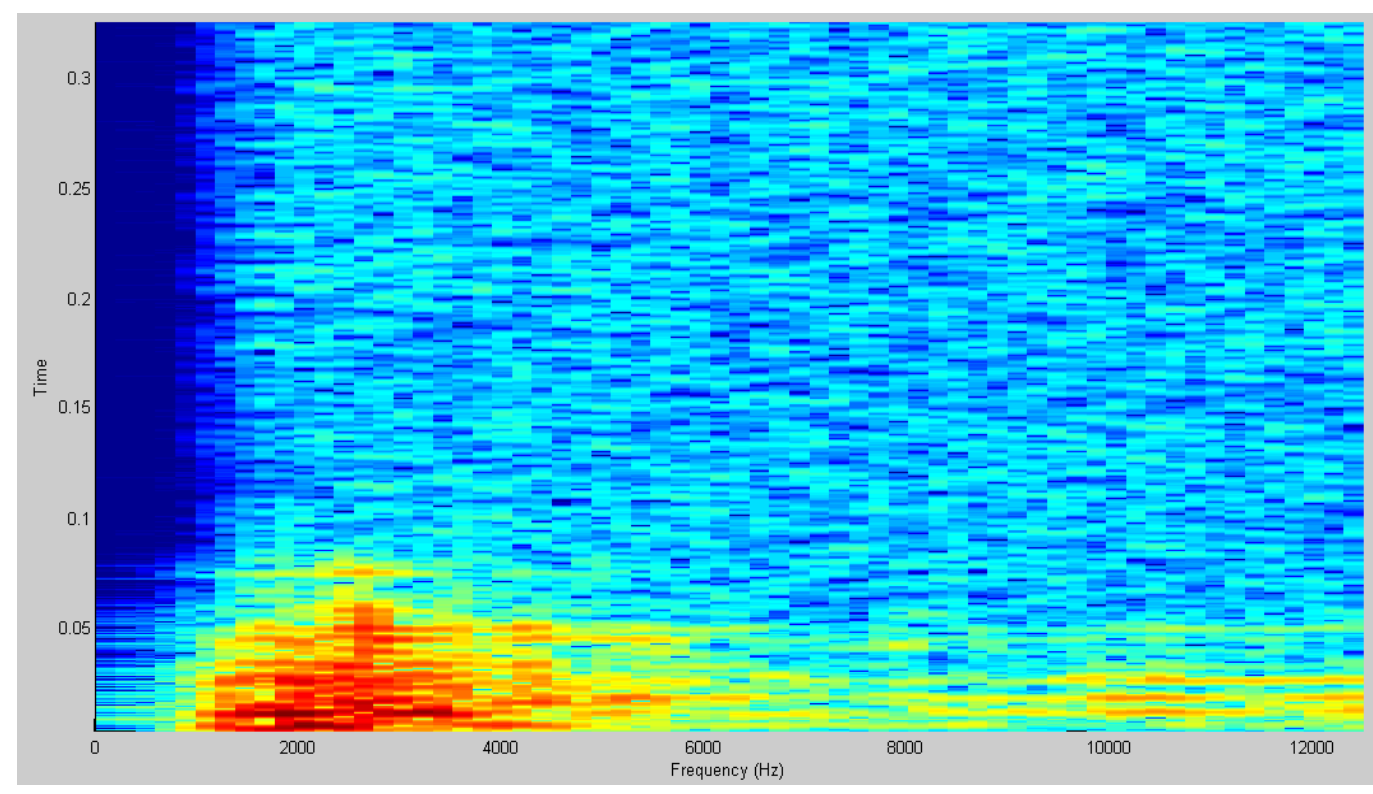

Figura 94 - Espectrograma do sinal dos ruídos de impacto. 
Adotando o critério da janela de tempo e mantendo a pré-filtragem em 0,02 $\mathrm{m} / \mathrm{s}^{2}$, foi registrada a ocorrência de 13 impactos dentro da caixa de direção e a maior severidade de impacto medida foi de $0,029 \mathrm{~m} / \mathrm{s}^{2}$.

No gráfico superior da figura 95 são ilustrados, em vermelho, os pontos de impacto detectados por este procedimento e no gráfico inferior são ilustrados os valores da severidade medidos para estes pontos.
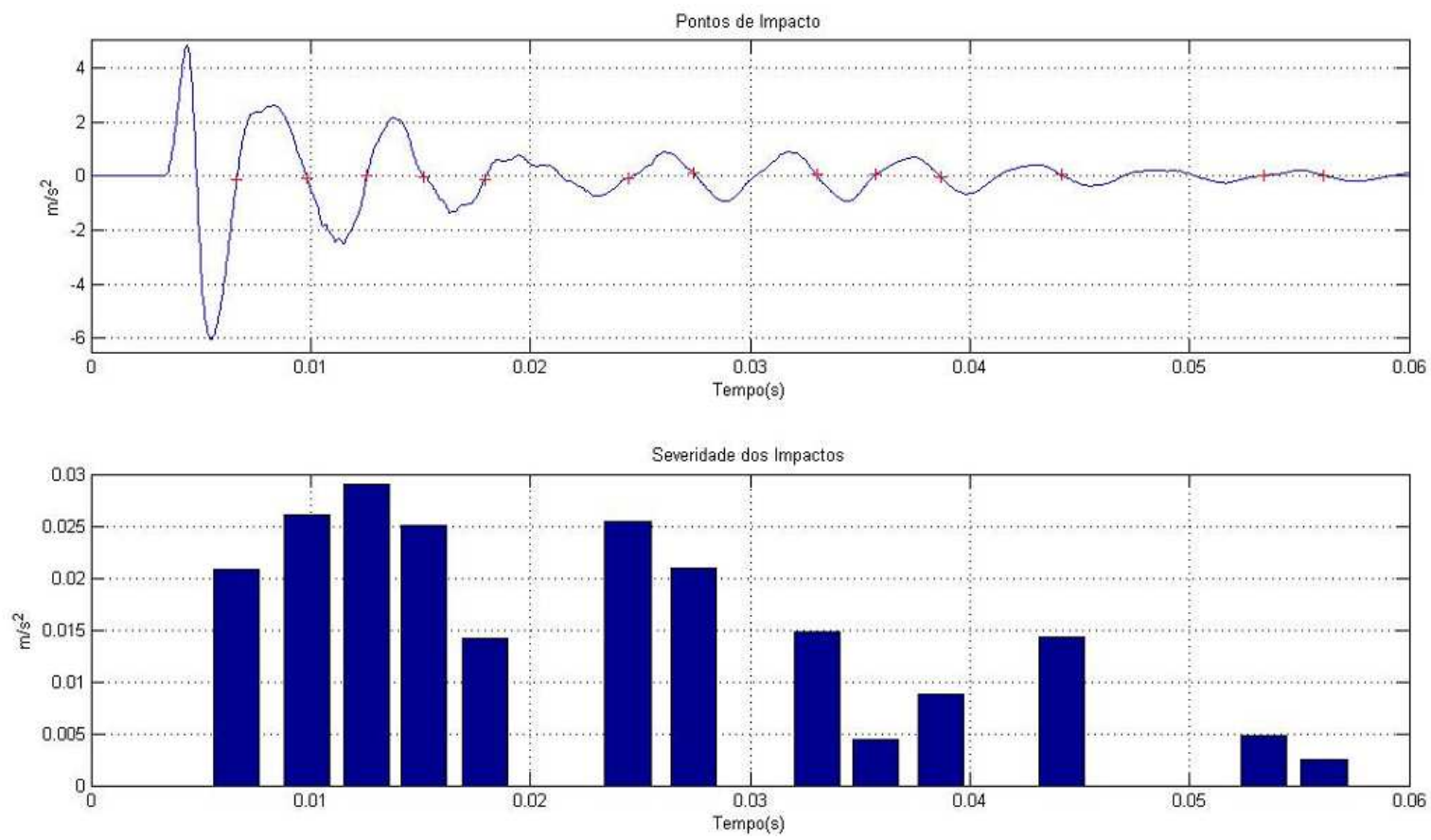

Figura 95 - Pontos de impacto e Severidade dos Impactos.

Pelos resultados obtidos com esses 5 sinais analisados, conclui-se que para os sinais medidos em laboratório, a wavelet de Daubechies de ordem 7 e a retirada dos 3 últimos níveis de detalhamento já são suficientes para retirar a maior parte dos ruídos de impacto do sinal original de vibração.

\subsection{Análise dos Sinais de Campo com Wavelet de Daubechies}

Considere agora o sinal de vibração medido em campo, no trecho da rua com paralelepípedos, e ilustrado na figura 96 a seguir. 


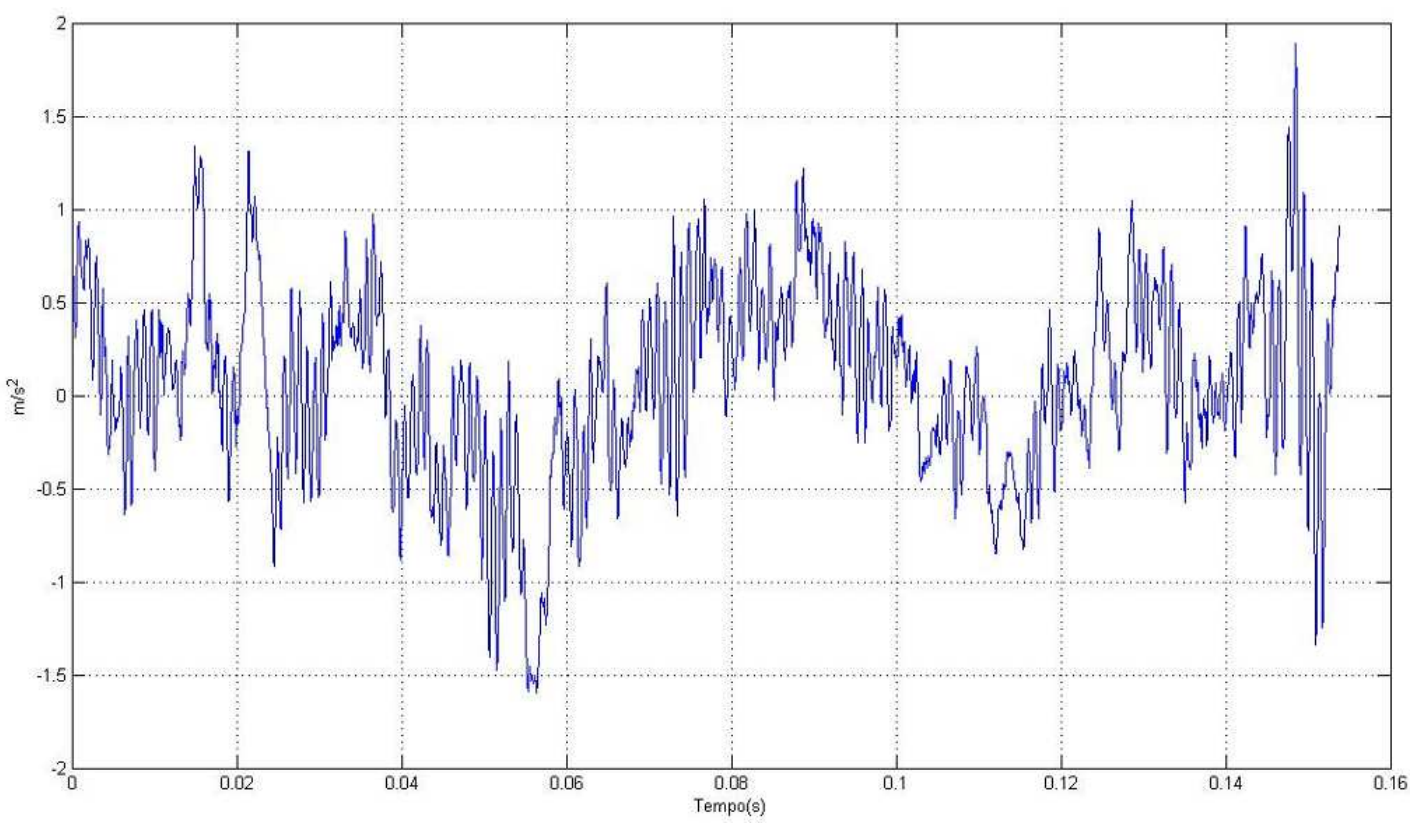

Figura 96 - Sinal de vibração real medido na rua de paralelepípedos.

Por esta figura, nota-se que este sinal real apresenta uma grande quantidade de ruídos de impacto em sua composição. Estes ruídos foram acentuados devido à presença dos paralelepípedos.

A figura 97 a seguir ilustra o espectrograma do sinal original. Por este resultado, nota-se a grande presença de frequências na ordem de grandeza de $\mathrm{kHz}$, indicando a presença de ruídos provenientes dos impactos da cremalheira contra o pinhão e bucha guia durante todo percurso.

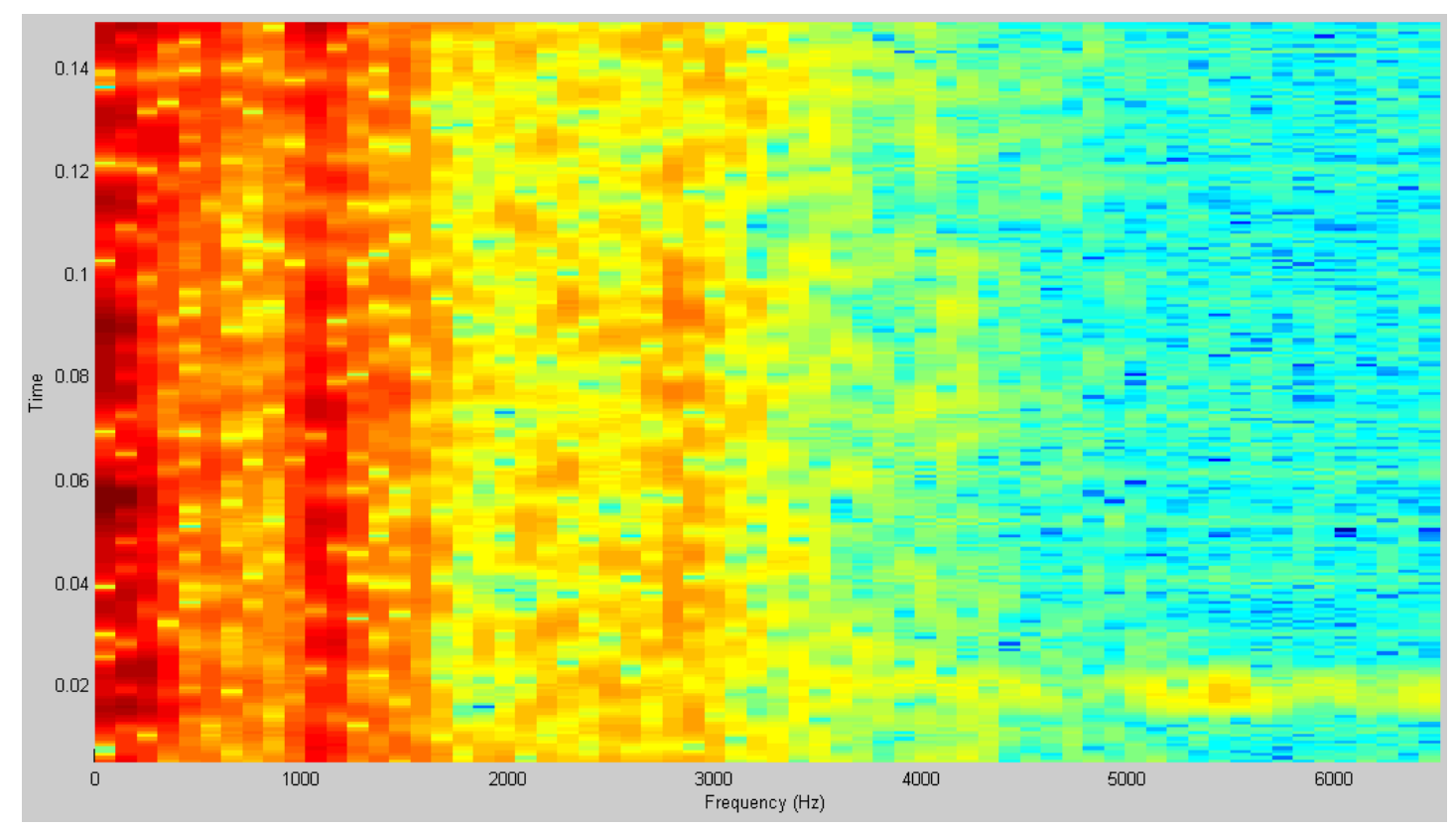

Figura 97 - Espectrograma do sinal original. 
Aplicando a wavelet de Daubechies de ordem 7 e retirando os 3 últimos níveis de detalhe do sinal original, obteve-se o resultado ilustrado na figura 98. Para melhor visualização do resultado, foi aplicado zoom sobre a parte inicial do sinal.

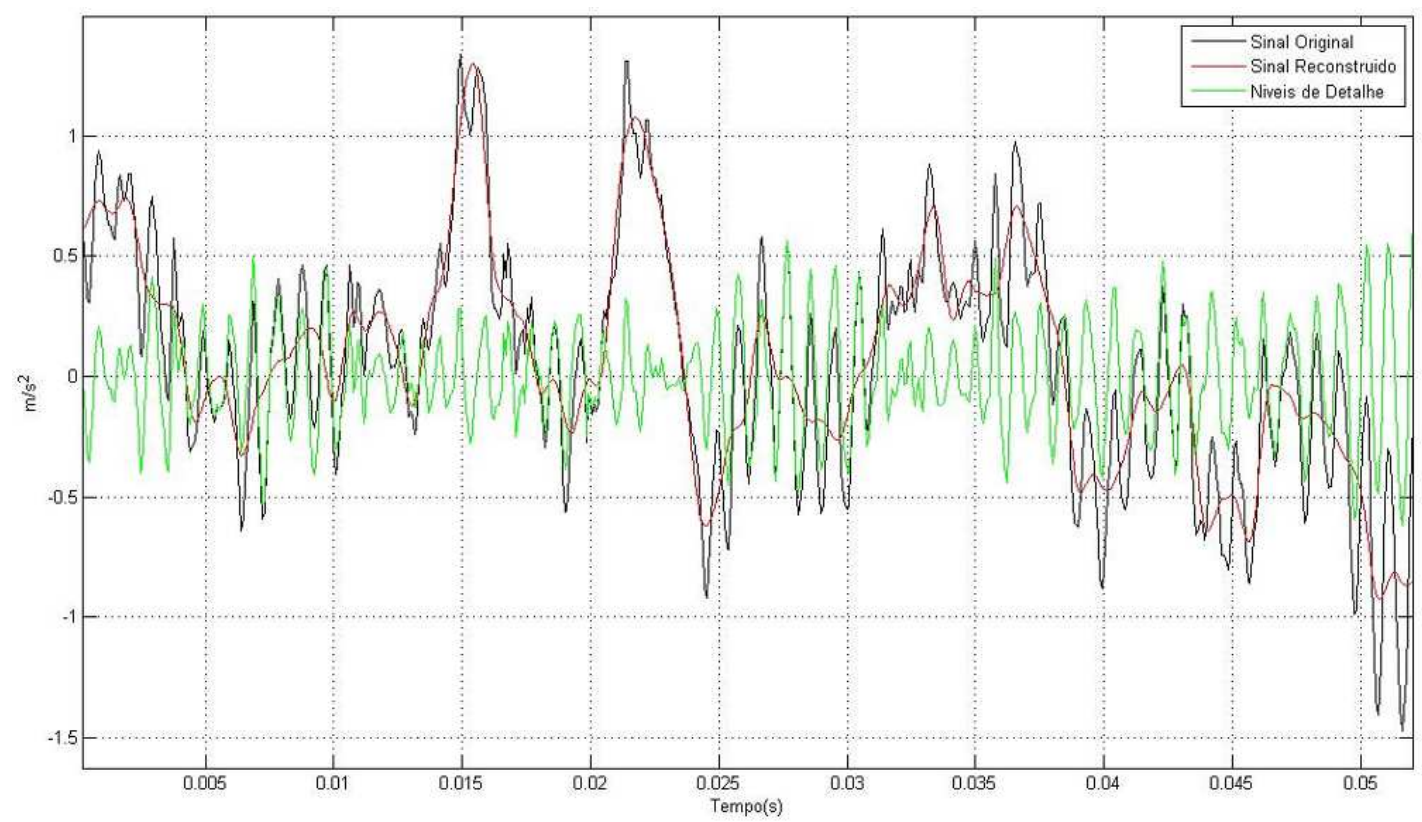

Figura 98 - Wavelet de Daubechies de ordem 7 e 3 níveis de detalhe.

Por este resultado, nota-se ainda a grande presença de ruídos de impacto no sinal reconstruído.

Na figura 99 é ilustrado o espectrograma do sinal reconstruído.

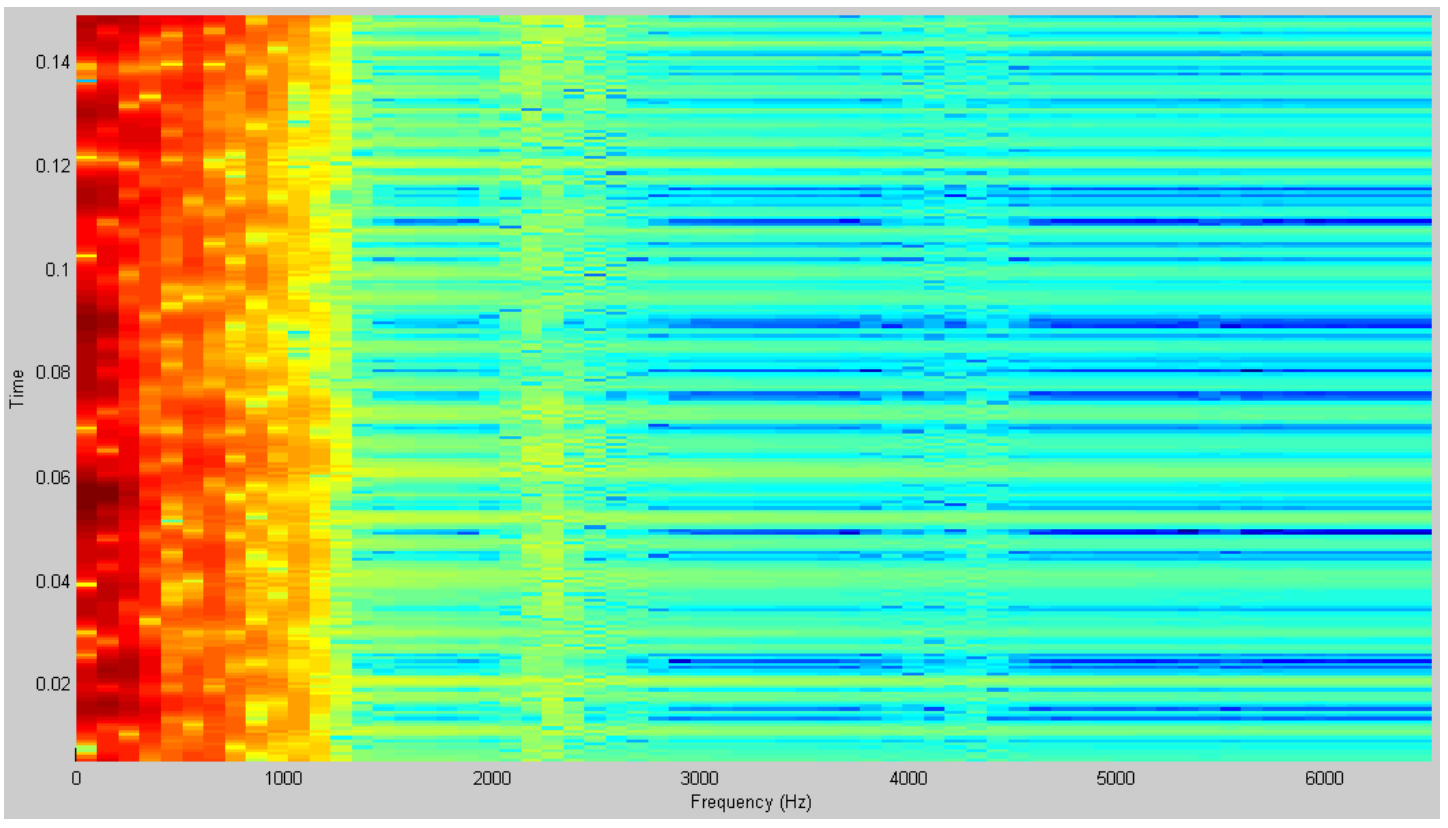

Figura 99 - Espectrograma do sinal reconstruído. 
Por este resultado, nota-se que ainda aparecem ruídos de impacto no sinal reconstruído os quais excitam frequências na ordem de grandeza de $\mathrm{kHz}$.

Para tentar contornar este problema, foi mantida a ordem da wavelet, mas foram retirados do sinal original os 4 últimos níveis de detalhe. A figura 100 ilustra o resultado obtido.

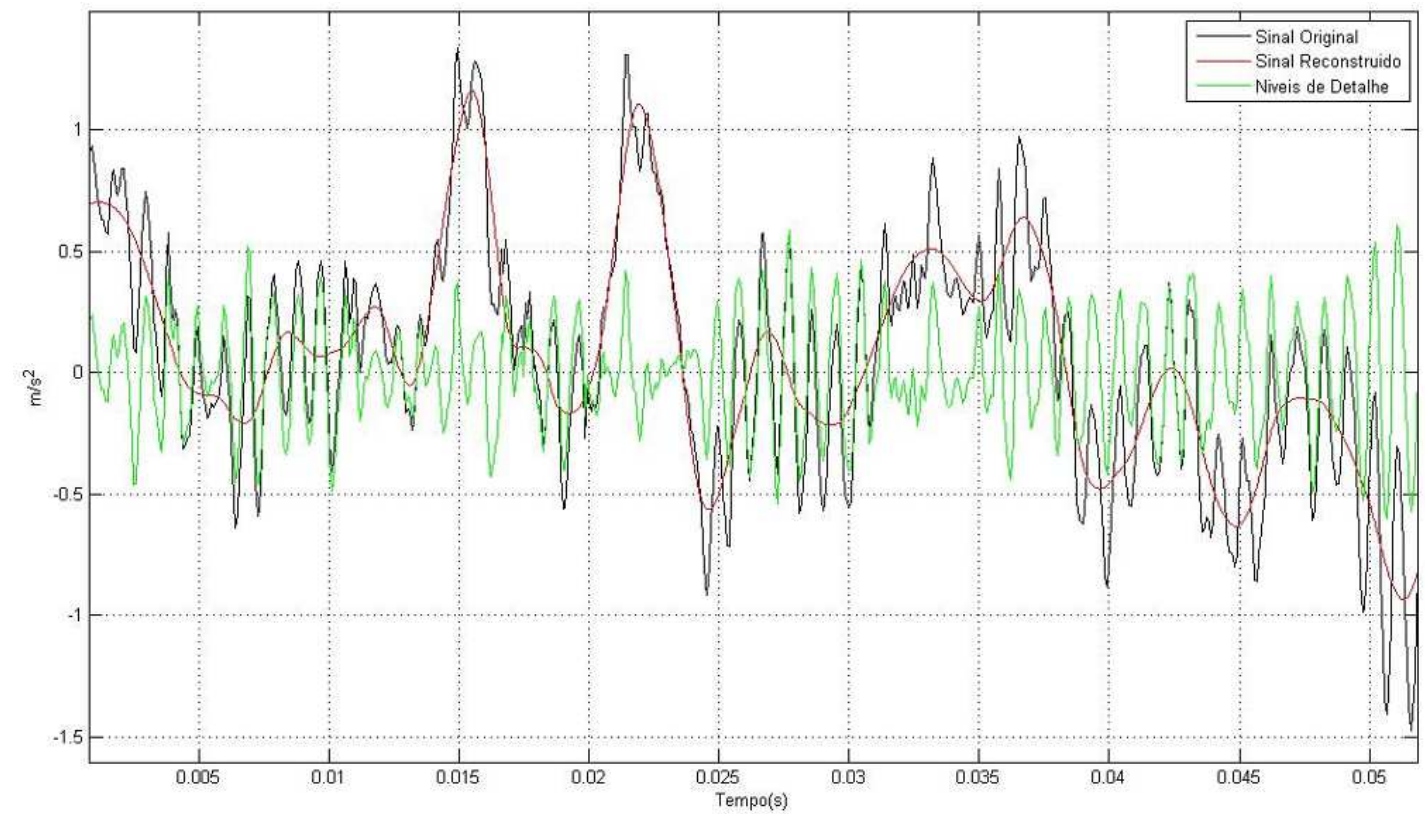

Figura 100 - Wavelet de Daubechies de ordem 7 e 4 níveis de detalhe.

Na figura 101 é ilustrado o espectrograma do sinal reconstruído.

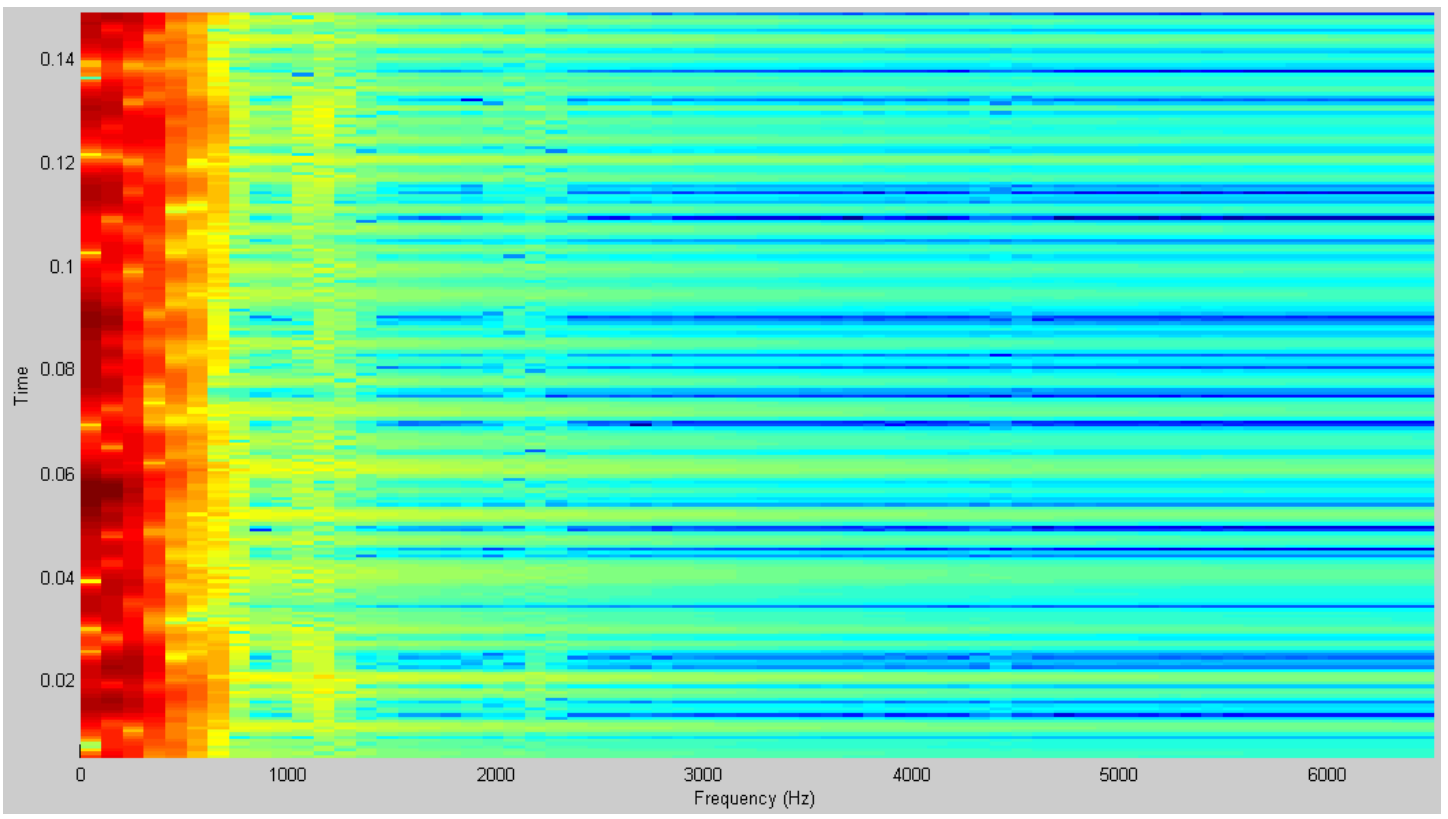

Figura 101 - Espectrograma do sinal reconstruído. 
Por este resultado, nota-se que predominam, no sinal reconstruído, as frequências em torno de $300 \mathrm{~Hz}$ e que ainda aparecem ruídos de impacto neste sinal.

A figura 102 abaixo ilustra o espectro de frequências do sinal reconstruído.

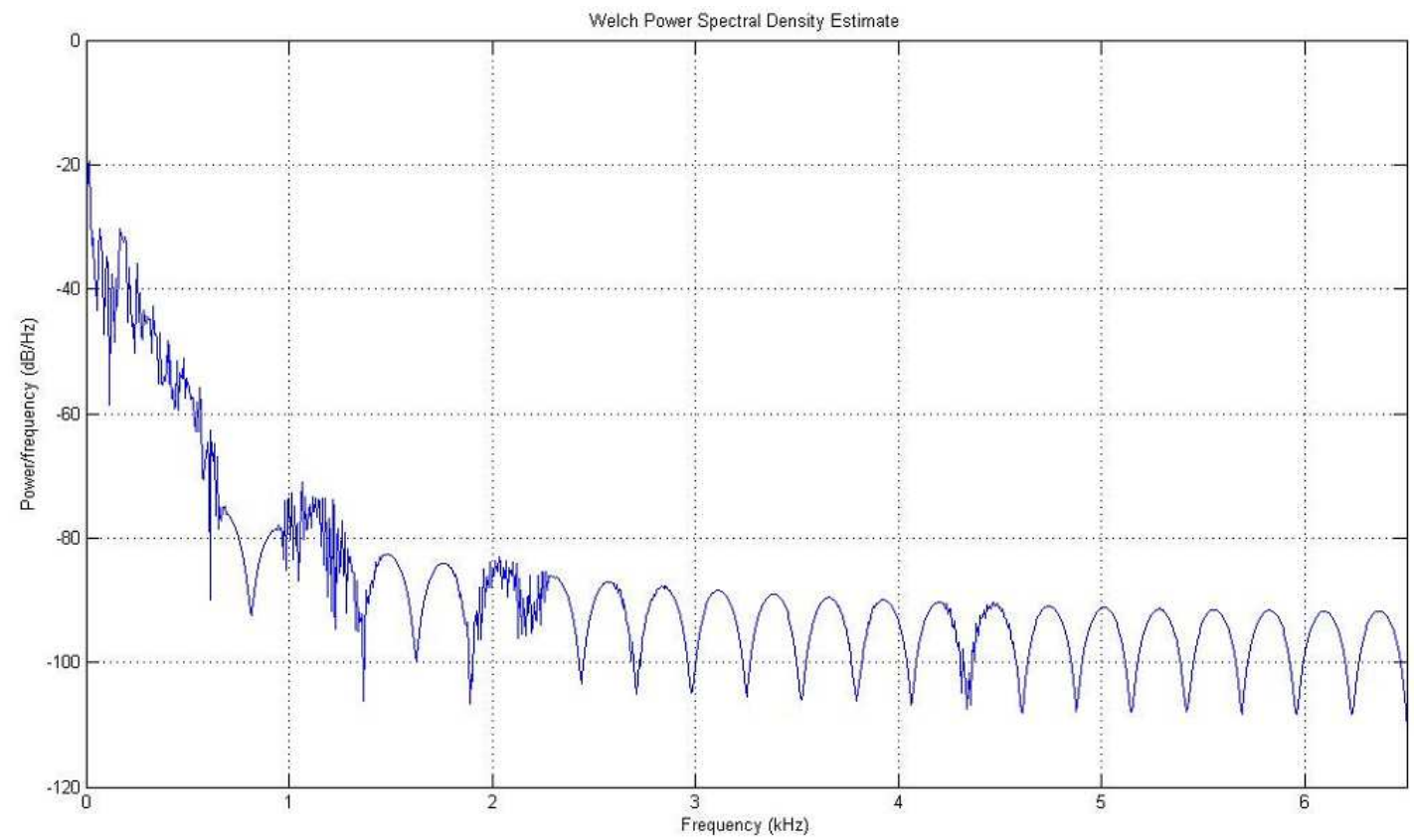

Figura 102 - Espectro de frequências do sinal reconstruído.

Por este resultado, nota-se que predominam as frequências em torno de 300 $\mathrm{Hz}$, indicando que grande parte dos ruídos de impacto foi retirada do sinal original de vibração.

A figura 103 ilustra o espectrograma do sinal dos ruídos de impacto retirados do sinal original. 


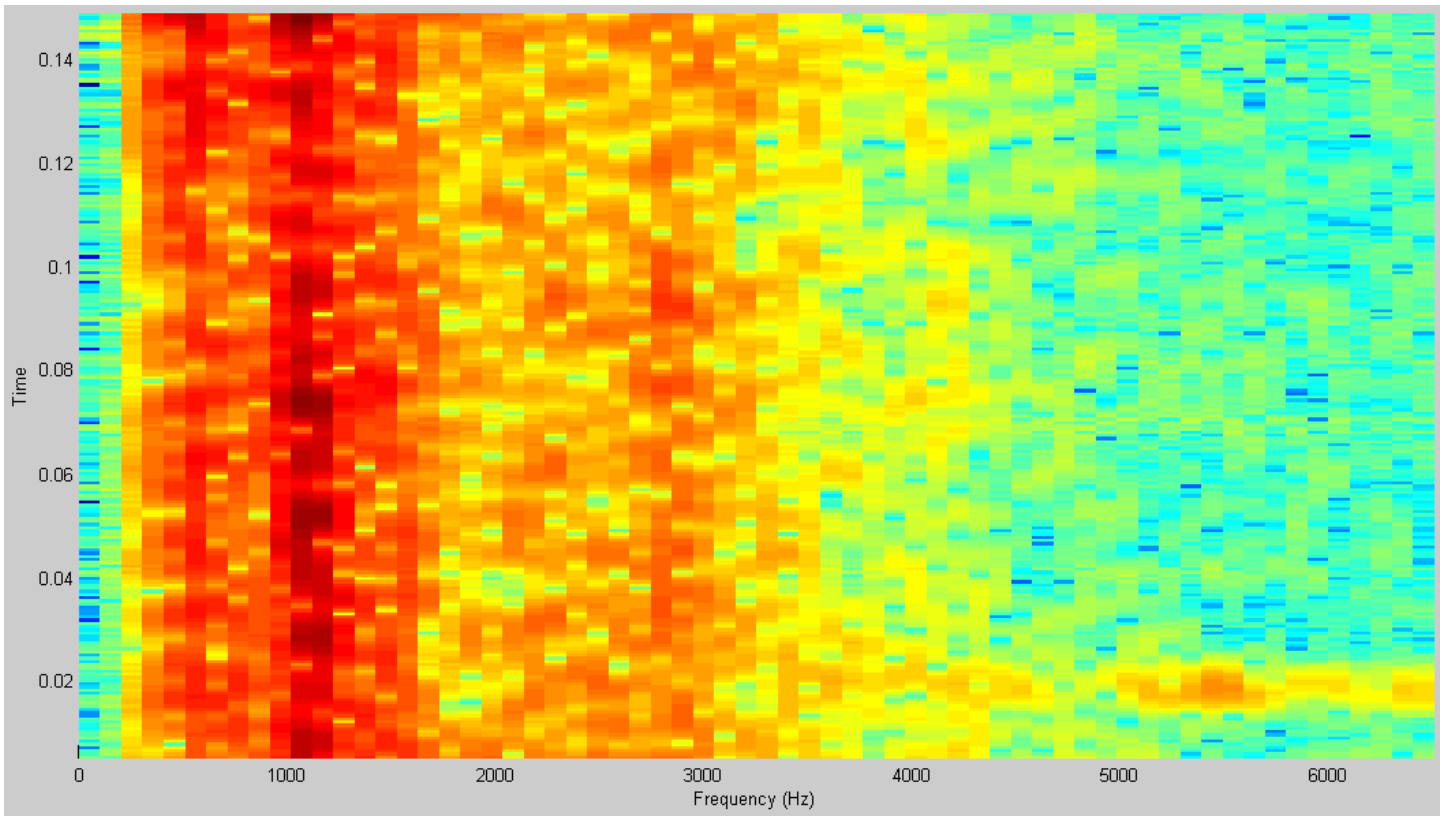

Figura 103 - Espectrograma do sinal dos ruídos de impacto.

Por este resultado, nota-se que predominam as freqüências na ordem de kHz, as quais representam os ruídos de impacto interno à caixa de direção.

A figura 104 ilustra apenas o sinal reconstruído. Comparando este sinal com o da figura 96, observa-se que grande parte dos ruídos de impacto foi retirada do sinal original de vibração.

Circulado em vermelho, encontra-se um trecho do sinal com frequência em torno de $300 \mathrm{~Hz}$.

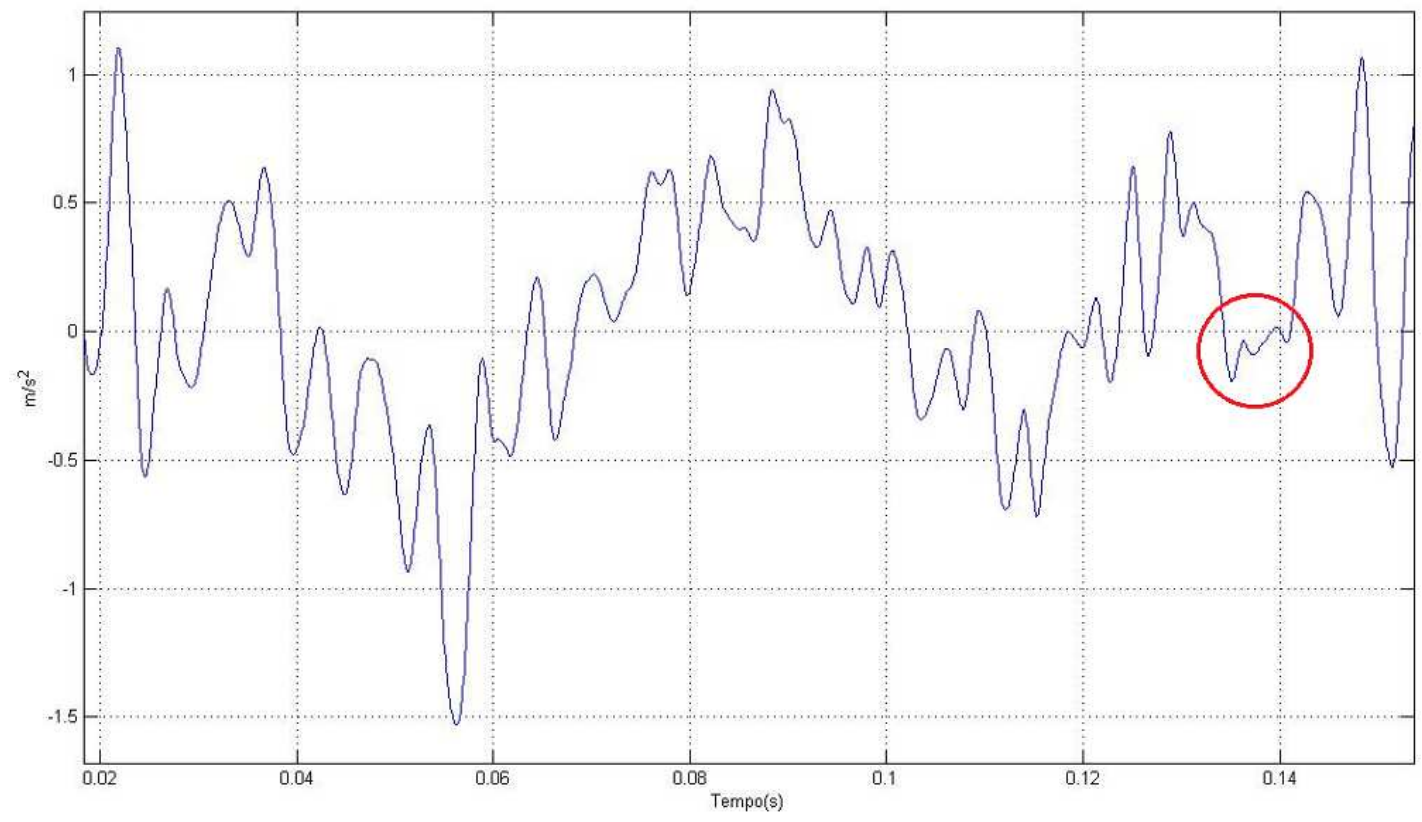

Figura 104 - Sinal reconstruído. 
Para tentar melhorar este resultado, foi mantida a ordem da wavelet de Daubechies e foram retirados os 5 últimos níveis de detalhe do sinal original. $\mathrm{O}$ resultado obtido encontra-se na figura 105 abaixo.

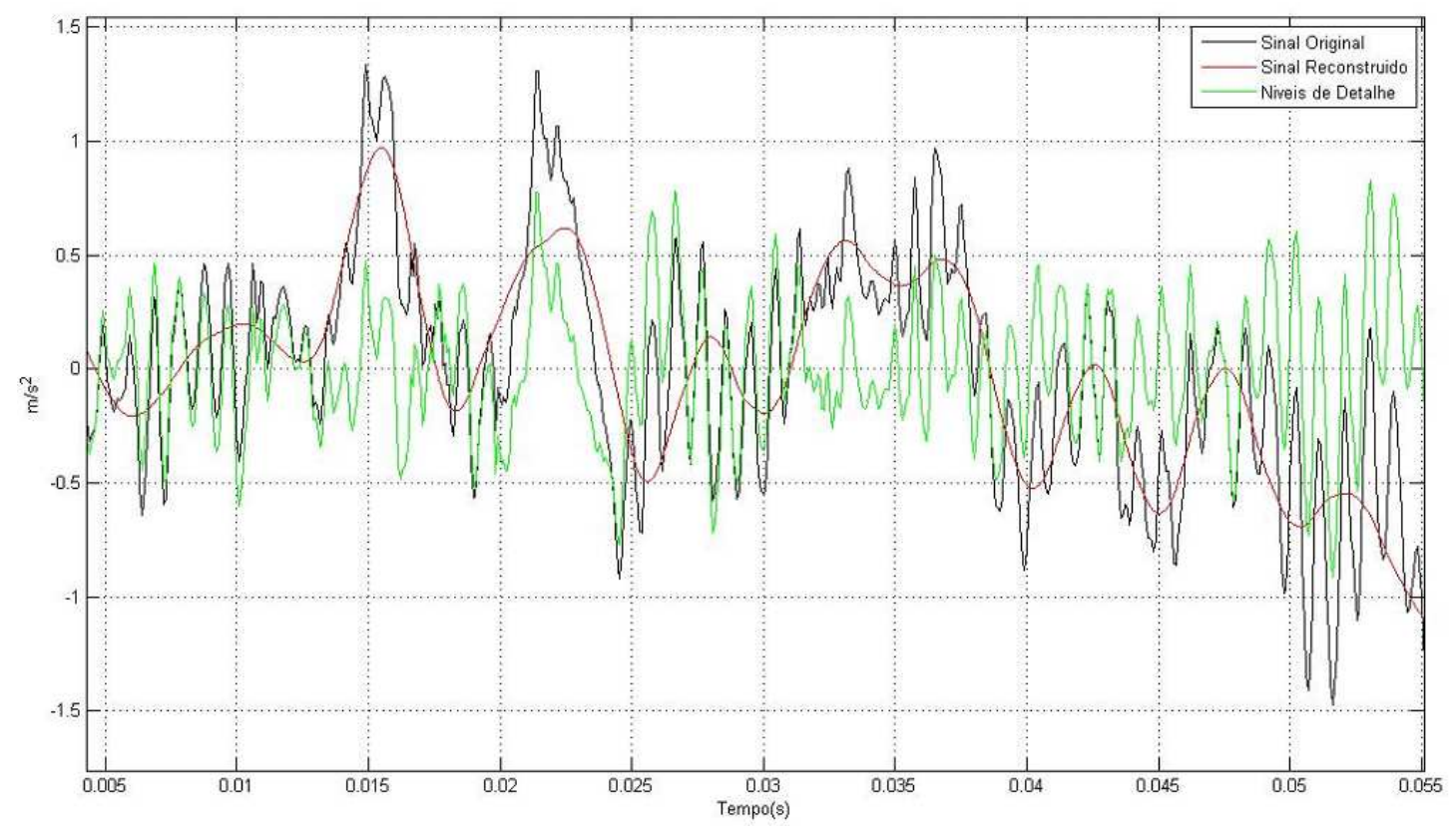

Figura 105 - Wavelet de Daubechies de ordem 7 e 5 níveis de detalhe.

Por este resultado, nota-se que ao se retirar 5 níveis de detalhe o sinal reconstruído começou a apresentar distorções como próximo a 20 milissegundos e começou a perder algumas de suas características importantes. Portanto, a tentativa de melhorar a filtragem do sinal foi prejudicada pela distorção causada no sinal.

Outra tentativa para melhorar este resultado foi aumentar a ordem da wavelet de Daubechies de 7 para 12 e retirar os 4 últimos níveis de detalhe do sinal original. O resultado obtido encontra-se na figura 106 abaixo. 


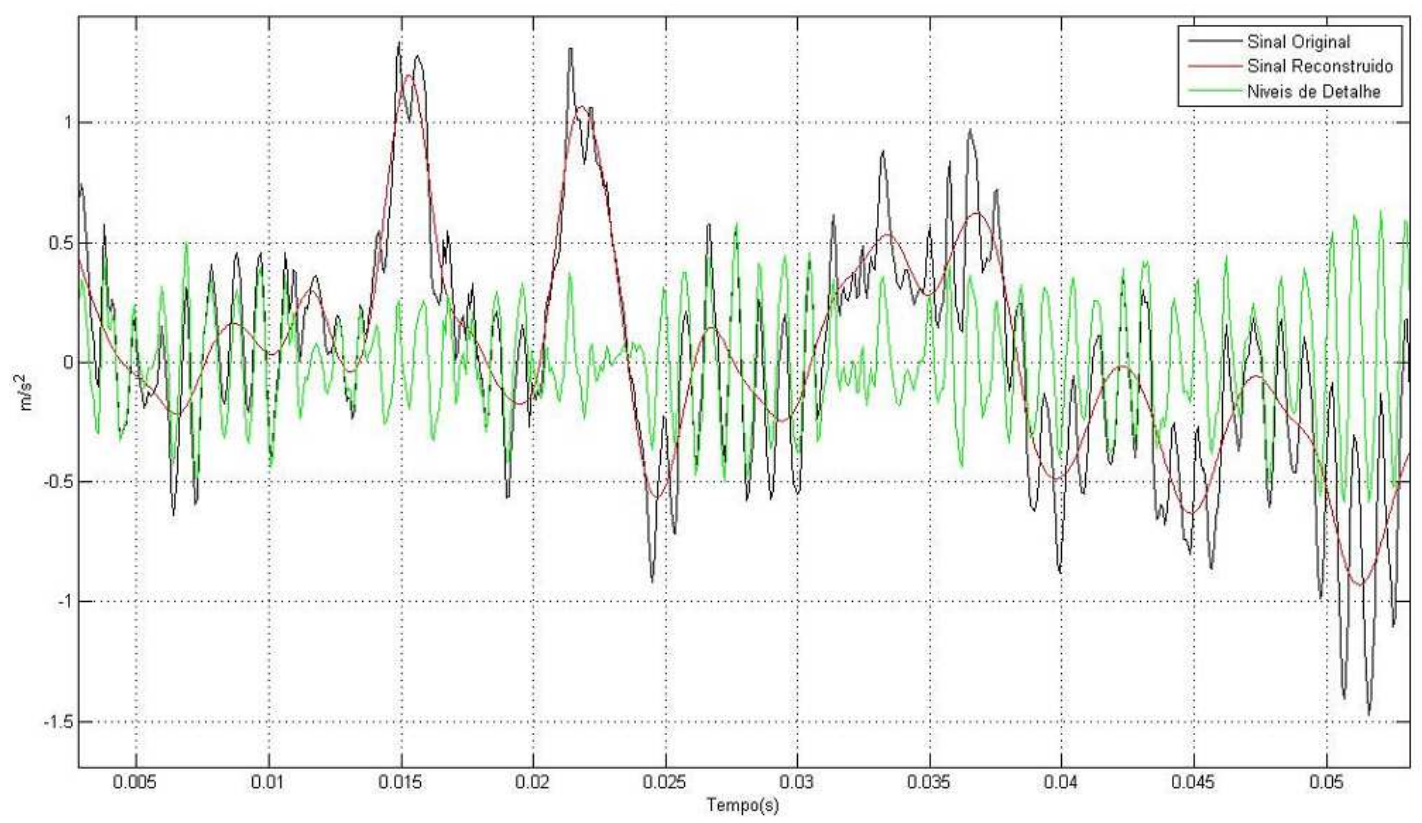

Figura 106 - Wavelet de Daubechies de ordem 12 e 4 níveis de detalhe.

Este resultado é parecido com o obtido na figura 100.

A figura 107 ilustra apenas o sinal reconstruído.

Este sinal é muito parecido com o obtido na figura 104.

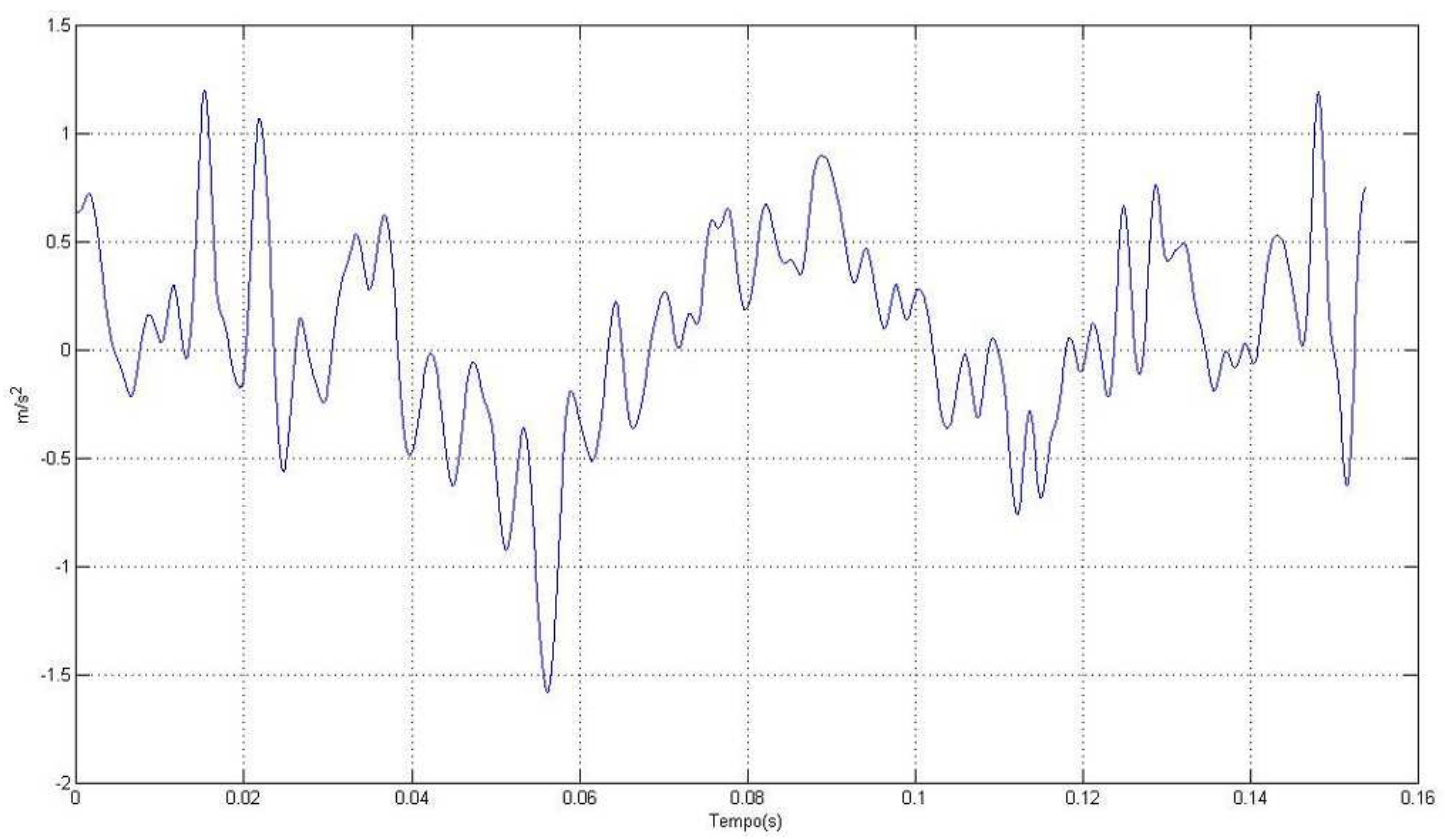

Figura 107 - Sinal reconstruído.

$\mathrm{Na}$ figura 108 é ilustrado o espectrograma do sinal reconstruído. Nota-se que predominam no sinal as frequências em torno de $300 \mathrm{~Hz}$. Este resultado é parecido com o obtido na figura 101. 


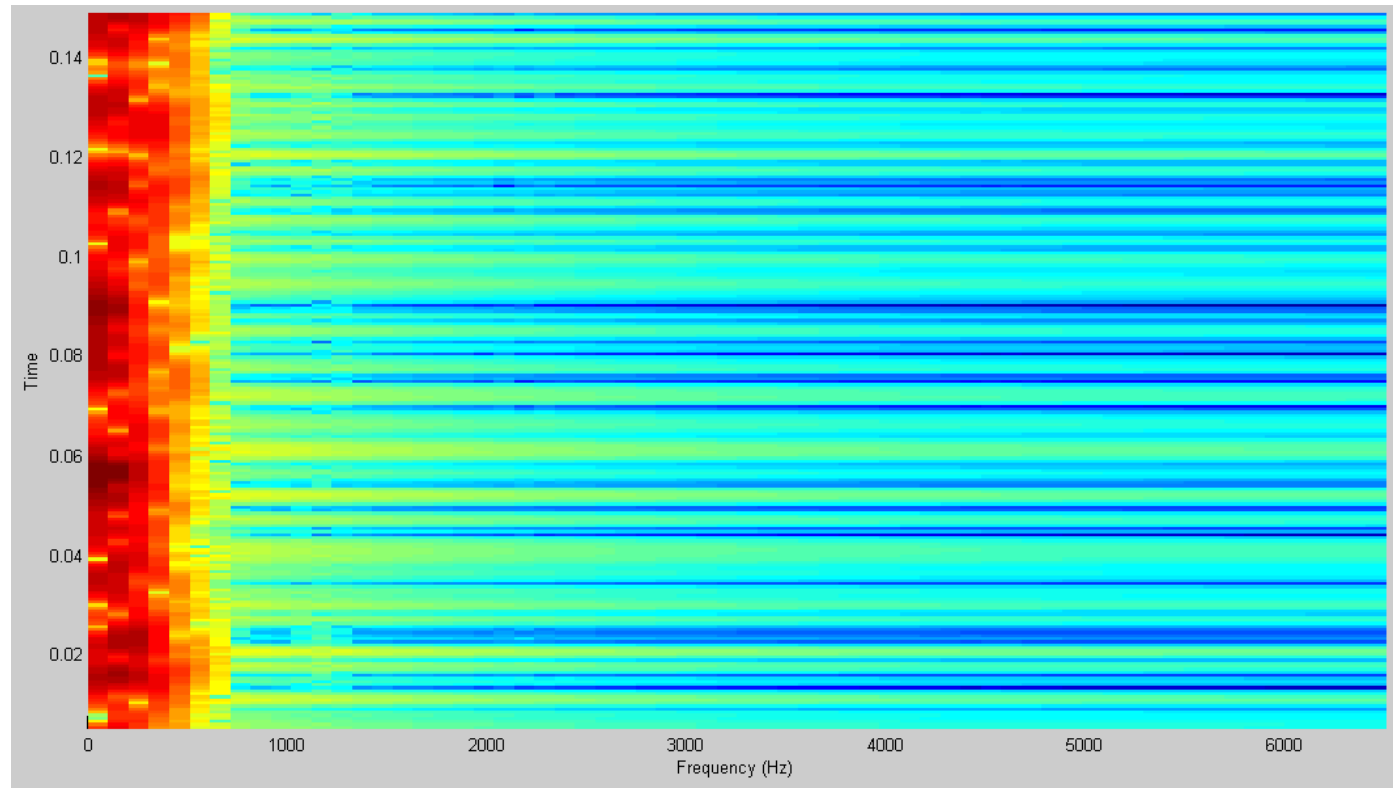

Figura 108 - Espectrograma do sinal reconstruído.

Portanto, com aumento da ordem da wavelet de Daubechies não foi possível melhorar o resultado obtido anteriormente.

Aumentando a ordem da wavelet para 18 e retirando os 4 últimos níveis de detalhe do sinal original, obteve-se o resultado ilustrado na figura 109 a seguir.

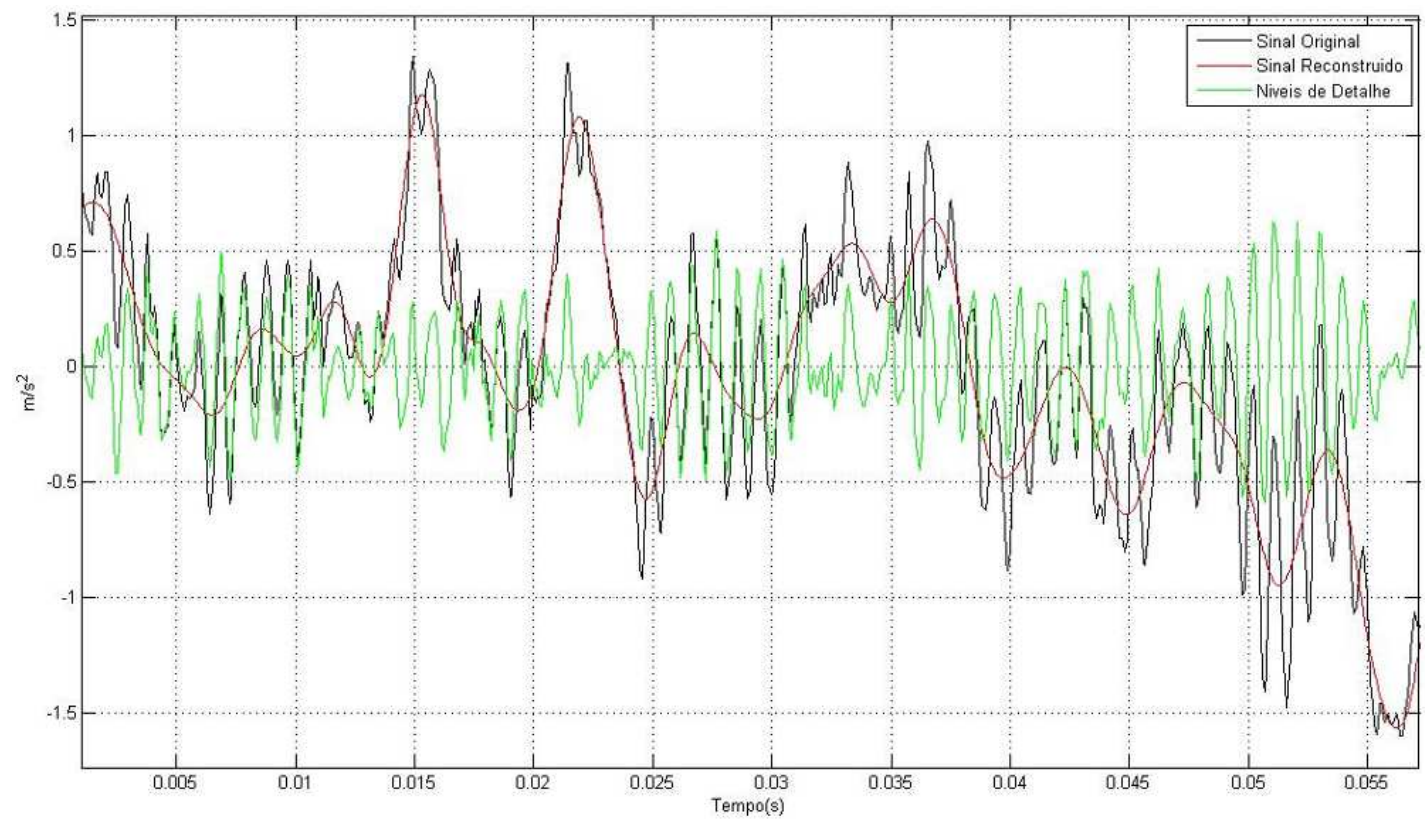

Figura 109 - Wavelet de Daubechies de ordem 18 e 4 níveis de detalhe.

Este resultado é parecido com os obtidos nas figuras 100 e 106. 
A figura 110 ilustra apenas o sinal reconstruído. Este resultado é muito parecido com os obtidos nas figuras 104 e 107.

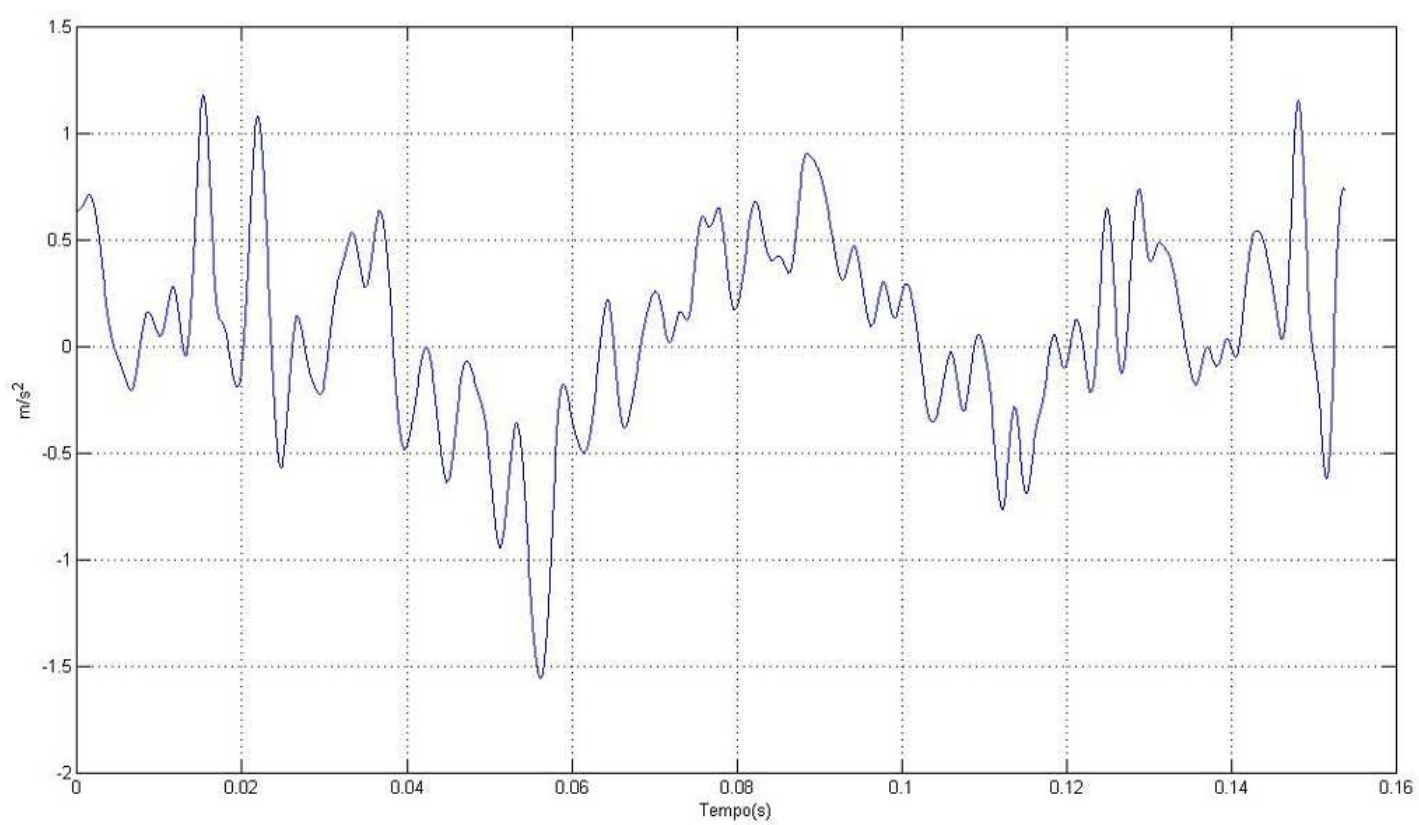

Figura 110 - Sinal reconstruído.

Na figura 111 é ilustrado o espectrograma do sinal reconstruído.

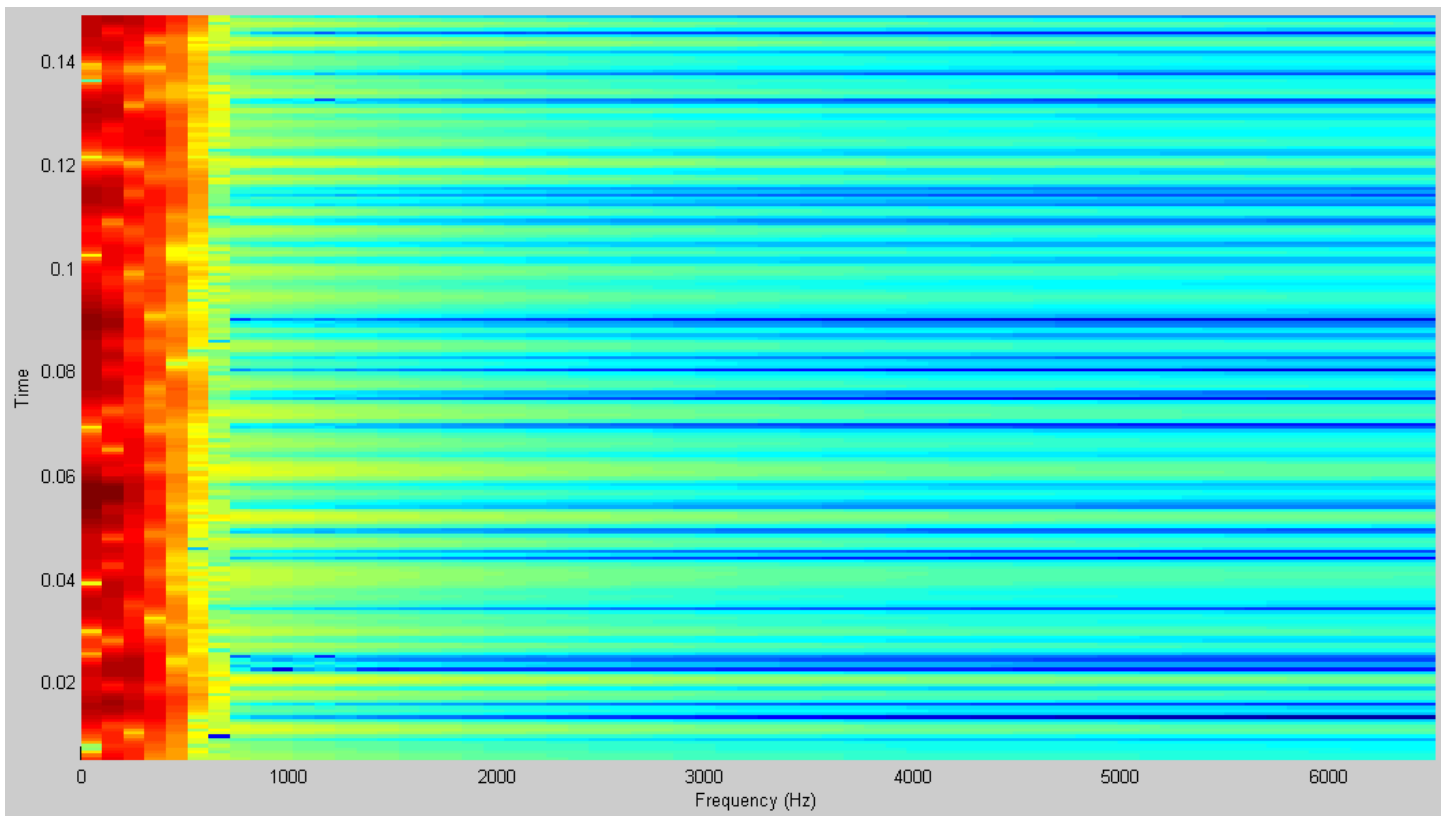

Figura 111 - Espectrograma do sinal reconstruído. 
Este resultado mostra que no sinal reconstruído predominam as frequências em torno de $300 \mathrm{~Hz}$. Este resultado é parecido com os resultados obtidos nas figuras 101 e 108.

Dos resultados obtidos, nenhum deles foi capaz de retirar totalmente os ruídos de impacto do sinal de vibração real sem distorcer ou retirar características importantes do sinal original. Porém, utilizando a wavelet de Daubechies de ordem 7 e retirando os 4 últimos níveis de detalhe, grande parte dos ruídos de impacto foi retirada do sinal original e através dos níveis de detalhe é possível quantificar a freqüência de ocorrência de impactos e a severidade dos mesmos.

Para quantificar a freqüência de ocorrência de impactos, foi realizada uma pré-filtragem no sinal original que eliminou os dados cujo módulo eram menores do que $0,02 \mathrm{~m} / \mathrm{s}^{2}$ e foi criada uma janela com largura de $1,3 \mathrm{~ms}$ que percorreu todo 0 sinal original. Verificou-se se o módulo do sinal original a cada janela de 1,3 ms ultrapassou, em algum momento, em 30\% o valor em módulo do sinal reconstruído sem os ruídos de impacto. Caso afirmativo, foi considerada a ocorrência de uma unidade de impacto. Para quantificar a severidade deste impacto, foi calculado o valor R.M.S do sinal referente aos ruídos de impacto nessa janela.

Adotando o critério da janela de tempo acima, foi registrada a ocorrência de 103 impactos dentro da caixa de direção e a maior severidade de impacto medida foi de $0,641 \mathrm{~m} / \mathrm{s}^{2}$.

No gráfico superior da figura 112 são ilustrados, em vermelho, os pontos de impacto detectados por este procedimento e no gráfico inferior são ilustrados os valores da severidade medidos para estes pontos. 

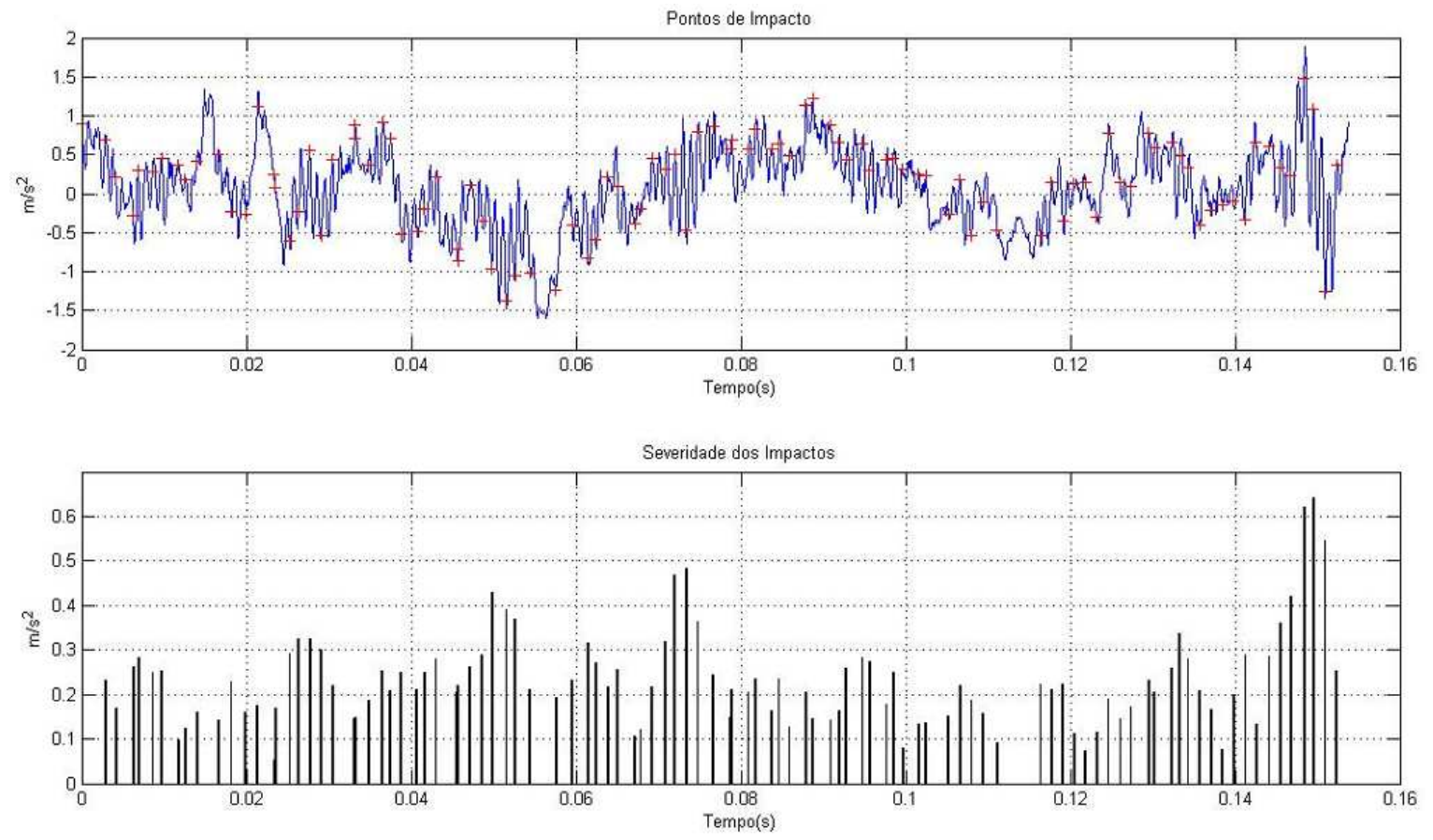

Figura 112 - Pontos de impacto e Severidade dos Impactos.

Considere agora outro sinal real de vibração ilustrado na figura 113 e medido com o carro em movimento na rua de paralelepípedos.

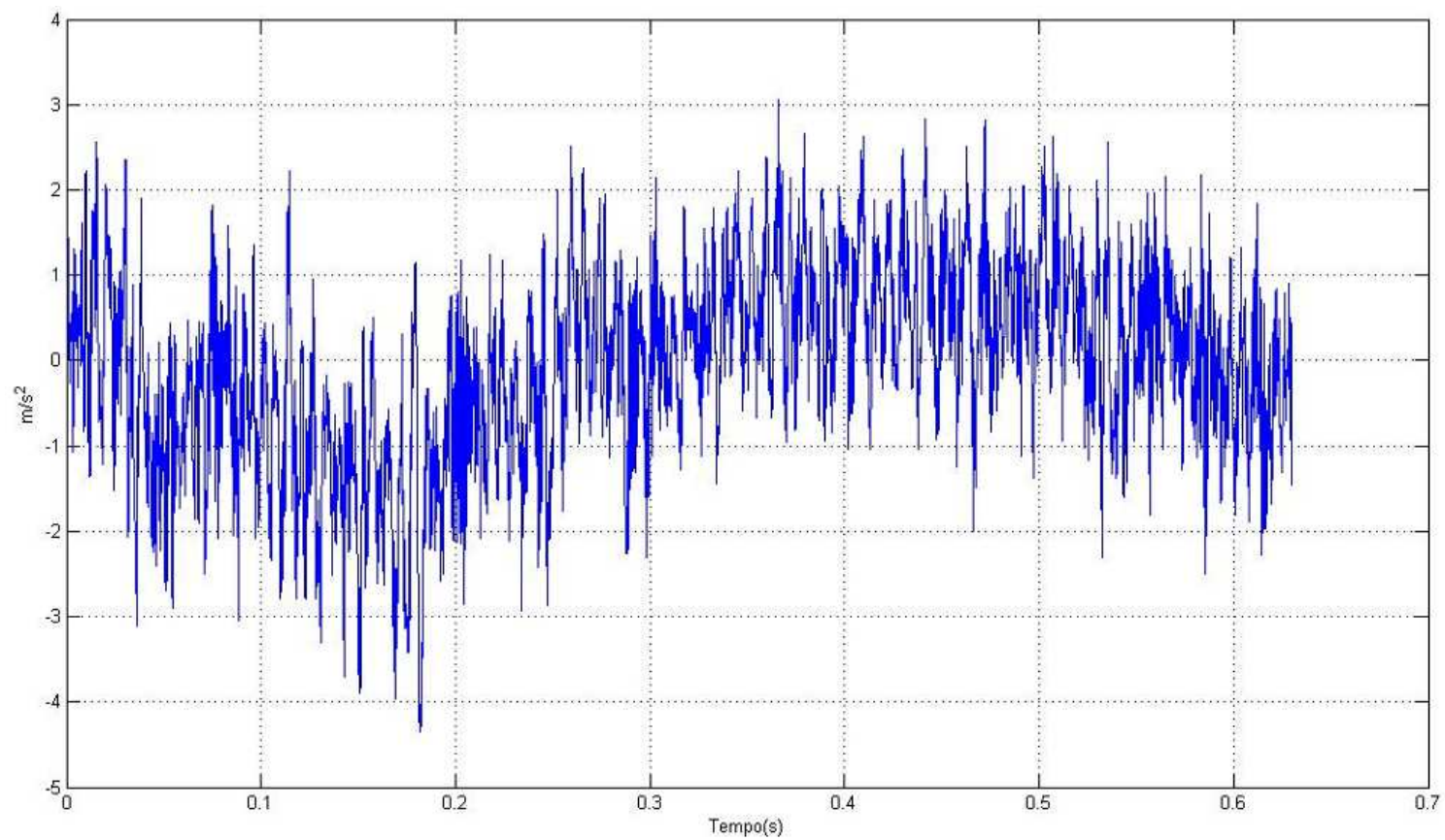

Figura 113 - Sinal de vibração real medido na rua de paralelepípedos.

A figura 114 ilustra o espectrograma do sinal original. 


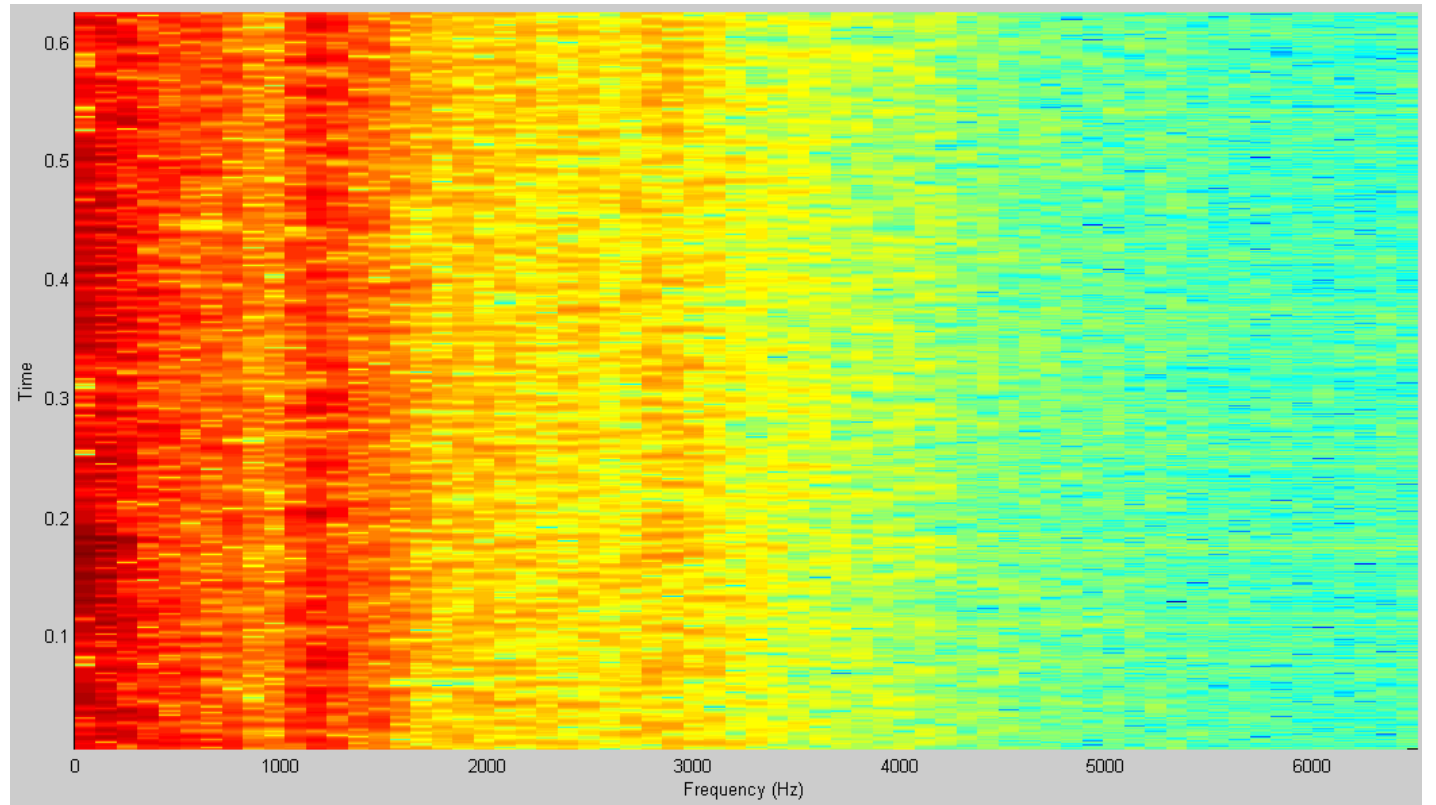

Figura 114 - Espectrograma do sinal original.

Por este resultado, nota-se a grande presença de ruídos de impacto, provenientes dos impactos da cremalheira contra o pinhão e bucha guia durante todo o percurso do automóvel, a qual excita diversas faixas de frequência.

Aplicando a wavelet de Daubchies de ordem 7 e retirando os 4 últimos níveis de detalhe do sinal original, obteve-se o resultado ilustrado na figura 115.

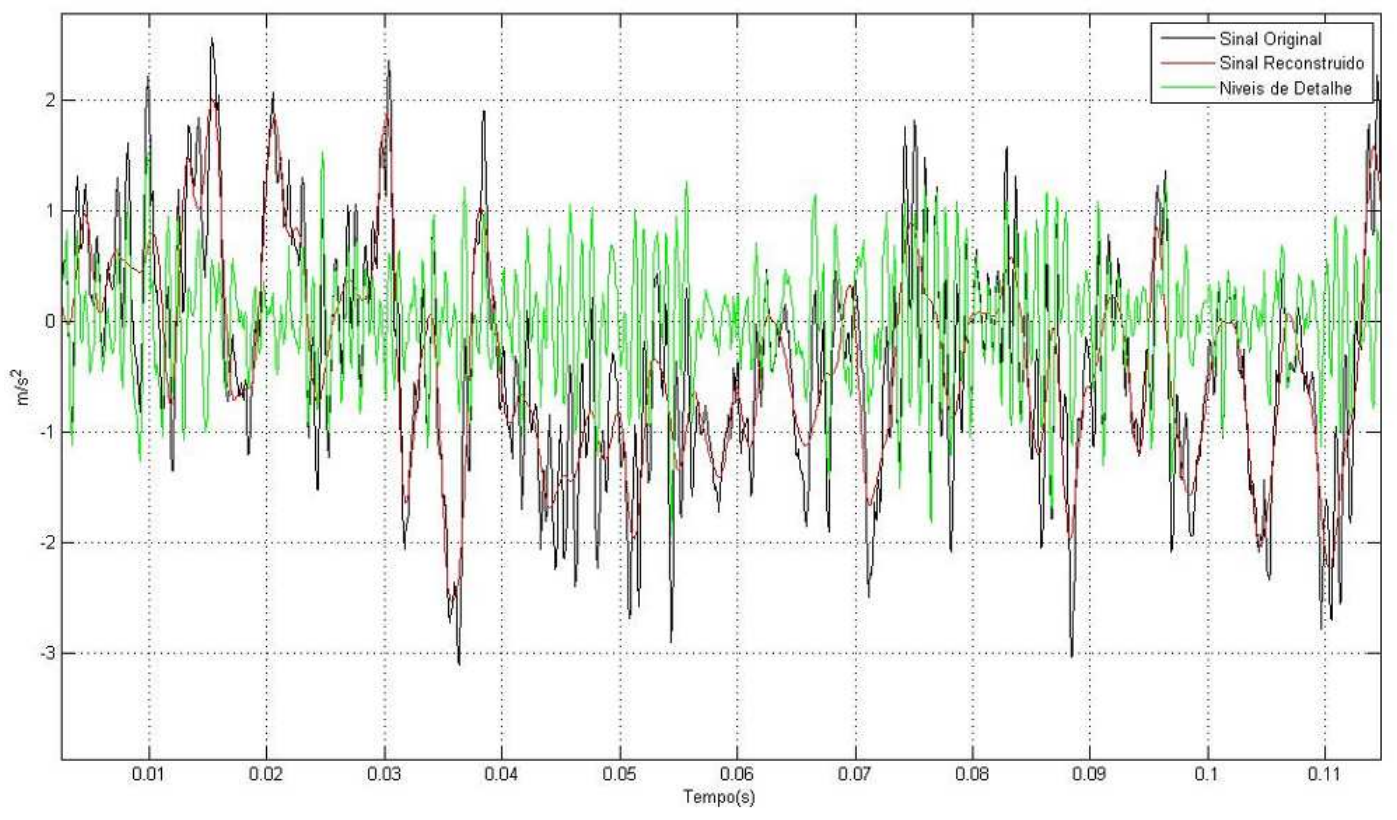

Figura 115 - Wavelet de Daubechies de ordem 7 e 4 níveis de detalhe. 
$\mathrm{Na}$ figura 116 a seguir, foi aplicado o espectrograma sobre o sinal reconstruído a fim de verificar quais frequências predominam neste sinal.

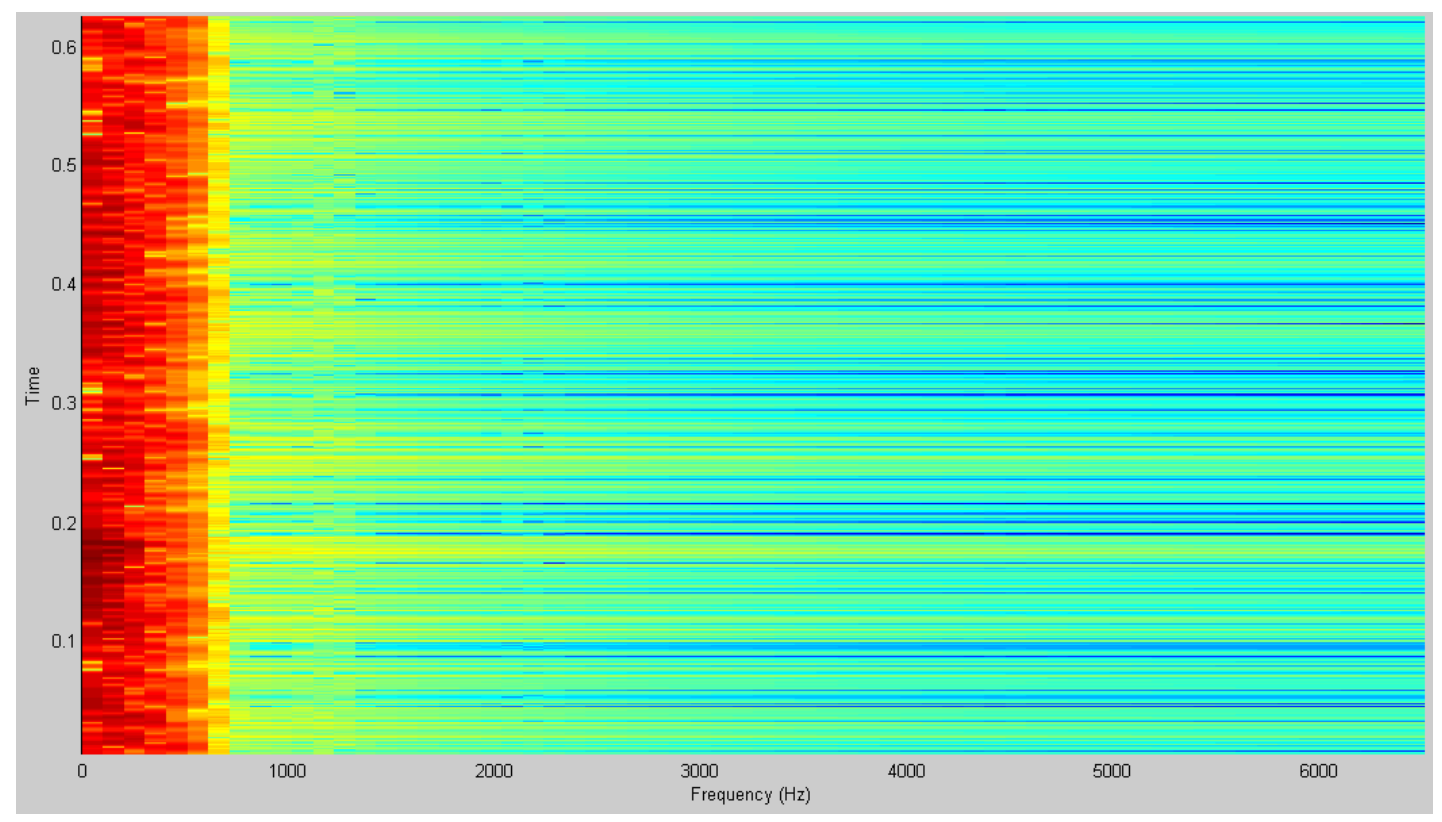

Figura 116 - Espectrograma do sinal reconstruído.

Por este resultado, nota-se que predominam as frequências em torno de 300 $\mathrm{Hz}$ e que ainda aparecem ruídos de impacto neste sinal que excitam diversas faixas de frequências.

Para tentar melhorar este resultado, manteve-se a ordem da wavelet e retiraram-se os 5 últimos níveis de detalhe do sinal original, obtendo o resultado ilustrado na figura 117 a seguir. 


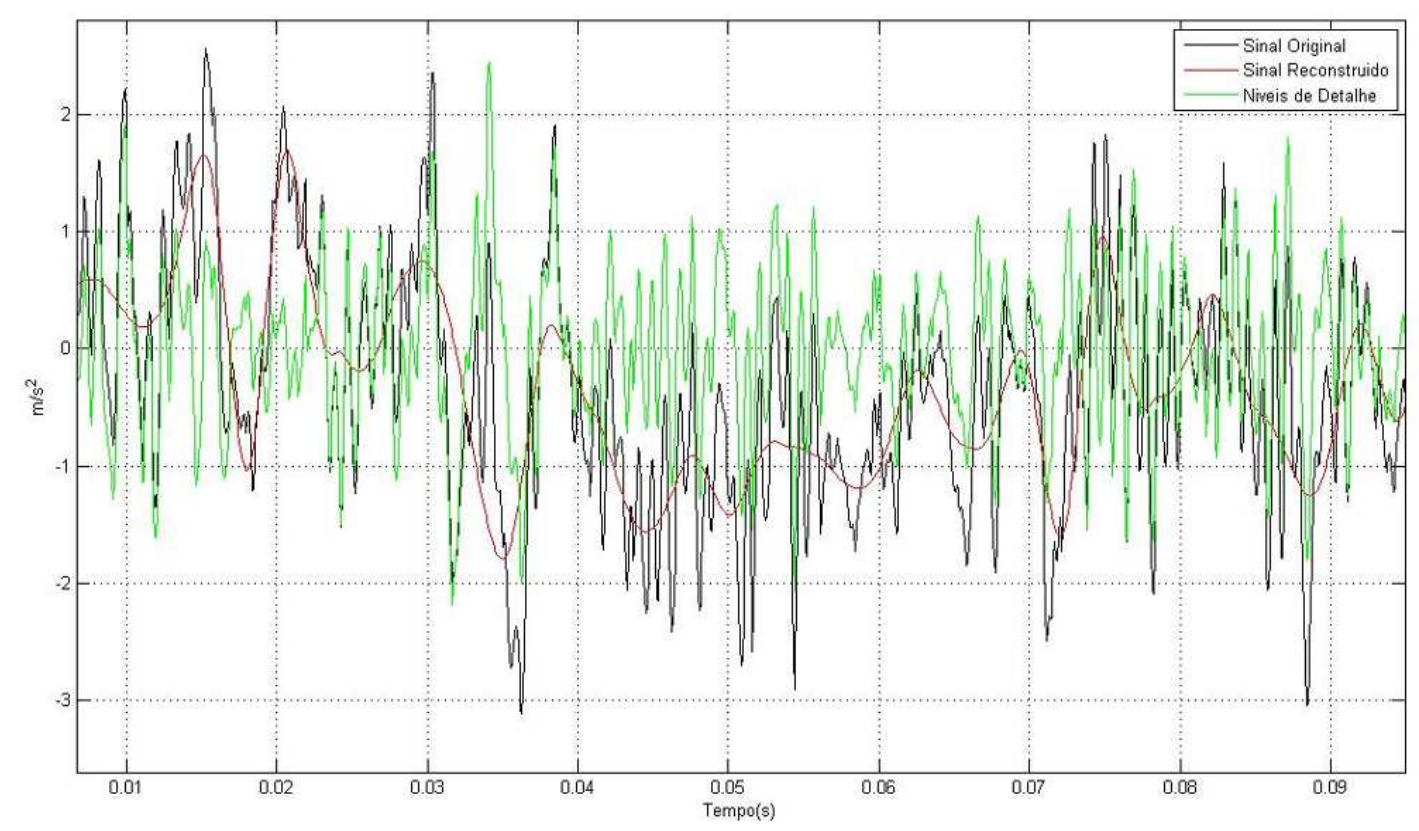

Figura 117 - Wavelet de Daubechies de ordem 7 e 5 níveis de detalhe.

Nota-se por este resultado, que próximos a 35 e 70 milissegundos o sinal reconstruído começou a perder algumas de suas características e começou a apresentar distorções. Portanto, a tentativa de melhorar a filtragem do sinal foi prejudicada pela distorção no sinal que esta causou.

Mantendo 4 níveis de detalhe mas aumentando a ordem da wavelet de Daubechies de 7 para 12, obteve-se o resultado ilustrado na figura 118 abaixo.

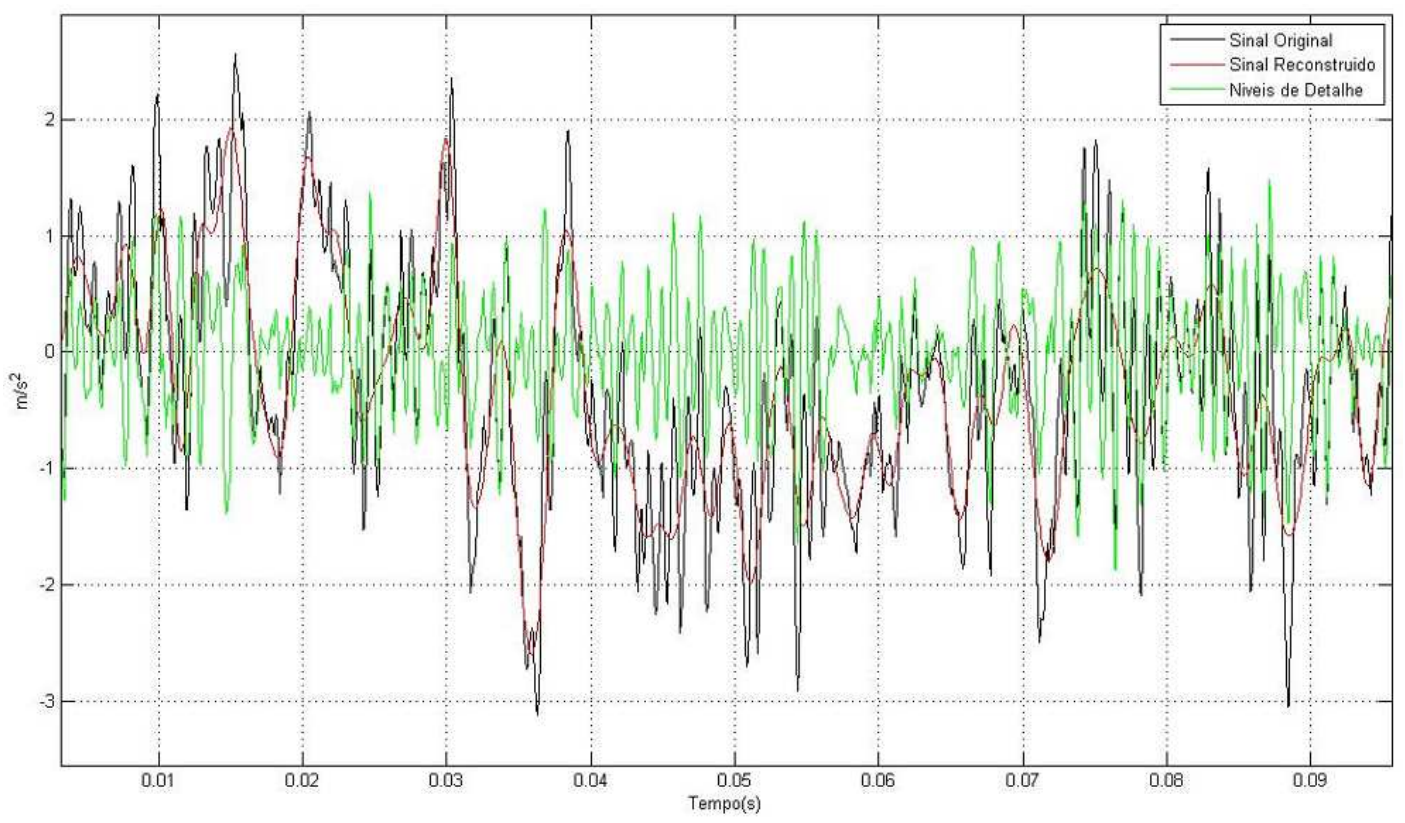

Figura 118 - Wavelet de Daubechies de ordem 12 e 4 níveis de detalhe. 
Este resultado é muito parecido com o obtido na figura 115.

$\mathrm{Na}$ figura 119 é ilustrado o espectrograma do sinal reconstruído. Nota-se que predominam as frequências em torno de $300 \mathrm{~Hz}$, indicando que grande parte dos ruídos de impacto foi retirada do sinal original. Este resultado é muito parecido com o obtido na figura 116.

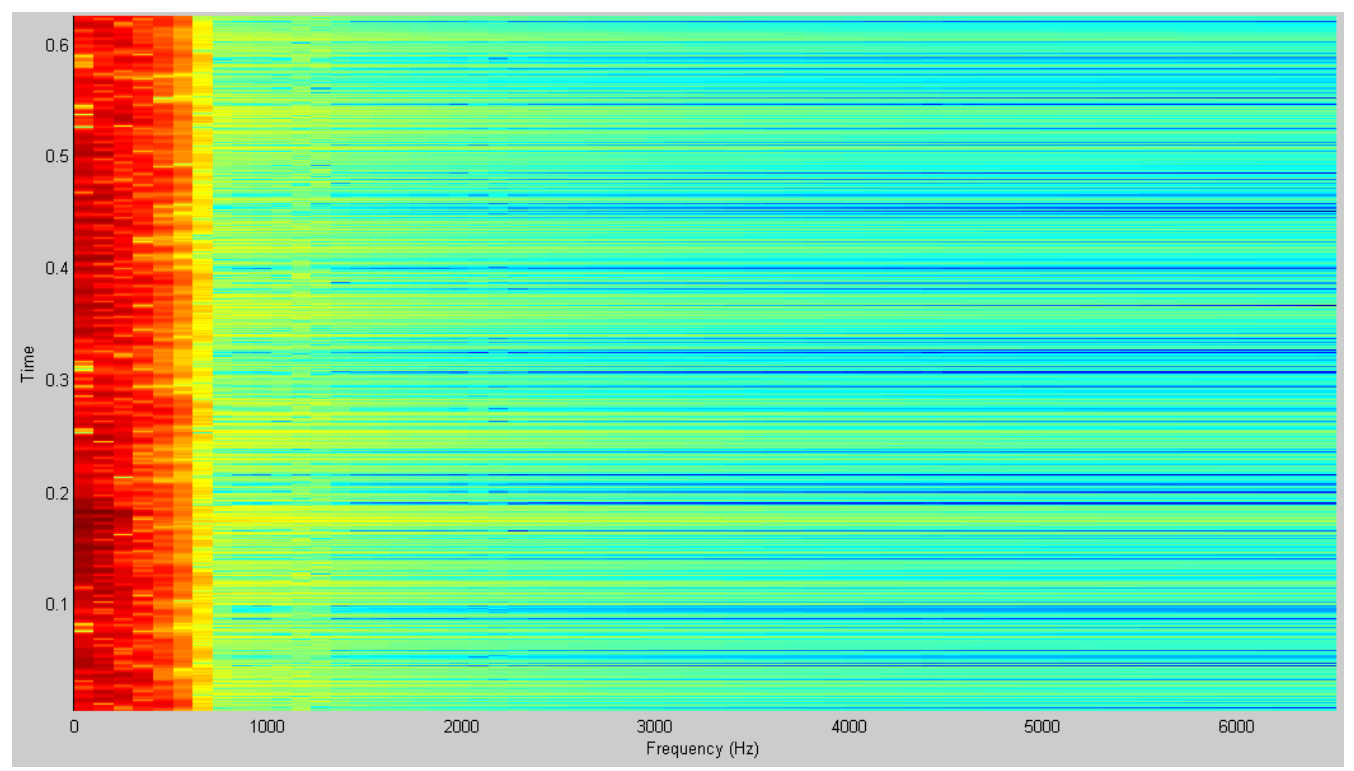

Figura 119 - Espectrograma do sinal reconstruído.

Portanto, o aumento da ordem da wavelet não resultou numa melhora no resultado.

Observa-se que utilizando a wavelet de ordem 7 e retirando os 4 últimos níveis de detalhe, a grande maioria dos ruídos de impacto foi separada do sinal original de vibração.

Na figura 120, é ilustrado o espectro de freqüência do sinal reconstruído. Nota-se que predominam as freqüências próximas a $300 \mathrm{~Hz}$, indicando que grande parte dos ruídos de impacto foi retirada do sinal original de vibração. 


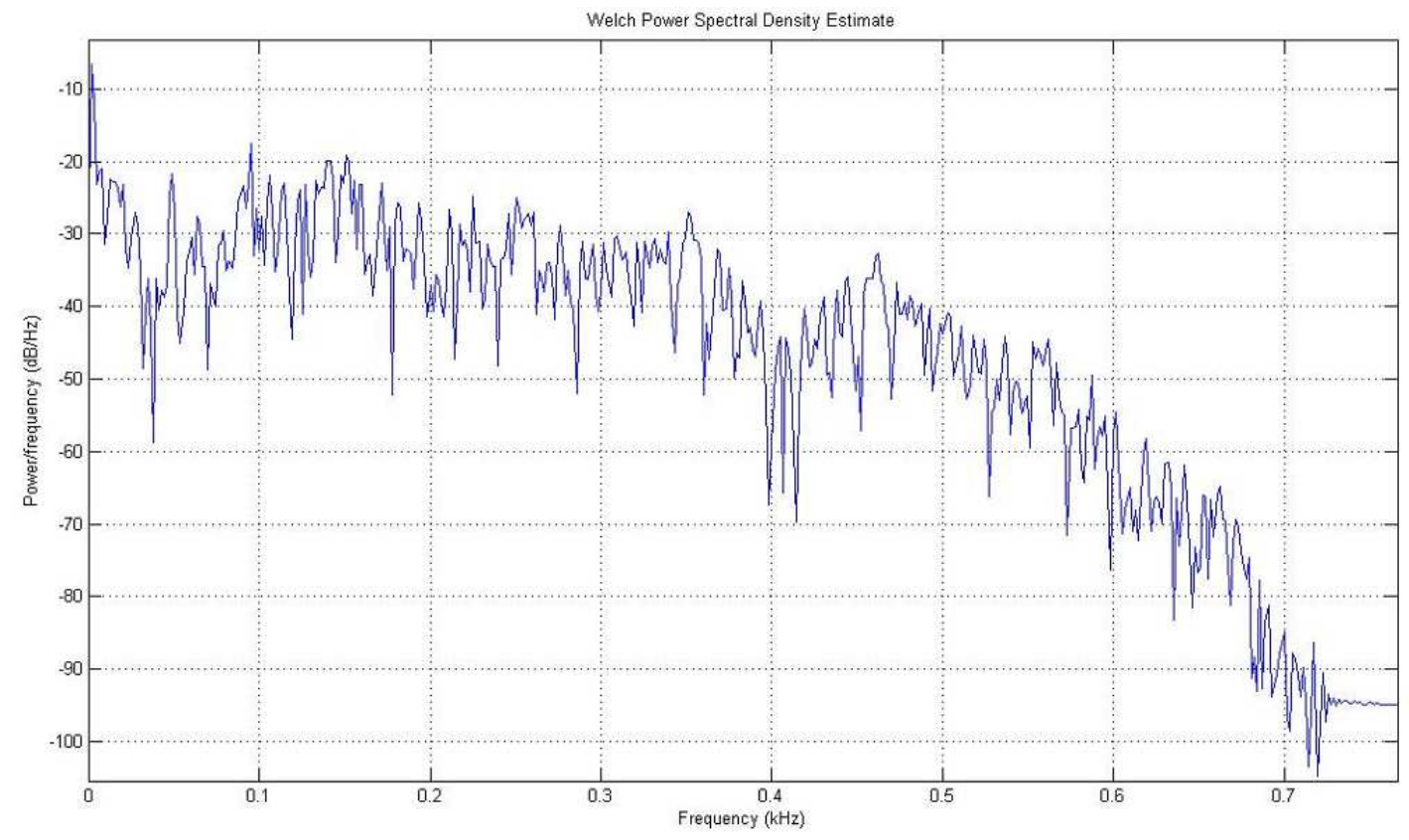

Figura 120 - Espectro de frequência do sinal reconstruído.

A figura 121 ilustra o espectrograma dos níveis de detalhes retirados do sinal original. Nota-se que predominam as freqüências na ordem de $\mathrm{kHz}$, as quais representam os ruídos de impacto interno à caixa de direção.

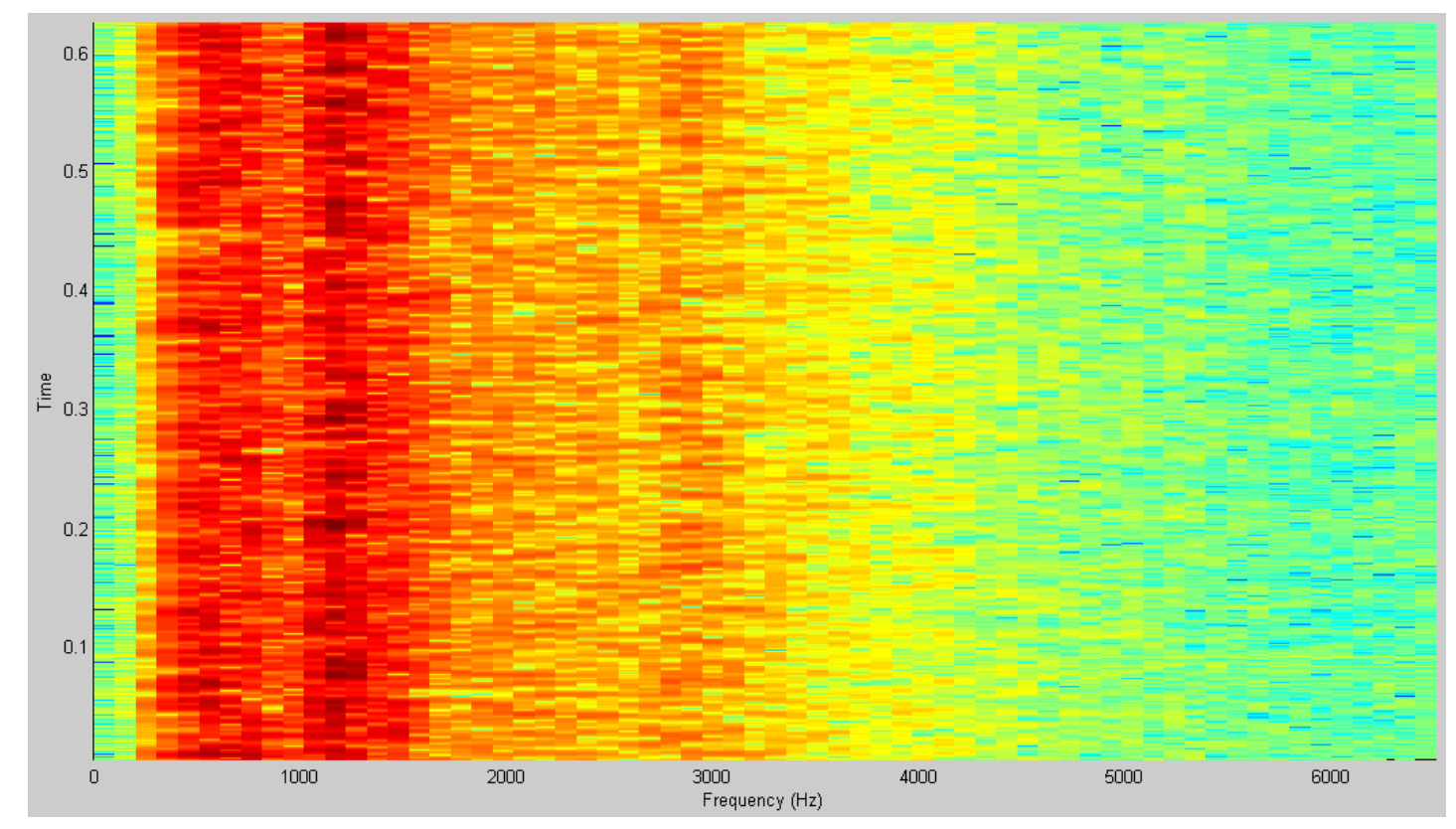

Figura 121 - Espectrograma do sinal dos ruídos de impacto.

Adotando o critério da janela de tempo e mantendo a pré-filtragem em 0,02 $\mathrm{m} / \mathrm{s}^{2}$, foi registrada a ocorrência de 430 impactos, dentro da caixa de direção, da 
cremalheira contra o pinhão e bucha guia e a maior severidade de impacto medida foi de $1,093 \mathrm{~m} / \mathrm{s}^{2}$.

No gráfico superior da figura 122 são ilustrados, em vermelho, os pontos de impacto detectados por este procedimento e no gráfico inferior são ilustrados os valores da severidade medidos para estes pontos.
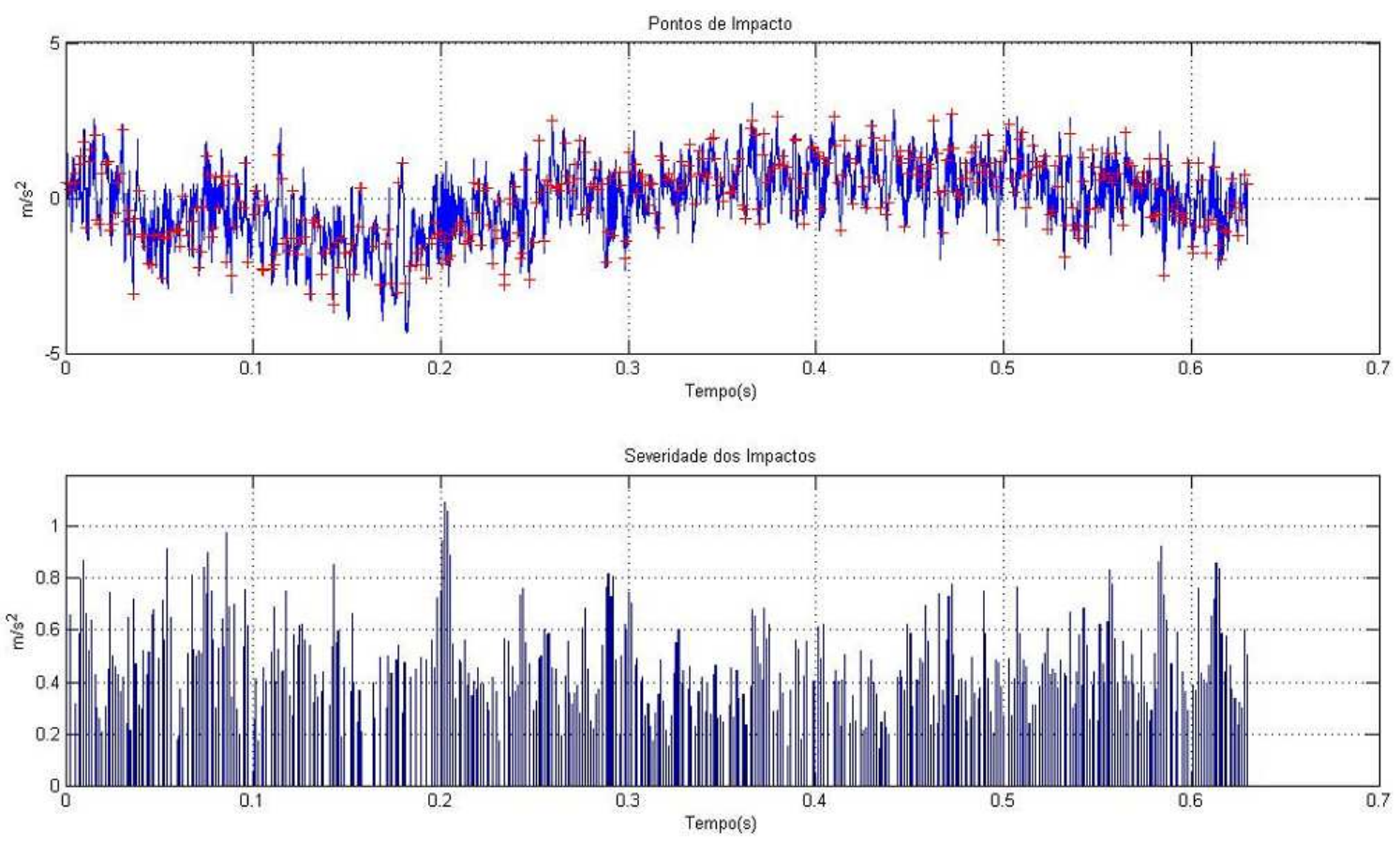

Figura 122 - Pontos de impacto e Severidade dos Impactos.

Considere novamente um novo sinal de vibração real ilustrado na figura 123 e medido com o veículo em movimento na rua de paralelepípedos. Nota-se a presença de impactos durante todo o sinal. 


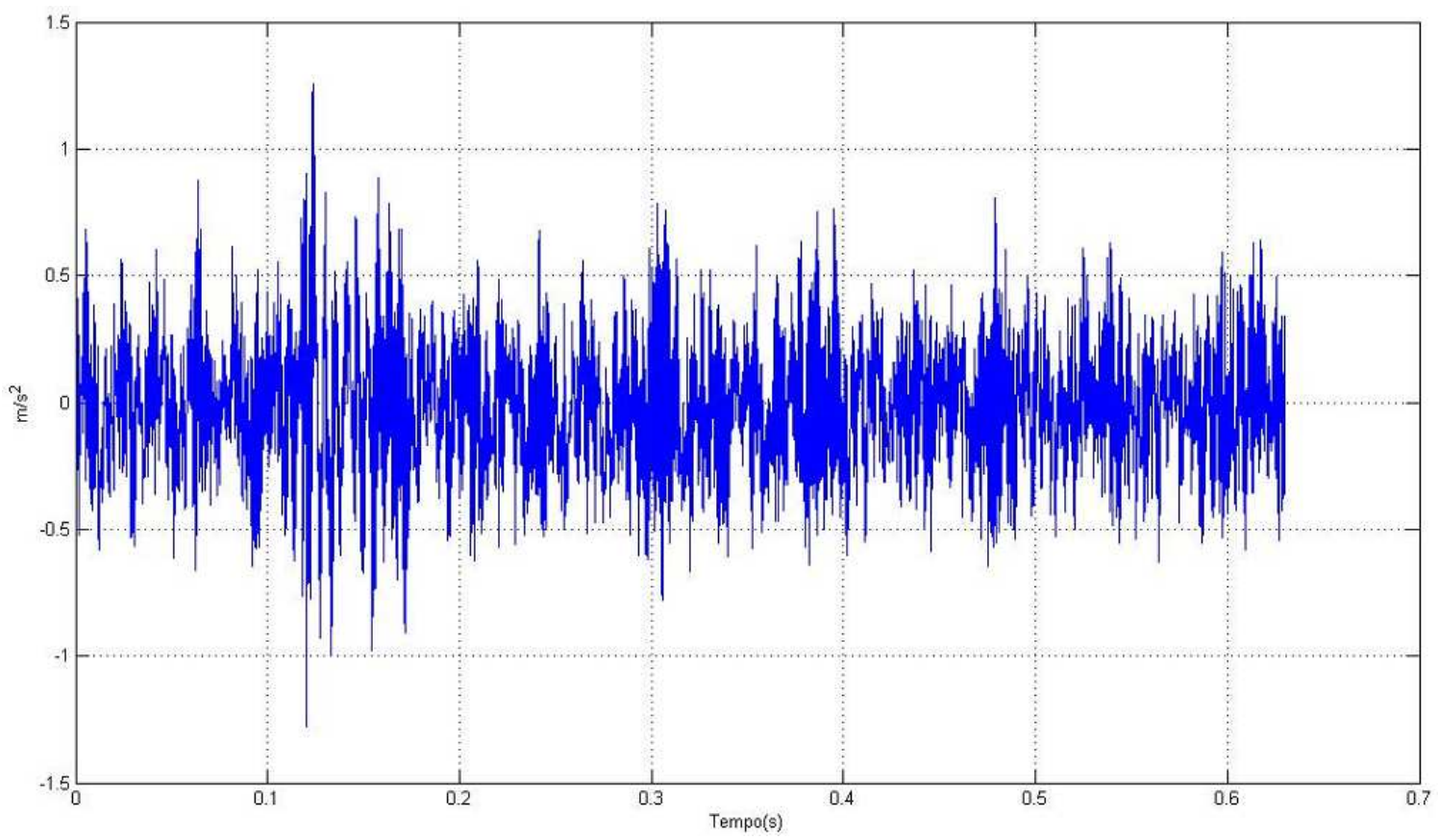

Figura 123 - Sinal de vibração real medido na rua de paralelepípedos.

A figura 124 ilustra o espectrograma do sinal original.

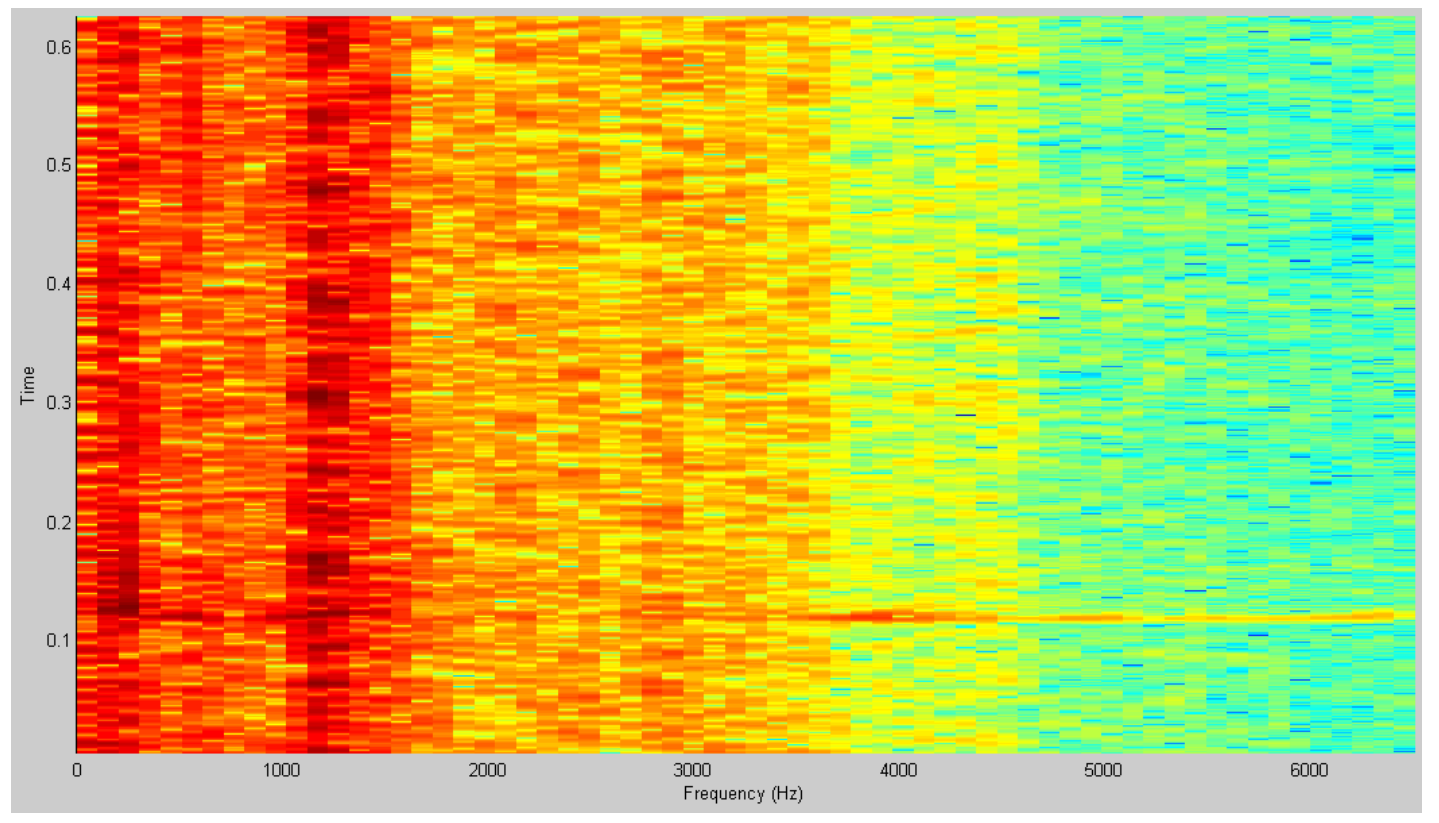

Figura 124 - Espectrograma do sinal original.

Por este resultado, nota-se a grande presença de frequências na ordem de grandeza de kHz, indicando a presença de ruídos de impacto provenientes dos impactos da cremalheira contra o pinhão e bucha guia durante todo o percurso. 
Aplicando a wavelet de Daubechies de ordem 7 e retirando os 4 últimos níveis de detalhe do sinal original, obteve-se o resultado ilustrado na figura 125.

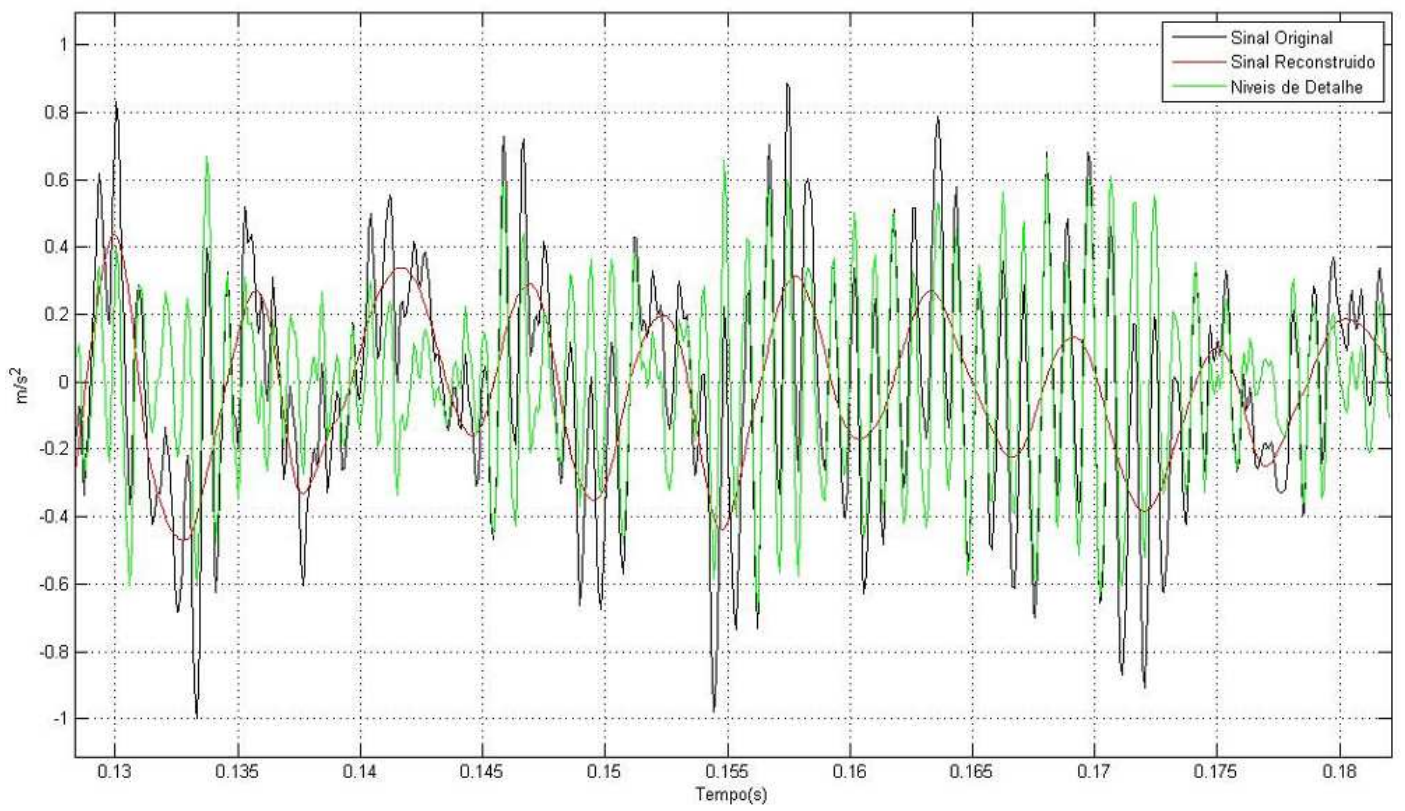

Figura 125 - Wavelet de Daubechies de ordem 7 e 4 níveis de detalhe.

$\mathrm{Na}$ figura 126 a seguir, foi aplicado o espectrograma sobre o sinal reconstruído a fim de verificar quais frequências predominam neste sinal.

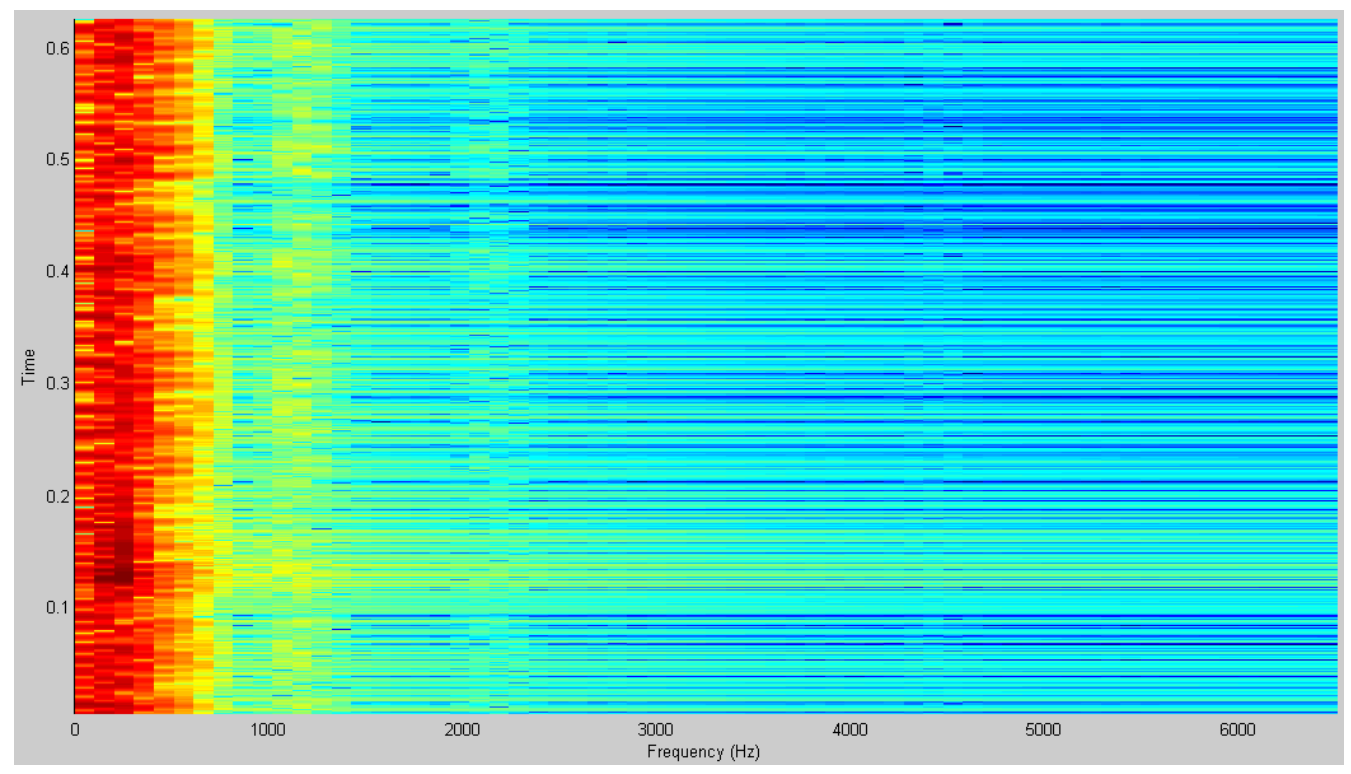

Figura 126 - Espectrograma do sinal reconstruído. 
Por este resultado, nota-se que predominam as frequências em torno de 300 $\mathrm{Hz}$ e que ainda aparecem ruídos de impacto neste sinal que excitam diversas faixas de frequências.

Para tentar melhorar este resultado foi mantida a ordem da wavelet e retiraram-se os 5 últimos níveis de detalhe do sinal original, obtendo o resultado ilustrado na figura 127 a seguir.

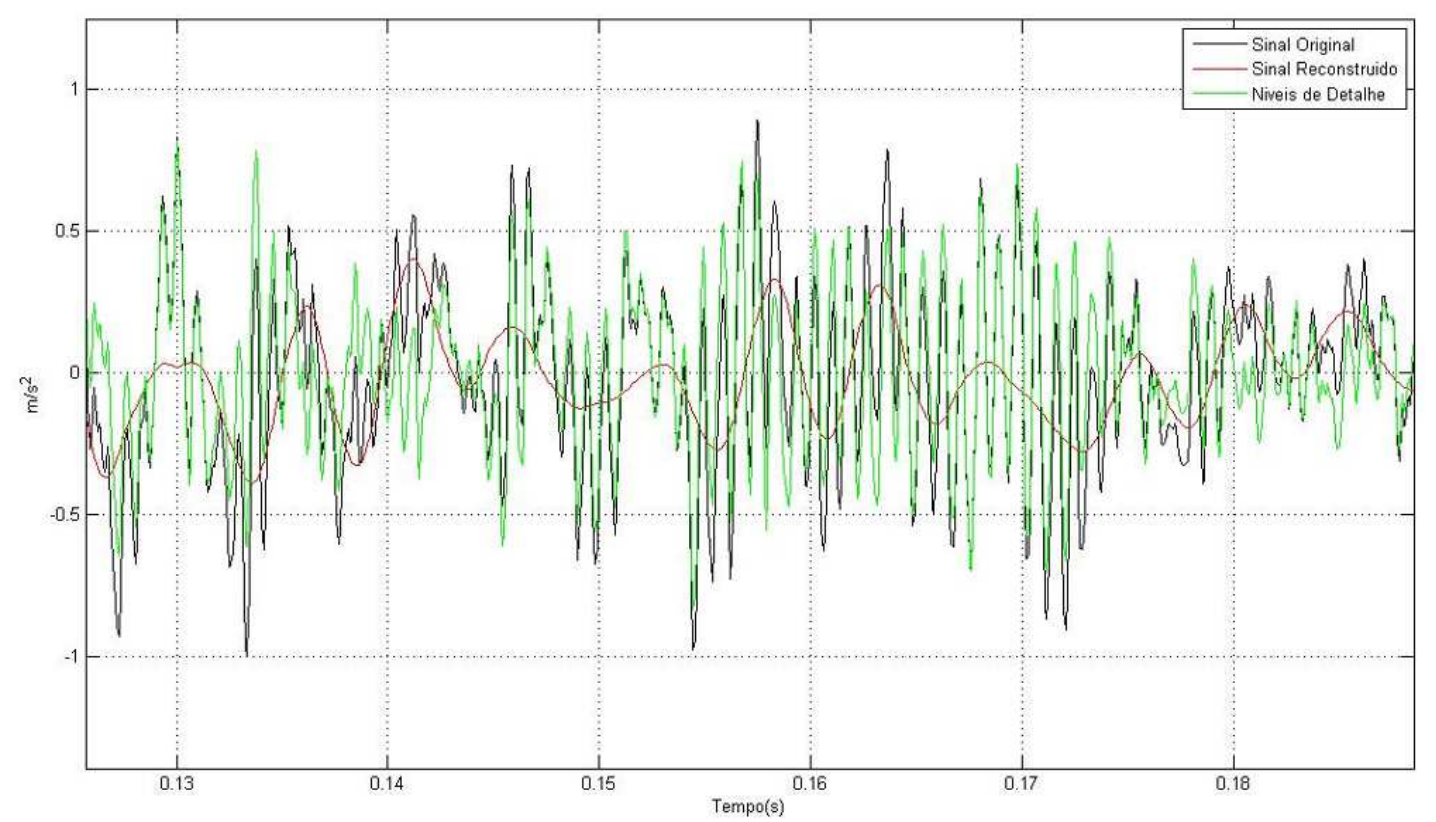

Figura 127 - Wavelet de Daubechies de ordem 7 e 5 níveis de detalhe.

Nota-se por este resultado que próximo a 150 e 170 milissegundos, o sinal reconstruído começou a perder algumas de suas características e começou a apresentar distorções. Portanto o aumento dos níveis de detalhe retirados do sinal original de vibração não ocasionou melhora no resultado.

Outra tentativa de melhorar o resultado obtido foi manter 4 níveis de detalhe mas aumentar a ordem da wavelet de Daubechies de 7 para 18, obtendo o resultado ilustrado na figura 128 abaixo.

Este resultado é muito parecido com o obtido na figura 125. 


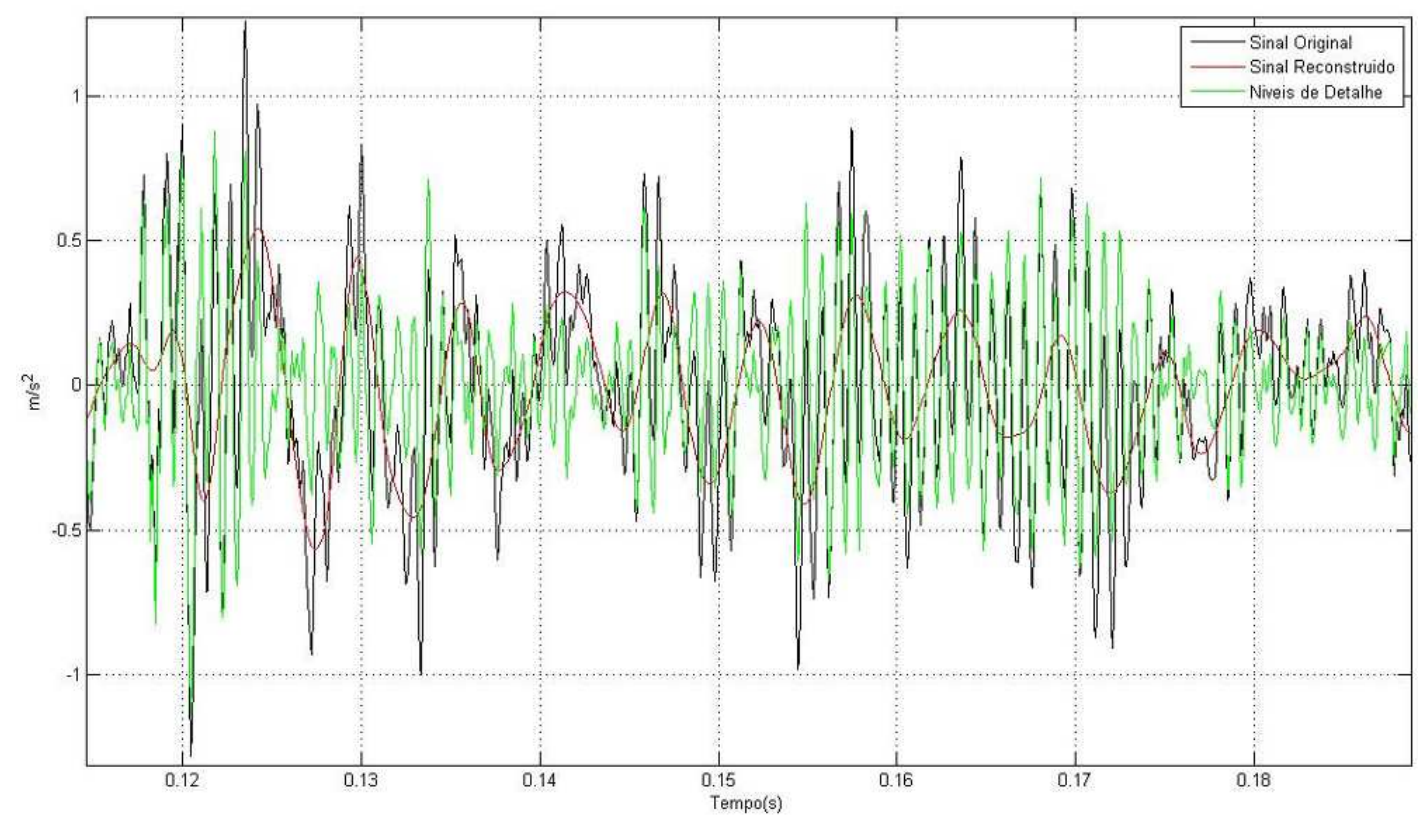

Figura 128 - Wavelet de Daubechies de ordem 18 e 4 níveis de detalhe.

Na figura 129 é ilustrado o espectrograma do sinal reconstruído.

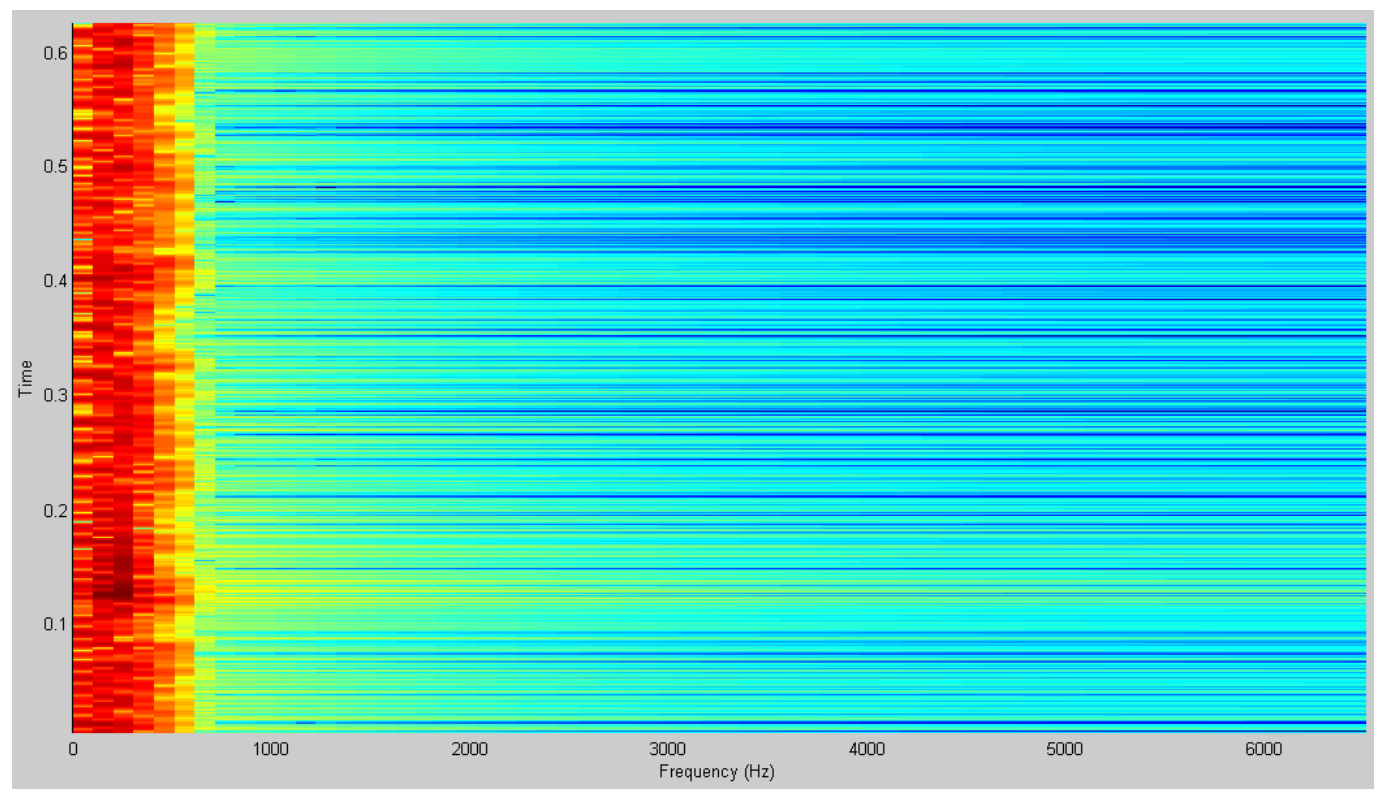

Figura 129 - Espectrograma do sinal reconstruído.

Nota-se que predominam as frequências em torno de $300 \mathrm{~Hz}$, indicando que grande parte dos ruídos de impacto foi retirada do sinal original. Este resultado é muito parecido com o obtido na figura 126.

Portanto, aumentando a ordem da wavelet não ocasionou uma melhora significativa no resultado obtido. 
Analisando o resultado obtido com a wavelet de Daubechies de ordem 7 e 4 níveis de detalhamento, observa-se que a grande maioria dos ruídos de impacto foi separada do sinal original de vibração.

$\mathrm{Na}$ figura 130, é ilustrado o espectro de freqüência do sinal reconstruído utilizando a wavelet de Daubechies de ordem 7 e 4 níveis de detalhamento. Nota-se que predominam as freqüências próximas a $300 \mathrm{~Hz}$, que representam as freqüências naturais de vibração transversal da cremalheira, indicando que grande parte dos ruídos de impacto foi retirada do sinal original de vibração.

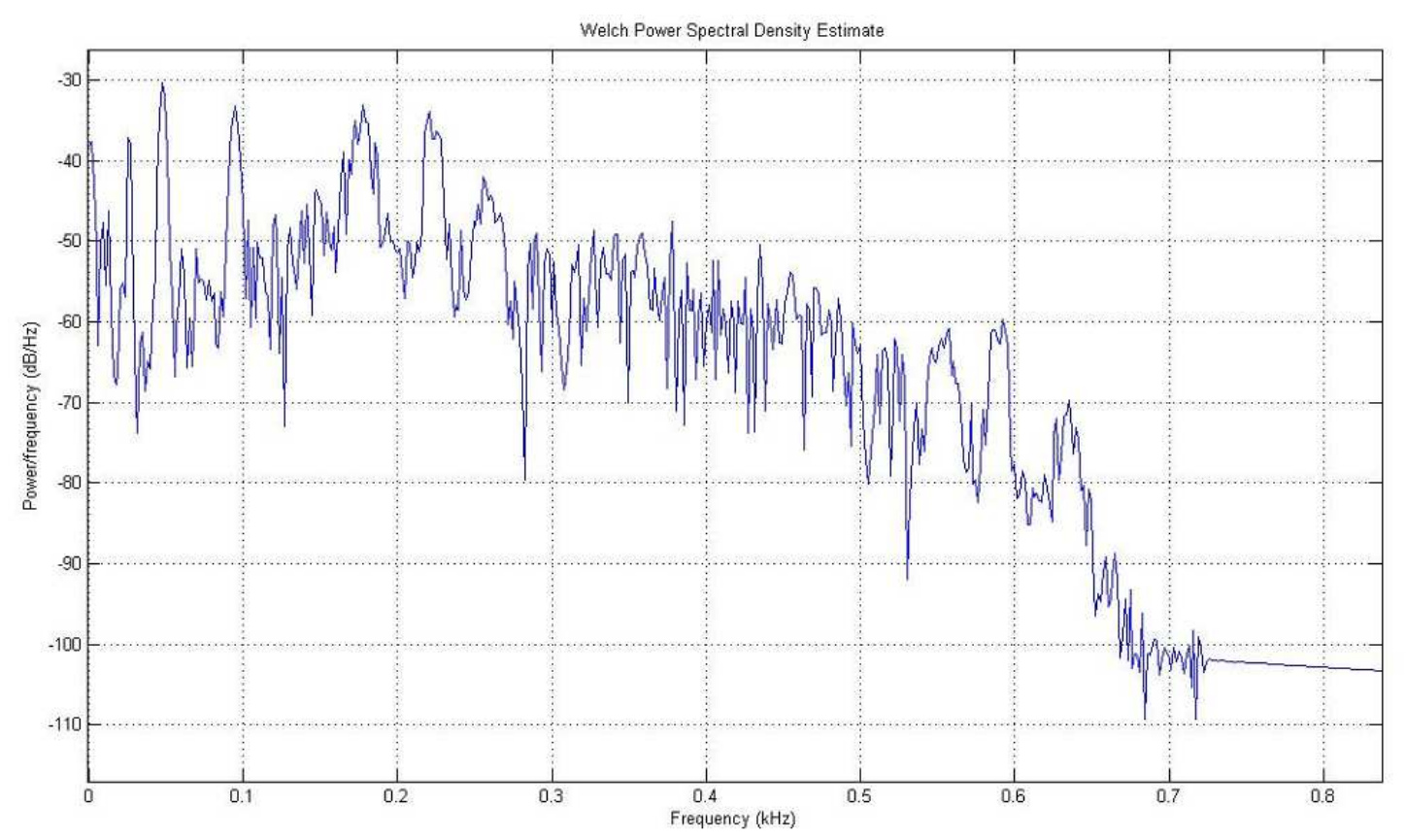

Figura 130 - Espectro de frequência do sinal reconstruído.

A figura 131 ilustra o espectrograma do sinal dos níveis de detalhes retirados do sinal original. Nota-se que predominam as freqüências na ordem de $\mathrm{kHz}$, as quais representam os ruídos de impacto dentro da caixa de direção. 


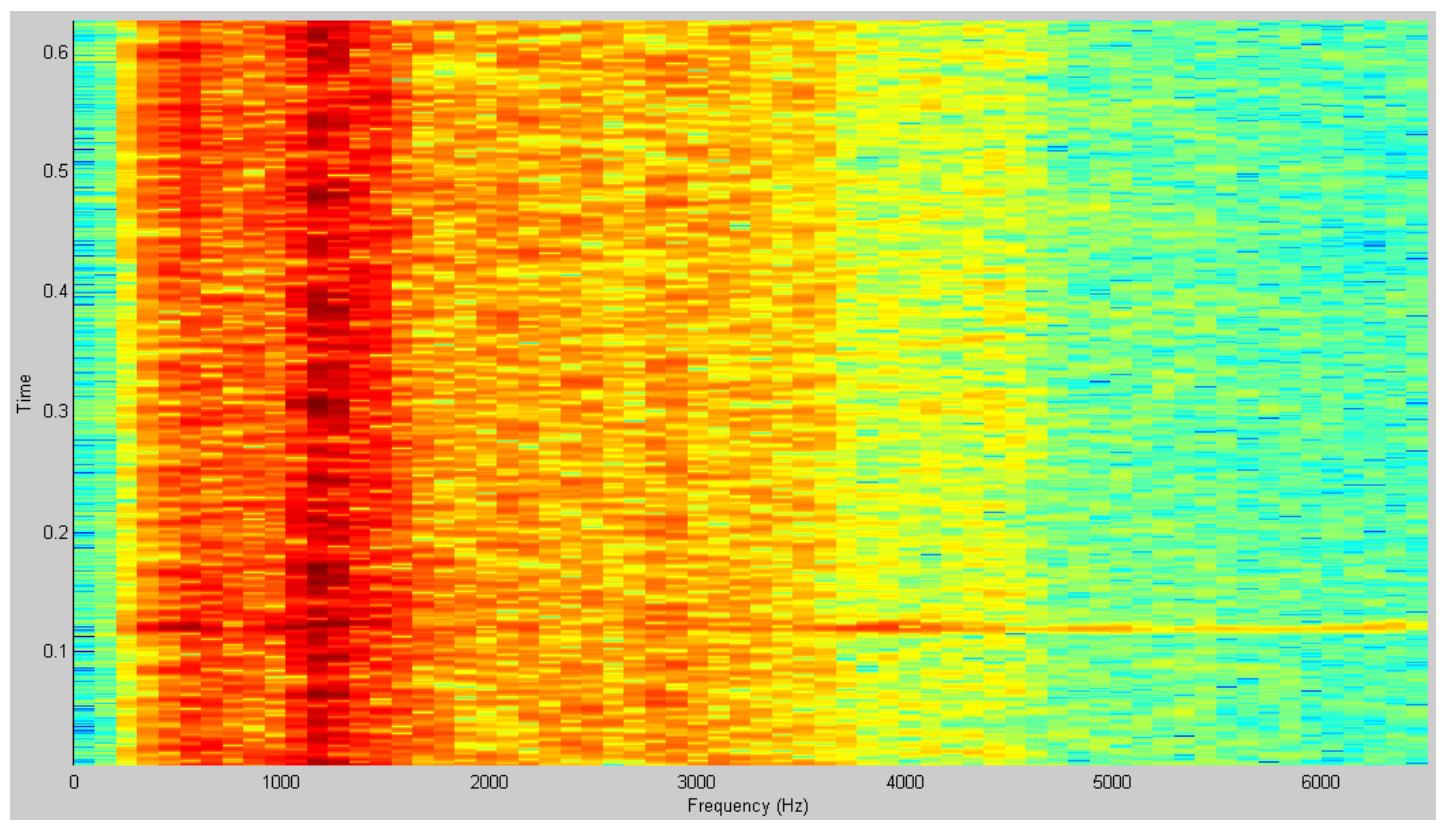

Figura 131 - Espectrograma do sinal dos ruídos de impacto.

Adotando o critério da janela de tempo e mantendo a pré-filtragem em 0,02 $\mathrm{m} / \mathrm{s}^{2}$, foi registrada a ocorrência de 456 impactos dentro da caixa de direção e a maior severidade de impacto medida foi de $0,558 \mathrm{~m} / \mathrm{s}^{2}$.

No gráfico superior da figura 132 são ilustrados, em vermelho, os pontos de impacto detectados por este procedimento e no gráfico inferior são ilustrados os valores da severidade medidos para estes pontos.
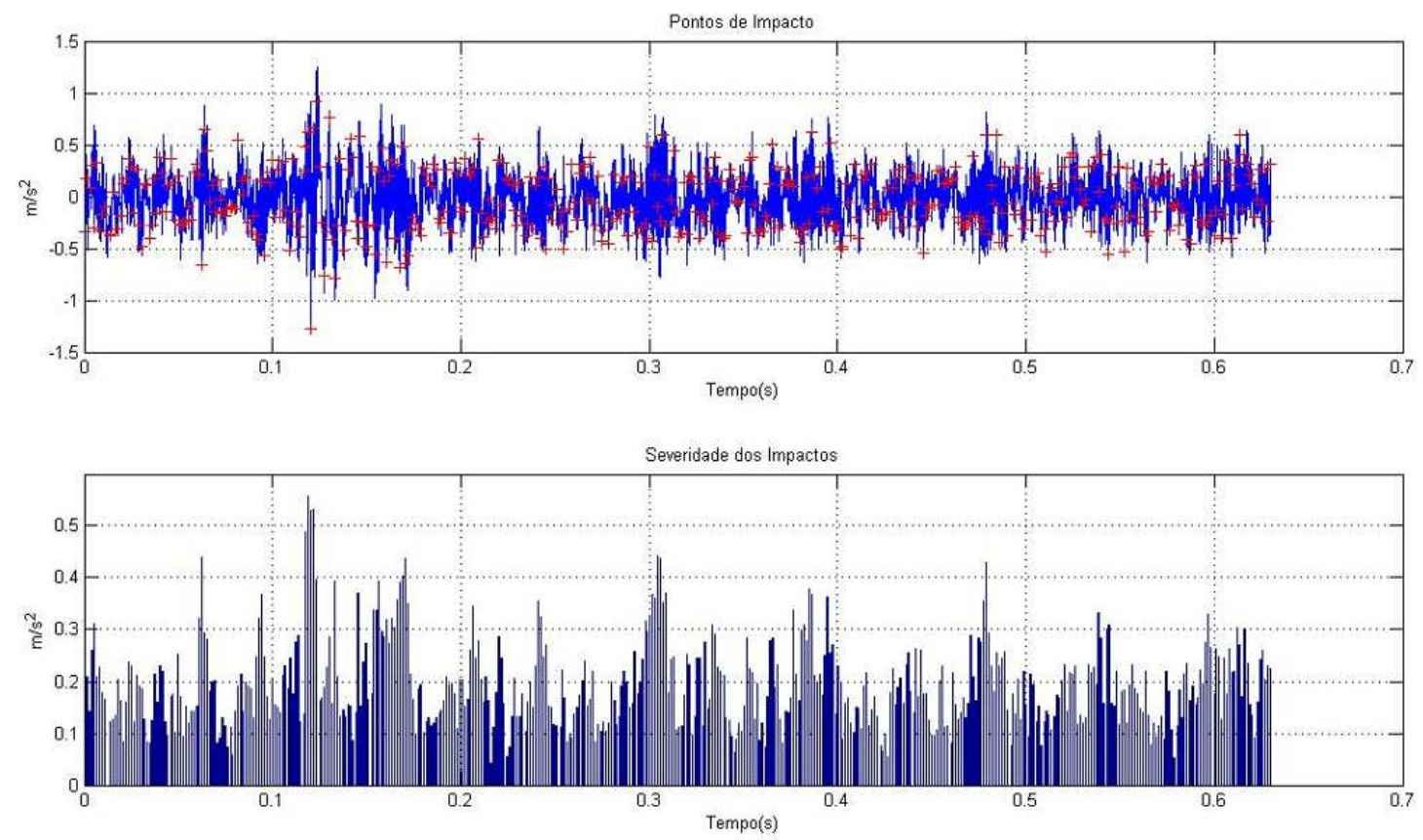

Figura 132 - Pontos de impacto e Severidade dos Impactos. 
Pelos resultados obtidos com esses três sinais analisados, conclui-se que para os sinais medidos em campo na rua de paralelepípedos, a wavelet de Daubechies de ordem 7 e 4 níveis de detalhamento já são suficientes para retirar a maior parte dos ruídos de impacto do sinal original de vibração.

\subsection{Análise dos Sinais de Campo com Wavelet de Newland}

Aplicando a wavelet de Newland sobre o mesmo sinal real ilustrado na figura 96 e retirando os 3 últimos níveis de detalhamento do sinal original, obteve-se o resultado ilustrado a seguir na figura 133.

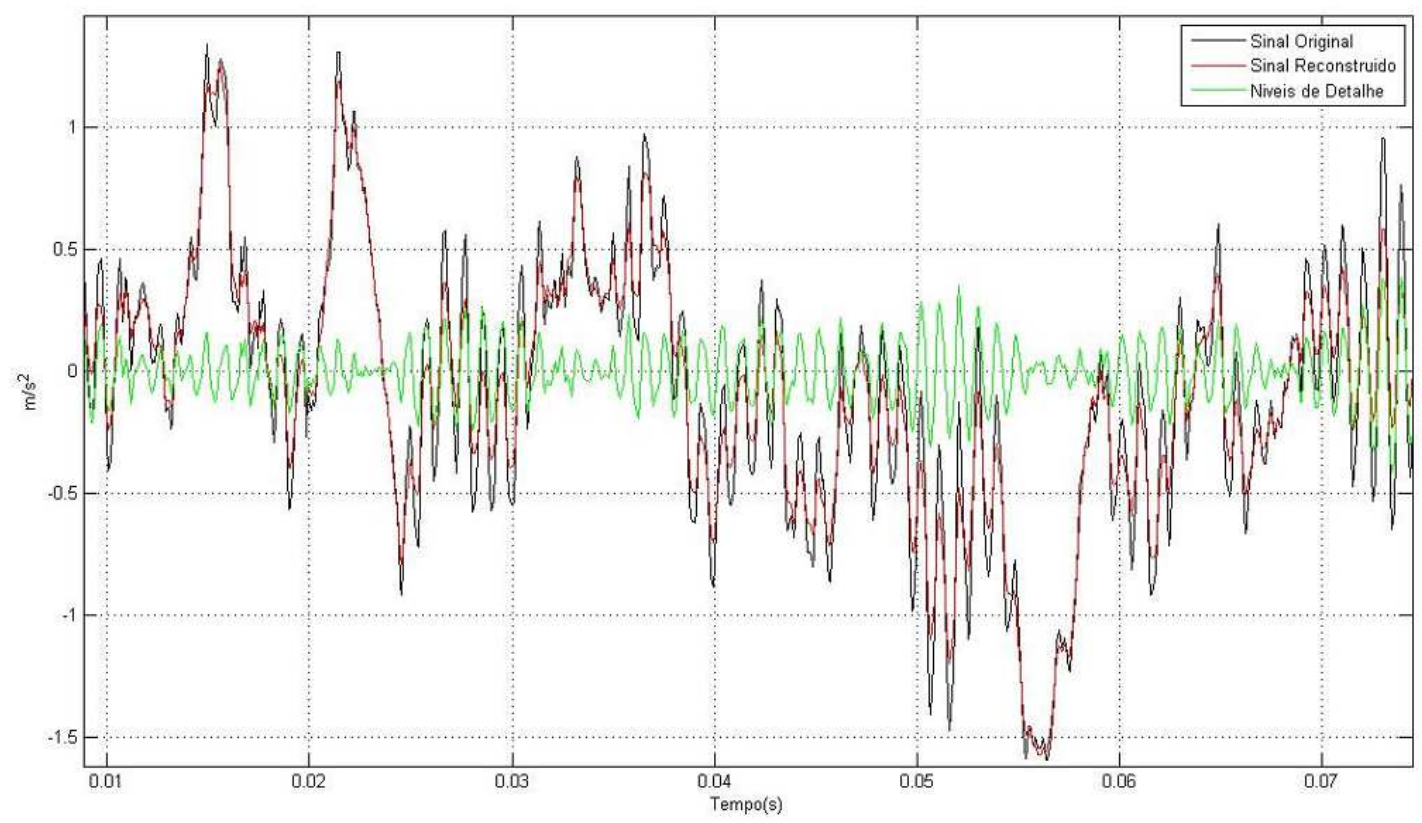

Figura 133 - Wavelet de Newland e 3 níveis de detalhe.

Por este resultado, nota-se que o sinal reconstruído apresenta ruídos de impacto. Isto pode ser comprovado através do espectrograma do sinal reconstruído e ilustrado na figura 134. 


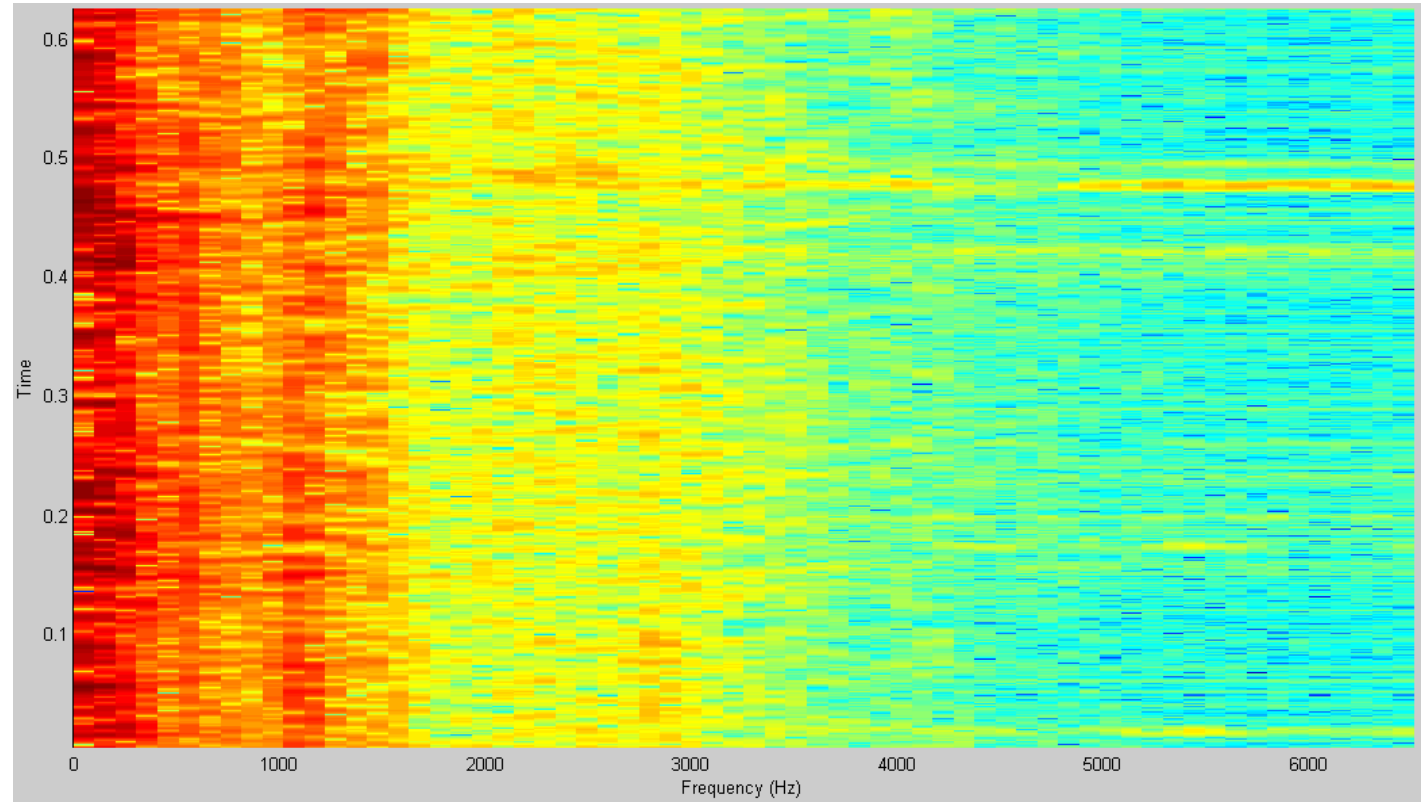

Figura 134 - Espectrograma do sinal reconstruído.

Para tentar melhorar este resultado, foram retirados os 4 últimos níveis de detalhe do sinal original e o resultado obtido encontra-se na figura 135.

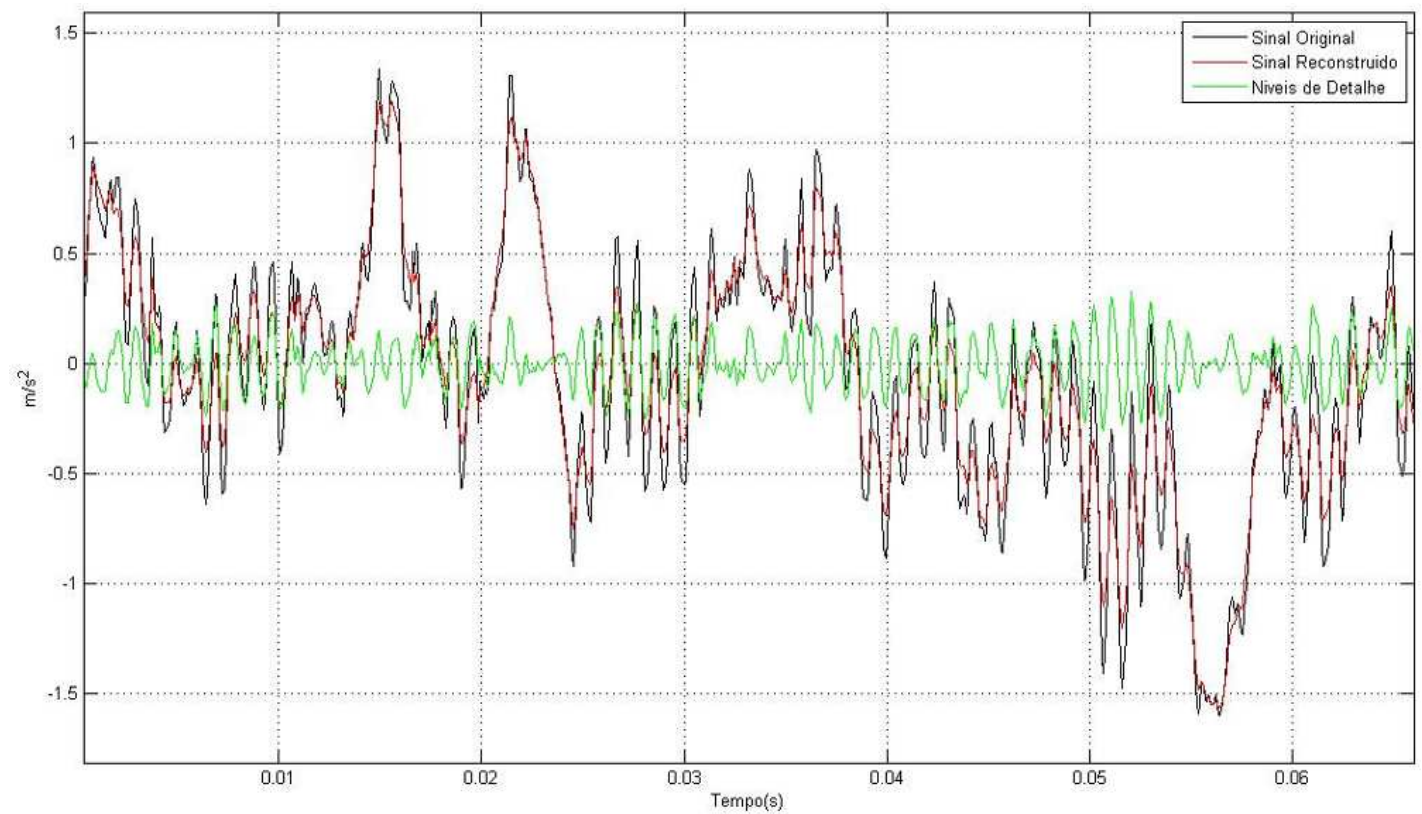

Figura 135 - Wavelet de Newland e 4 níveis de detalhe.

Na figura 136 é ilustrado o espectrograma do sinal reconstruído. 


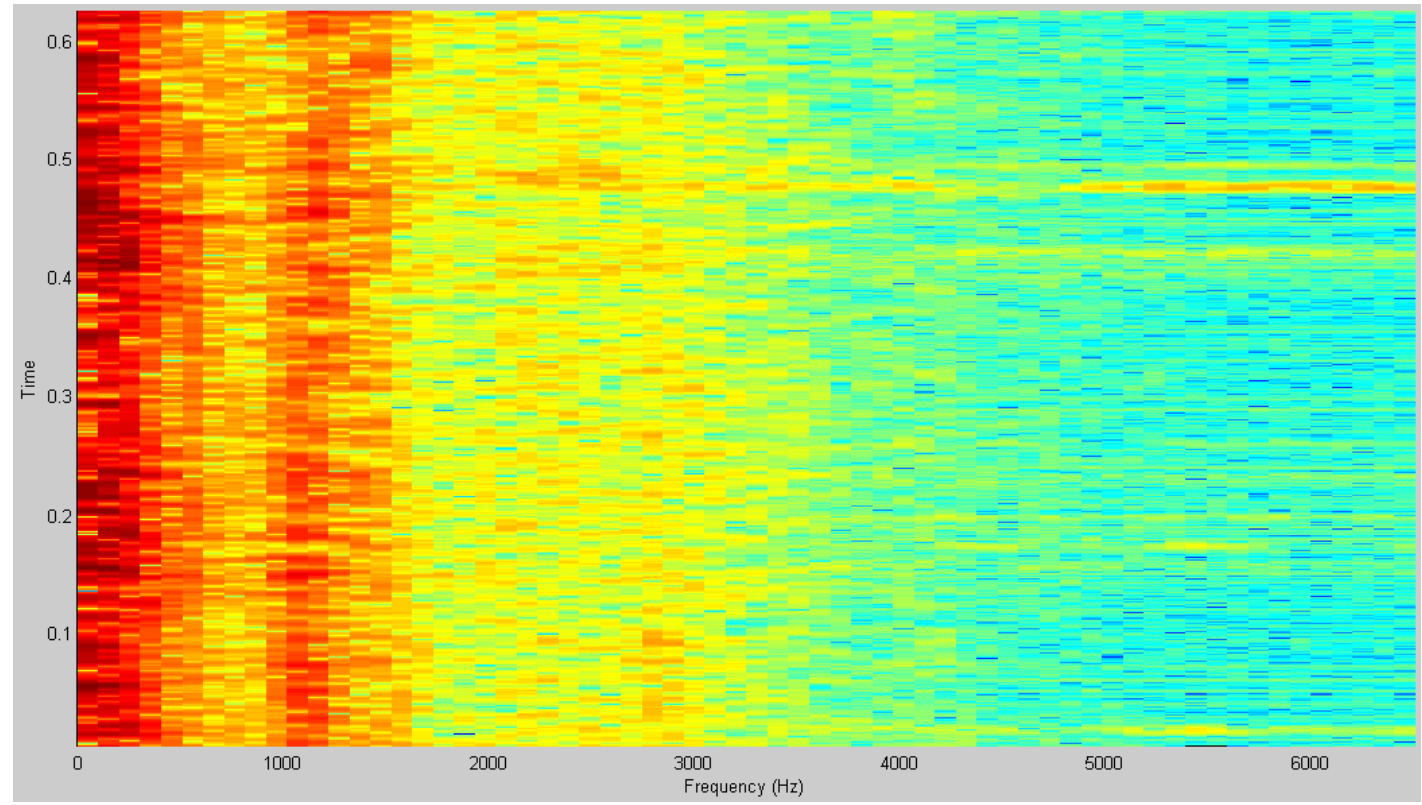

Figura 136 - Espectrograma do sinal reconstruído.

Por este resultado, nota-se que no sinal reconstruído aparecem frequências na ordem de grandeza de $\mathrm{kHz}$, indicando que ainda aparecem ruídos de impacto neste sinal.

Para tentar melhorar este resultado, foram retirados os 7 últimos níveis de detalhe do sinal original e o resultado obtido encontra-se na figura 137 a seguir.

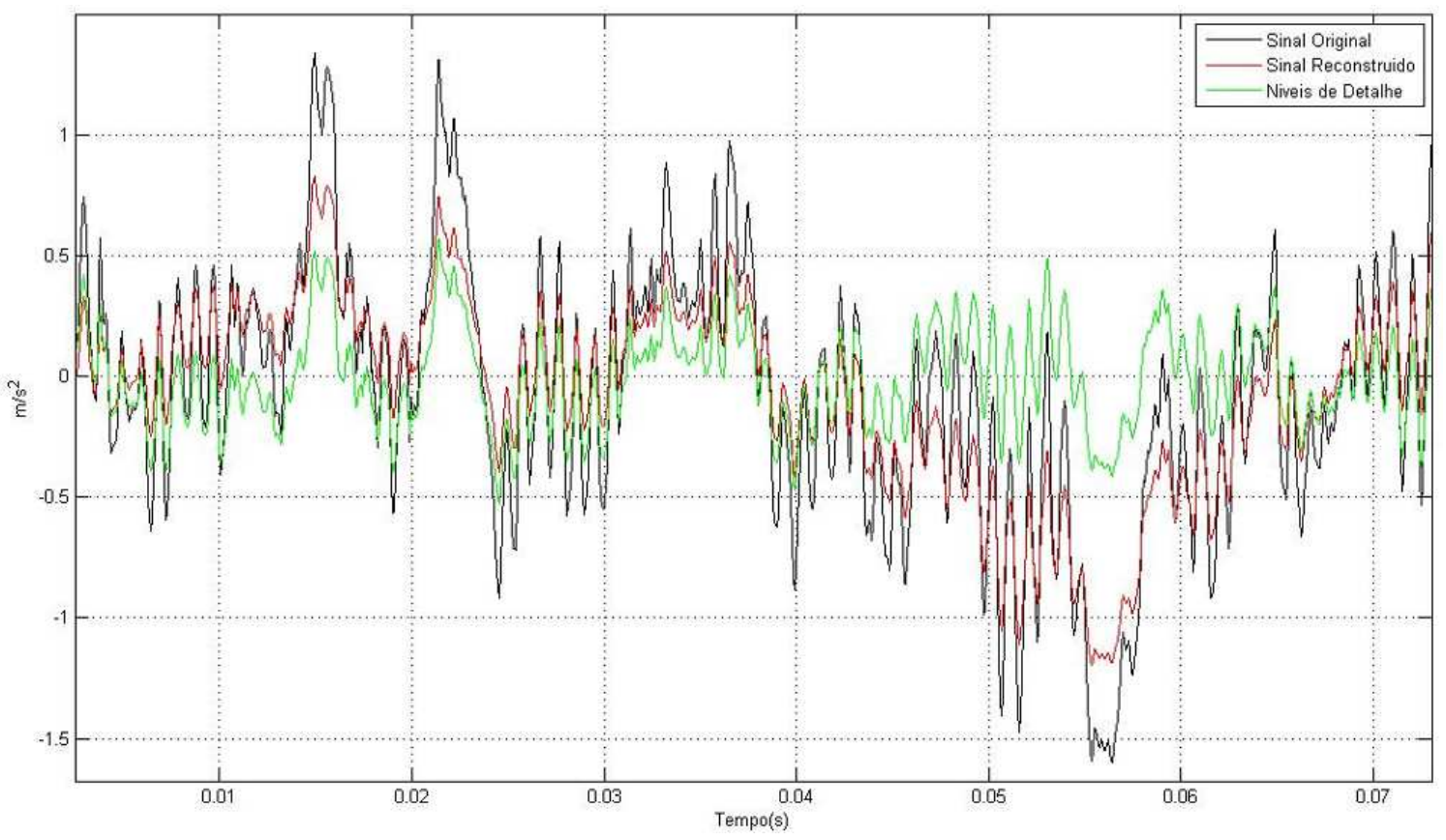

Figura 137 - Wavelet de Newland e 7 níveis de detalhe. 
Por este resultado, nota-se que o sinal reconstruído além de apresentar perdas de suas características, ainda apresenta ruídos de impacto na sua constituição. Isto pode ser observado através do espectrograma do sinal reconstruído e ilustrado na figura 138.

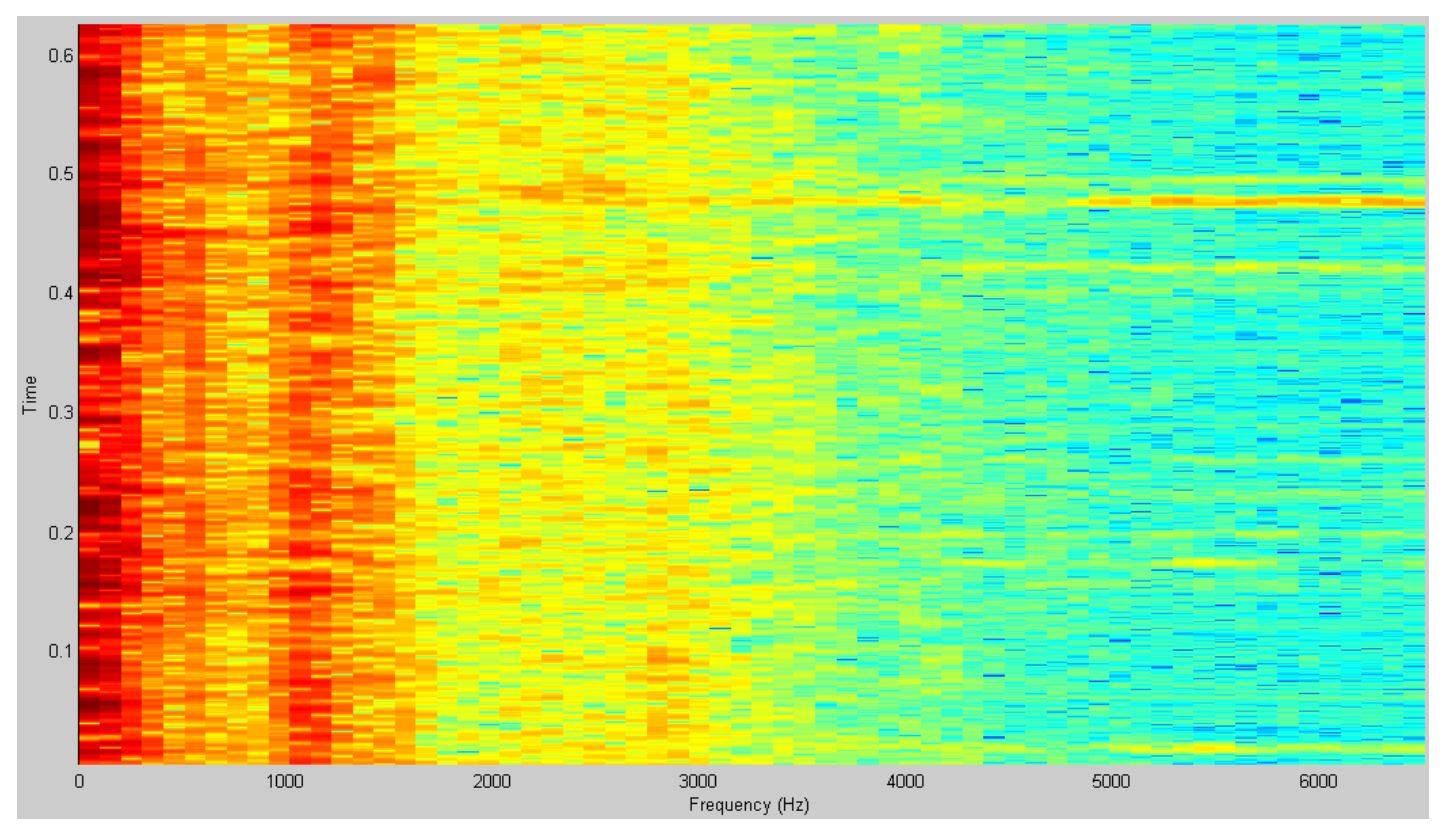

Figura 138 - Espectrograma do sinal reconstruído.

Portanto a wavelet de Newland não possui boas propriedades para separar os ruídos de impacto do sinal de vibração real e assim esta wavelet não foi utilizada para detecção dos impactos nos sinais medidos em campo.

\subsection{Análise dos Sinais de Campo em Estrada com Wavelet de Daubechies}

Considere o sinal real, medido em campo com o veículo em movimento na rodovia Ayrton Senna, ilustrado na figura 139. Este sinal foi dividido em cinco trechos para uma melhor análise. 


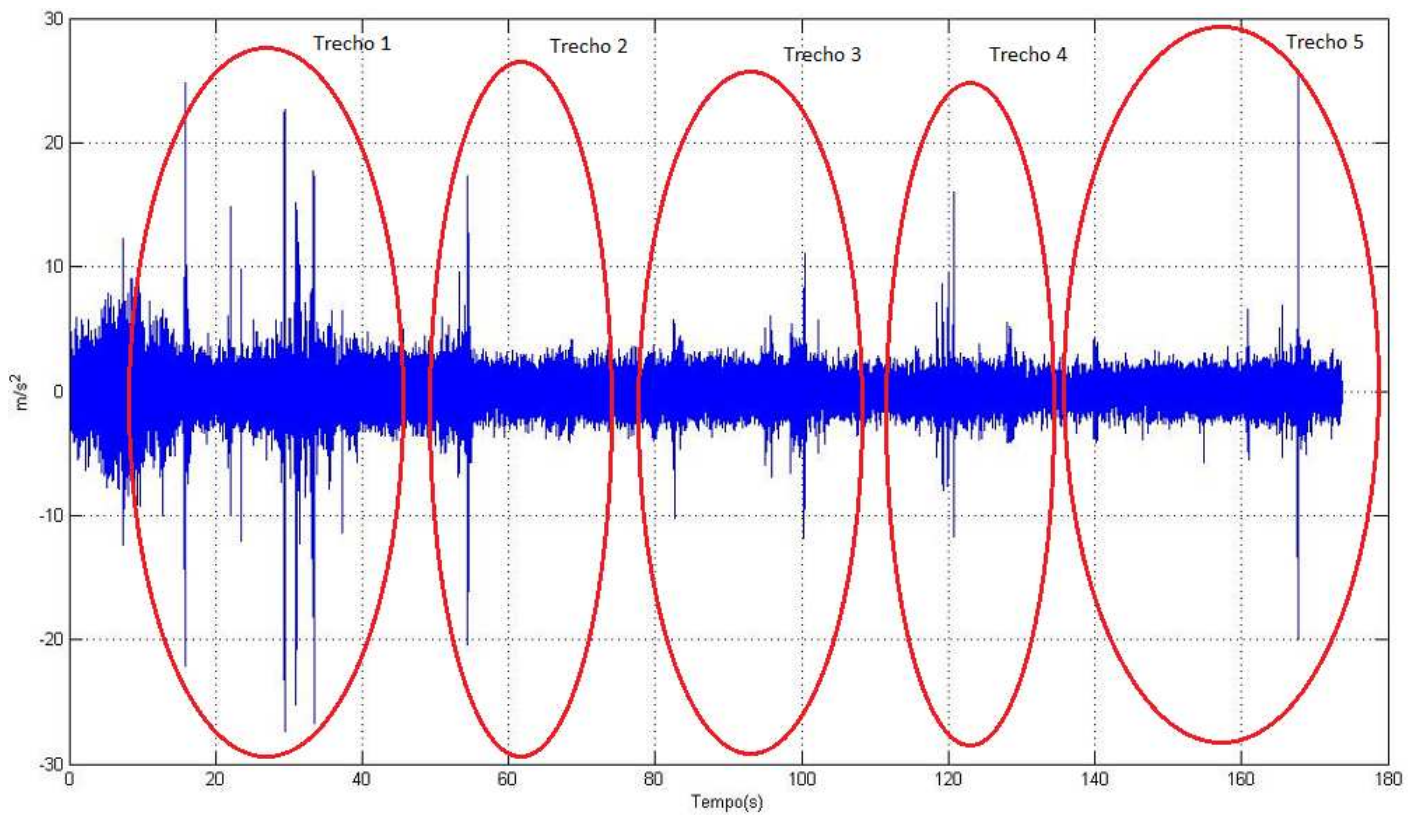

Figura 139 - Sinal de vibração real medido na rodovia Ayrton Senna.

O trecho 1 do sinal acima está ilustrado na figura 140 abaixo.

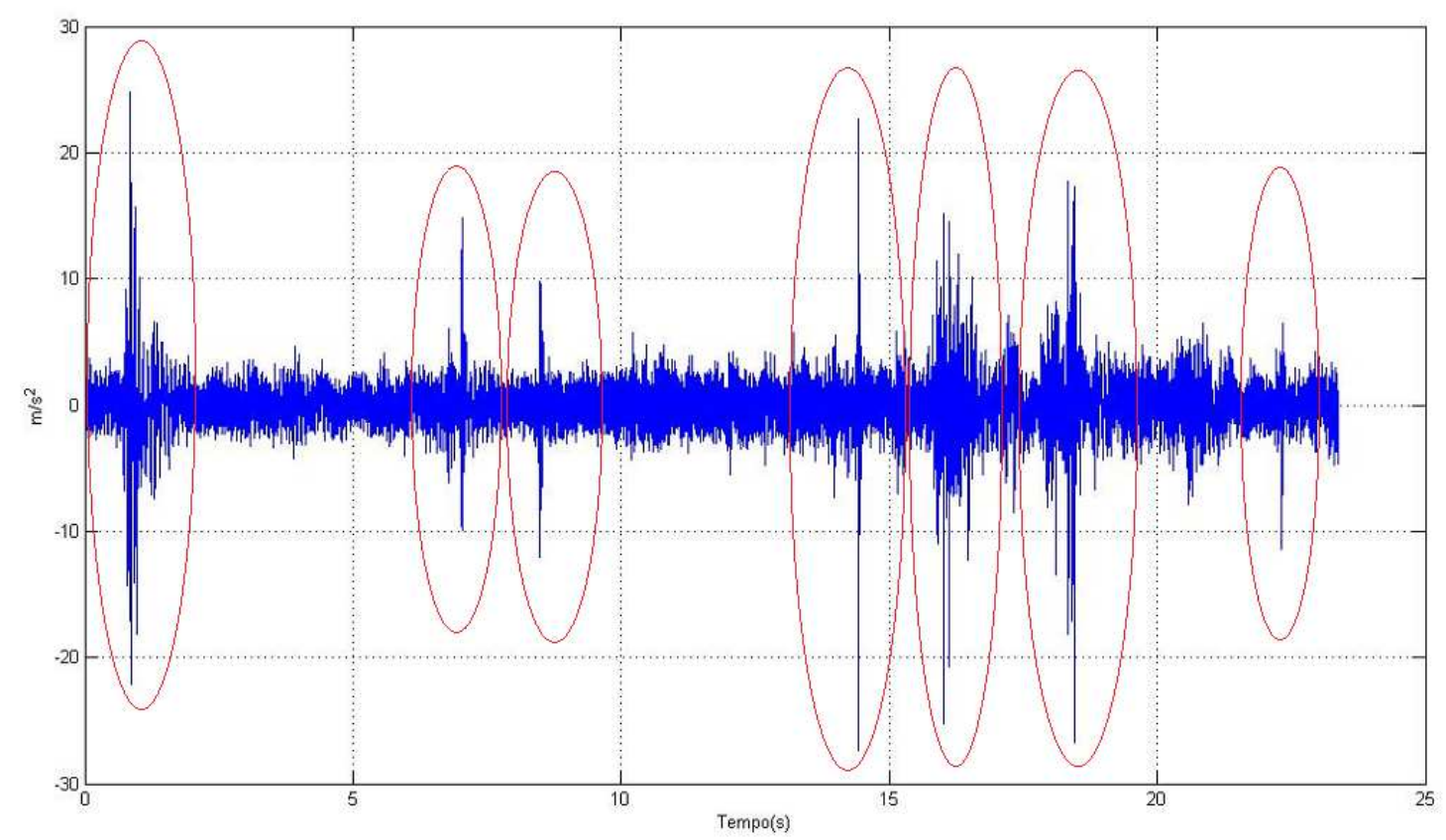

Figura 140 - Trecho 1 do sinal.

Visualmente, pode-se identificar neste sinal a ocorrência de impactos próximos a $0,8 \mathrm{~s}, 7,0 \mathrm{~s}, 8,5 \mathrm{~s}, 14,5 \mathrm{~s}, 16,0 \mathrm{~s}, 18,5 \mathrm{~s}$ e $22,5 \mathrm{~s}$ segundos.

A figura 141 ilustra espectrograma do sinal original. 


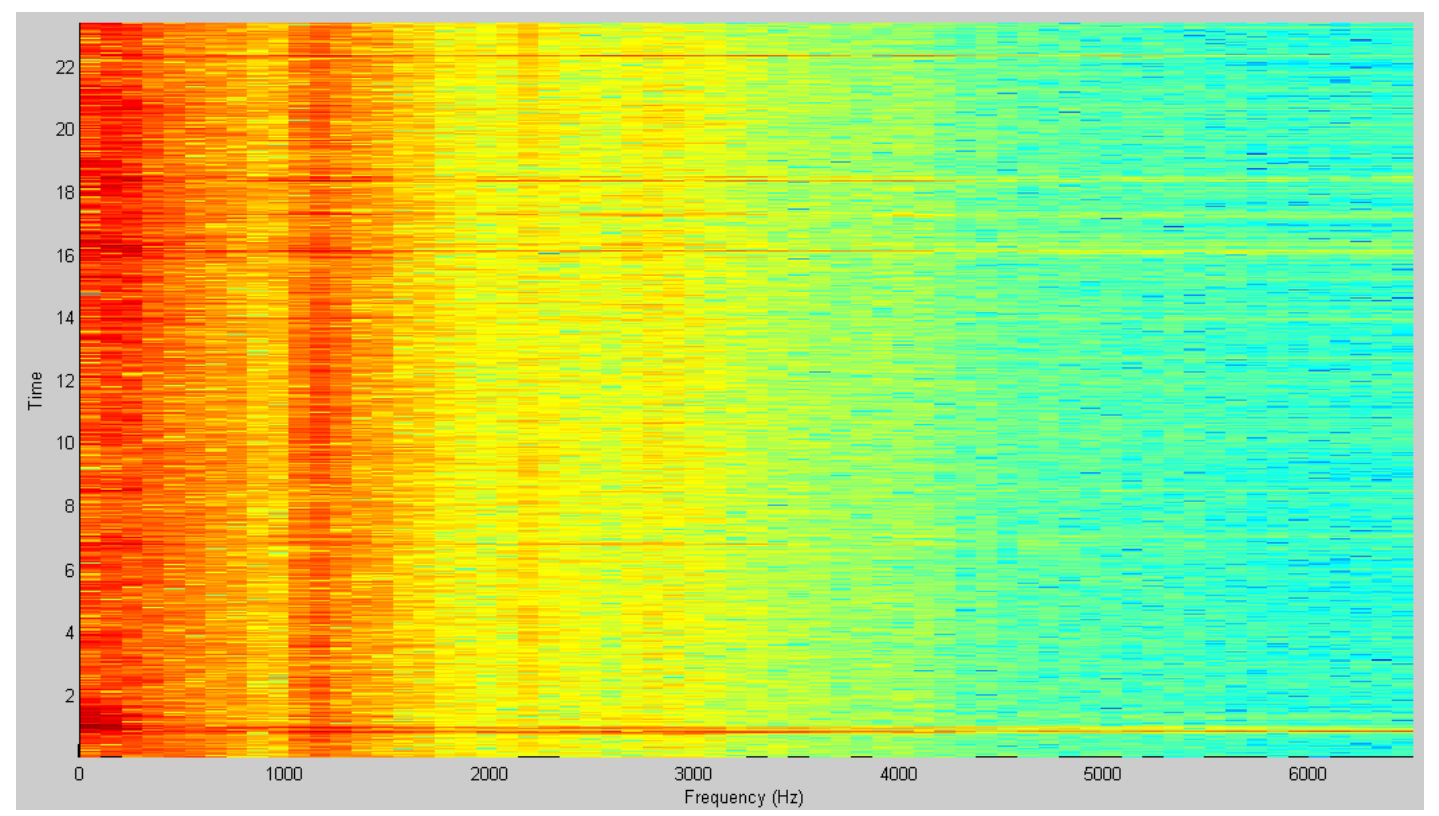

Figura 141 - Espectrograma do sinal original.

Por este resultado, nota-se a presença de frequências na ordem de grandeza de $\mathrm{kHz}$, indicando a presença de ruídos de impacto provenientes dos impactos da cremalheira contra o pinhão e bucha guia.

Observa-se também, que os impactos excitam diversas faixas de freqüência próximos aos tempos citados acima.

Adotando como parâmetro de entrada os resultados obtidos com os sinais reais na pista com paralelepípedos, foi aplicado a wavelet de Daubechies de ordem 7 e retirado os 4 últimos níveis de detalhe do sinal original, obtendo-se o resultado ilustrado na figura 142. 


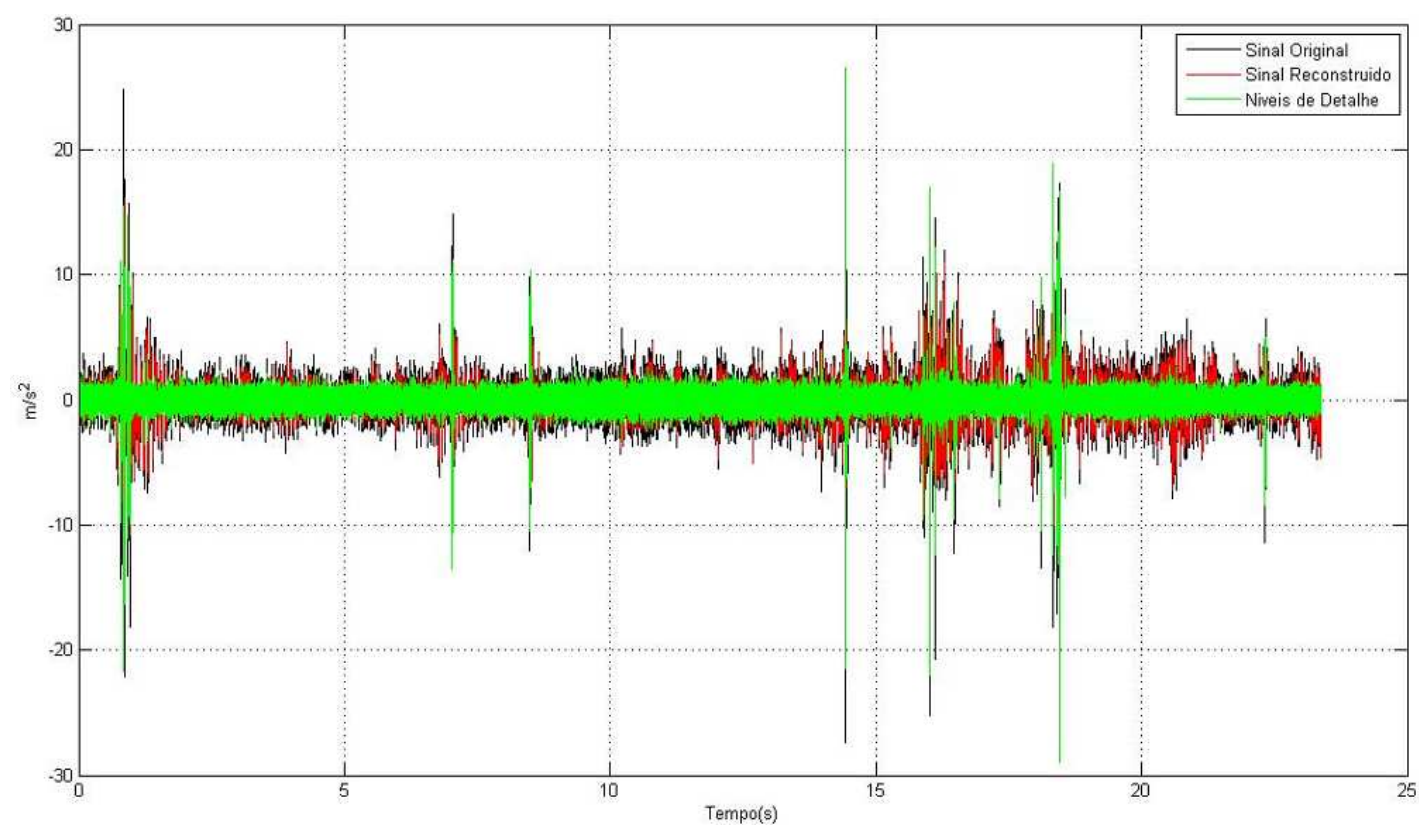

Figura 142 - Wavelet de Daubechies de ordem 7 e 4 níveis de detalhe.

A figura 143 ilustra zoom sobre o trecho inicial para melhor visualização.

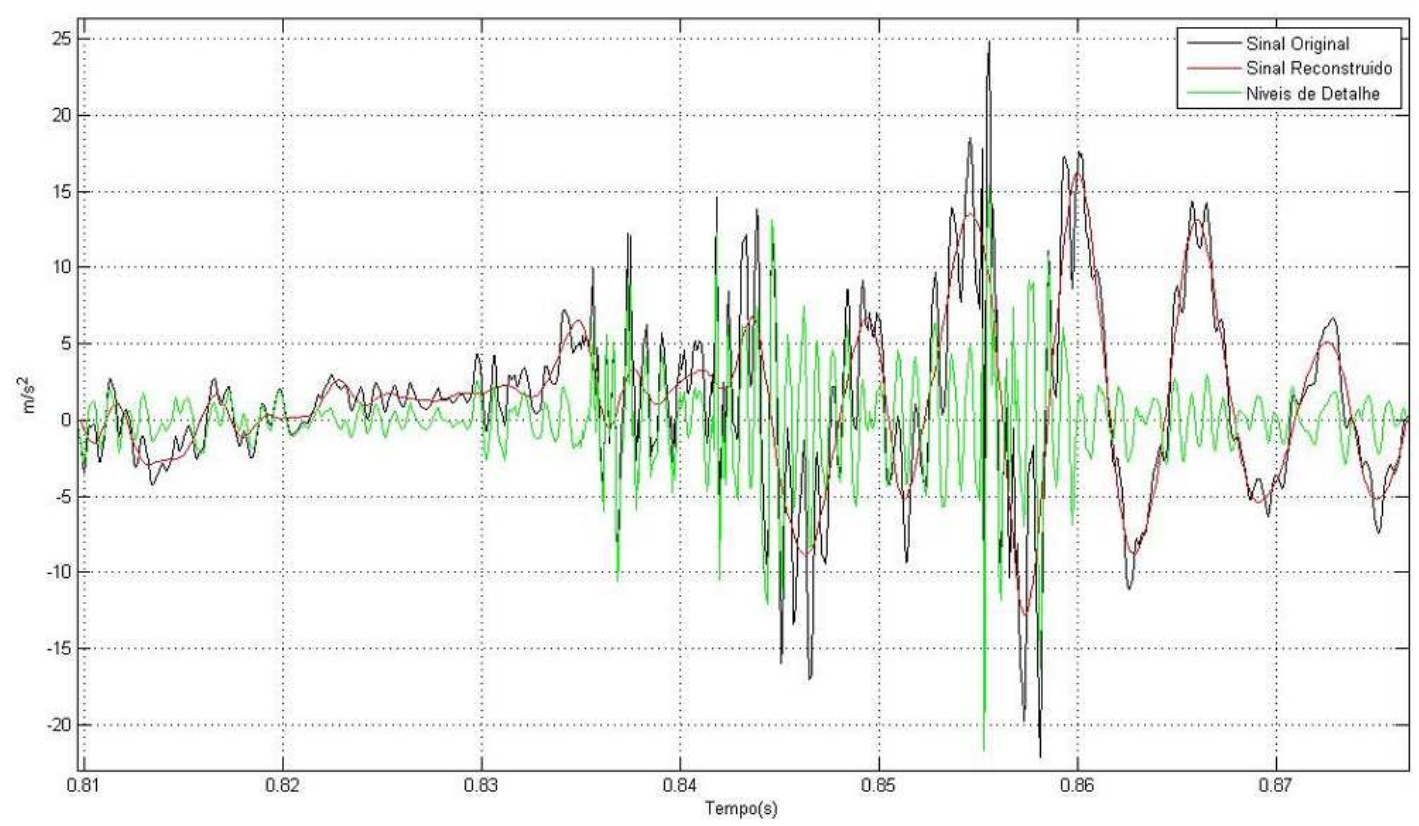

Figura 143 - Zoom sobre trecho inicial.

A figura 144 ilustra o espectro de frequência do sinal reconstruído. 


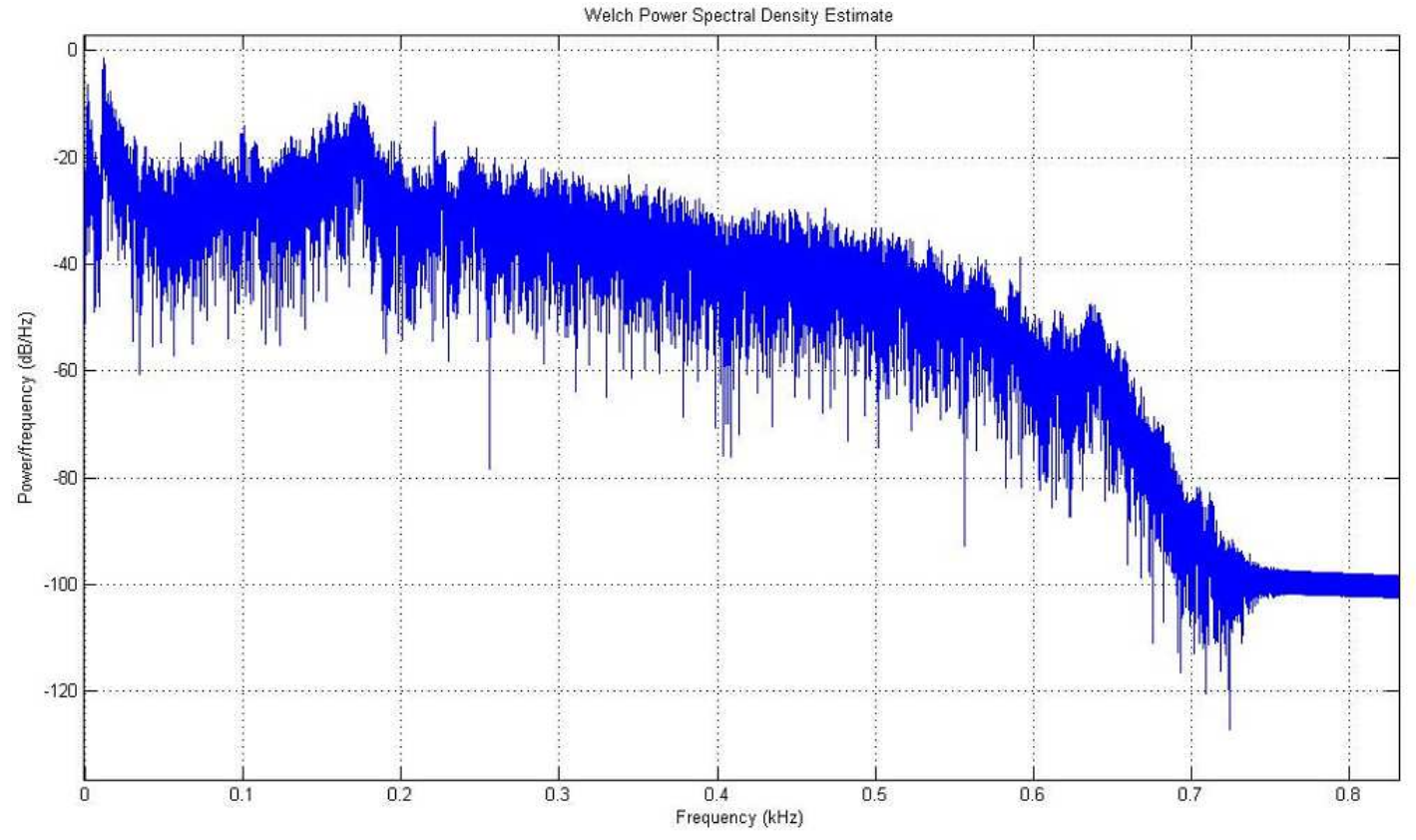

Figura 144 - Espectro de frequência do sinal reconstruído.

Nota-se que predominam as freqüências próximas a $150 \mathrm{~Hz}$, a qual representa a freqüência natural de vibração transversal da cremalheira, indicando que grande parte dos ruídos de impacto foi retirada do sinal original de vibração.

A figura 145 abaixo ilustra o espectrograma do sinal reconstruído.

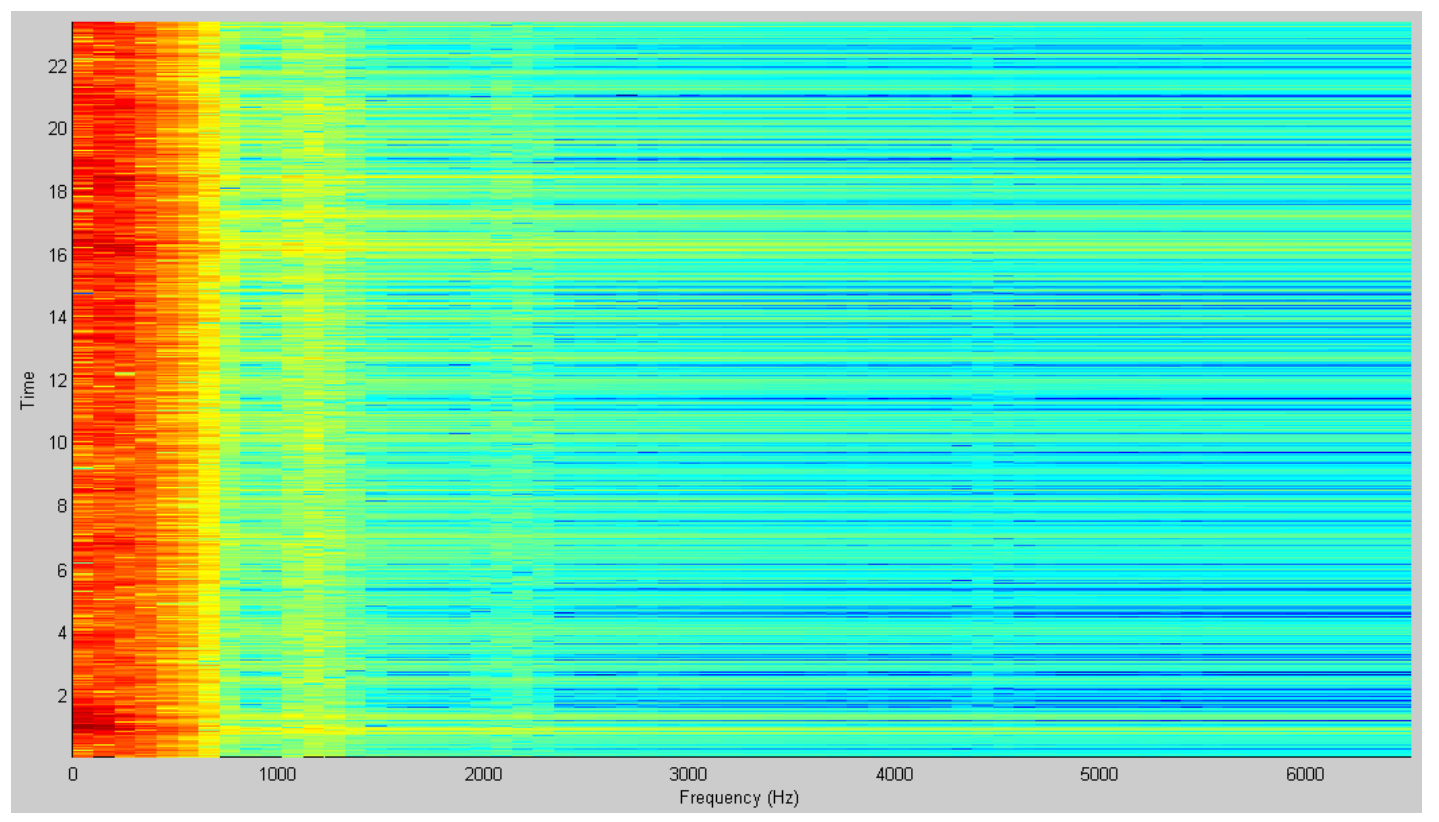

Figura 145 - Espectrograma do sinal reconstruído.

Nota-se que a maior parte das frequências na ordem de $\mathrm{kHz}$ foi retirada do sinal original mas ainda aparecem ruídos de impacto. 
A figura 146 ilustra o espectro de frequências do sinal dos ruídos de impacto.

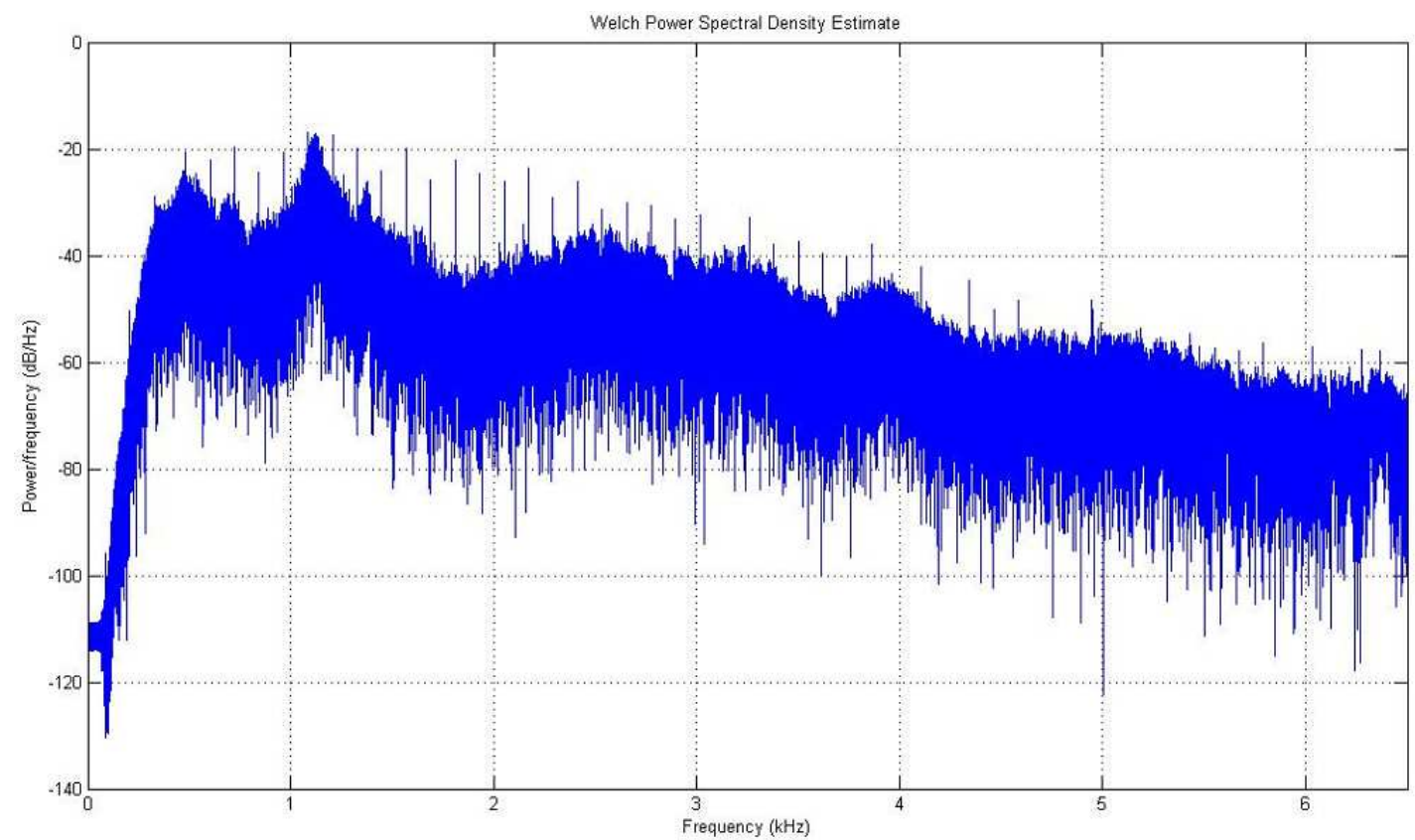

Figura 146 - Espectro de frequências do sinal dos ruídos de impacto.

Por este resultado, nota-se que predominam as frequências na ordem de grandeza de $\mathrm{kHz}$, as quais se referem aos impactos que ocorrem entre a cremalheira contra o pinhão e a bucha guia.

Para quantificar a freqüência de ocorrência de impactos, foi realizada uma pré-filtragem no sinal original que eliminou os dados cujo módulo eram menores do que $3 \mathrm{~m} / \mathrm{s}^{2}$ e foi criada uma janela com largura de 1,3 ms que percorreu todo o sinal original. Verificou-se se o módulo do sinal original a cada janela de 1,3 ms ultrapassou, em algum momento, em 20 vezes o valor em módulo do sinal reconstruído sem os ruídos de impacto. Caso afirmativo, foi considerada a ocorrência de uma unidade de impacto. Para quantificar a severidade deste impacto, foi calculado o valor R.M.S do sinal de ruídos de impacto nessa janela.

Adotando este procedimento, foi registrada a ocorrência de 44 impactos dentro da caixa de direção e a maior severidade de impacto medida foi de 13,271 $\mathrm{m} / \mathrm{s}^{2}$.

No gráfico superior da figura 147 são ilustrados, em vermelho, os pontos de impacto detectados por este procedimento e no gráfico inferior são ilustrados os valores da severidade medidos para estes pontos. 

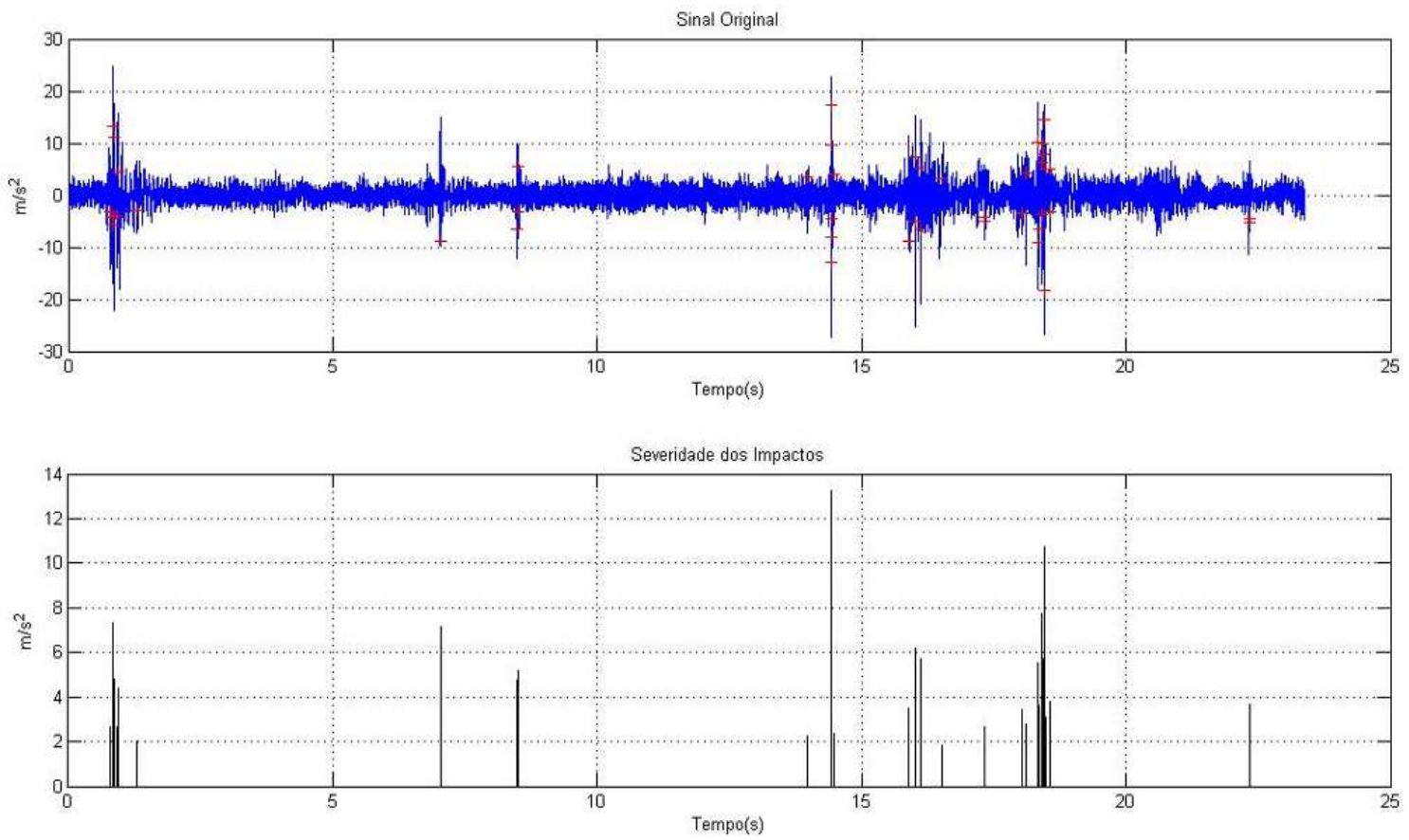

Figura 147 - Pontos de Impacto e Severidade dos Impactos.

Por este resultado, nota-se que o critério detectou as 7 regiões de impacto neste sinal.

O trecho 2 do sinal acima está ilustrado na figura 148 abaixo.

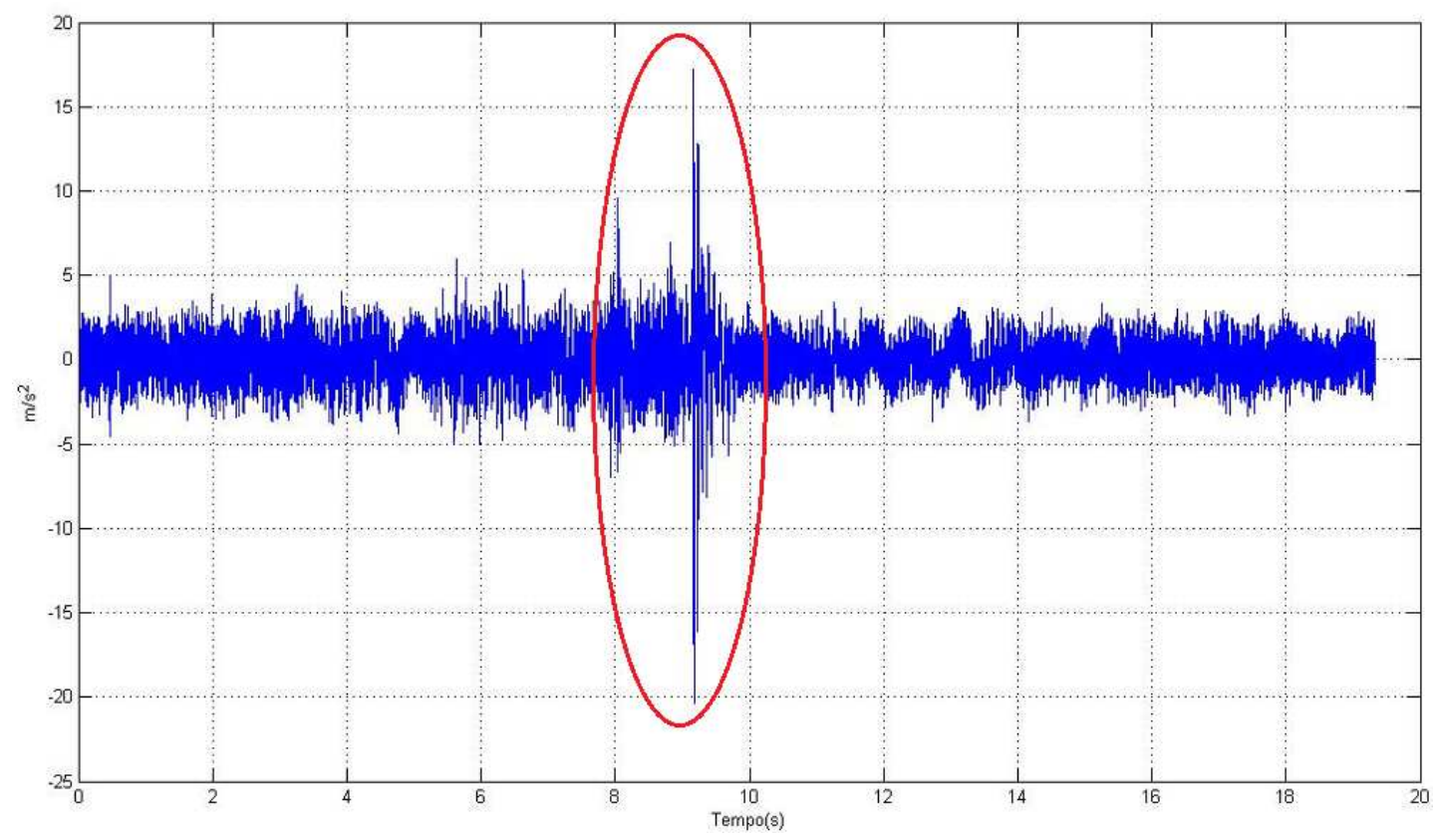

Figura 148 - Trecho 2 do sinal.

Visualmente, pode-se identificar neste sinal a ocorrência de impacto próximo a 9 segundos. 
Observa-se também que próximo ao tempo citado acima, os impactos excitam diversas faixas de frequência.

A figura 149 ilustra espectrograma do sinal original.

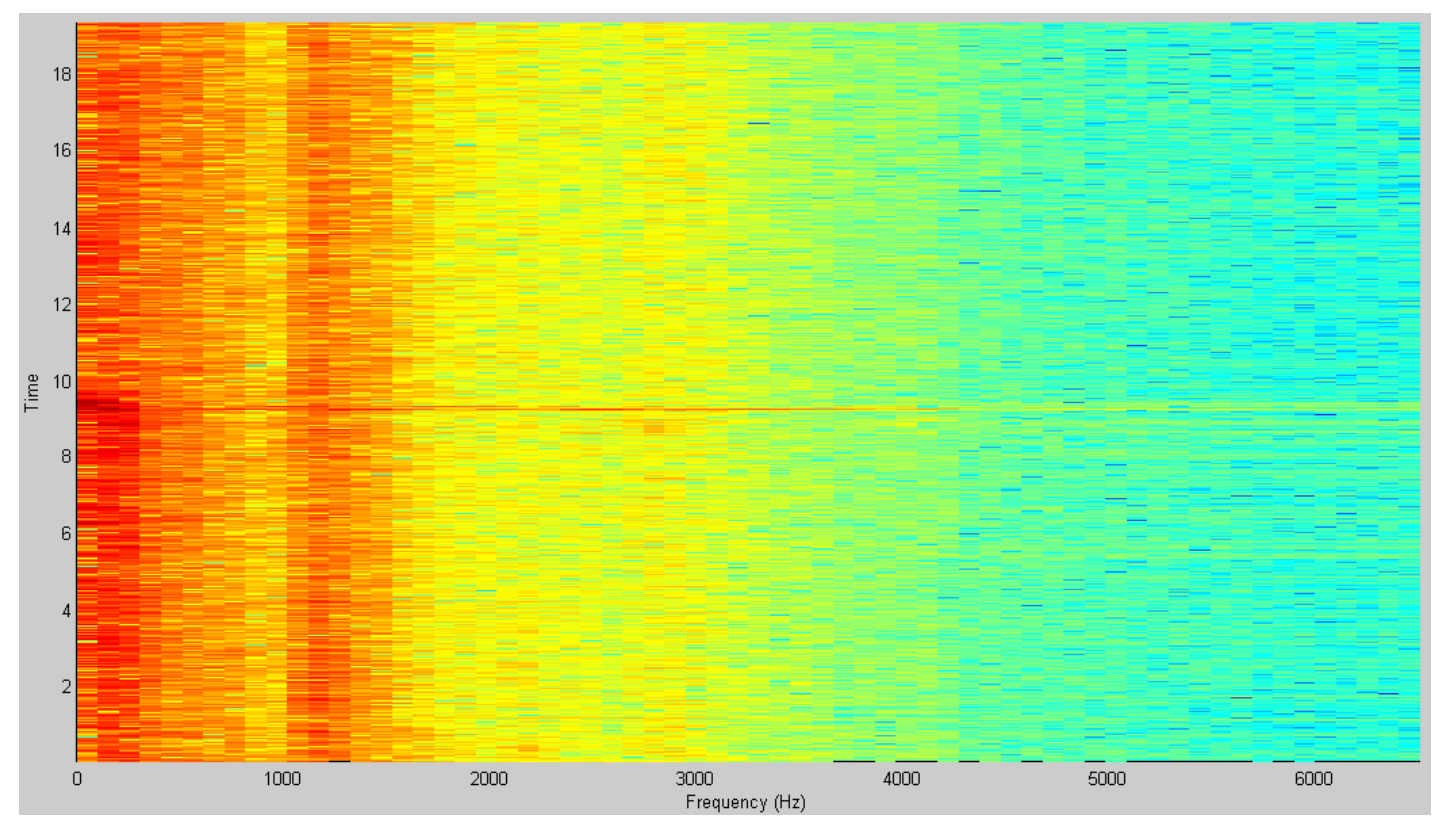

Figura 149 - Espectrograma do sinal original.

Por este resultado, nota-se a presença de frequências na ordem de grandeza de $\mathrm{kHz}$, indicando a presença de ruídos de impacto provenientes dos impactos da cremalheira contra o pinhão e bucha guia.

Adotando como parâmetro de entrada os resultados obtidos com os sinais reais na pista com paralelepípedos, foi aplicado a wavelet de Daubechies de ordem 7 e retirado os 4 últimos níveis de detalhe do sinal original, obtendo o resultado ilustrado na figura 150. 


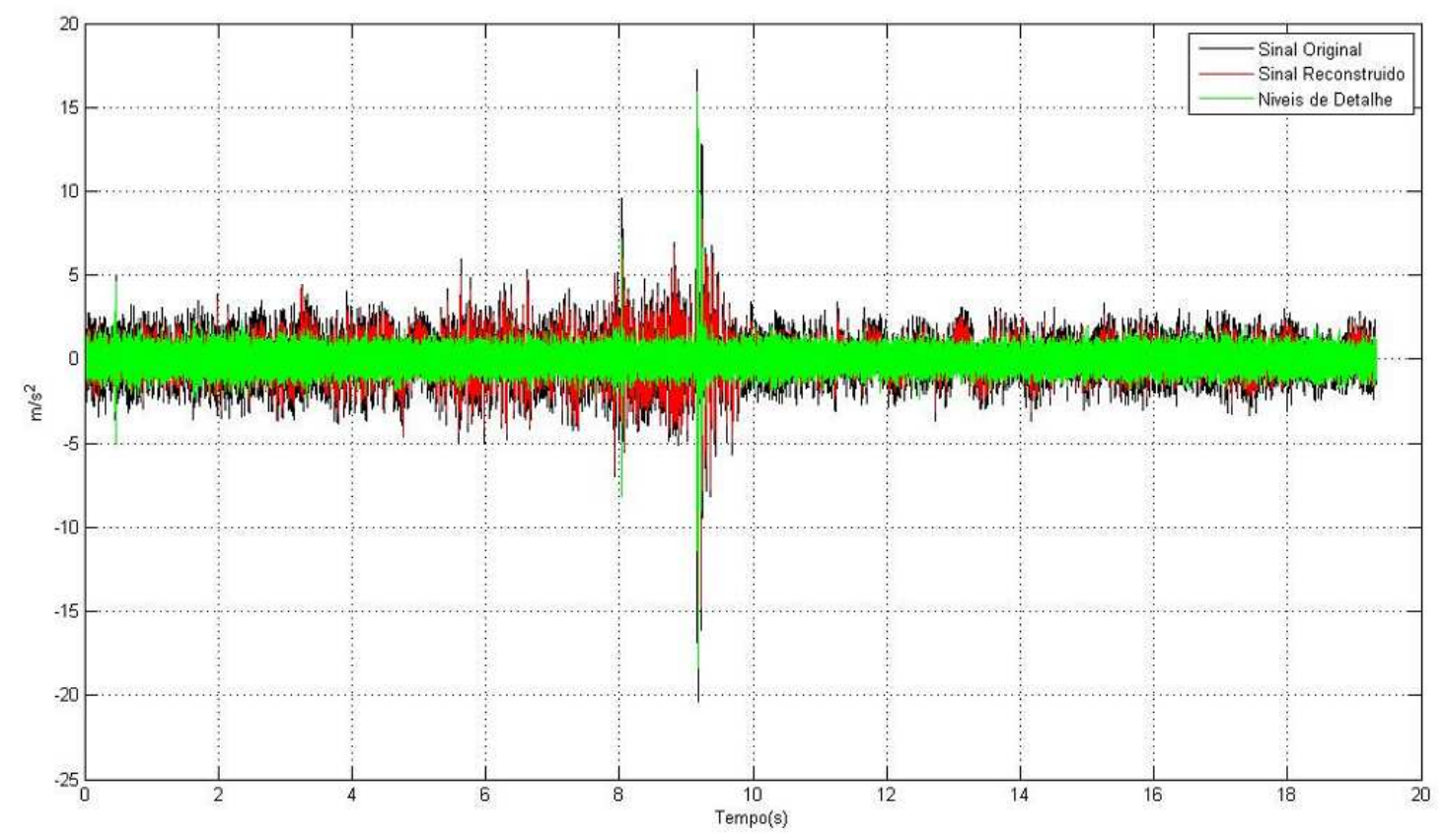

Figura 150 - Wavelet de Daubechies de ordem 7 e 4 níveis de detalhe.

A figura 151 ilustra zoom sobre a região de impacto para melhor visualização.

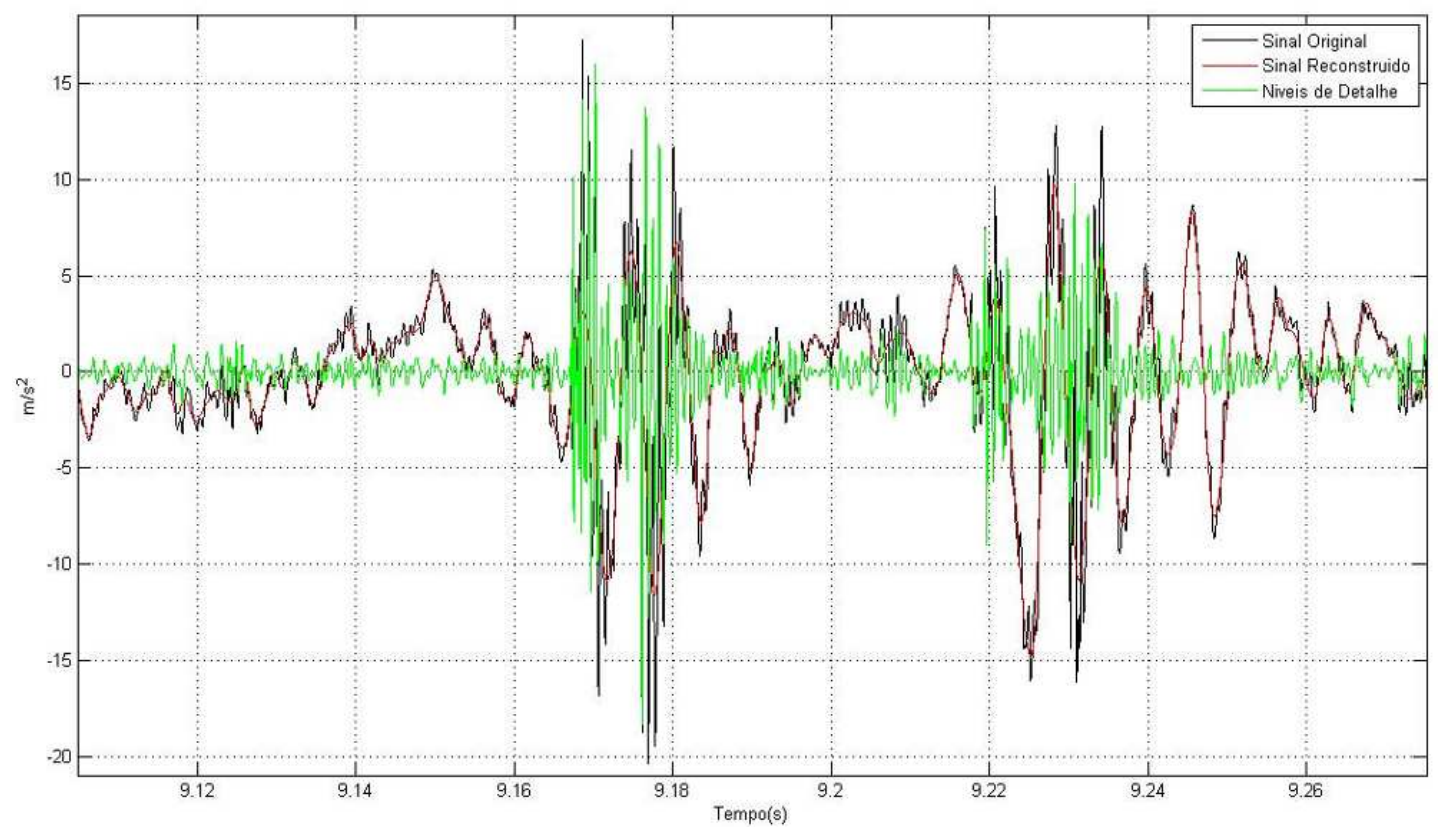

Figura 151 - Zoom sobre a região de impacto.

A figura 152 abaixo ilustra o espectro de frequência do sinal reconstruído. 


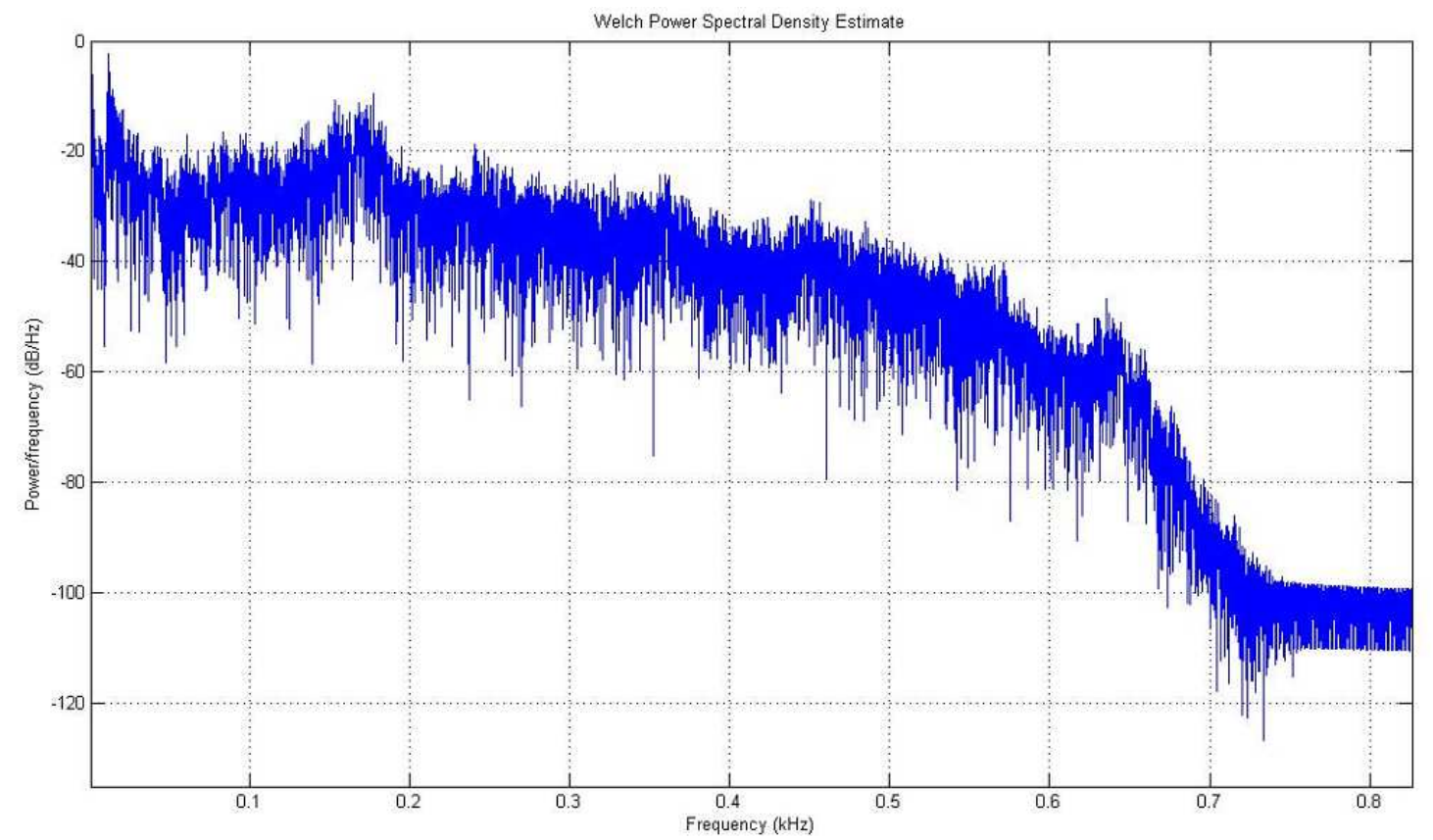

Figura 152 - Espectro de frequência do sinal reconstruído.

Nota-se que predominam as freqüências próximas a $150 \mathrm{~Hz}$, a qual representa a freqüência natural de vibração transversal da cremalheira, indicando que grande parte dos ruídos de impacto foi retirada do sinal original de vibração.

A figura 153 abaixo ilustra o espectrograma do sinal reconstruído.

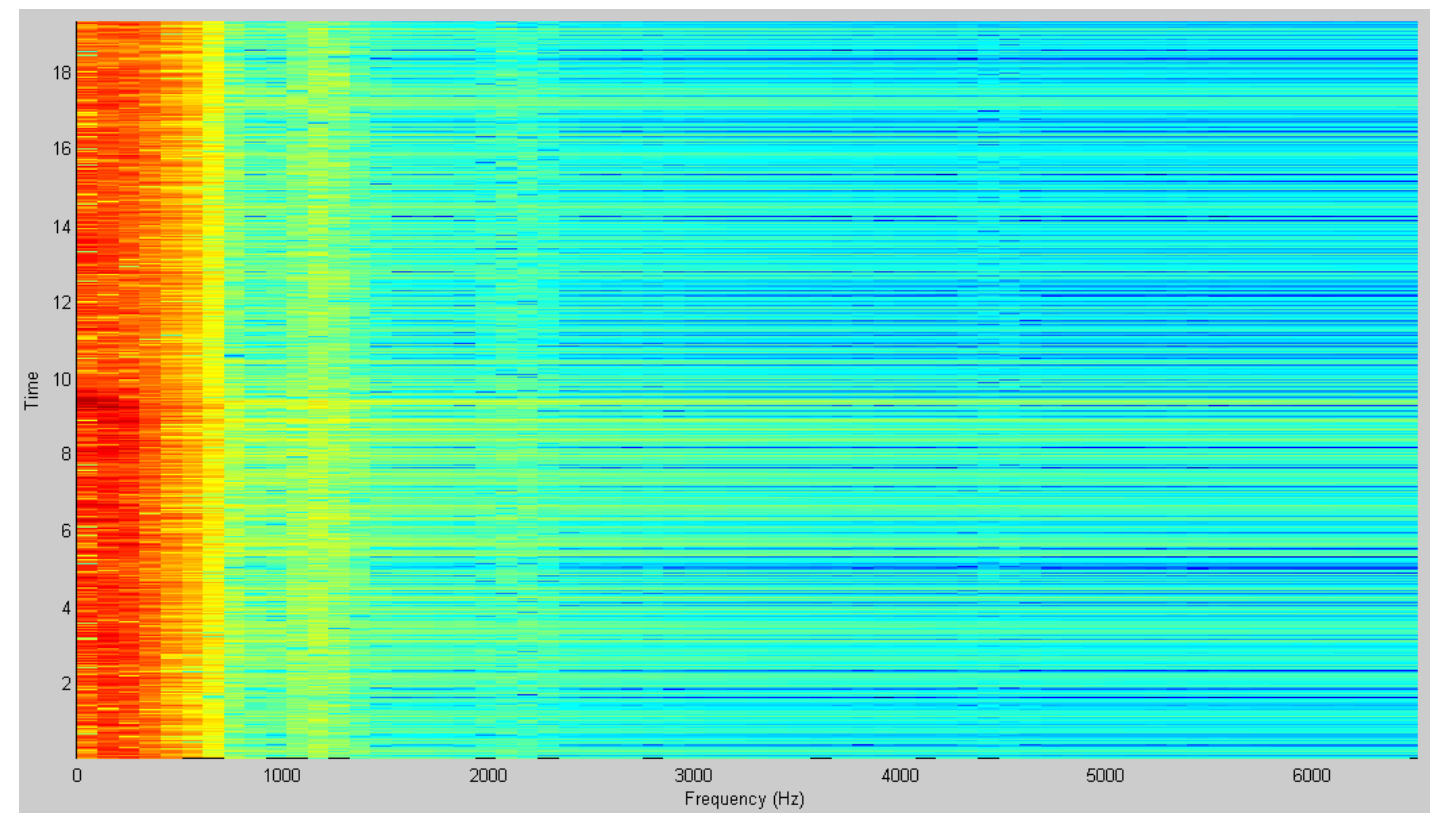

Figura 153 - Espectrograma do sinal reconstruído.

Nota-se que a maior parte das frequências na ordem de $\mathrm{kHz}$ foi retirada do sinal original, mas ainda aparecem ruídos de impacto. 
A figura 154 ilustra o espectro de frequências do sinal dos ruídos de impacto.

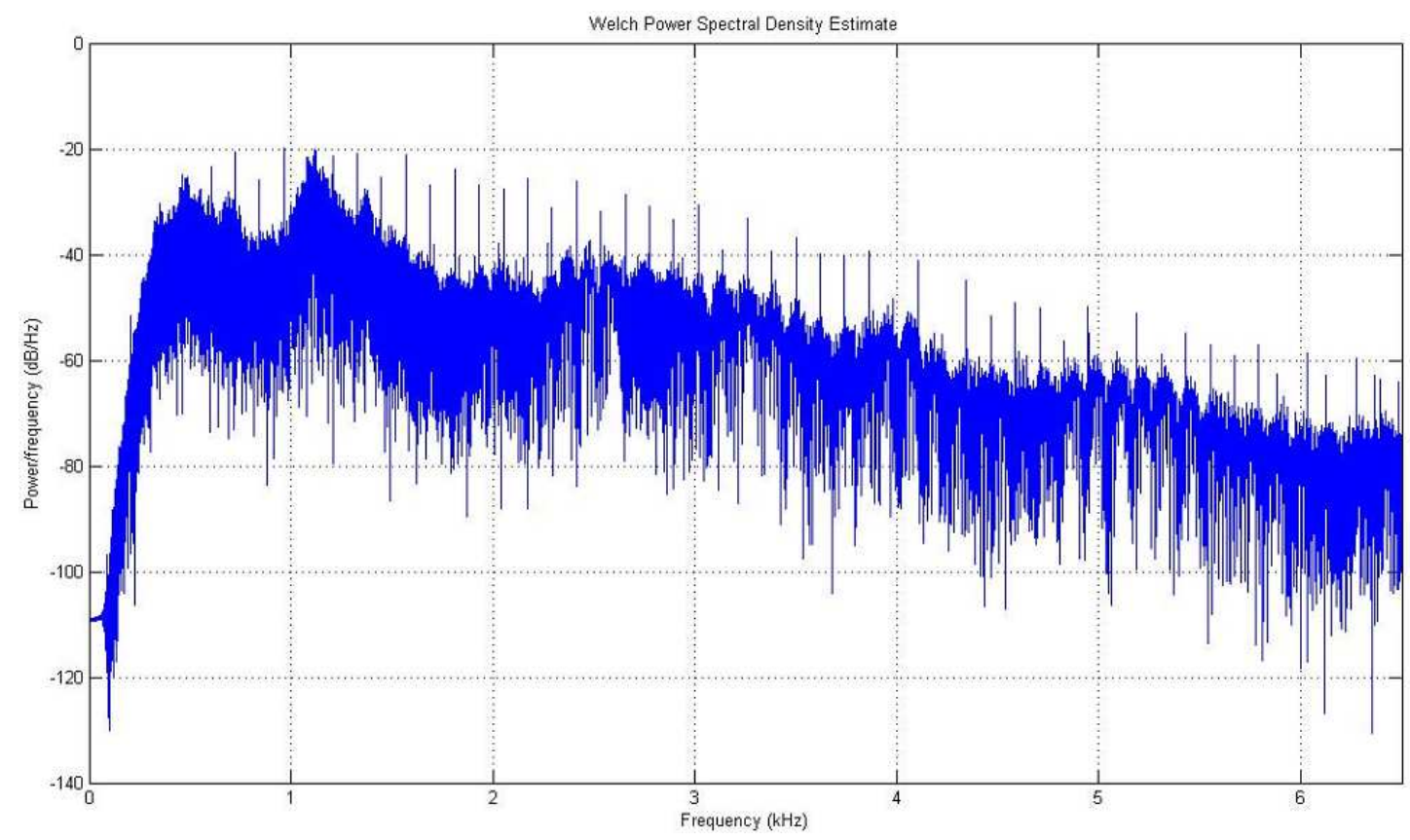

Figura 154 - Espectro de frequências do sinal dos ruídos de impacto.

Por este resultado, nota-se que predominam as frequências na ordem de grandeza de $\mathrm{kHz}$, as quais se referem aos impactos que ocorrem entre a cremalheira contra o pinhão e a bucha guia.

Adotando o critério da janela de tempo e mantendo a pré-filtragem em $3 \mathrm{~m} / \mathrm{s}^{2}$, foi registrada a ocorrência de 7 impactos dentro da caixa de direção e a maior severidade de impacto medida foi de $8,63 \mathrm{~m} / \mathrm{s}^{2}$.

No gráfico superior da figura 155 são ilustrados, em vermelho, os pontos de impacto detectados por este procedimento e no gráfico inferior são ilustrados os valores da severidade medidos para estes pontos. 

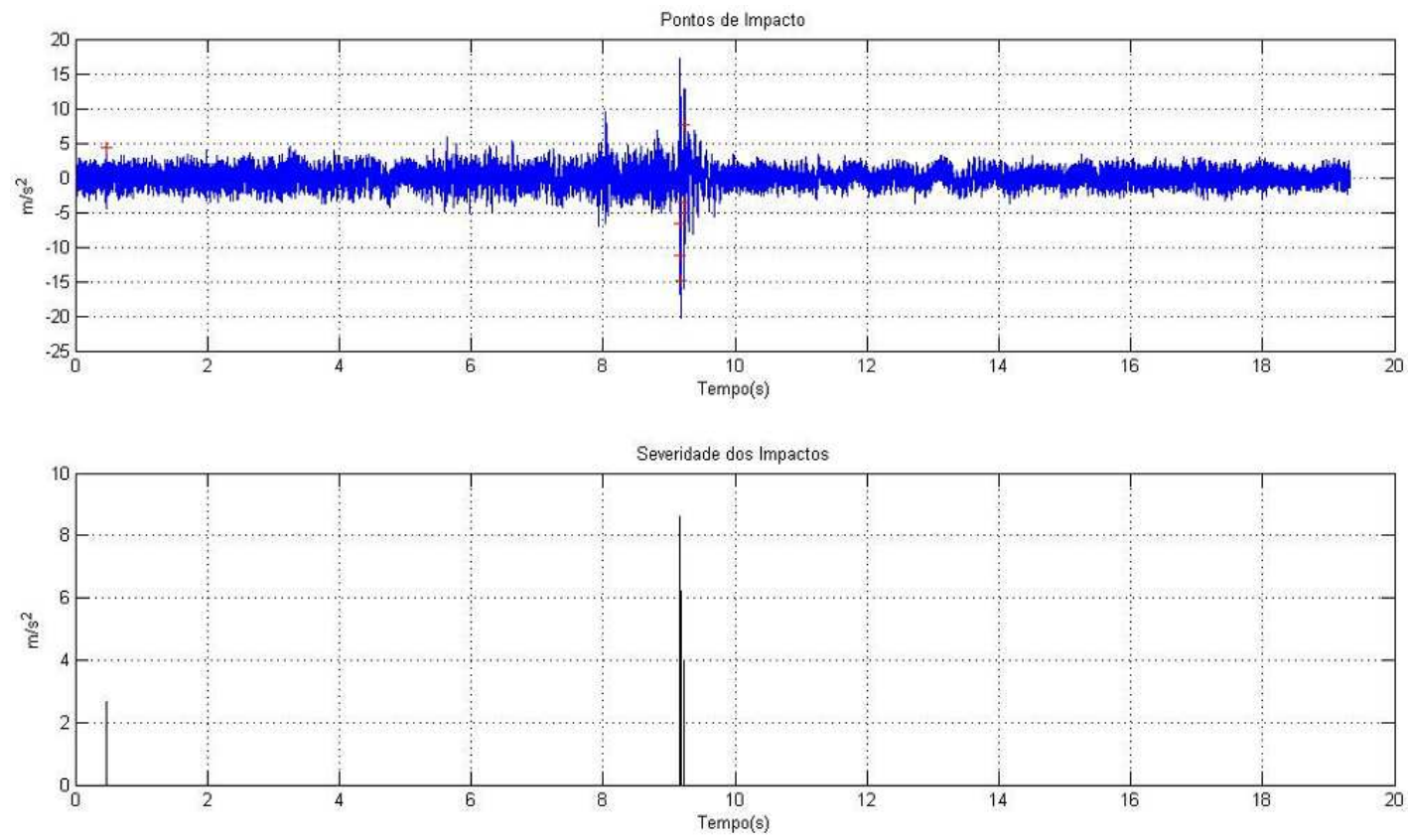

Figura 155 - Pontos de Impacto e Severidade dos Impactos.

Por este resultado, nota-se que o critério detectou a região de impacto neste sinal.

O trecho 3 do sinal acima está ilustrado na figura 156 abaixo.

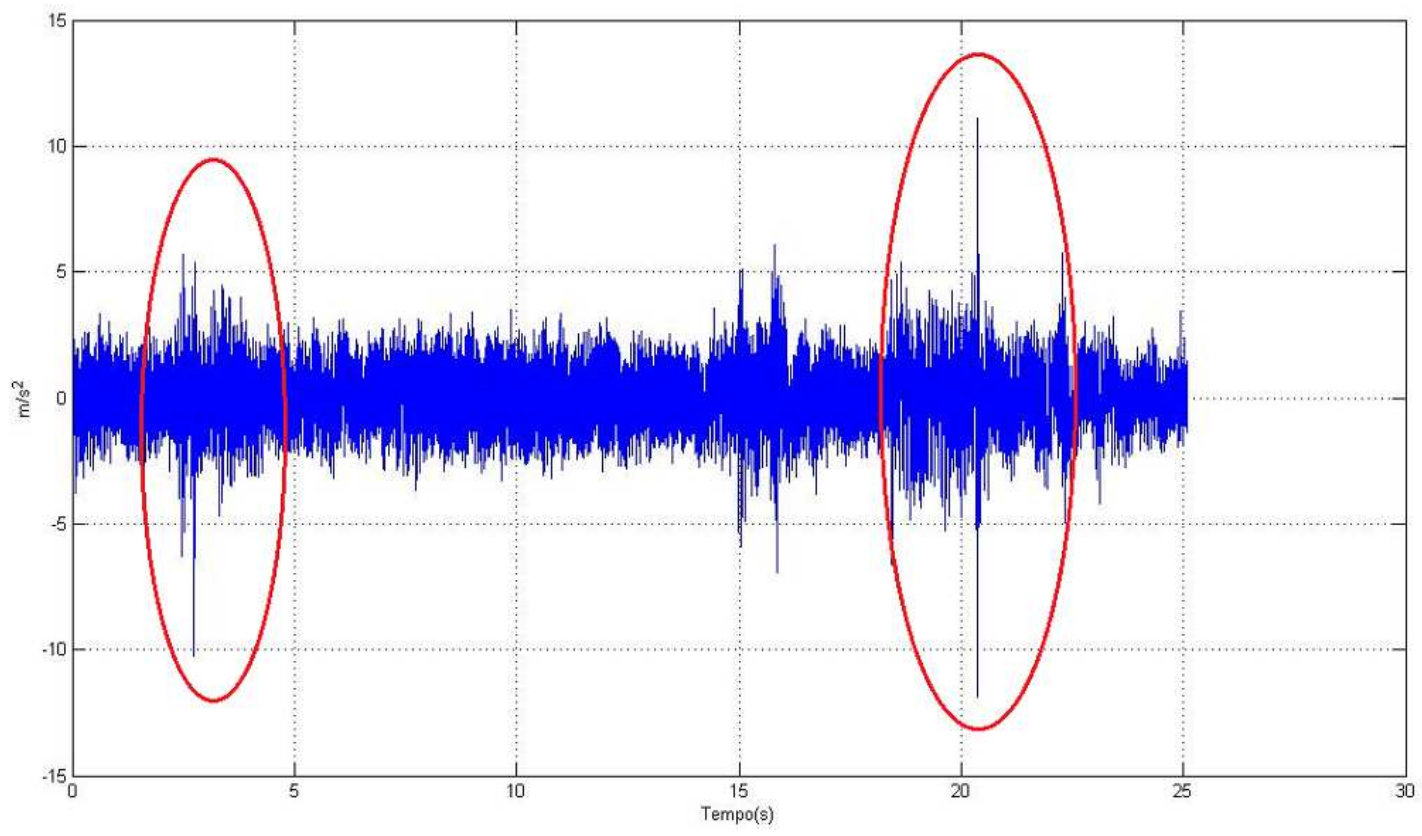

Figura 156 - Trecho 3 do sinal.

Visualmente, pode-se identificar neste sinal a ocorrência de impactos próximos a 2,5 e 20 segundos.

A figura 157 ilustra espectrograma do sinal original. 


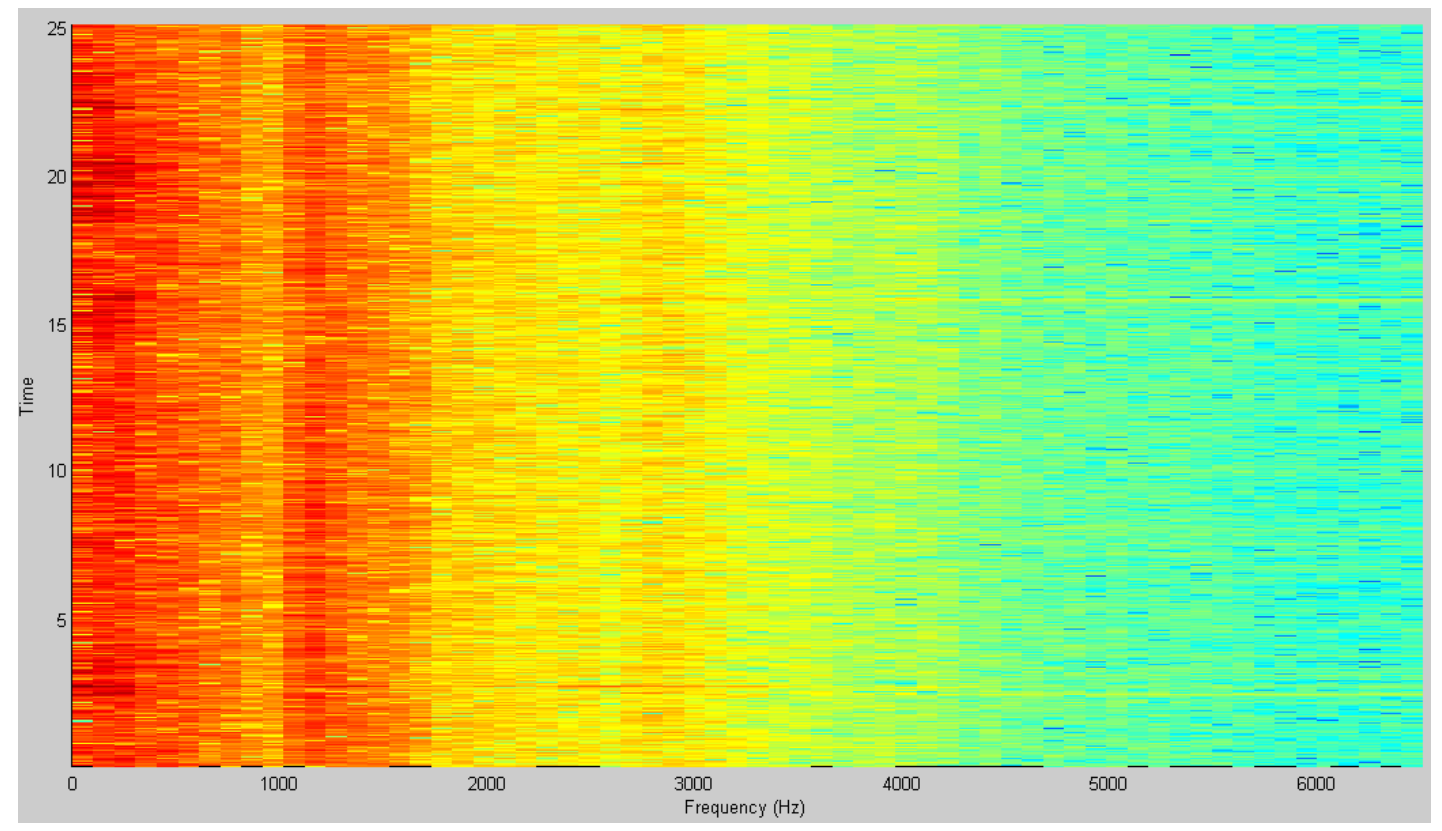

Figura 157 - Espectrograma do sinal original.

Por este resultado, nota-se a presença de frequências na ordem de grandeza de $\mathrm{kHz}$, indicando a presença de ruídos de impacto provenientes dos impactos da cremalheira contra o pinhão e bucha guia.

Adotando como parâmetro de entrada os resultados obtidos com os sinais reais na pista, foi aplicado a wavelet de Daubechies de ordem 7 e retirado os 4 últimos níveis de detalhe do sinal original, obtendo o resultado ilustrado na figura 158.

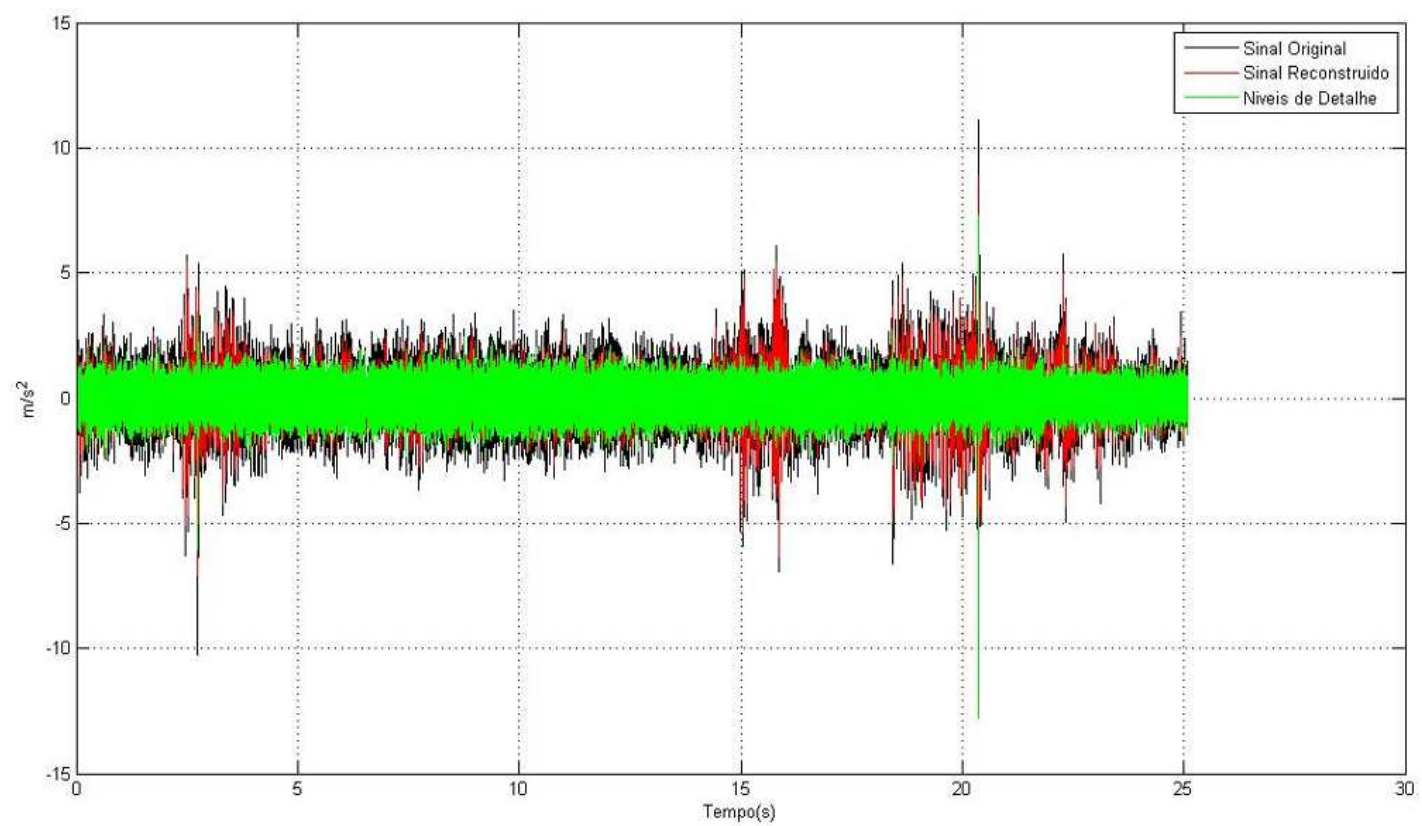

Figura 158 - Wavelet de Daubechies de ordem 7 e 4 níveis de detalhe. 
A figura 159 ilustra zoom sobre a região de 20 segundos para melhor visualização.

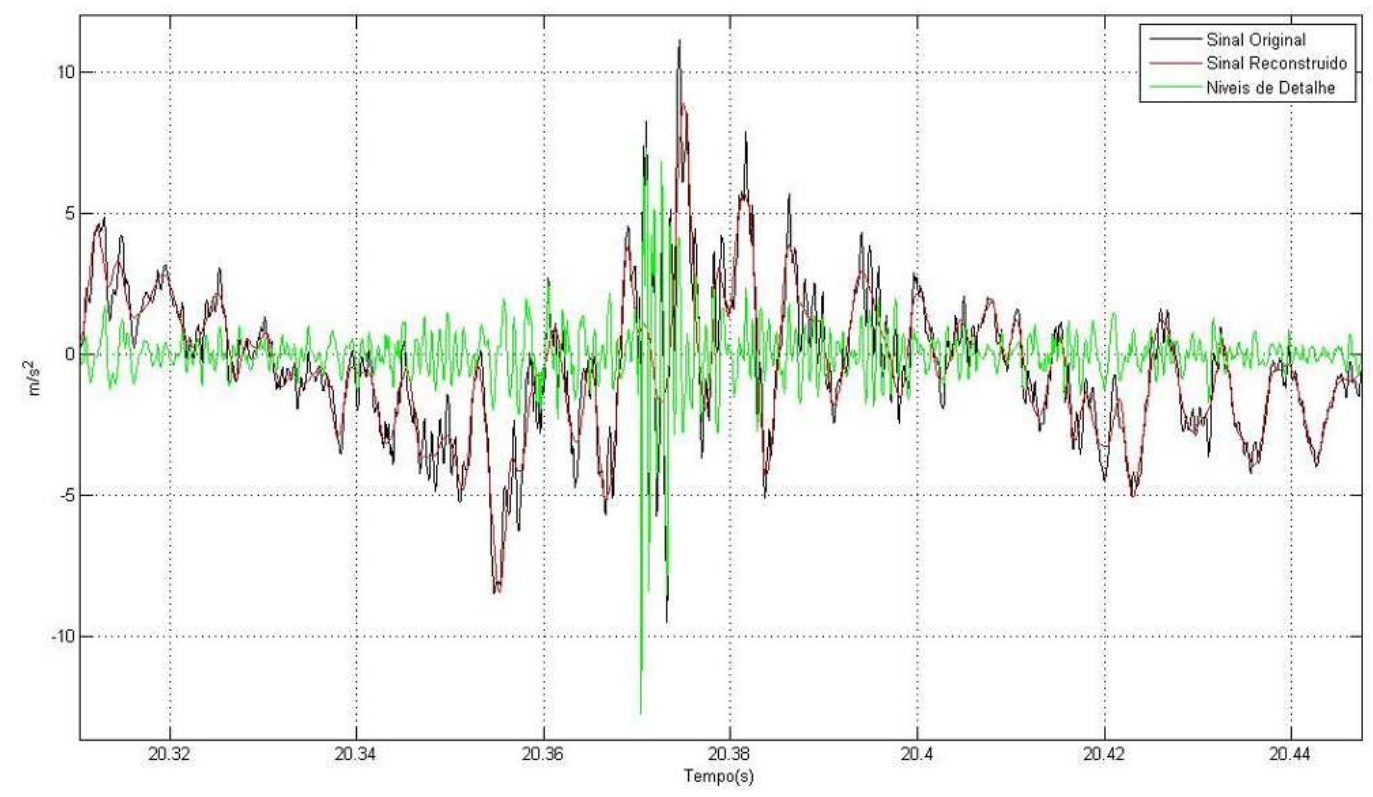

Figura 159 - Zoom sobre região de 20 segundos.

A figura 160 abaixo ilustra o espectro de frequência do sinal reconstruído.

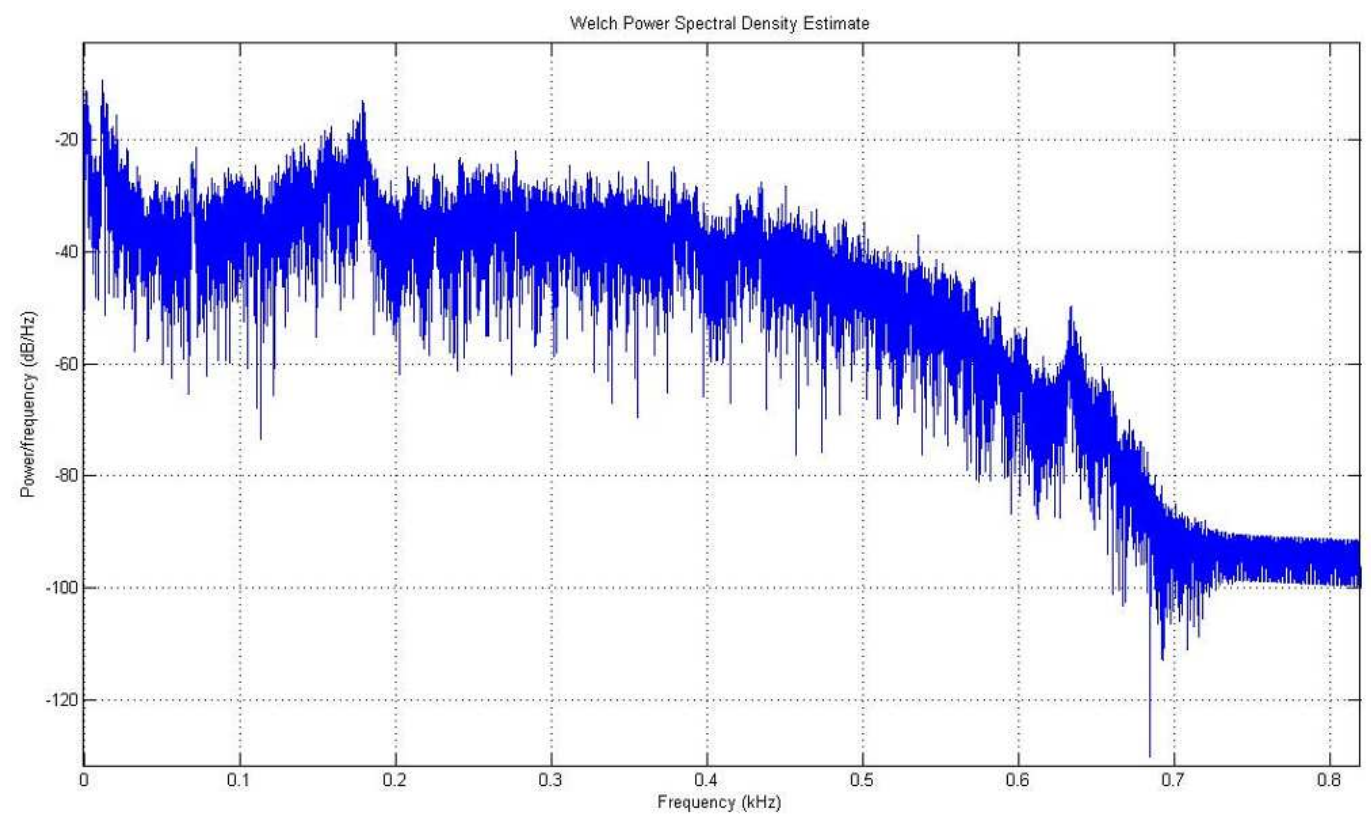

Figura 160 - Espectro de frequência do sinal reconstruído.

Nota-se que predominam as freqüências próximas a $150 \mathrm{~Hz}$, a qual representa a freqüência natural de vibração transversal da cremalheira, indicando que grande parte dos ruídos de impacto foi retirada do sinal original de vibração. 
A figura 161 abaixo ilustra o espectrograma do sinal reconstruído.

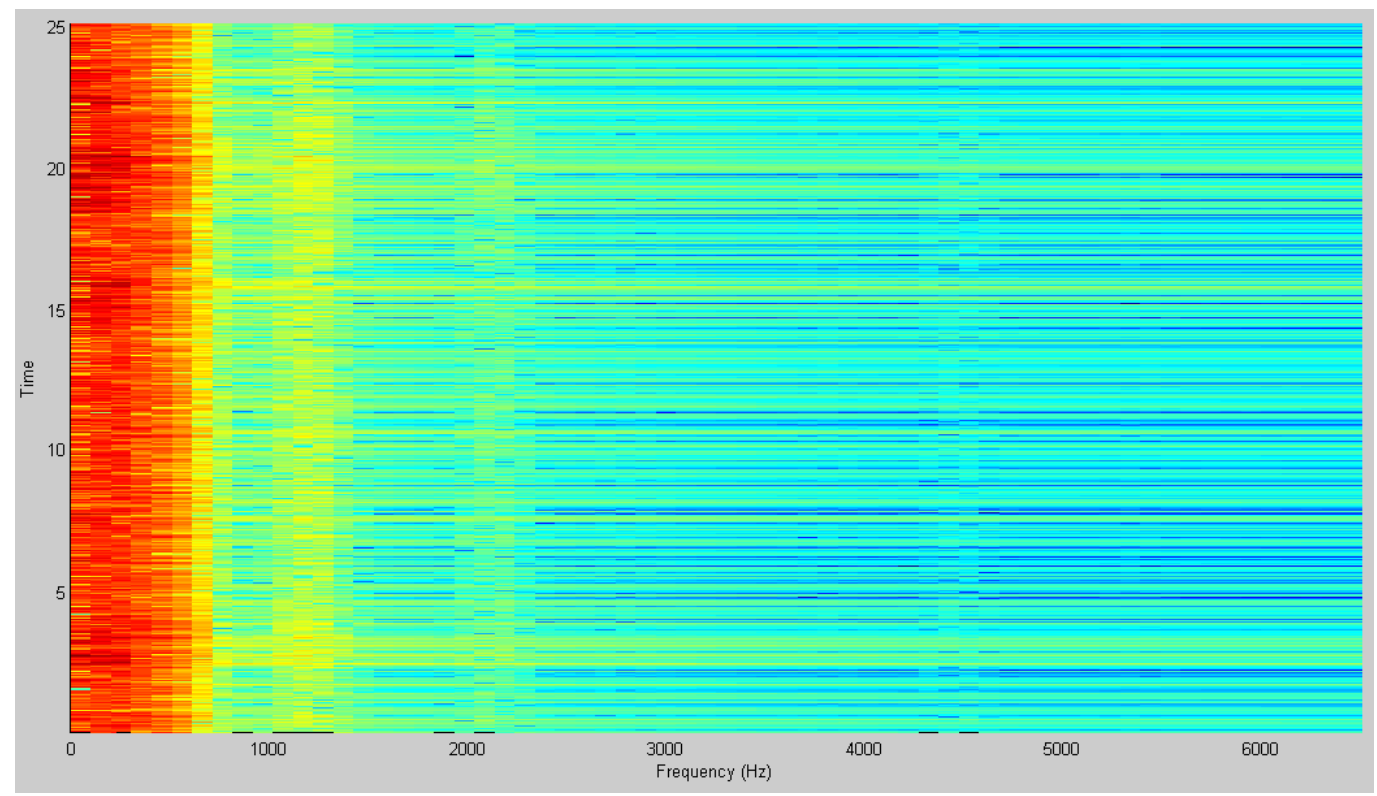

Figura 161 - Espectrograma do sinal reconstruído.

Nota-se que a maior parte das frequências na ordem de $\mathrm{kHz}$ foi retirada do sinal original, mas ainda aparecem ruídos de impacto no sinal reconstruído.

A figura 162 ilustra o espectro de frequências do sinal dos ruídos de impacto.

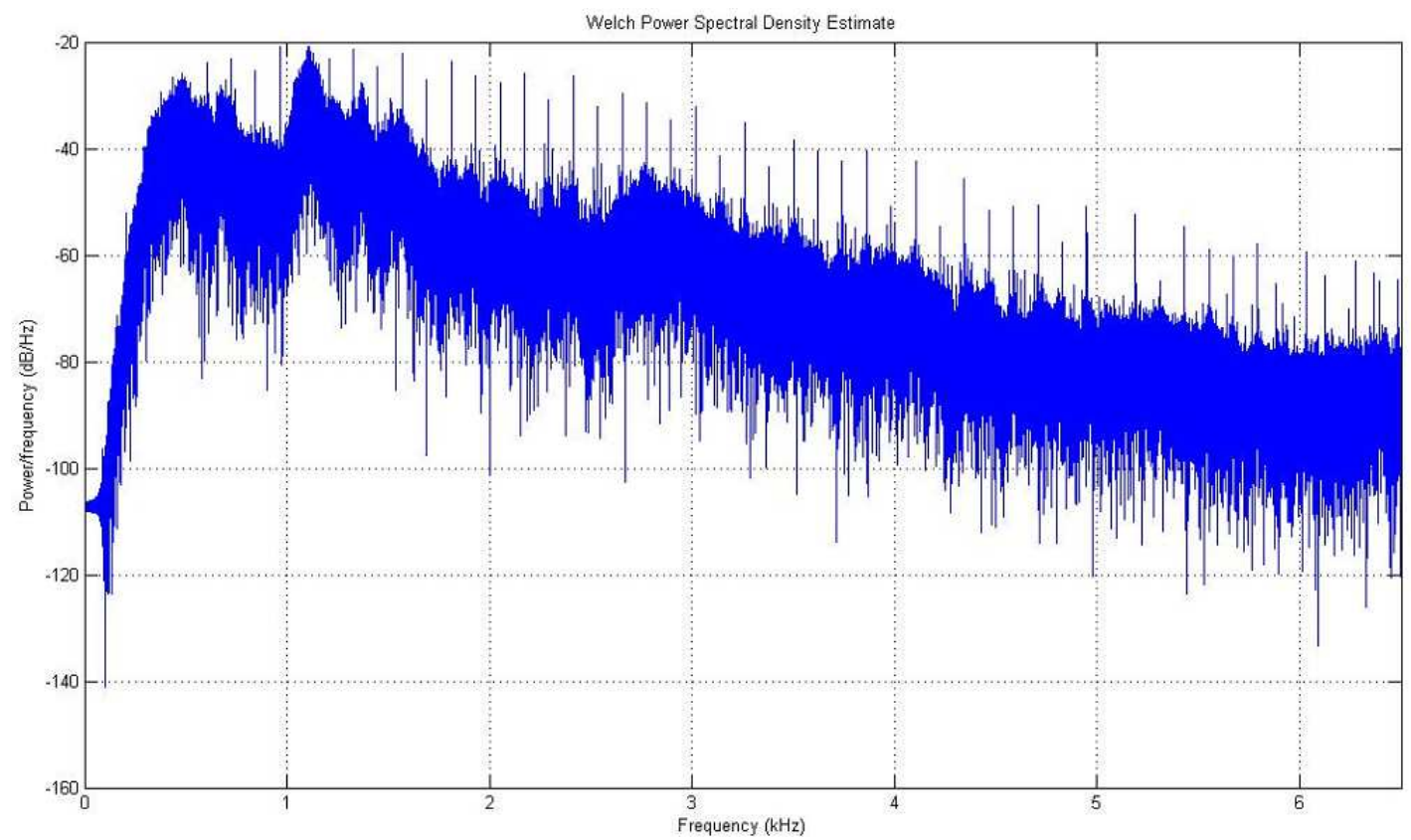

Figura 162 - Espectro de frequências do sinal dos ruídos de impacto. 
Por este resultado, nota-se que predominam as frequências na ordem de grandeza de $\mathrm{kHz}$, as quais se referem aos impactos que ocorrem entre a cremalheira contra o pinhão e a bucha guia.

Adotando o critério da janela de tempo e mantendo a pré-filtragem em $3 \mathrm{~m} / \mathrm{s}^{2}$, foi registrada a ocorrência de 3 impactos dentro da caixa de direção e a maior severidade de impacto medida foi de $4,540 \mathrm{~m} / \mathrm{s}^{2}$.

No gráfico superior da figura 163 são ilustrados, em vermelho, os pontos de impacto detectados por este procedimento e no gráfico inferior são ilustrados os valores da severidade medidos para estes pontos.
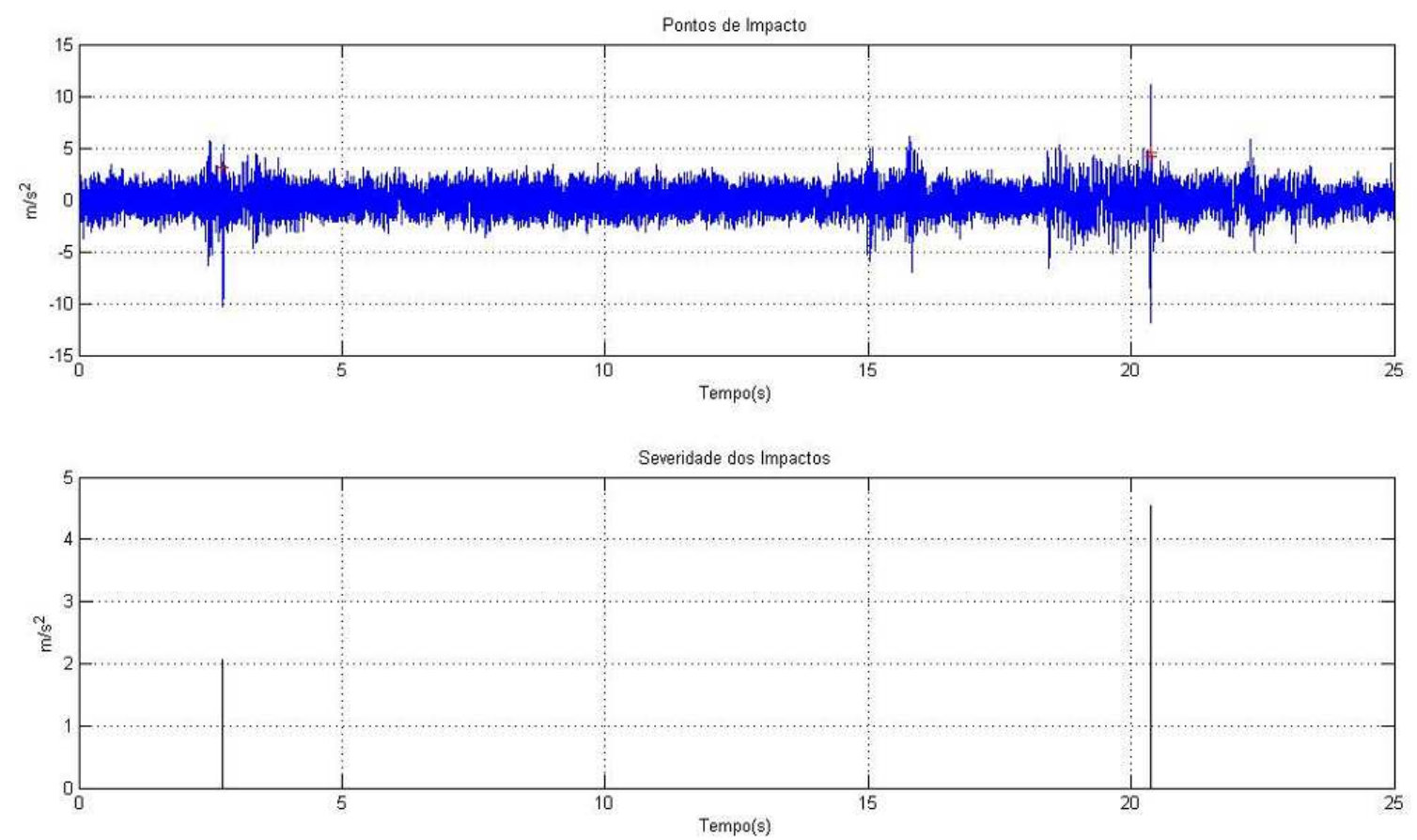

Figura 163 - Pontos de Impacto e Severidade de Impactos.

Por este resultado, nota-se que o procedimento detectou as 2 regiões de impacto neste sinal.

O trecho 4 do sinal está ilustrado na figura 164 abaixo. 


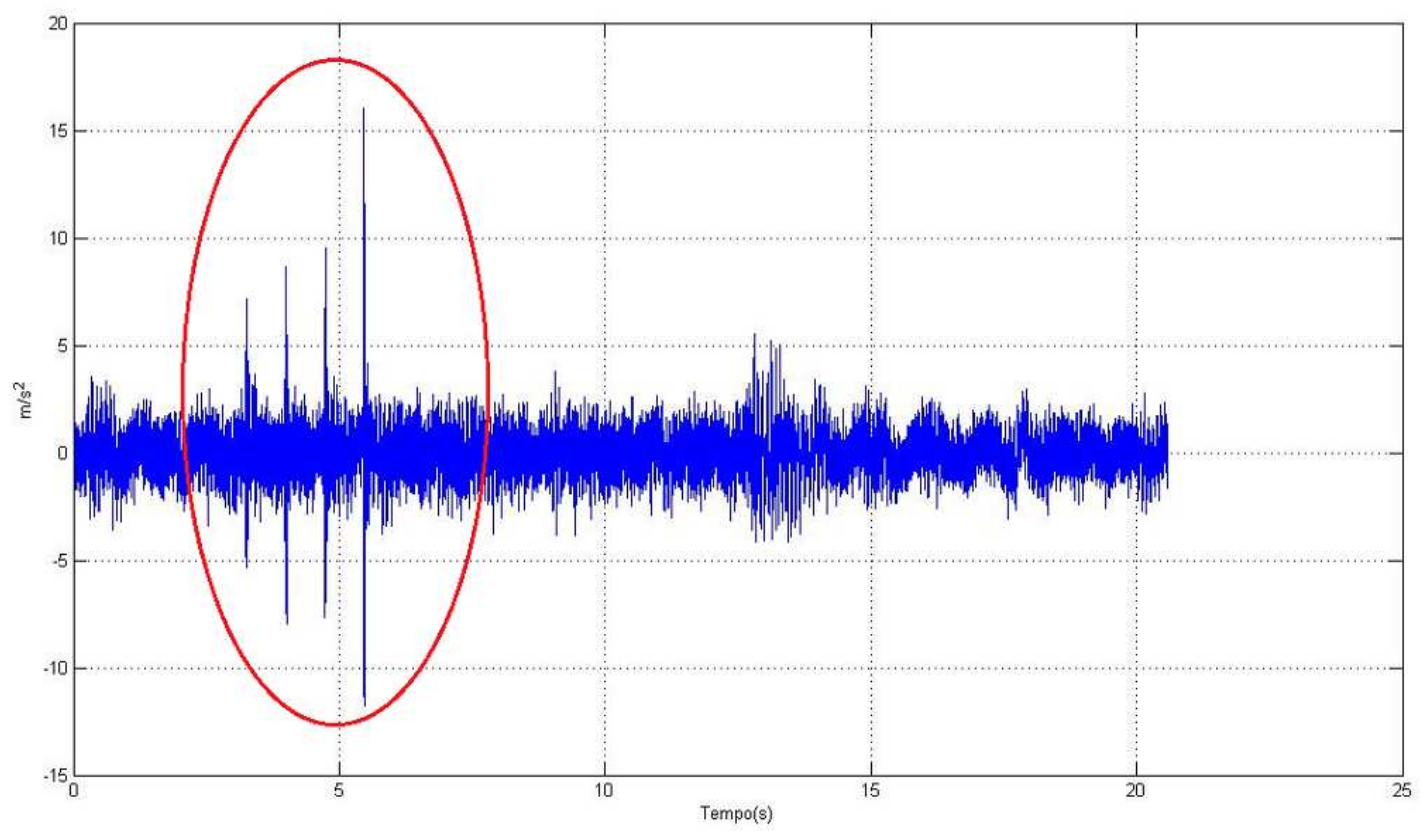

Figura 164 - Trecho 4 do sinal.

Visualmente, pode-se identificar neste sinal a ocorrência de impactos próximos a 5 segundos.

A figura 165 ilustra espectrograma do sinal original.

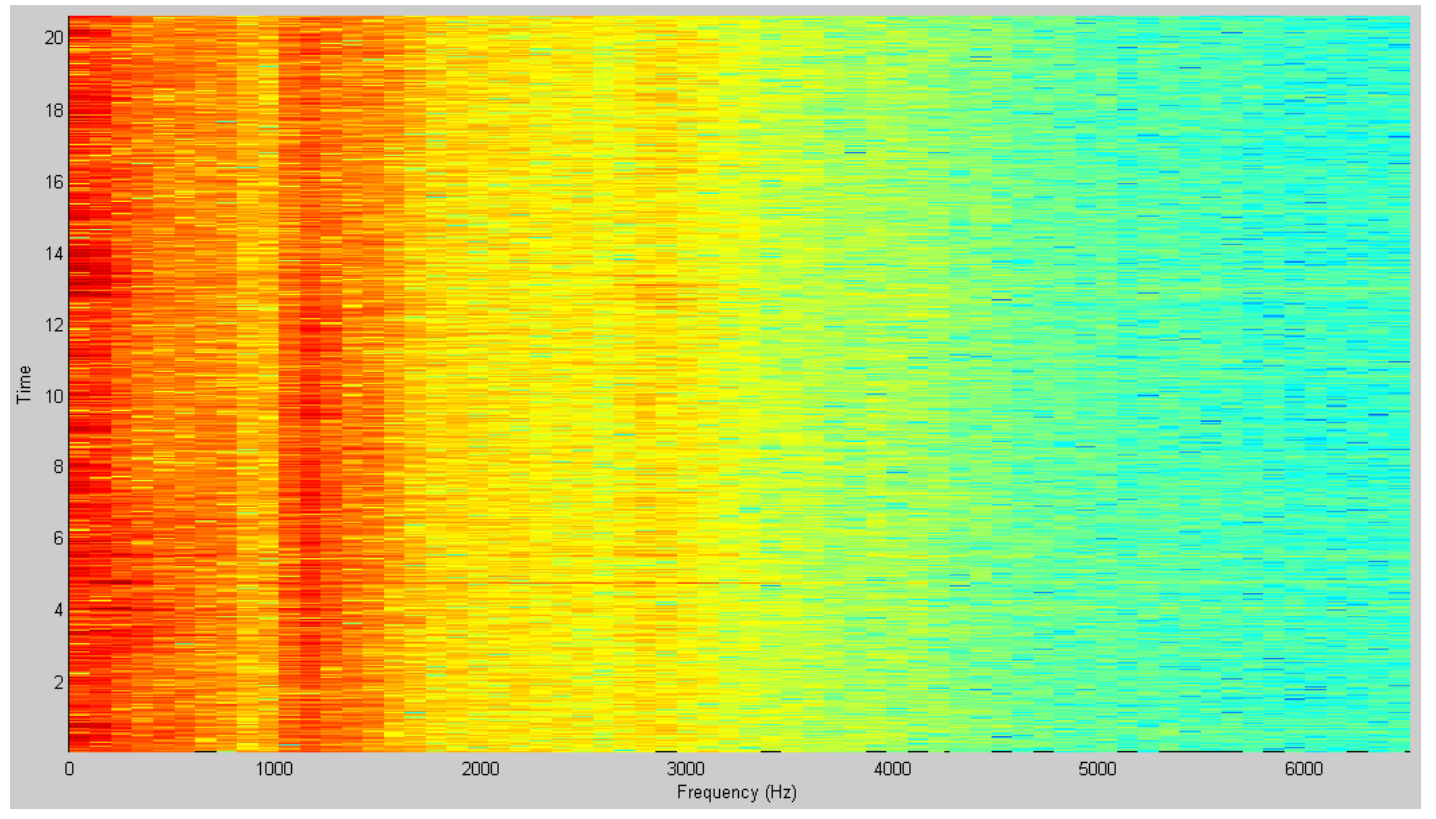

Figura 165 - Espectrograma do sinal original.

Por este resultado, nota-se a presença de frequências na ordem de grandeza de $\mathrm{kHz}$, indicando a presença de ruídos de impacto provenientes dos impactos da cremalheira contra o pinhão e bucha guia. 
Adotando como parâmetro de entrada os resultados obtidos com os sinais reais na pista com paralelepípedos, foi aplicado a wavelet de Daubechies de ordem 7 e retirado os 4 últimos níveis de detalhe do sinal original, obtendo o resultado ilustrado na figura 166.

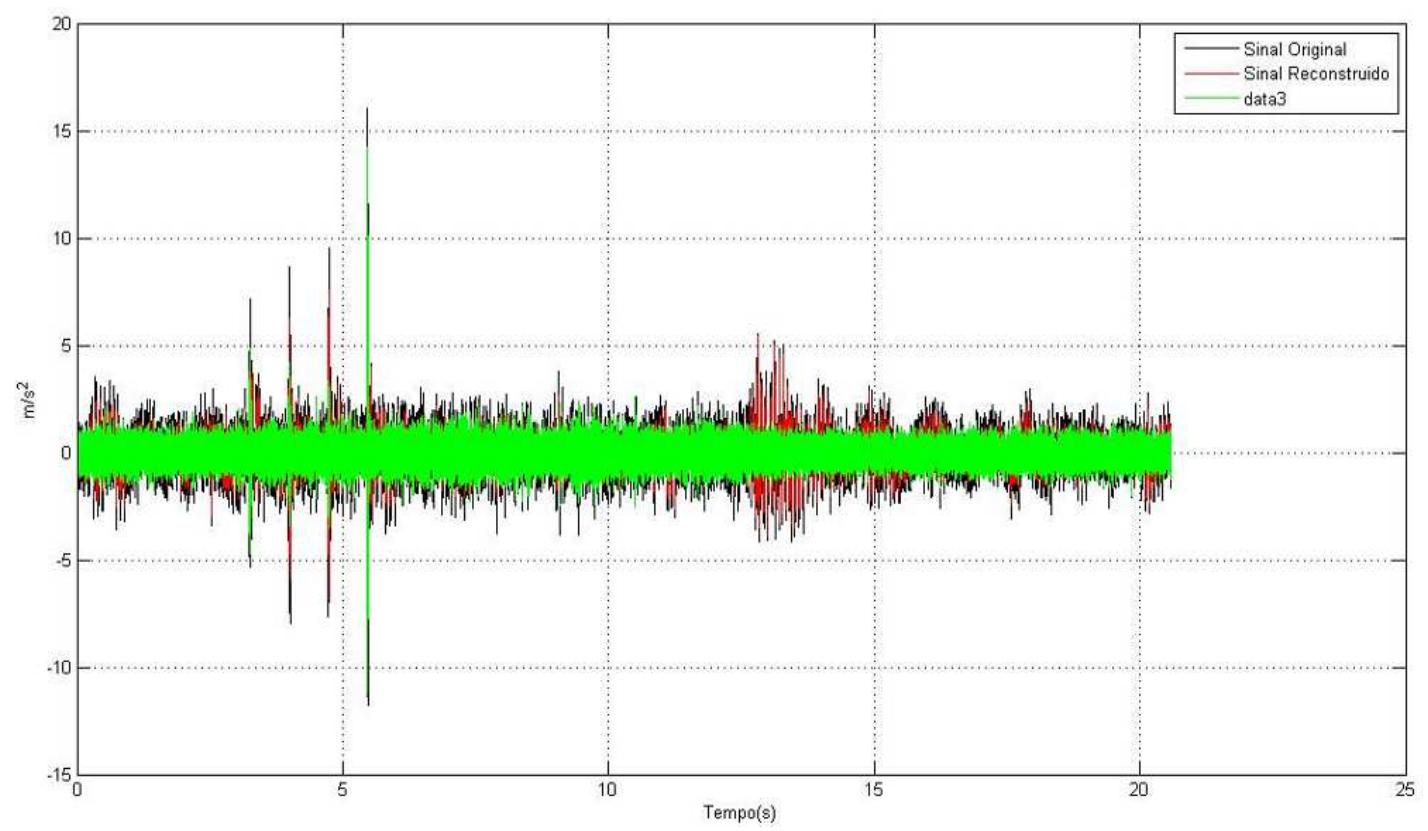

Figura 166 - Wavelet de Daubechies de ordem 7 e 4 níveis de detalhe.

A figura 167 ilustra zoom sobre a região de 5 segundos para melhor visualização.

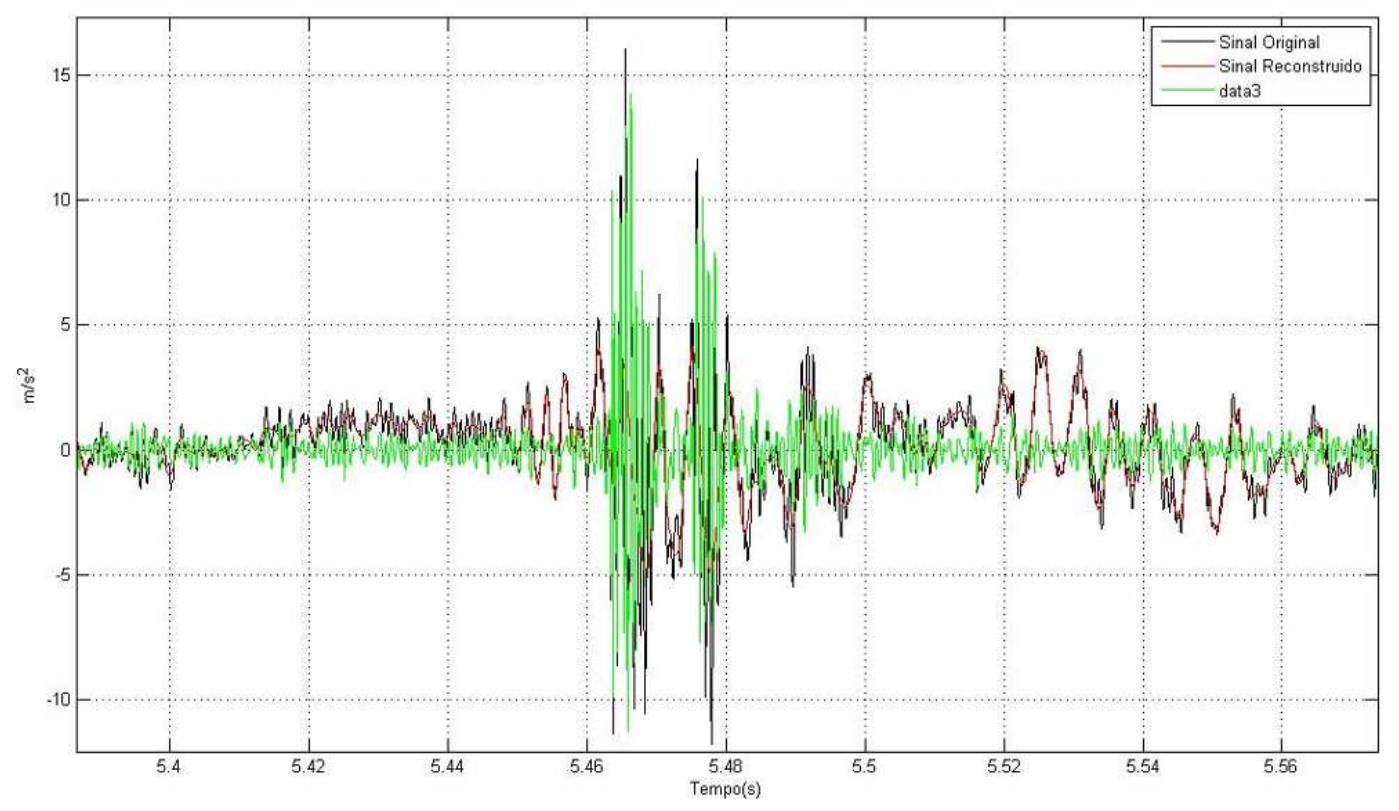

Figura 167 - Zoom sobre região em torno de 5 segundos. 
A figura 168 abaixo ilustra o espectro de frequência do sinal reconstruído.

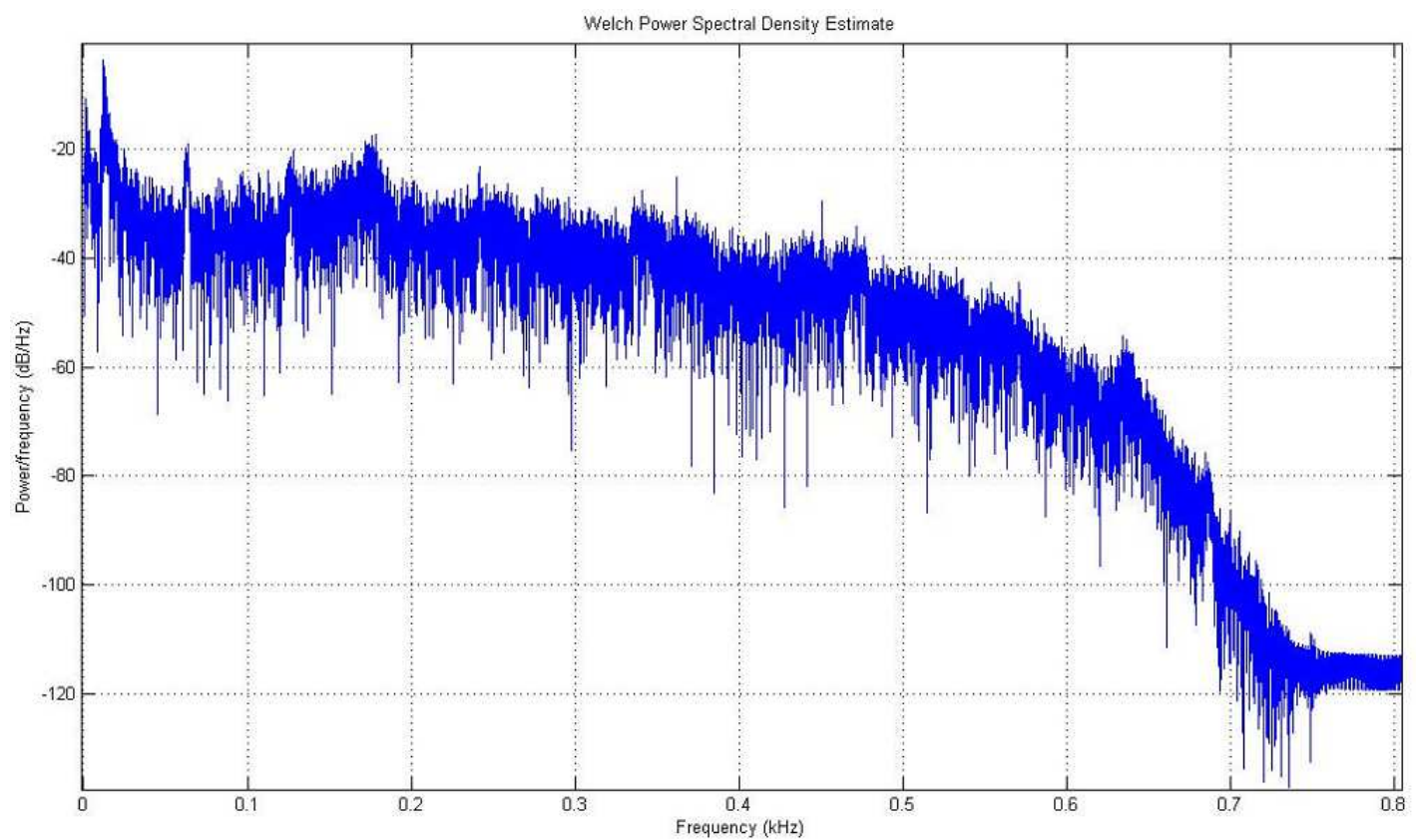

Figura 168 - Espectro de frequência do sinal reconstruído.

Nota-se que predominam as freqüências próximas a $120 \mathrm{~Hz}$, a qual representa a freqüência natural de vibração transversal da cremalheira, indicando que grande parte dos ruídos de impacto foi retirada do sinal original de vibração.

A figura 169 abaixo ilustra o espectrograma do sinal reconstruído.

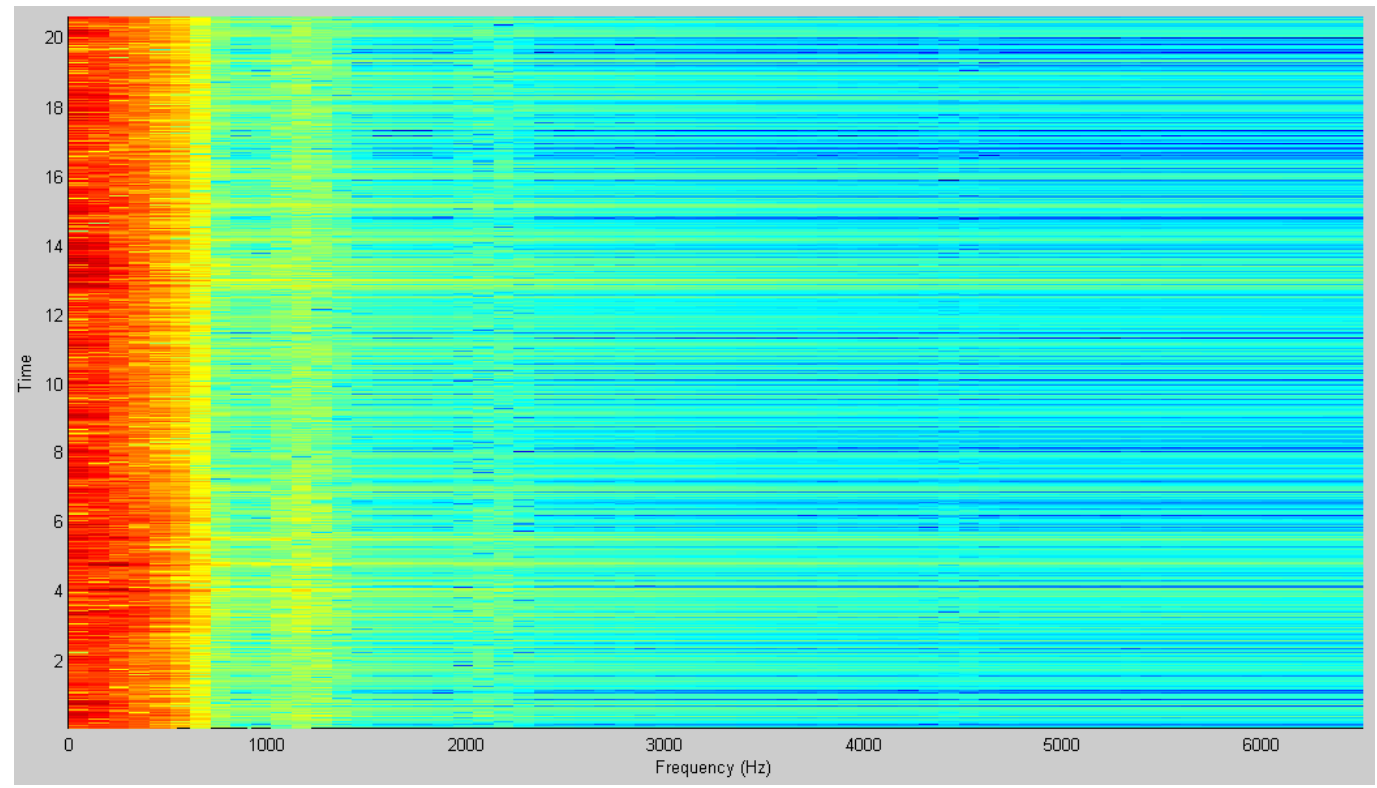

Figura 169 - Espectrograma do sinal reconstruído. 
Nota-se que a maior parte das frequências na ordem de $\mathrm{kHz}$ foi retirada do sinal original, mas ainda aparecem ruídos de impacto no sinal reconstruído.

A figura 170 ilustra o espectro de frequências do sinal dos ruídos de impacto.

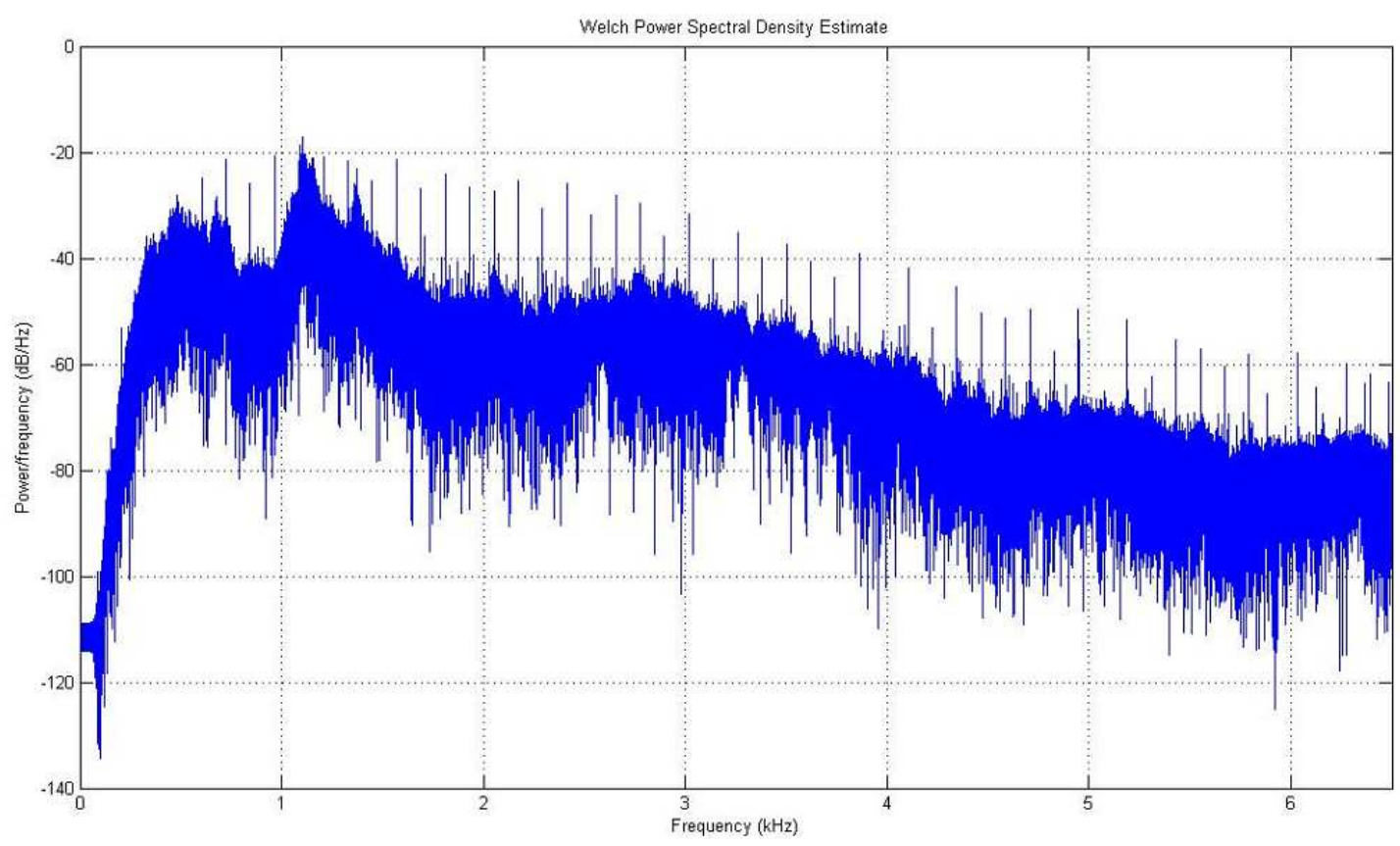

Figura 170 - Espectro de frequências do sinal dos ruídos de impacto.

Por este resultado, nota-se que predominam as frequências na ordem de grandeza de $\mathrm{kHz}$, as quais se referem aos impactos que ocorrem entre a cremalheira contra o pinhão e a bucha guia.

Adotando o critério da janela de tempo e mantendo a pré-filtragem em $3 \mathrm{~m} / \mathrm{s}^{2}$ mas ajustando o valor relativo de 20 vezes para 5 vezes, foi registrada a ocorrência de 12 impactos dentro da caixa de direção e a maior severidade de impacto medida foi de $7,919 \mathrm{~m} / \mathrm{s}^{2}$.

No gráfico superior da figura 171 são ilustrados, em vermelho, os pontos de impacto detectados por este procedimento e no gráfico inferior são ilustrados os valores da severidade medidos para estes pontos. 

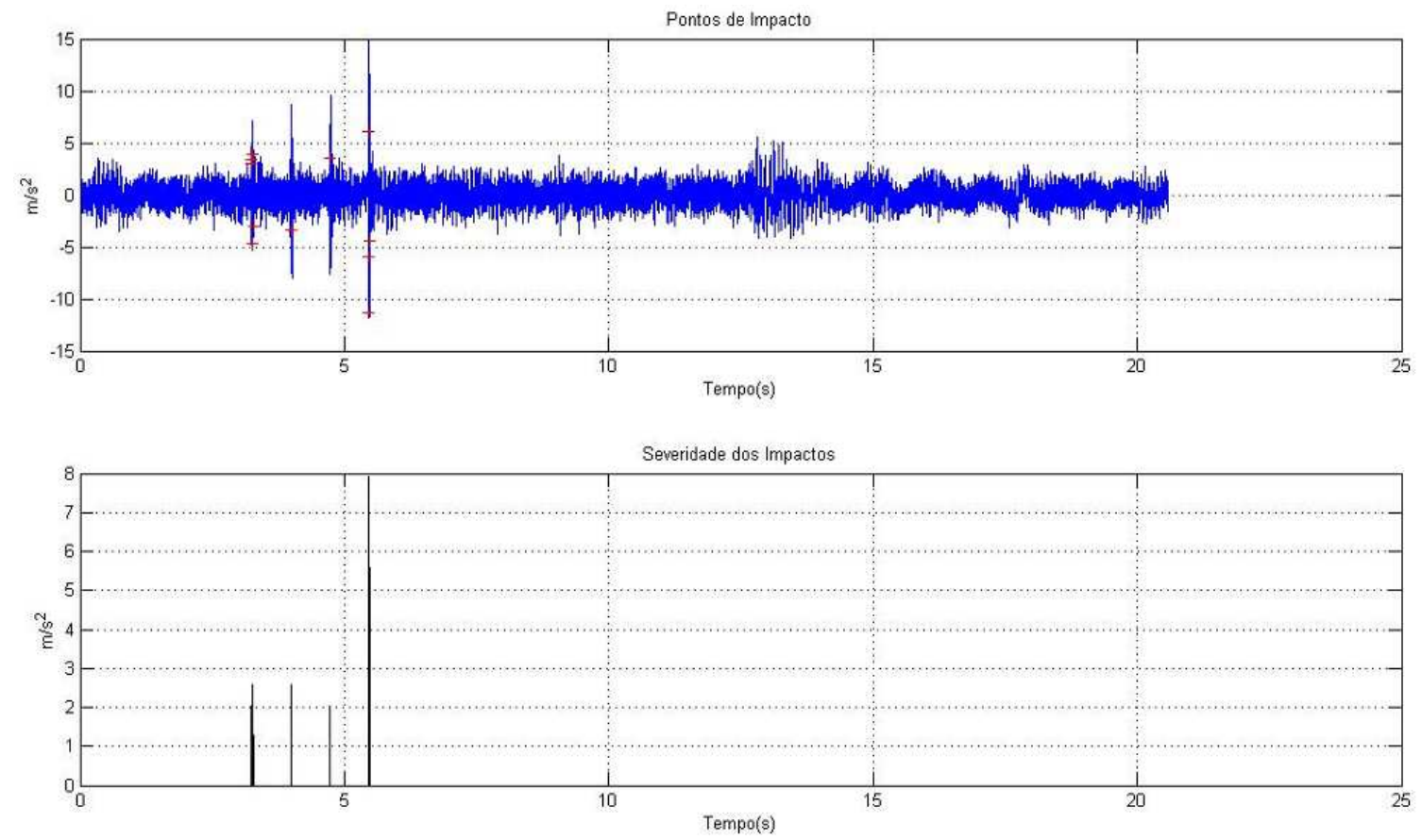

Figura 171 - Pontos de Impacto.

Por este resultado, nota-se que o procedimento detectou as 4 regiões de impacto neste sinal.

O trecho 5 do sinal está ilustrado na figura 172 abaixo.

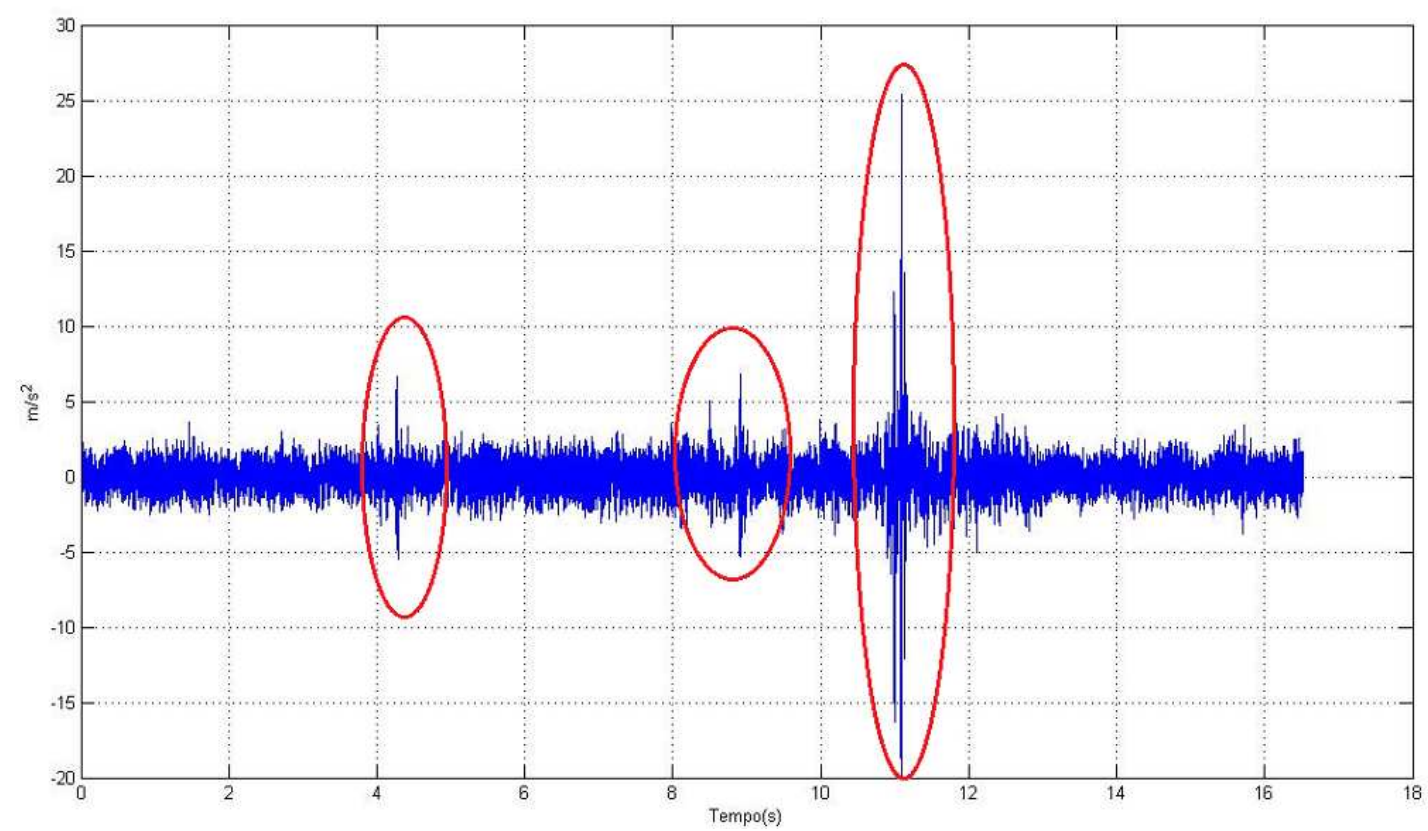

Figura 172 - Trecho 5 do sinal.

Visualmente, pode-se identificar neste sinal a ocorrência de impactos próximos a 4, 9 e 11 segundos. 
A figura 173 ilustra espectrograma do sinal original.

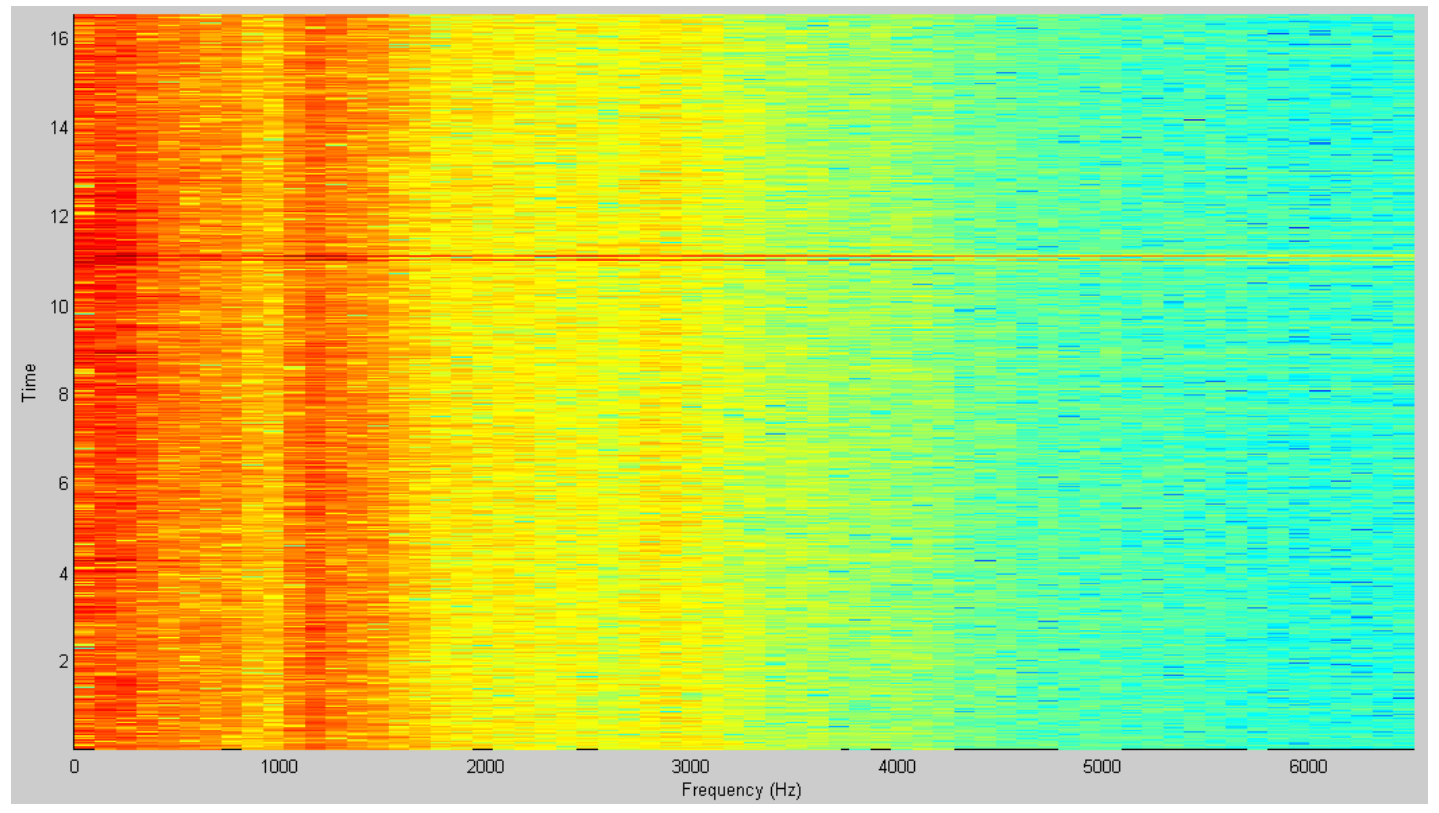

Figura 173 - Espectrograma do sinal original.

Por este resultado, nota-se a presença de frequências na ordem de grandeza de $\mathrm{kHz}$, indicando a presença de ruídos de impacto provenientes dos impactos da cremalheira contra o pinhão e bucha guia.

Adotando como parâmetro de entrada os resultados obtidos com os sinais reais na pista com paralelepípedos, foi aplicado a wavelet de Daubechies de ordem 7 e retirado os 4 últimos níveis de detalhe do sinal original, obtendo o resultado ilustrado na figura 174. 


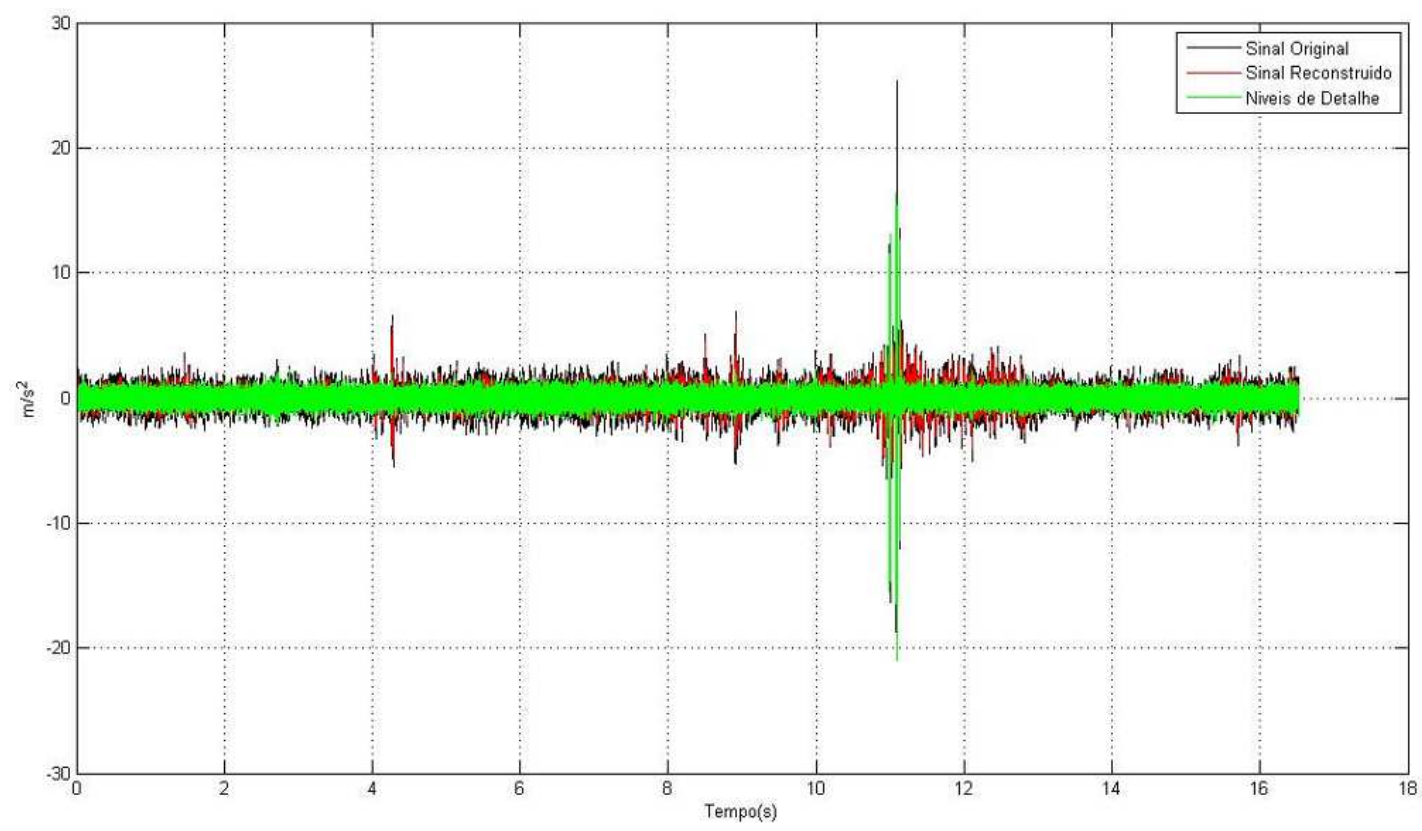

Figura 174 - Wavelet de Daubechies de ordem 7 e 4 níveis de detalhe.

A figura 175 ilustra zoom sobre a região de 11 segundos para melhor visualização.

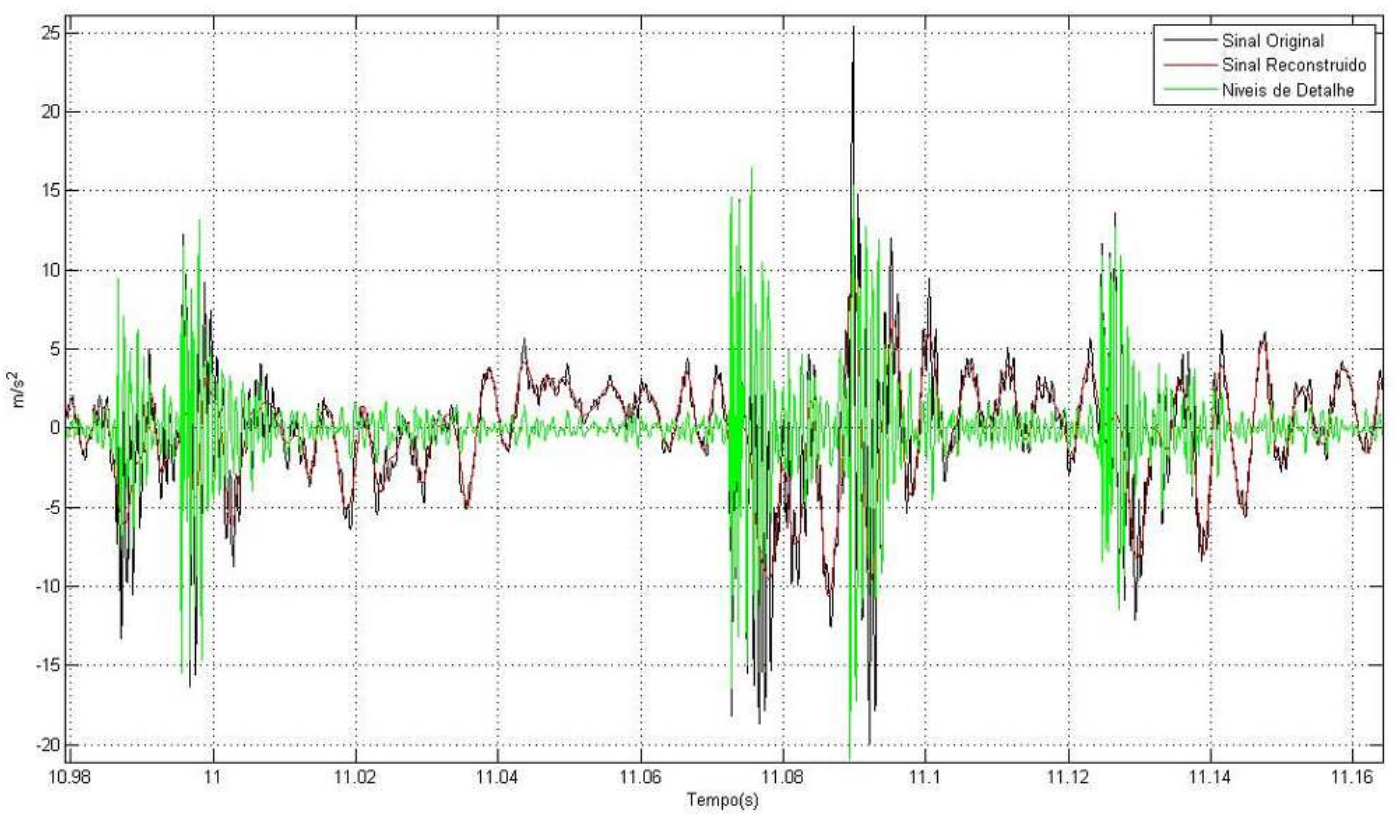

Figura 175 - Zoom sobre a região em torno de 11 segundos.

A figura 176 abaixo ilustra o espectro de frequência do sinal reconstruído. 


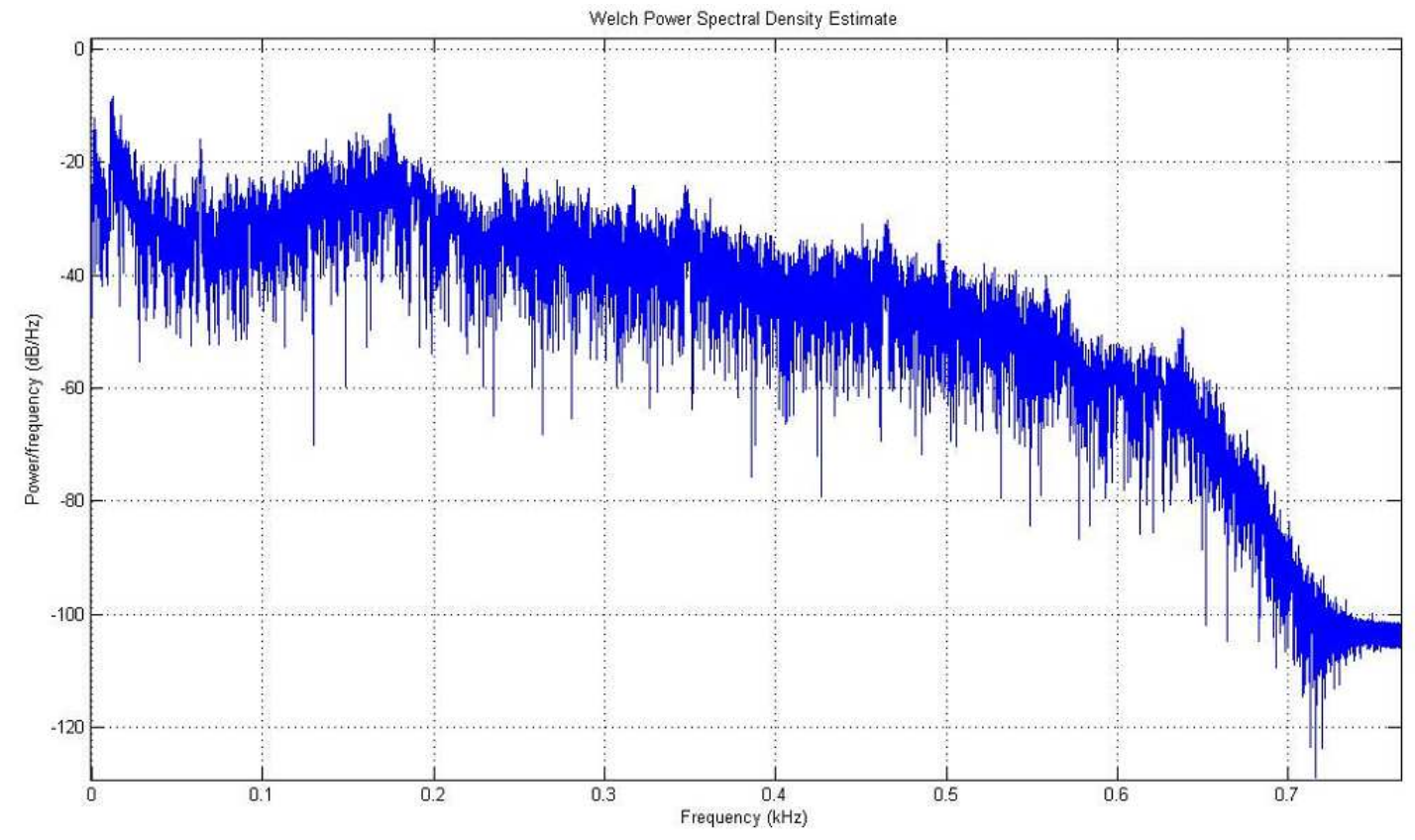

Figura 176 - Espectro de frequência do sinal reconstruído.

Nota-se que predominam as freqüências próximas a $150 \mathrm{~Hz}$, a qual representa a freqüência natural de vibração transversal da cremalheira, indicando que grande parte dos ruídos de impacto foi retirada do sinal original de vibração.

A figura 177 abaixo ilustra o espectrograma do sinal reconstruído.

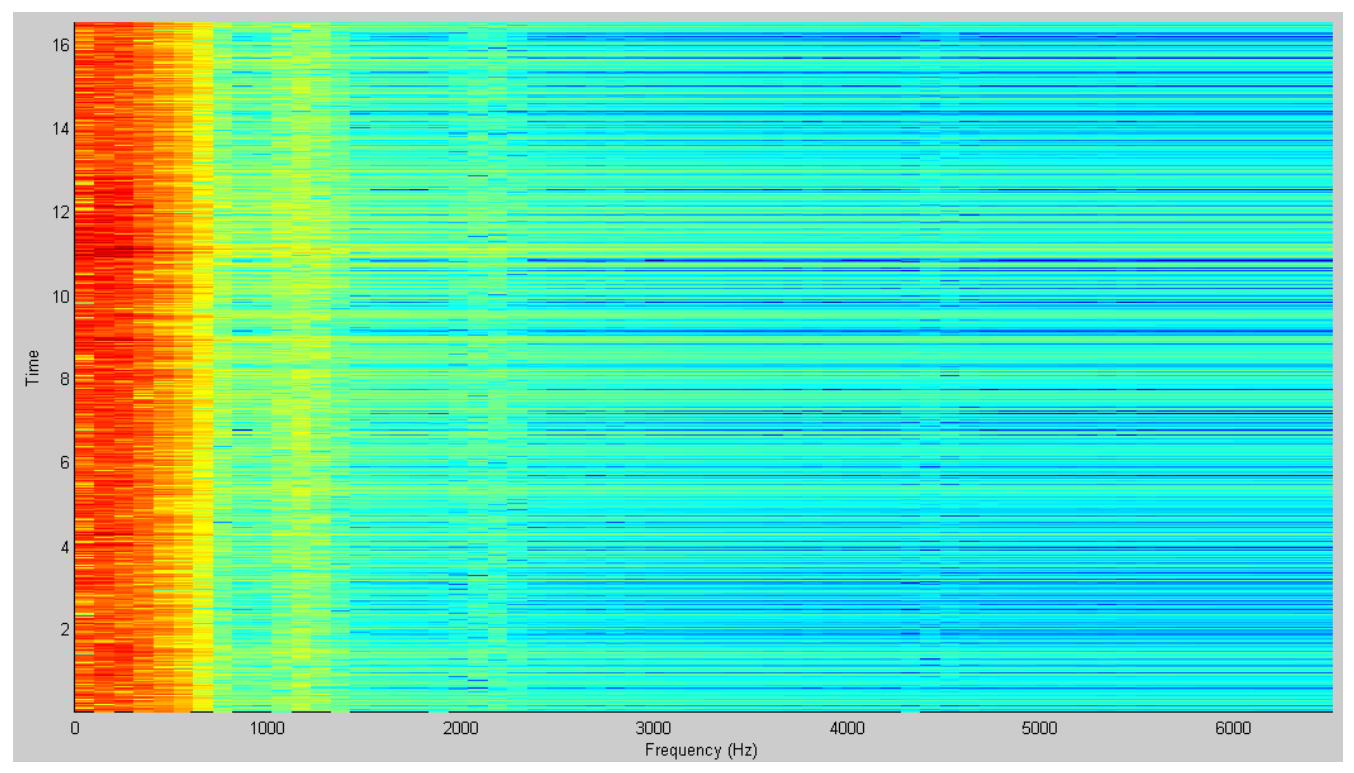

Figura 177 - Espectrograma do sinal reconstruído.

Nota-se que a maior parte das frequências na ordem de $\mathrm{kHz}$ foi retirada do sinal original mas ainda aparecem ruídos de impacto no sinal reconstruído.

A figura 178 ilustra o espectro de frequências do sinal dos ruídos de impacto. 


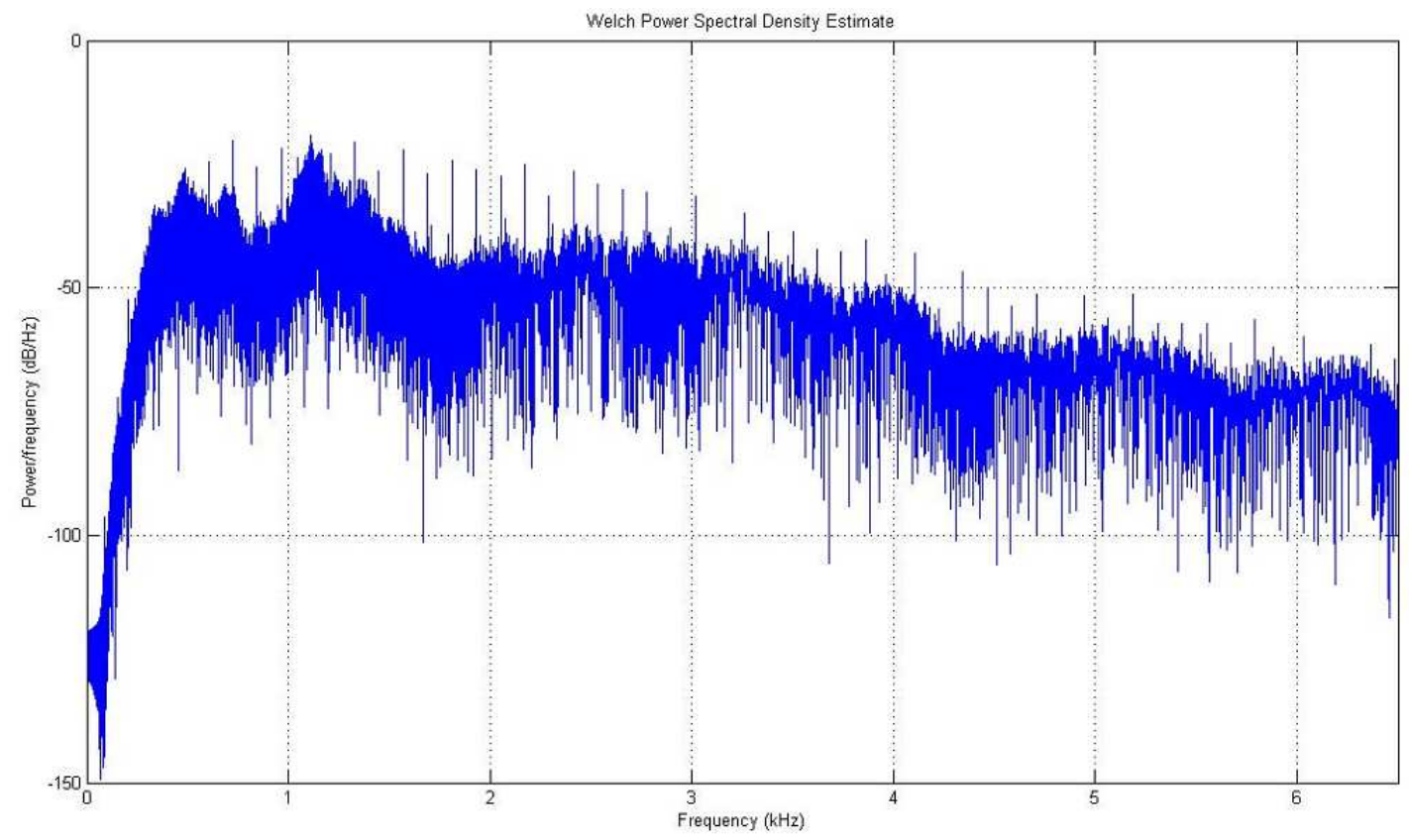

Figura 178 - Espectro de frequências do sinal dos ruídos de impacto.

Por este resultado, nota-se que predominam as frequências na ordem de grandeza de $\mathrm{kHz}$, as quais se referem aos impactos que ocorrem entre a cremalheira contra o pinhão e a bucha guia.

Adotando o critério da janela de tempo e mantendo a pré-filtragem em 3,5 $\mathrm{m} / \mathrm{s}^{2}$, mas ajustando o valor relativo de 5 vezes para 1,5 vezes, foi registrada a ocorrência de 54 impactos dentro da caixa de direção e a maior severidade de impacto medida foi de $10,209 \mathrm{~m} / \mathrm{s}^{2}$.

No gráfico superior da figura 179 são ilustrados, em vermelho, os pontos de impacto detectados por este procedimento e no gráfico inferior são ilustrados os valores da severidade medidos para estes pontos. 

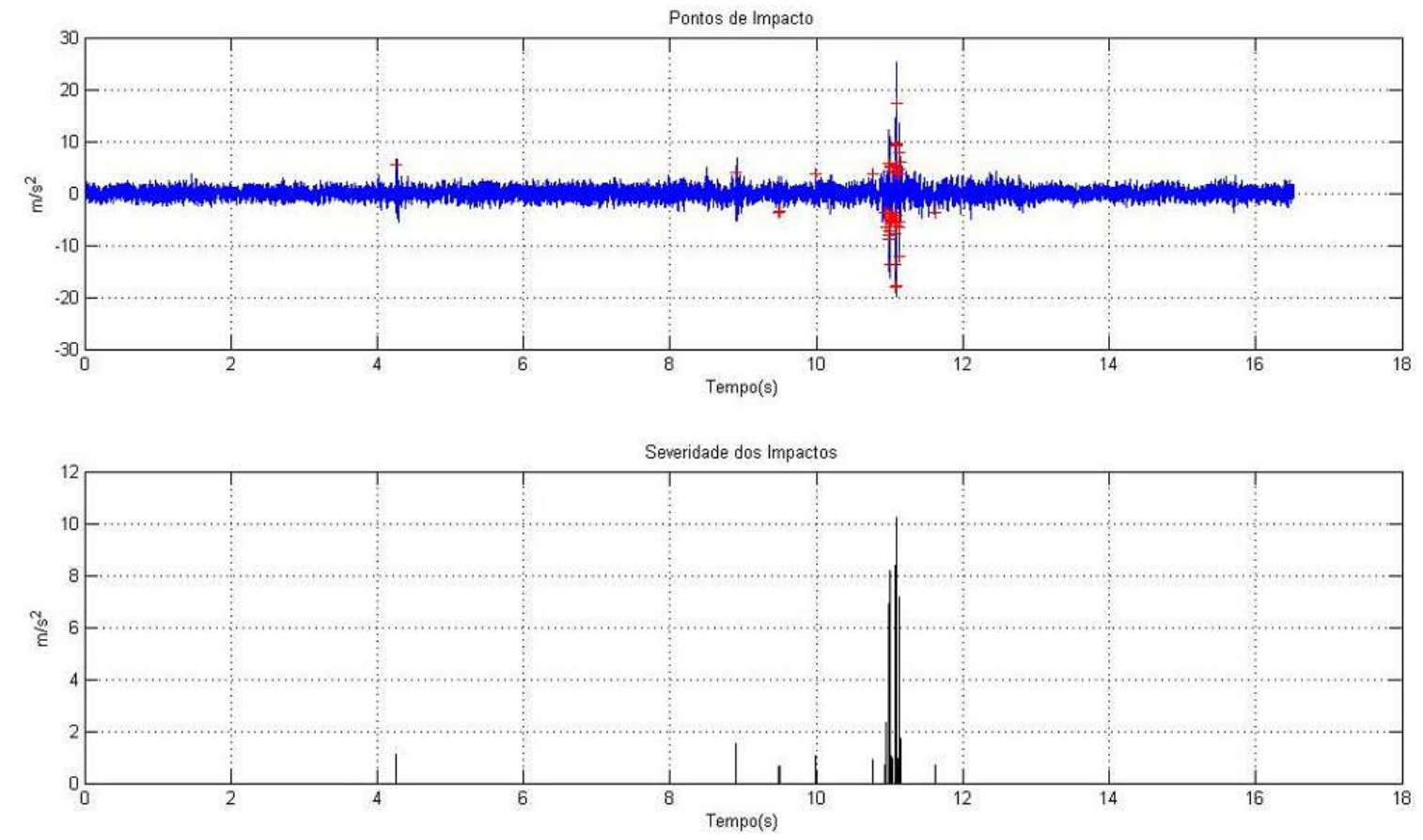

Figura 179 - Pontos de Impacto.

Por este resultado, nota-se que o procedimento detectou as 3 regiões de impacto neste sinal.

Pelos resultados obtidos com esses 5 sinais analisados, conclui-se que para os sinais medidos em campo na rodovia Ayrton Senna, a wavelet de Daubechies de ordem 7 e 4 níveis de detalhamento já são suficientes para retirar a maior parte dos ruídos de impacto do sinal original de vibração.

O critério da janela utilizado foi eficaz na detecção dos intervalos de tempo em que ocorreram os impactos da cremalheira contra o pinhão e bucha guia.

\subsection{Análise dos Sinais de Laboratório com Emissão Acústica}

A seguir serão apresentados os resultados obtidos com a emissão acústica.

$\mathrm{Na}$ figura 180 são mostrados duas formas de onda e respectivos espectros dos sinais de emissão acústica medidos nos ensaios com excitação por martelo. Verifica-se a predominância das altas freqüências no sinal captado. Percebe-se que, 
as vibrações transversais da cremalheira, excitadas pelas pancadas, não são registradas pela emissão acústica.

Foram aplicadas cerca de 250 pancadas com o martelo. Cada pancada era seguida de 2 a 6 registros de emissão acústica, perfazendo um total de 1.000 registros detectados. Na figura 181 são mostrados os pontos de impacto localizados pelo software de emissão acústica. Pode-se observar uma nuvem de eventos localizados próximo do ponto de excitação (em torno da coordenada $50 \mathrm{~mm}$ ), outra nuvem próxima ao engrenamento com o pinhão (em torno de $170 \mathrm{~mm}$ ) e finalmente uma nuvem bastante dispersa próxima do êmbolo do cilindro hidráulico (em torno de $500 \mathrm{~mm}$ ). Entretanto, devido à forte dispersão dos pontos localizados, não é possível assegurar-se sobre a localização correta dos pontos de impacto. Embora o sistema tenha se mostrado bastante sensível à detecção dos sinais de emissão acústica produzidos pelos impactos internos, ainda serão necessários mais estudos para aumentar a confiança na capacidade deste sistema para localizar os impactos.

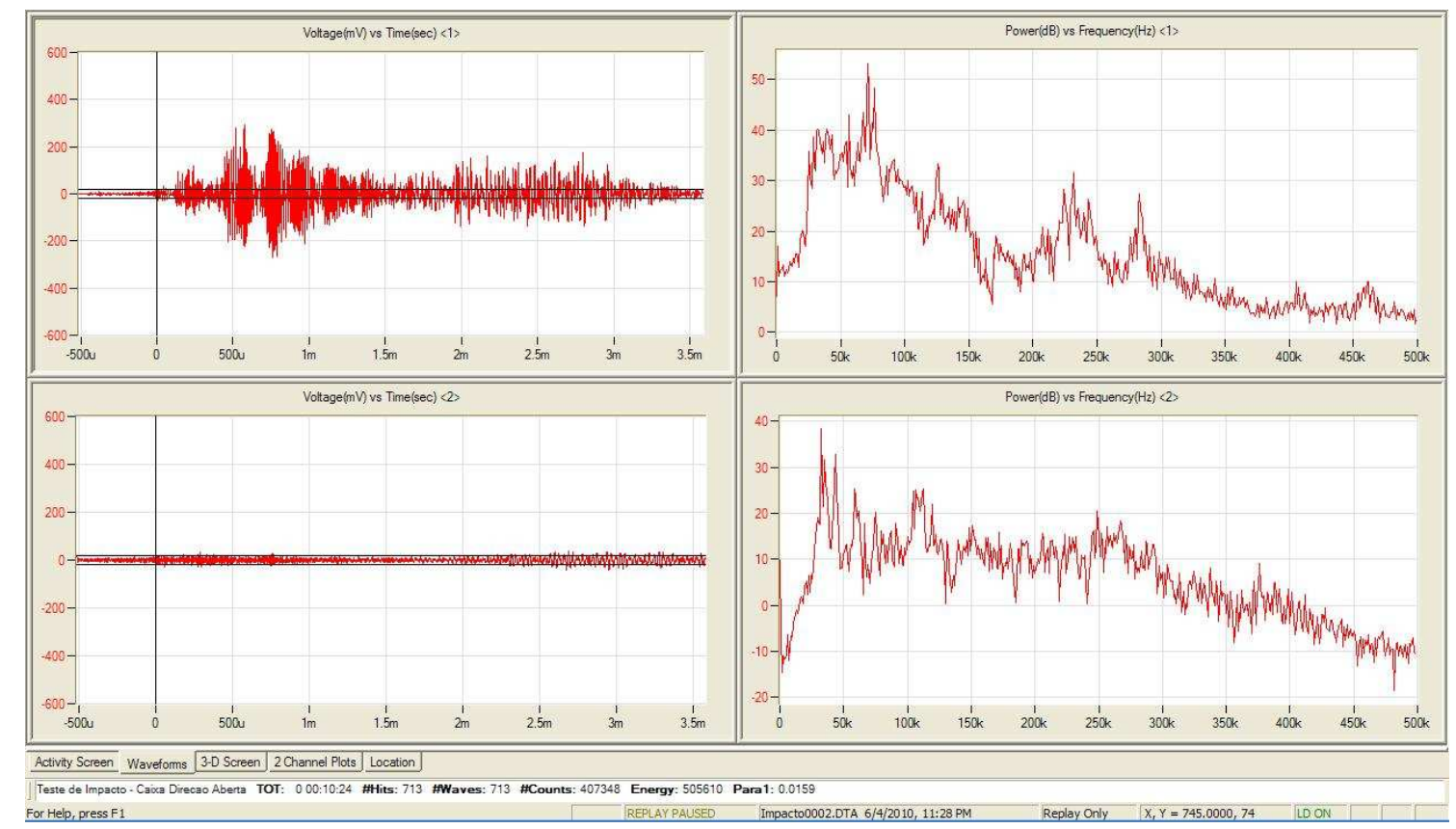

Figura 180 - Forma de onda e espectro dos sinais típicos de emissão acústica - Impacto Interno. 


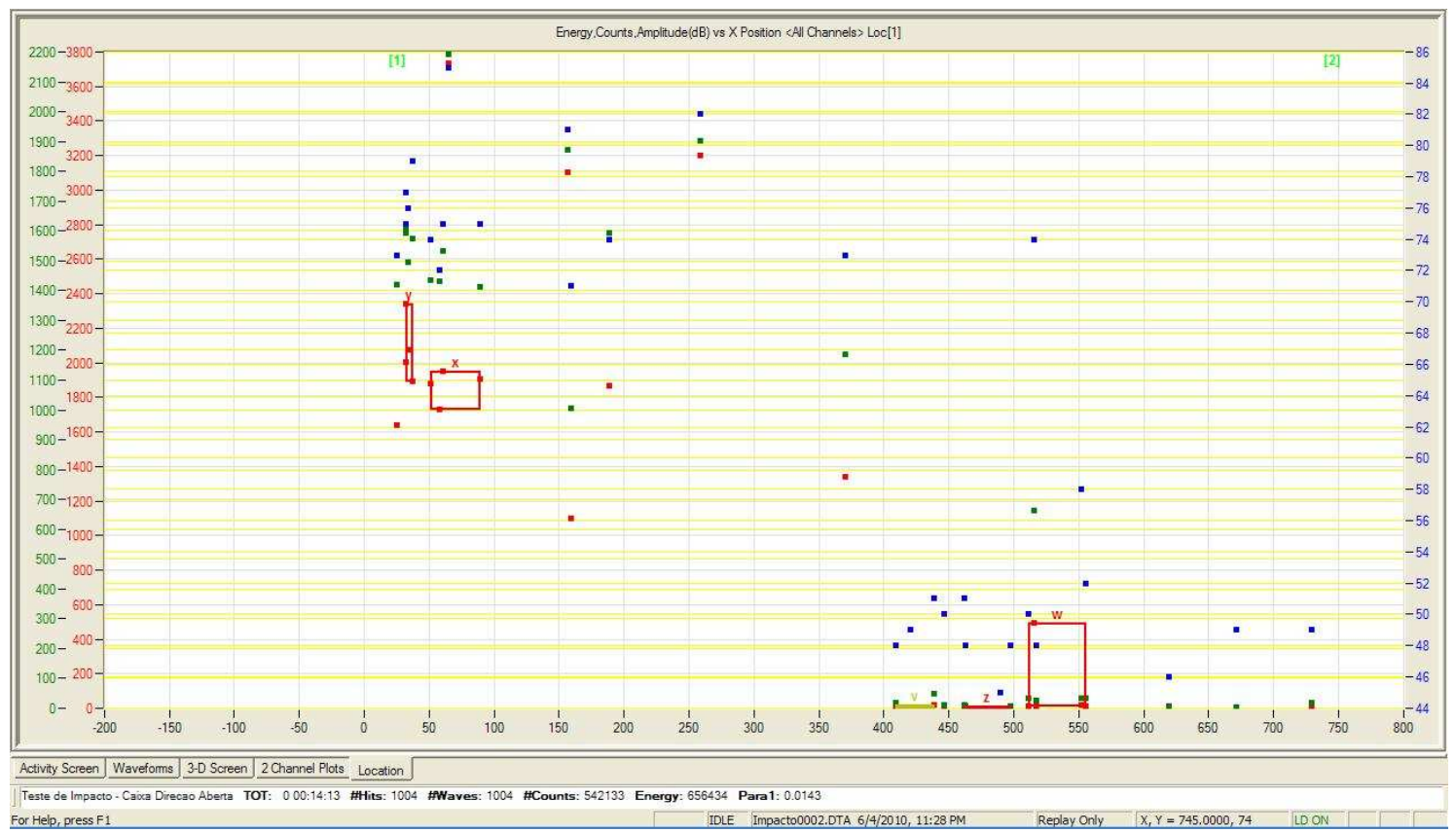

Figura 181 - Localização dos pontos de excitação - Amplitude X Posição Impacto Interno.

\subsection{Discussão dos Resultados}

Neste parágrafo serão discutidos os resultados obtidos com as técnicas de Transformada de Wavelet e Emissão Acústica.

As figuras aqui apresentadas são figuras já mostradas anteriormente no trabalho, reproduzidas somente para facilitar o acompanhamento da discussão aqui apresentada.

A figura 182 ilustra o resultado obtido a partir da aplicação da Transformada de Wavelet sobre sinal medido em laboratório utilizando wavelets da família de Daubechies. Observa-se pela curva do sinal reconstruído, em vermelho, que os ruídos de impacto, em verde, foram retirados do sinal original, em preto.

A figura 183 mostra que a metodologia adotada e aplicada sobre este sinal de laboratório foi capaz de quantificar a ocorrência dos impactos dentro da caixa de direção. Isto pode ser observado pelos pontos em vermelho no gráfico superior desta figura. A metodologia também foi capaz de quantificar a severidade desses impactos que pode ser observada no gráfico inferior desta mesma figura. 


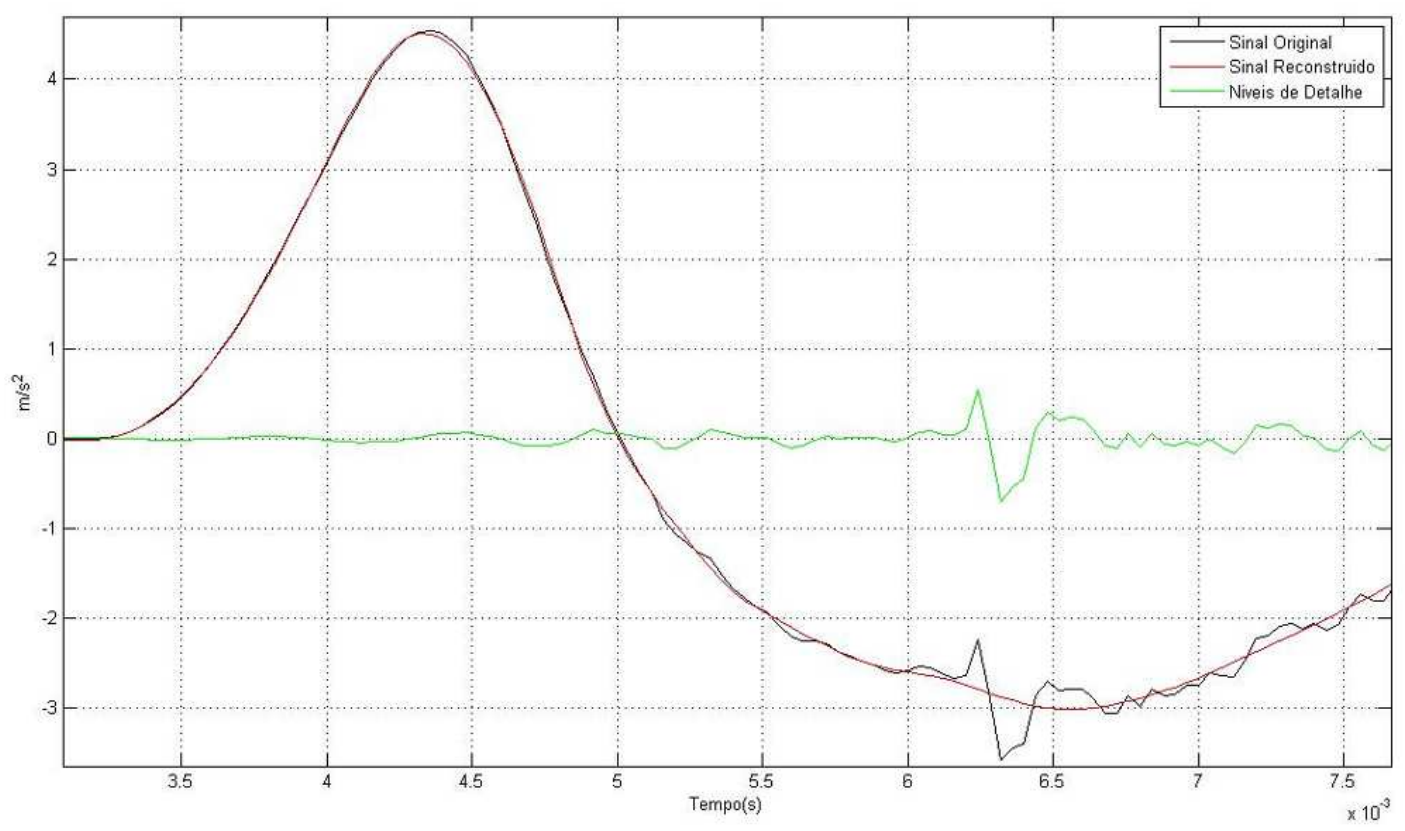

Figura 182 - Wavelet de Daubechies de ordem 7 e 3 níveis de detalhamento.
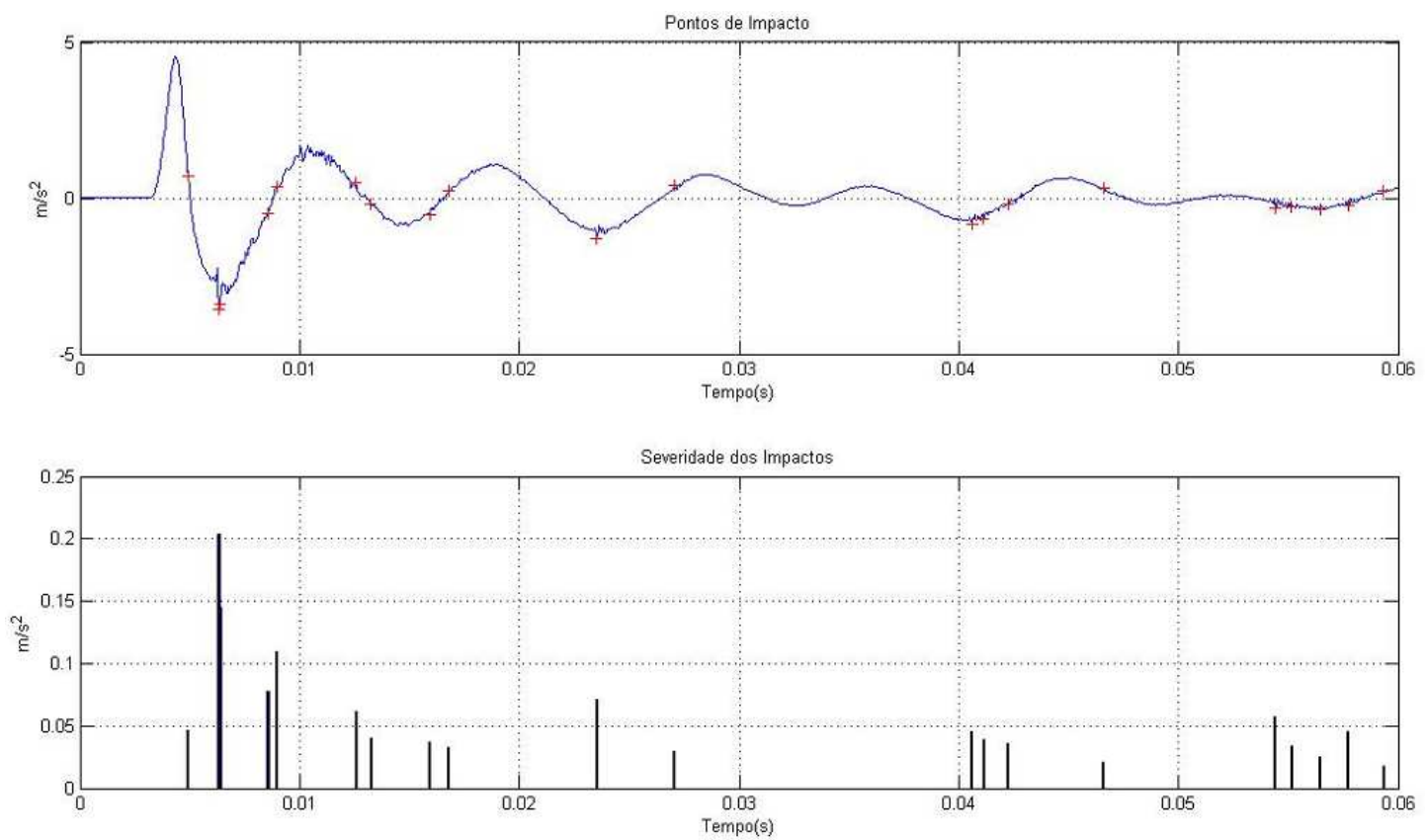

Figura 183 - Pontos de impacto e Severidade dos Impactos.

A figura 184 ilustra o resultado obtido a partir da aplicação da Transformada de Wavelet sobre sinal medido em campo, na rua de paralelepípedos, utilizando wavelets da família de Daubechies. Observa-se pela curva do sinal reconstruído, em vermelho, que os ruídos de impacto, em verde, foram retirados do sinal original, em preto. 
A figura 185 mostra que a metodologia adotada e aplicada sobre este sinal de campo foi capaz de quantificar a ocorrência dos impactos dentro da caixa de direção. Isto pode ser observado pelos pontos em vermelho no gráfico superior desta figura. A metodologia também foi capaz de quantificar a severidade desses impactos que pode ser observada no gráfico inferior desta mesma figura. Nota-se que a freqüência de ocorrência de impactos neste sinal é bem maior do que no sinal medido em laboratório.

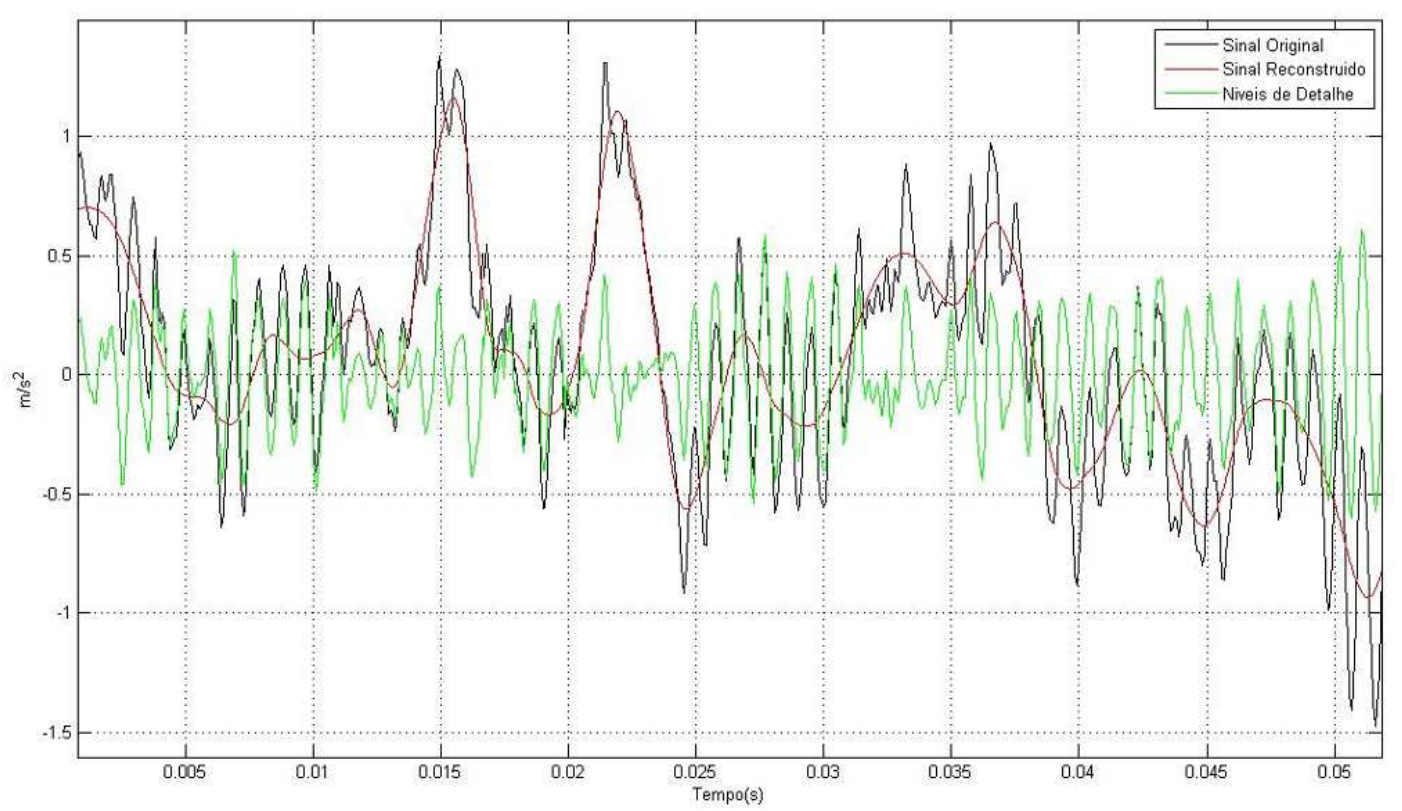

Figura 184 - Wavelet de Daubechies de ordem 7 e 4 níveis de detalhe.
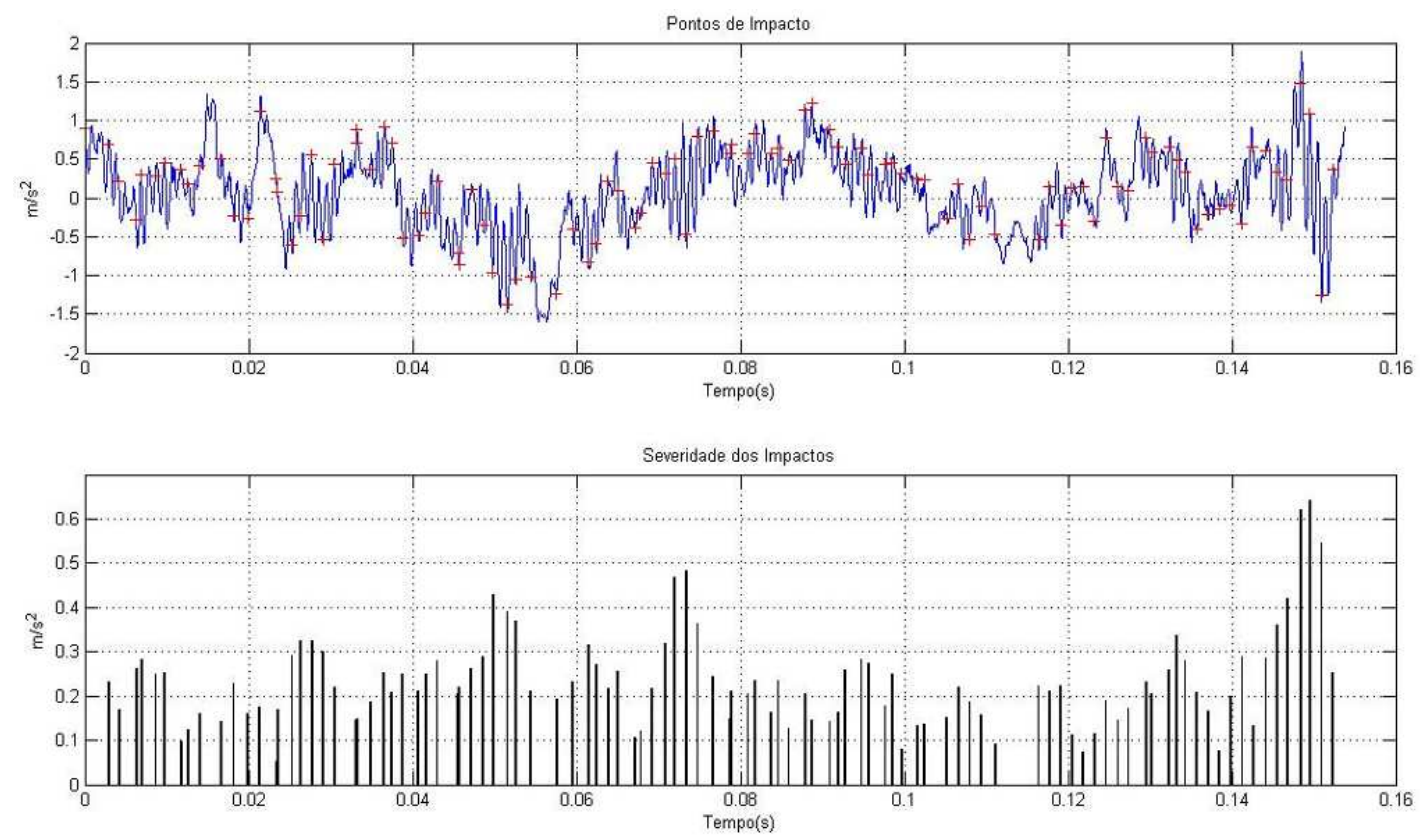

Figura 185 - Pontos de impacto e Severidade dos Impactos. 
A figura 186 ilustra o resultado obtido a partir da aplicação da Transformada de Wavelet sobre sinal medido em campo, na rodovia Ayrton Senna, utilizando wavelets da família de Daubechies. Observa-se pela curva do sinal reconstruído, em vermelho, que os ruídos de impacto, em verde, foram retirados do sinal original, em preto.

A figura 187 mostra que a metodologia adotada e aplicada sobre este sinal de campo foi capaz de quantificar a ocorrência dos impactos dentro da caixa de direção. Isto pode ser observado pelos pontos em vermelho no gráfico superior desta figura. A metodologia também foi capaz de quantificar a severidade desses impactos que pode ser observada no gráfico inferior desta mesma figura. Nota-se que a severidade dos impactos neste sinal é maior do que no sinal medido na rua de paralelepípedos e no sinal medido em laboratório.

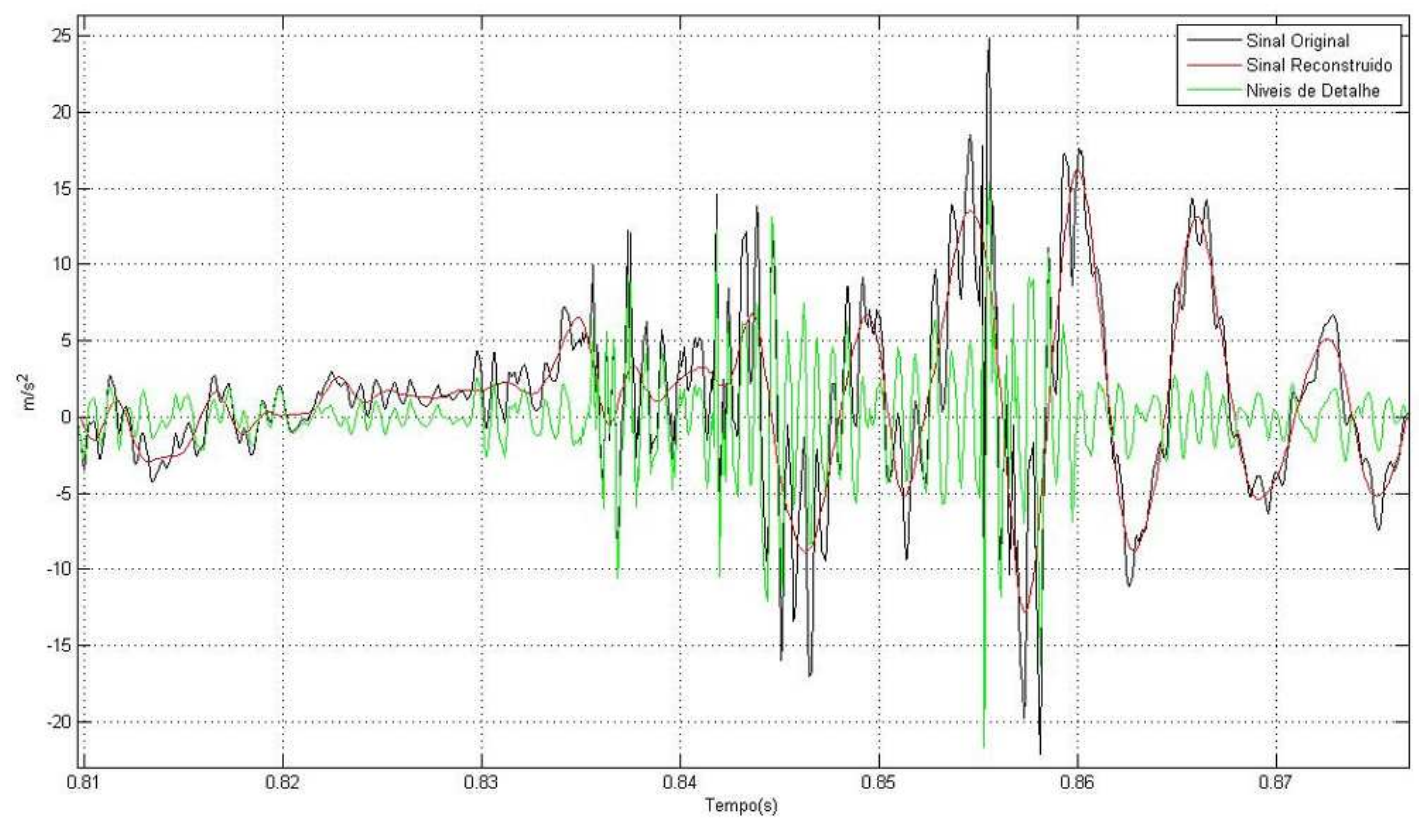

Figura 186 - Wavelet de Daubechies de ordem 7 e 4 níveis de detalhe. 

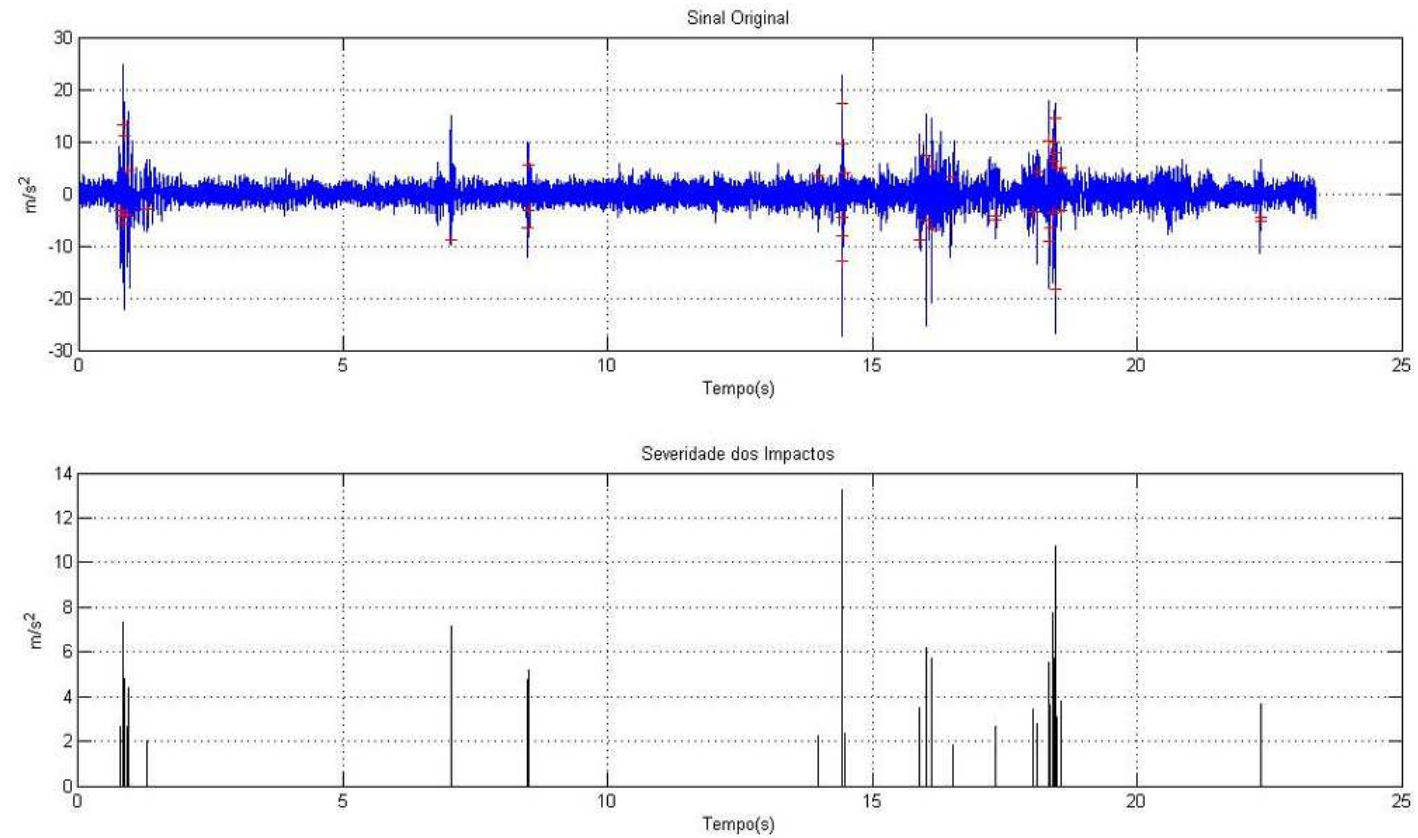

Figura 187 - Pontos de Impacto e Severidade dos Impactos.

A figura 188 ilustra o resultado obtido a partir da aplicação da Transformada de Wavelet sobre sinal medido em laboratório utilizando wavelets da família de Newland. Observa-se pela curva do sinal reconstruído, em vermelho, que os ruídos de impacto, em verde, não foram completamente removidos do sinal original, em preto. Esta família de wavelets não foi capaz de separar os ruídos de impacto do sinal original para os sinais medidos em campo e em laboratório.

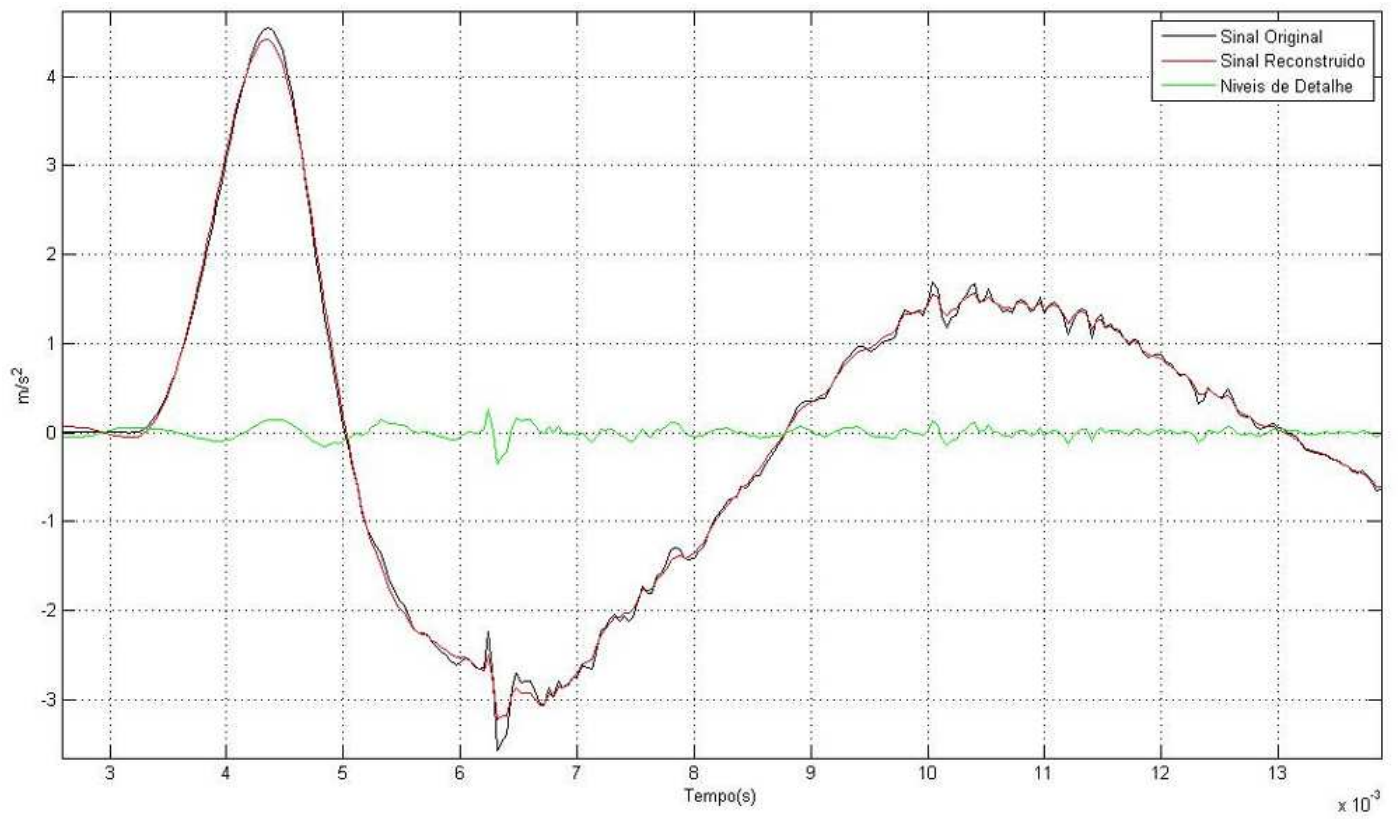

Figura 188 - wavelet de Newland e 4 níveis de detalhamento. 
De uma maneira geral, para todos os sinais analisados, a aplicação da wavelet de Daubechies de ordem 7 mostrou-se eficiente para separar os ruídos de impacto do sinal de vibração original.

Para os sinais medidos em laboratório, a retirada dos 3 últimos níveis de detalhe foi suficiente para retirar os ruídos do sinal original. Já para os sinais medidos em campo, foi necessário retirar os 4 últimos níveis de detalhe para extrair plenamente os ruídos de impacto do sinal original.

A Tabela 5 mostra um quadro de resumo e comparação dos sinais medidos em campo e em laboratório.

Tabela 5 - Quadro de Resumo

\begin{tabular}{|c|c|c|c|c|c|c|c|c|c|c|c|c|c|}
\hline & \multicolumn{5}{|c|}{ Laboratório } & \multicolumn{3}{c|}{ Rua de } \\
Paralelepípedos & \multicolumn{5}{c|}{ Rodovia Ayrton Senna } \\
\hline Sinais & $\begin{array}{c}\text { Sinal } \\
1\end{array}$ & $\begin{array}{c}\text { Sinal } \\
2\end{array}$ & $\begin{array}{c}\text { Sinal } \\
3\end{array}$ & $\begin{array}{c}\text { Sinal } \\
4\end{array}$ & $\begin{array}{c}\text { Sinal } \\
5\end{array}$ & $\begin{array}{c}\text { Sinal } \\
1\end{array}$ & $\begin{array}{c}\text { Sinal } \\
2\end{array}$ & $\begin{array}{c}\text { Sinal } \\
3\end{array}$ & Sinal 1 & $\begin{array}{c}\text { Sinal } \\
2\end{array}$ & $\begin{array}{c}\text { Sinal } \\
3\end{array}$ & $\begin{array}{c}\text { Sinal } \\
4\end{array}$ & Sinal 5 \\
\hline $\begin{array}{c}\text { Duração } \\
(\mathrm{s})\end{array}$ & 0,33 & 0,33 & 0,33 & 0,33 & 0,33 & 0,15 & 0,63 & 0,63 & 23,40 & 19,33 & 25,10 & 20,58 & 16,52 \\
\hline $\begin{array}{c}\text { Número de } \\
\text { impactos }\end{array}$ & 20 & 25 & 21 & 42 & 13 & 103 & 430 & 456 & 44 & 7 & 3 & 12 & 54 \\
\hline $\begin{array}{c}\text { Severidade } \\
\left(\mathrm{m} / \mathrm{s}^{2}\right)\end{array}$ & 0,200 & 0,038 & 0,051 & 0,070 & 0,029 & 0,641 & 1,093 & 0,558 & 13,271 & 8,63 & 4,540 & 7,919 & 10,209 \\
\hline
\end{tabular}

Pelos resultados obtidos, nota-se que os sinais medidos na rua de paralelepípedos apresentam maiores freqüências de ocorrência de impactos mecânicos dentro da caixa de direção em relação aos outros sinais medidos. Mas, a severidade do impacto desses sinais é menor do que os sinais medidos na Rodovia Ayrton Senna. Isto ocorre porque na rua de paralelepípedos, o veículo trafegava em baixa velocidade. Os sinais medidos na Rodovia Ayrton Senna apresentam maiores severidades de impacto em relação aos demais sinais medidos. Isto ocorre devido a maior velocidade do veículo durante a medição dos sinais.

A figura 189 mostra que os resultados obtidos com a emissão acústica neste trabalho não foram satisfatórios devido a grande dispersão dos resultados. $E$, portanto, não possibilitou uma comparação direta com os resultados obtidos com a Transformada de Wavelet. 


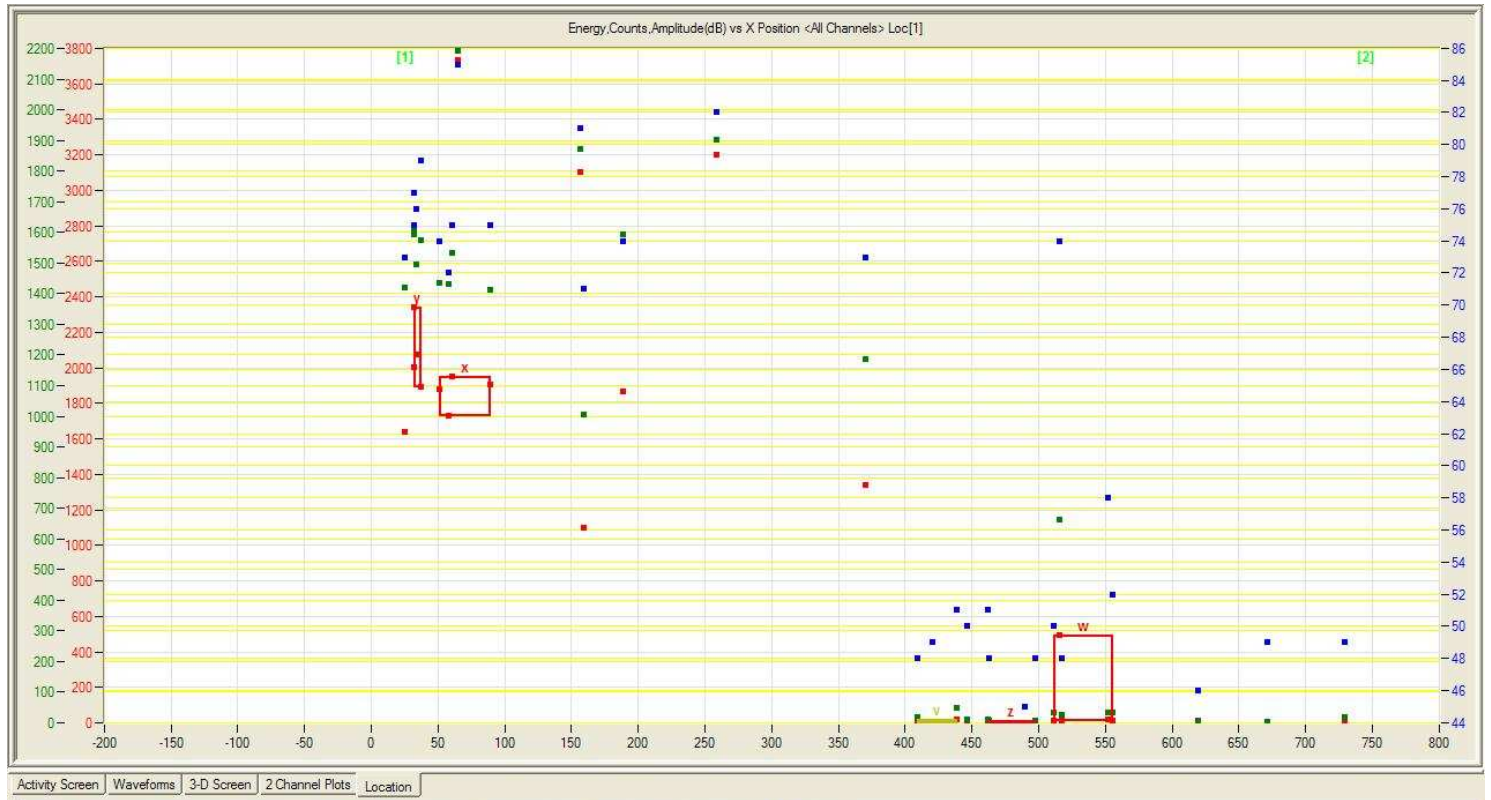

Figura 189 - Localização dos pontos de excitação - Amplitude X Posição Impacto Interno. 


\section{CONCLUSÃO}

Para os sinais de vibração medidos em laboratório, a Transformada de Wavelet mostrou-se eficiente na detecção da ocorrência de impactos internos em caixas de direção automotiva.

Para os sinais de vibração medidos em campo, na rua de paralelepípedos, a Transformada de Wavelet apresentou dificuldades para segregar os ruídos de impacto devido à grande quantidade dos mesmos. Entretanto, a transformada foi capaz de detectar a grande maioria destes ruídos, atendendo as necessidades deste trabalho.

Para os sinais de vibração medidos em campo, na rodovia Ayrton Senna, a Transformada de Wavelet mostrou-se eficiente na detecção da ocorrência de impactos internos em caixas de direção automotiva.

As Wavelets da família de Daubechies apresentaram melhores desempenhos em comparação com a Wavelet Harmônicas de Newland na detecção e remoção dos ruídos de impacto do sinal de vibração medido.

A Wavelet Harmônica de Newland não foi capaz de separar os ruídos de impacto do sinal original de vibração.

Para melhor desempenho do método, deve-se aperfeiçoar a relação entre a ordem da Wavelet de Daubechies utilizada e os níveis de detalhe retirados do sinal, uma vez que aumentando os níveis de detalhe retirados, o sinal reconstruído começa a perder suas características e aumentando ou diminuindo a ordem da wavelet, o sinal reconstruído começa a apresentar distorções.

O valor eficaz do sinal de impacto foi utilizado para quantificar a severidade do impacto, entretanto estudos mais aprofundados são necessários para determinar os parâmetros ideais e valores admissíveis para avaliação do nível de ruído. Com isso, é possível obter um critério quantitativo para avaliação do ruído de impacto na caixa de direção, retirando-se assim a subjetividade desta avaliação.

O critério do valor relativo mostrou-se eficiente na detecção dos intervalos de tempo em que aconteceram os impactos para os sinais medidos em laboratório e na rodovia Ayrton Senna, mas estudos devem ser realizados para combinar novos critérios e obter resultados estatisticamente mais significativos. 
Sobre a comparação entre a detecção de impactos pela análise de Wavelet e por Emissão Acústica, não foi possível realizar uma comparação direta dos dois procedimentos de detecção de impactos na cremalheira. Não há experiência acumulada para assegurar com confiança a capacidade de localização dos pontos de impacto com a utilização da emissão acústica, embora tenha-se mostrado bastante sensível em detectar registros de emissão acústica produzidos pela excitação com martelo instrumentado.

Há necessidade de realizar maiores estudos com a técnica de emissão acústica antes de ser possível fazer uma comparação realista das duas técnicas. A principal dificuldade está em sincronizar e correlacionar os sinais medidos pelos dois sistemas. Em emissão acústica são medidos sinais mecânicos de altíssima freqüência (acima de $50 \mathrm{kHz}$ ), enquanto os registros de vibração utilizados na análise por wavelets são de baixa freqüência (abaixo de $1000 \mathrm{~Hz}$ ). Não foi possível até o momento sincronizar os dois sistemas de medição que trabalham com freqüências de amostragem bastante desiguais (3.000 amostras/s para vibrações e $10^{6}$ amostras/s para emissão acústica).

Entretanto, foi possível constatar que as duas técnicas parecem promissoras em detectar a ocorrência de impactos internos e para avaliar a severidade desses impactos. Não há conhecimento suficiente e confiança nas técnicas para localizar os pontos de impacto. Serão necessários novos estudos em sistemas mecânicos simplificados para ampliar o domínio da técnica de emissão acústica. Deve-se aplicar a técnica em sistemas onde só exista um ponto de impacto possível e cuja localização seja bem definida.

Comparando-se os dois sistemas pode-se dizer que:

a. O sistema de emissão acústica é bastante sensível e parece bastante promissor para detecção de impactos, entretanto, como a magnitude da emissão acústica não tem um significado muito preciso seu uso para avaliação objetiva da severidade dos impactos pode ser limitado;

b. A detecção dos impactos pela análise de vibração pela transformada de wavelet mostrou-se capaz de detectar os impactos, com a vantagem de permitir correlacionar o sinal dos impactos com o sinal de vibração de baixa freqüência, isso permite entender melhor o mecanismo de ocorrência de impactos e tem como vantagem a possibilidade de remover o sinal de impacto do registro de vibração;

c. Ambas as técnicas precisam ser aprimoradas para permitir a avaliação objetiva da severidade de ocorrência de impactos, entretanto, ambas 
mostram-se promissoras em permitir uma avaliação relativa da severidade dos impactos, por exemplo, para estudos dos efeitos de modificações introduzidas sobre um mesmo sistema.

Como sugestão de melhoria, pode-se citar a troca do martelo com ponta de borracha pelo uso de excitador eletrodinâmico com sinal excitação harmônica para poder ter um sinal mais controlado e de duração maior e com maior número de impactos para tornar possível a comparação com emissão acústica, uma vez que esta última trabalha com dados estatísticos e, portanto requer uma grande quantidade de medições. 


\section{REFERÊNCIAS BIBLIOGRÁFICAS}

BOGESS, A., NARCOWICH, F., J. A First Course in Wavelets with Fourier Analysis. First Edition, Texas A \& M University, Texas: Prentice Hall, 2001, p. 1-182.

BURRUS, C. S., GOPINATH, R, A., GUO, H. Introduction to Wavelets and Wavelet Transforms. Electrical and Computer Engineering Department and Computer and Information Technology Institute Rice University. Houston, Texas: Prentice Hall, 1998, p. 1 - 9.

CRUZ, J. M. X. da Estudo de Caso de Ruído Knock Noise em Mecanismo de Direção Hidráulica Tipo Pinhão-Cremalheira. Dissertação de Mestrado. Escola Politécnica da Universidade de São Paulo. São Paulo, 2006, p. 2 39.

LAMBERTI, N., GIUA, P. E., PAPPALARDO, M. Modello Matriciale e Suo Impiego Nell' Ottimizzazione Della Risposta Impulsiva Del Transduttore Multielemento. Technical Report, Università di Salerno, 1987.

LEAHY, M., MBA, D., COOPER, P., MONTGOMERY, A., OWEN, D. Acoustic Emission for the Detection of Shaft-to-Seal rubbing in large power generation turbines. Advanced Materials Research. Cranfield University. 2006. 6 p.

LI,L., QU,L., LIAO, X. Haar Wavelet for Machine Fault Diagnosis. Science Direct. Institute of Mechanical and Material Engineering, China Three Gorges University. July 2006. 14 p.

LIMA, P. C. de Wavelets: Uma introdução. Departamento de MatemáticaICEX - UFMG. 2003. 25p. 
MAHMOUD, M. I., DESSOUKY, M. I. M., DEYAB, S., ELFOULY, F. H. Comparison Between Haar and Daubechies Wavelet Transformions on FPGA Technology. World Academy of Science, Engineering and Technology. 2007. 5 p.

MERTINS, A. Signal Analysis Wavelets, Filters Banks, Time-Frequency Transforms and Applications. Great Britain: Bookcraft Ltda. 1999, p. 210263.

MIETTINEN, J., PATANIITTY, P. Acoustic Emission in Monitoring Extremely Slowly Rotating Rollig Bearging. In: Proceedings of COMADEN 99. Tampere University of Technology, Machine Design. 1999. 10 p.

NEWLAND, D., E. An Introduction to Random Vibrations, Spectral and Wavelet Analysis. University of Cambridge, England: Longman Scientific \& Technical, Third Edition, 1993. 477 p.

NEWLAND, D., E. Harmonic Wavelet Analysis. Mathematical Physical \& Engineering Sciences. Department of Engineering, University of Cambridge, U.K. 1993. 24 p.

NIGRO,P.,S.,B. Geração de Ação Dinâmica de Estruturas Baseada em Transformada de Wavelet Harmônica. Dissertação de Mestrado. São Paulo, 2009.

PENG, Z. K., CHU, F. L. Application of the Wavelet Transform in Machine Condition Monitoring and Fault Diagnostics: a Review With Bibliography. Science Direct. Department of Precision Instruments, Tsinghua University, China. November 2002. 23 p.

PONGE-FERREIRA, W. Estudo do Knock Noise em Direção com Assistência Hidráulica. Laboratório de Equipamentos Mecânicos e Estrutura - IPT - CINTEQ. São Paulo, 2007. 


\section{BIBLIOGRAFIA CONSULTADA}

ARCE, G. R. A General Weighted Median Filter Structure Admitting Negative Weights. IEEE Transactions on Signal Processing. December 1998. Vol. 46. $11 \mathrm{p}$.

BATISTA, A., ENGLISH, M. Ventricular Late Potential Analysis with Musical and Harmonic Wavelets. Medical Engineering \& Physics 20 (1998) 773-779. November 1998. 7 p.

HÁRDLE, W., KERKYACHARIAN, G., PICARD, D., TSYBAKOV, A. Wavelets, Approximation and Statistical Applications. Seminar Berlim - Paris. 284 p.

KIM, D. H., LEE, W. K., KIM, S. W. Analysis of Acoustic Emission Signal for the Detection of Defective Manufactures in Press Process. World Academy of Science, Engineering and Technology, 2009. 5 p.

MALLAT, S. G. A Theory for Multiresolution Signal Decomposition: The Wavelet Representation. IEEE Transactions on Pattern Analysis and Machine Intelligence, Vol. II, NO. 7, July 1989. p. 674-693.

MALLAT, S., HWANG, W. L. Singularity Detection and Processing with Wavelets. IEEE Transactions on Information Theory, Vol. 38, NO. 2, March 1992. p. $617-643$.

NATHALIE, D., ESCUdiÉ, B., GUILlemain, P., MARTINET, R., K., TCHAMITCHIAN, P., TORRÉSANI, B. Asymptotic Wavelet and Gabor Analysis: Extraction of Instantaneous Frequencies. IEEE Transactions on Information Theory, Vol. 38, NO. 2, March 1992. p. 644-664.

NEWLAND, D. E. Some Properties of Discrete Wavelet Maps. Department of Engineering, University of Cambridge. 1994. p. 59 - 69. 
RIOUL, O., DUHAMEL, P. Fast Algorithms for Discrete and Continuos Wavelet Transforms. IEEE Transactions on Information Theory, Vol. 38, NO. 2, March 1992. P. $569-586$.

TORRENCE, C., COMPO, G. P. A Pratical Guide to Wavelet Analysis. American Meteorological Society, October 1997. 18 p.

VETTERLI, M. Wavelets, Approximation and Compression. IEEE Signal Processing Magazine. September 2001. 15 p.

VIERIA, S. R., TONELI, C. A. Z., JUNIOR, F. W. A., CARVALHO, L. M. T. Avaliação de Transformadas Wavelets para Fusão de Imagens SPOT 4 e Comparações de Classificações de uma Imagem Fusionada e de uma Imagem SPOT 5. Anais XIII Simpósio Brasileiro de Sensoriamento Remoto. Florianópolis, Abril 2007. 8 p. 


\section{APÊNDICES}

No apêndice A são apresentadas as funções de Newland implementadas em Matlab.

No apêndice B é apresentado umas das funções desenvolvidas em Matlab com a utilização da wavelet de Daubechies.

\subsection{APÊNDICE A - FUNCÕES DE NEWLAND}

A seguir encontram-se as funções da transformada harmônica de wavelet e da transformada inversa de wavelet obtidas a partir de Newland (1993) e implementadas em Matlab.

A função hwtdn(f) retorna uma lista cujos elementos são os coeficientes da transformada harmônica de wavelet dos elementos de f. A funçao ihwtdn(f) é a função inversa.

É necessário que f tenha $2^{n}$ elementos sendo $n$ um inteiro. Sua transformada $a$ também possui $2^{n}$ elementos. Os elemetos de f podem ser reais ou complexos. Os elementos de $a$ são complexos.

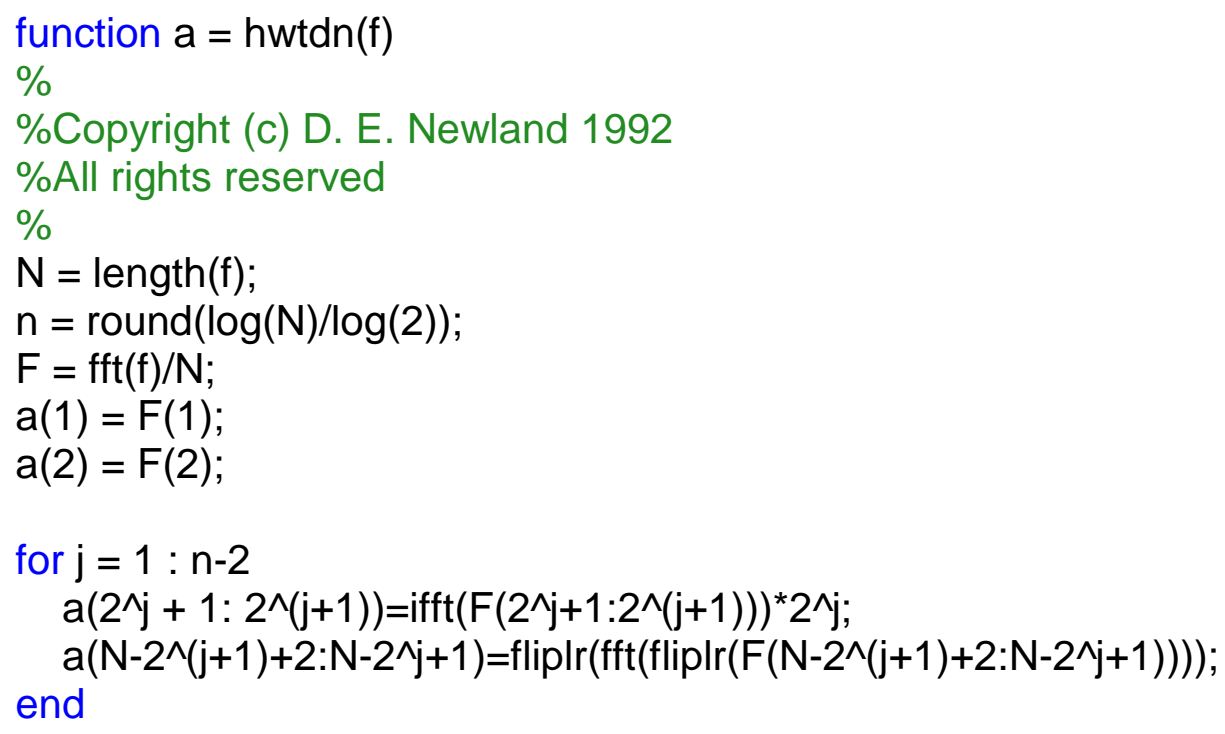




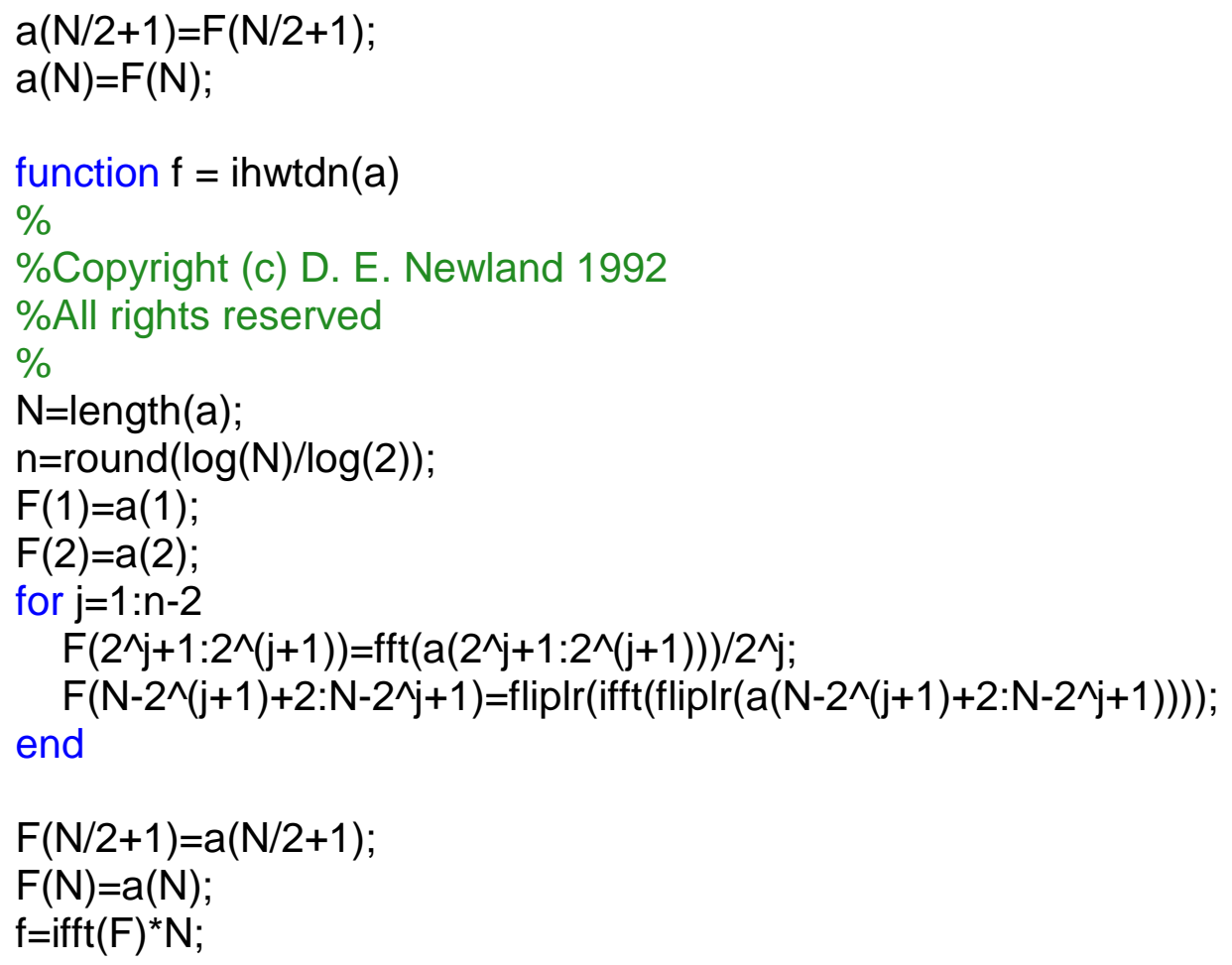

\subsection{APÊNDICE B - FUNCÕES DE DAUBECHIES}

Abaixo, encontra-se uma função desenvolvida em Matlab que lê um arquivo .txt que contem no mínimo uma coluna de tempo e uma coluna de dados. Em seguida é aplicada a Transformada de Wavelet utilizando a família de wavelets de Daubechies e são quantificadas a freqüência de ocorrência de impactos e a severidade de ocorrência dos mesmos e por último são gerados diversos gráficos de resultados.

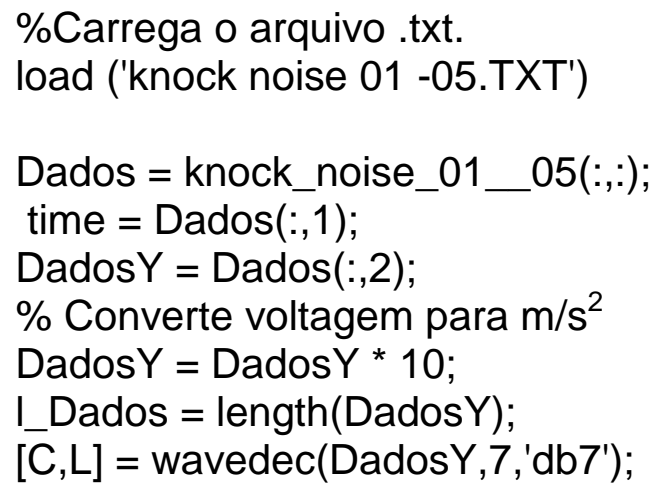




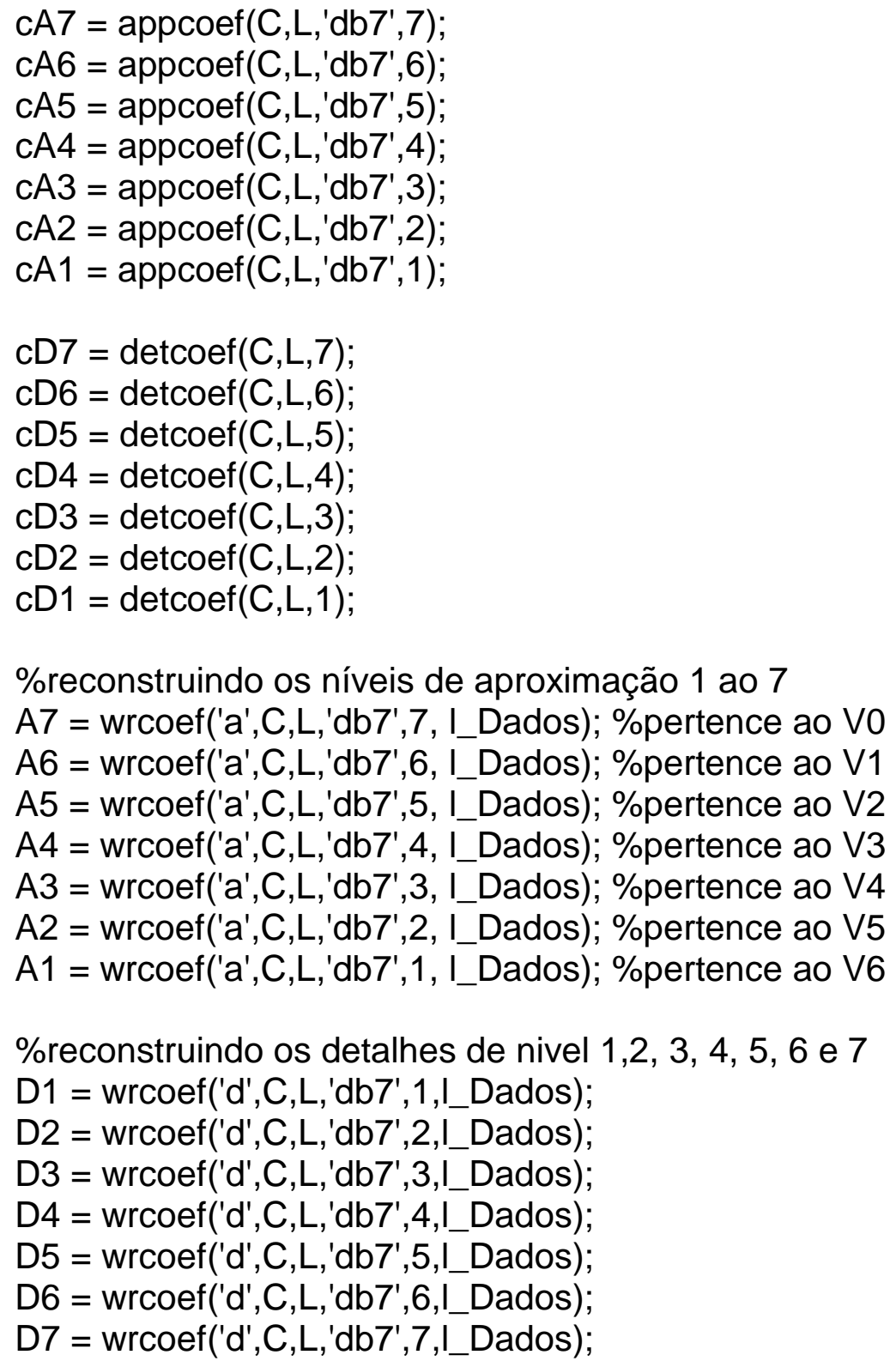

\%reconstruindo os níveis de aproximação 1 ao 7

A7 = wrcoef('a',C,L,'db7',7, I_Dados); \%pertence ao V0 $A 6=\operatorname{wrcoef}(' a ', C, L, ' d b 7$ ',6, I_Dados); \%pertence ao V1 A5 = wrcoef('a',C,L,'db7',5, I_Dados); \%pertence ao V2 A4 = wrcoef('a',C,L,'db7',4, I_Dados); \%pertence ao V3 A3 = wrcoef('a',C,L,'db7',3, I_Dados); \%pertence ao V4 $\mathrm{A} 2$ = wrcoef('a',C,L,'db7',2, I_Dados); \%pertence ao V5 A1 = wrcoef('a',C,L,'db7',1, I_Dados); \%pertence ao V6

\%reconstruindo os detalhes de nivel 1,2, 3, 4, 5, 6 e 7

D1 = wrcoef('d',C,L,'db7',1,I_Dados);

D2 = wrcoef('d',C,L,'db7',2,I_Dados);

D3 = wrcoef('d',C,L,'db7',3,I_Dados);

D4 = wrcoef('d',C,L,'db7',4,I_Dados);

D5 = wrcoef('d',C,L,'db7',5,I_Dados);

D6 = wrcoef('d',C,L,'db7',6,I_Dados);

D7 = wrcoef('d',C,L,'db7',7,I_Dados);

figure

plot(time,DadosY)

xlabel('Tempo(s)')

ylabel('m/ $\left.\mathrm{s}^{2 \prime}\right)$

grid

figure

spectrogram(DadosY,128,120,128,1.3003e+004)

A=DadosY-D1-D2-D3-D4;

$\mathrm{D}=\mathrm{D} 1+\mathrm{D} 2+\mathrm{D} 3+\mathrm{D} 4$;

$\mathrm{DT}=\mathrm{D}^{\prime} ;$

rmst(DT) 


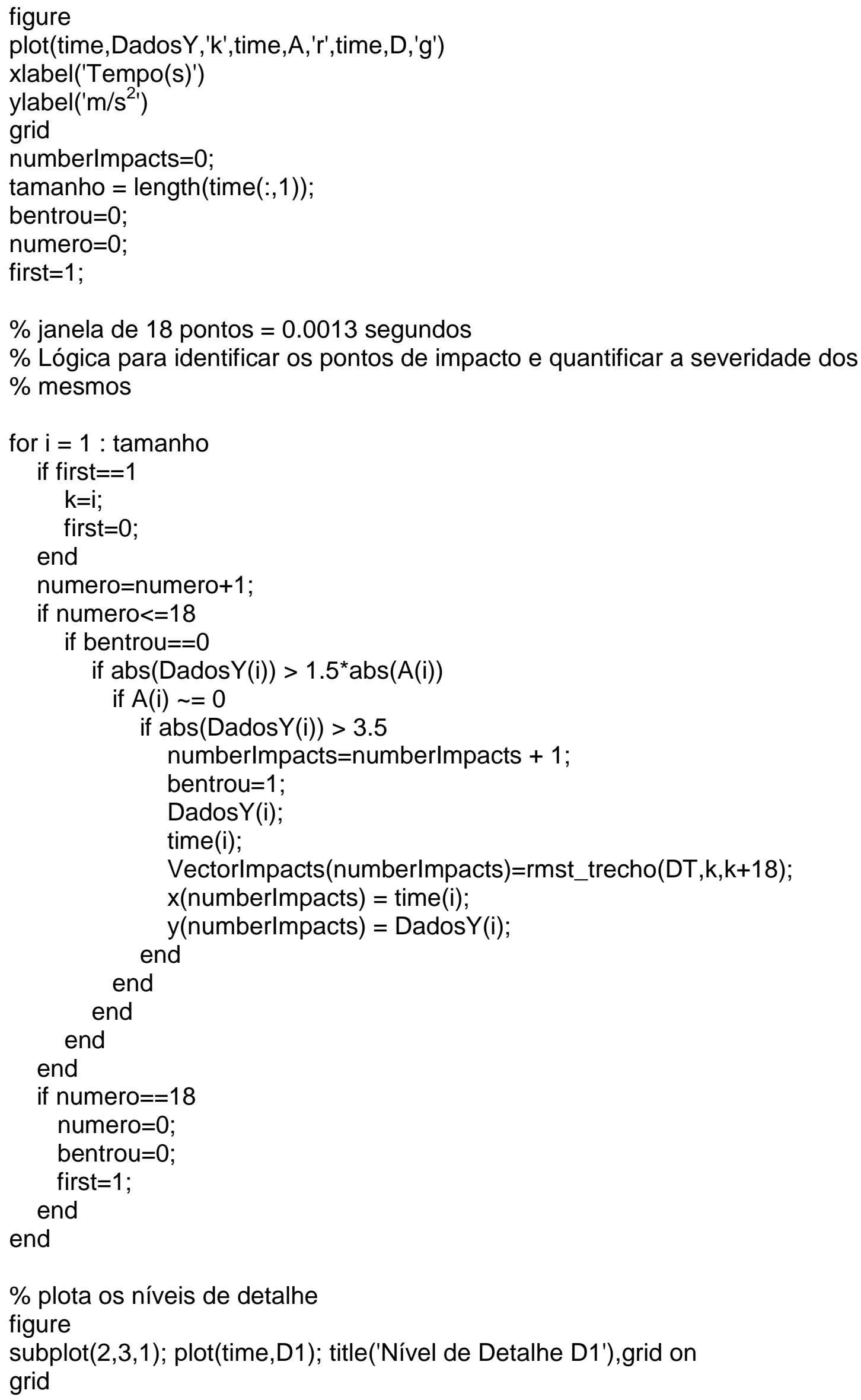


subplot(2,3,2); plot(time,D2); title('Nível de Detalhe D2'), grid on grid

subplot(2,3,3); plot(time,D3); title('Nível de Detalhe D3'),grid on grid

subplot(2,3,4); plot(time,D4); title('Nível de Detalhe D4'), grid on grid

subplot(2,3,5); plot(time,D5); title('Nível de Detalhe D5'),grid on grid

subplot(2,3,6); plot(time,D6); title('Nível de Detalhe D6'),grid on grid

figure

spectrogram $(D, 128,120,128,1.3003 e+004)$

numberlmpacts

$\max ($ Vectorlmpacts)

figure

pwelch(A,I_Dados,[ ],[ ],1.3003e+004);

figure

pwelch(D,I_Dados,[ ],[ ],1.3003e+004);

figure

plot(time,A);

xlabel('Tempo(s)')

ylabel $\left(' \mathrm{~m} / \mathrm{s}^{2}\right)$

grid

figure

spectrogram $(A, 128,120,128,1.3003 e+004)$

figure

subplot(2,1,1); plot(time,DadosY); title('Pontos de Impacto'),grid on xlabel('Tempo(s)')

ylabel $\left(' \mathrm{~m} / \mathrm{s}^{2}\right)$

$\operatorname{axis}\left(\left[\begin{array}{llll}0 & 18 & -30 & 30\end{array}\right]\right)$

hold on

plot $\left(x, y,{ }^{\prime}++^{\prime}\right)$; grid on

hold off

subplot(2,1,2); bar(x,Vectorlmpacts); title('Severidade dos Impactos'), grid on xlabel('Tempo(s)')

ylabel $\left(' \mathrm{~m} / \mathrm{s}^{2}\right)$

axis([ $\left.\left[\begin{array}{llll}0 & 18 & 0 & 12\end{array}\right]\right)$ 
\% Função que calcula o valor eficaz do impacto function RMST= rms(varargin, inicioT, fimT)

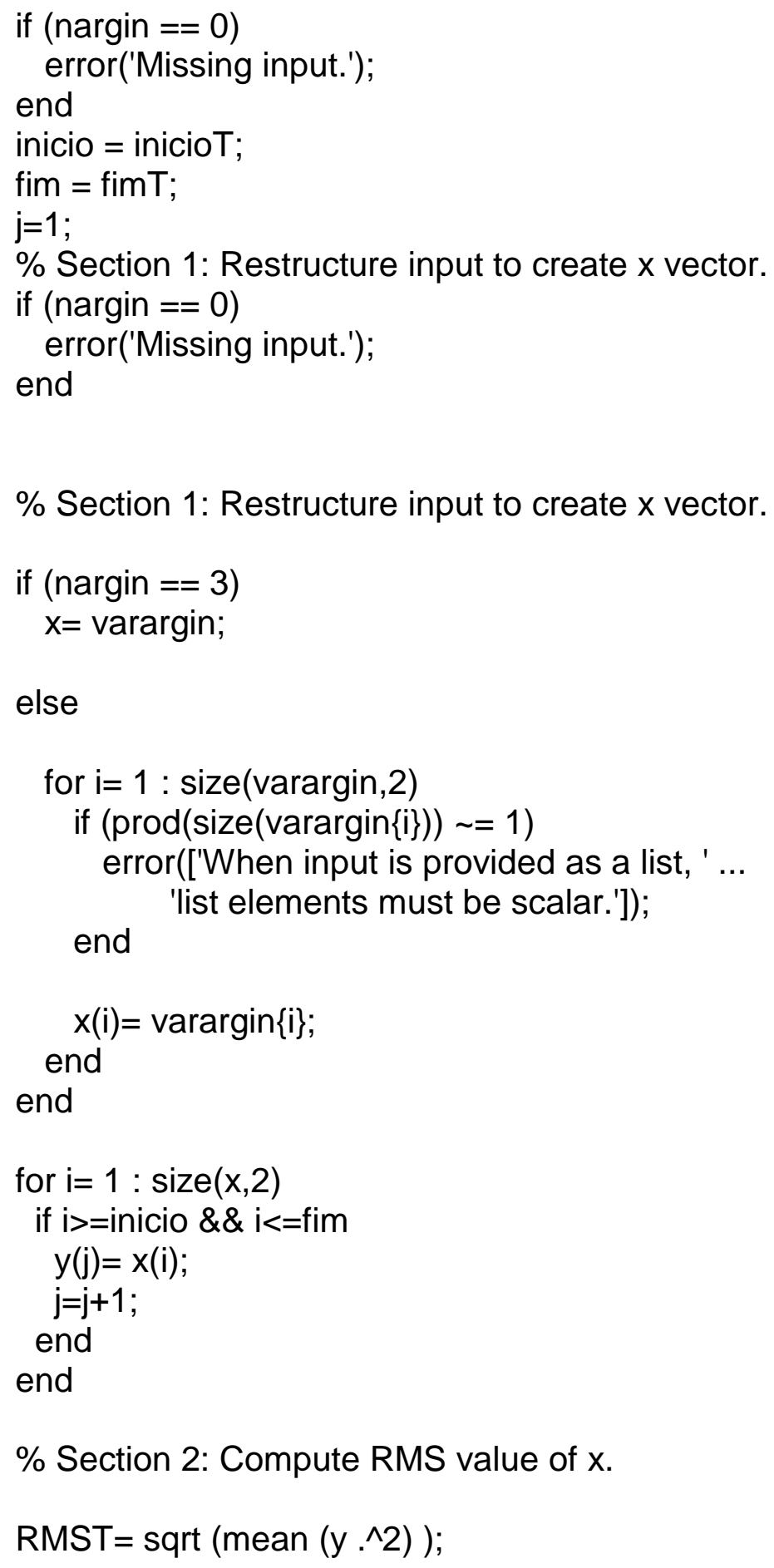

